\title{
CSNI Project for Fracture Analyses of Large-Scale International Reference Experiments (Project FALSIRE)
}

Manuscript Completed: December 1992

Date Published: June 1993

Prepared by

B. R. Bass, C. E. Pugh, J. Keeney-Walker, Oak Ridge National Laboratory

H. Schulz, J. Sievers, Gesellschaft für Anlagen-und Reaktorsicherheit

Oak Ridge National Laboratory

Oak Ridge, TN 37831-6285

Gesellschaft für Anlagen-und Reaktorsicherheit

Department of Structural Mechanics (GRS)

Köln, Federal Republic of Germany

\section{Prepared for}

Division of Engineering

Office of Nuclear Regulatory Research

U.S. Nuclear Regulatory Commission

Washington, DC 20555

NRC FIN B5703 


\section{ABSTRACT}

A summary of the recently completed Phase I of the Project for Fracture Analysis of Large-Scale International Reference Experiments (Project FALSIRE) is presented. Project FALSIRE was created by the Fracture Assessment Group (FAG) of Principal Working Group No. 3 of the Organization for Economic Cooperation and Development/Nuclear Energy Agency's Committee on the Safety of Nuclear Installations (CSNI). The CSNI/FAG was formed to evaluate fracture prediction capabilities currently used in safety assessments of nuclear vessel components. Members are from laboratories and research organizations in Western Europe, Japan, and the United States of America (U.S.A.). To meet its obligations, the CSNI/FAG planned Project FALSIRE to assess various fracture methodologies through interpretive analyses of selected large-scale fracture experiments. The six experiments used in Project FALSIRE (performed in the Federal Republic of Germany, Japan, the United Kingdom, and the U.S.A.) were designed to examine various aspects of crack growth in reactor pressure vessel (RPV) steels under pressurized-thermal-shock (PTS) loading conditions. The CSNI/FAG established a common format for comprehensive statements of these experiments, including supporting information and available analysis results. These statements formed the basis for evaluations that were performed by an international group of analysts using a variety of structural and fracture mechanics techniques. A 3-d workshop was held in Boston, Massachusetts (U.S.A.), during May 1990, at which 37 participants representing 19 organizations presented a total of 39 analyses of the experiments. The analysis techniques employed by the participants included engineering and finite-element methods, which were combined with $J_{R}$ fracture methodology and the French local approach. For each experiment, analysis results provided estimates of variables such as crack growth, crack-mouth-opening displacement, temperature, stress, strain, and applied $J$ and $K$ values. A comparative assessment and discussion of the analysis results are presented; also, the current status of the entire results data base is summarized. Generally, these results highlight the importance of adequately modeling structurai behavior of specimens before performing fracture mechanics evaluations. Applications of the various fracture methodologies were found to be partially successful in some cases but not in others. Based on these assessments, some conclusions concerning predictive capabilities of selected ductile fracture methodologies, as applied to RPVs subjected to PTS loading, are given, and recommendations for future development of fracture methodologies are made. Finally, proposals for future work in the context of a Phase II of Project FALSIRE are included. 


\section{Contents}

Abstract $\ldots \ldots \ldots \ldots \ldots \ldots \ldots \ldots \ldots \ldots \ldots \ldots \ldots \ldots \ldots \ldots \ldots$ iii

List of Figures $\ldots \ldots \ldots \ldots \ldots \ldots \ldots \ldots \ldots \ldots \ldots \ldots \ldots \ldots$ vii

List of Tables $\ldots \ldots \ldots \ldots \ldots \ldots \ldots \ldots \ldots \ldots \ldots \ldots \ldots \ldots \ldots \ldots$

Executive Summary $\ldots \ldots \ldots \ldots \ldots \ldots \ldots \ldots \ldots \ldots \ldots \ldots \ldots \ldots \ldots$

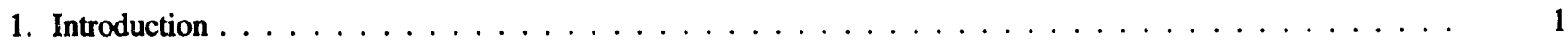

References $\ldots \ldots \ldots \ldots \ldots \ldots \ldots \ldots \ldots \ldots \ldots \ldots \ldots \ldots \ldots \ldots \ldots \ldots \ldots \ldots \ldots$

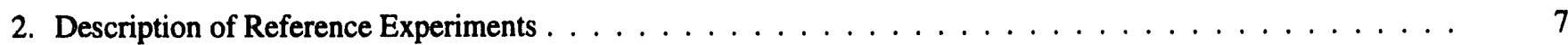

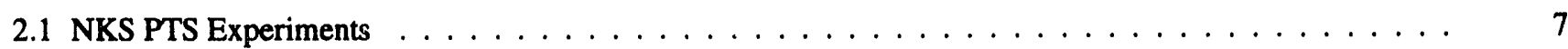

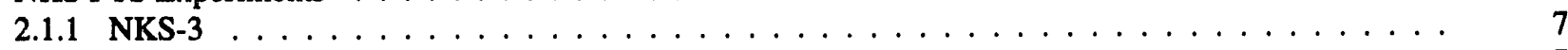

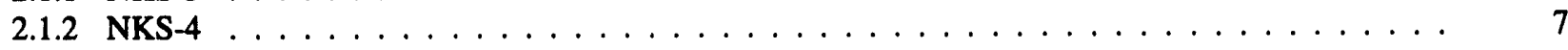

2.2 PTSE-2 $\ldots \ldots \ldots \ldots \ldots \ldots \ldots \ldots \ldots \ldots \ldots \ldots \ldots \ldots \ldots \ldots \ldots$

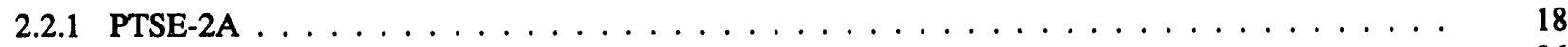

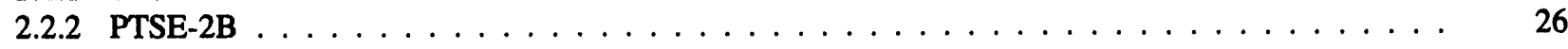

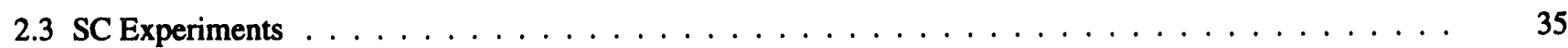

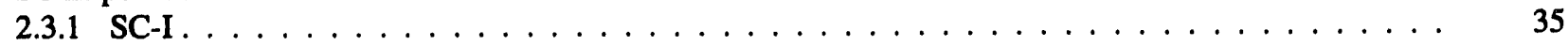

2.3 .2 SC-II $\ldots \ldots \ldots \ldots \ldots \ldots \ldots \ldots \ldots \ldots \ldots \ldots \ldots \ldots \ldots$

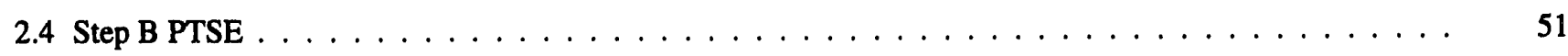

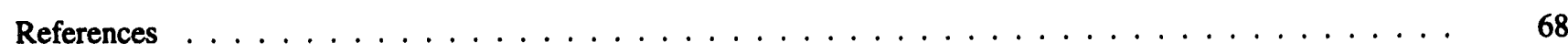

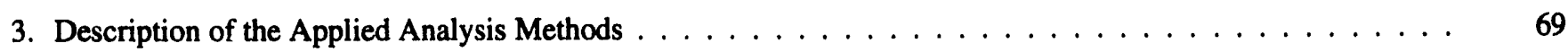

3.1 Structural Mechanics Analysis Methods $\ldots \ldots \ldots \ldots \ldots \ldots$

3.2 Fracture Mechanics Analysis Methods . . . . . . . . . . . . . . . . . . . . 69

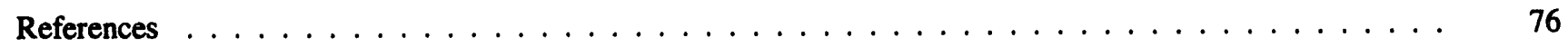

4. Comparative Assessments and Discussion of the Analysis Results . . . . . . . . . . . . . . . . 79

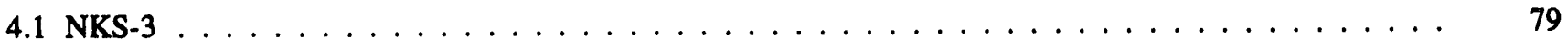

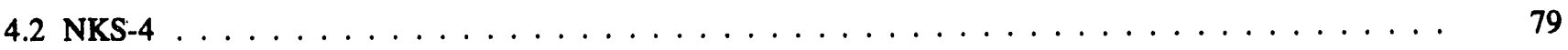

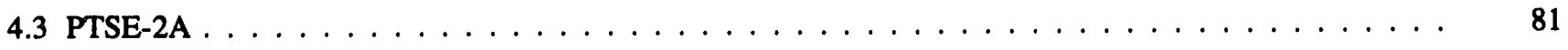

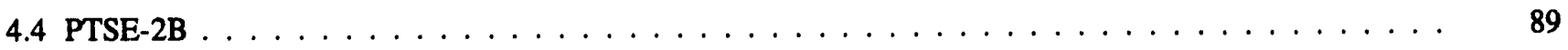

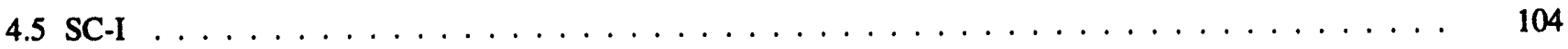

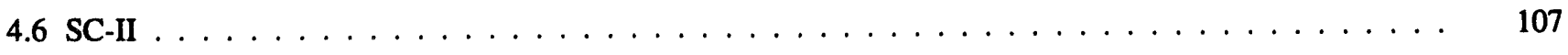

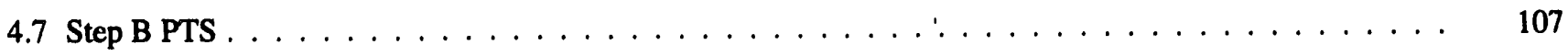




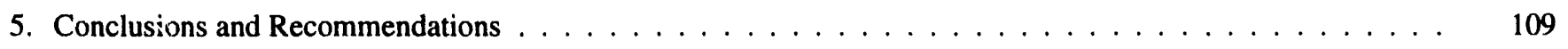

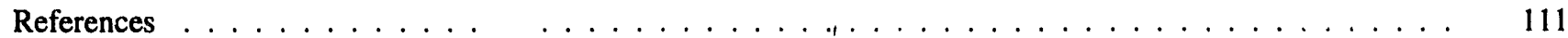

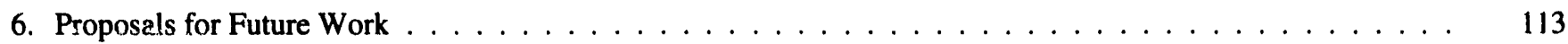

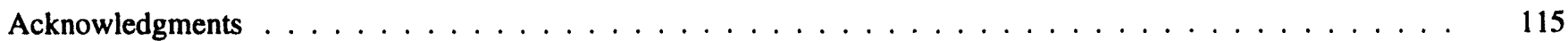

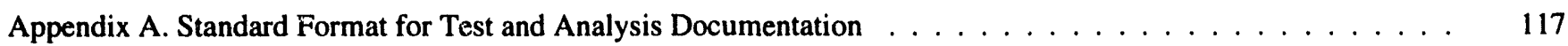

Appendix B. Additional Analysis Results from Project FALSIRE $\ldots \ldots \ldots \ldots \ldots \ldots \ldots$ 


\section{List of Figures}

Figure

Page

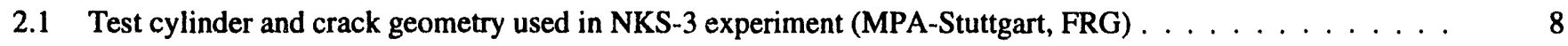

2.2 Loading and test material data $(\mathrm{NKS}-3$ specimen $) \ldots \ldots \ldots \ldots \ldots$

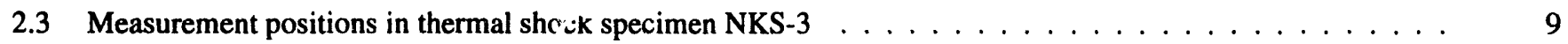

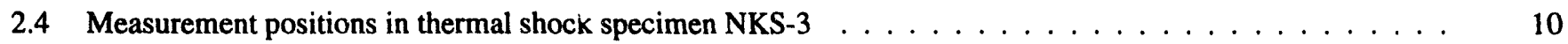

2.5 Charpy V-notch impact energy vs temperature for NKS-3 material $\ldots \ldots \ldots \ldots \ldots$

2.6 Fracture toughness vs temperature for NKS-3 material $\ldots \ldots \ldots \ldots \ldots \ldots$

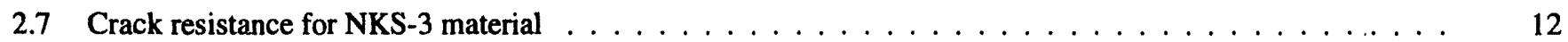

2.8 Internal pressure vs time in $\mathrm{NKS}-3$ experiment $\ldots \ldots \ldots \ldots \ldots \ldots \ldots$

2.9 Axial load vs time in NKS-3 experiment $\ldots \ldots \ldots \ldots \ldots \ldots \ldots$

2.10 Measured temperature profiles across wall thickness as function of time (NKS-3 experiment) $\ldots \ldots \ldots \ldots$

2.11 Results from crack extension measurement on fracture surface of NKS-3 specimen $\ldots \ldots \ldots \ldots$

2.12 Test cylinder and crack geometry used in NKS-4 experiment (MPA-Stuttgart, FRG) . . . . . . . . . 15

2.13 Loading and material data $(\mathrm{NKS}-4$ specimen $) \ldots \ldots \ldots \ldots \ldots$

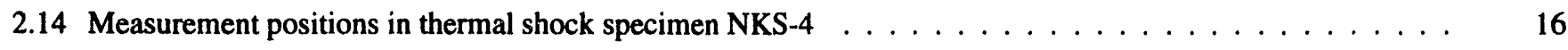

2.15 Temperature-dependent true stress-true strain curves for NKS-4 specimen $\ldots \ldots \ldots \ldots \ldots$

2.16 Charpy V-notch impact energy vs temperature for NKS-4 material $\ldots \ldots \ldots \ldots \ldots$

2.17 Crack resistance of NKS-4 material: (a) detailed plot of $\mathrm{J}_{\mathrm{R}}$ curve at $160^{\circ} \mathrm{C}(b)$ summary

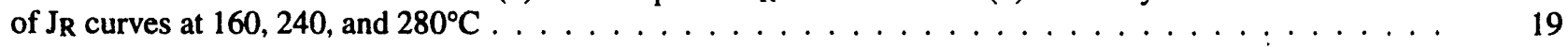

2.18 Internal pressure vs time in NKS-4 experiment: $(a)$ NKS- $4 / 1 ;(b)$ NKS- $4 / 2 \ldots \ldots \ldots \ldots$

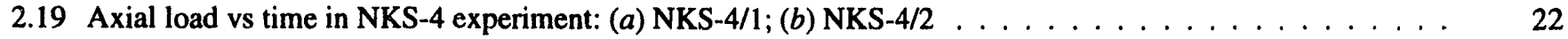

2.20 Measured temperature profiles across wall thickness as function of time in NKS-4 experiments:

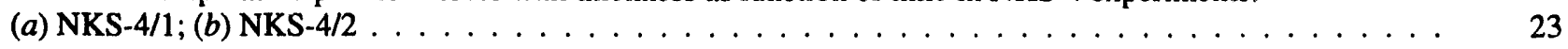

2.21 Heat transfer coefficients vs time for NKS-4 experiments: $(a)$ NKS-4/1; $(b)$ NKS- $4 / 2 \ldots \ldots \ldots$

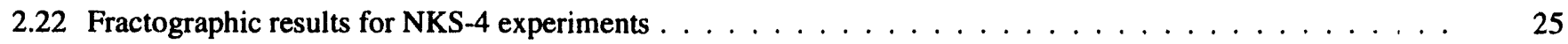

2.23 Test vessel and cràck geometry for PTSE-2A, transient A (ORNL, U.S.A) $\ldots \ldots \ldots \ldots$

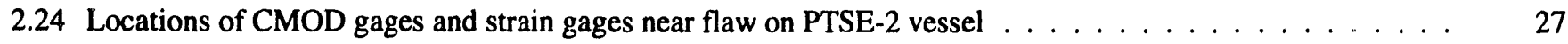

2.25 Thermocouple thimble and near-surface thermocouple locations in PTSE-2 vessel . . . . . . . . . . . 28

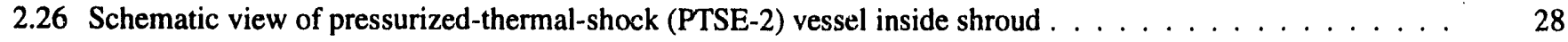




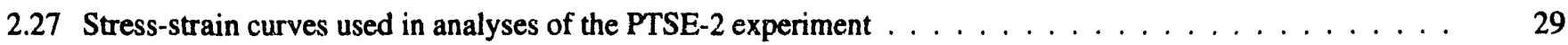

2.28 (a) Crack-arrest toughness data for characterization piece PTC1 (PTSE-2); (b) fracture toughness data for characterization piece PTC1 (PTSE-2) $\ldots \ldots \ldots \ldots \ldots \ldots \ldots \ldots$

2.29 Comparison of J-integral $\left(\mathrm{J}_{\mathrm{m}}\right)$ resistance curves at three test temperatures for PTSE-2 (TS orientation)

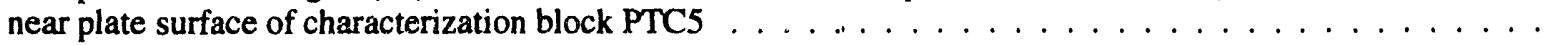

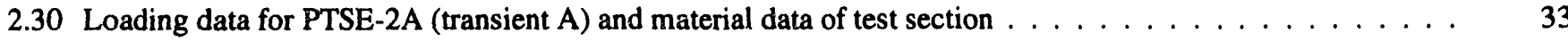

2.31 Temperature and pressure vs time data recorded for PTSE-2 transients: (a) PTSE-2A and (b) PTSE-2B . . 34

2.32 Time-dependent values of $h$ (heat convection coefficient) and $T_{B}$ (bulk coolant temperature) established from pretest thermo-hydraulic measurement and heat transfer analyses for PTSE-2A . . . . . . 36

2.33 CMOD vs time at center of flaw for PTSE-2A transient $\ldots \ldots \ldots \ldots \ldots \ldots$

2.34 CMOD vs time during early phase of PTSE-2A measured at center of flaw $(\mathrm{z}=0)$ and $100 \mathrm{~mm}$

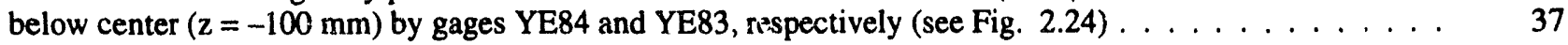

2.35 CMOD vs time for final phase of PTSE-2A $\ldots \ldots \ldots \ldots \ldots$

2.36 Crack geometry and loading data for PTSE-2B, transient $\mathbf{F} \ldots \ldots \ldots \ldots \ldots$

2.37 Typical CMOD behavior during PTSE-2B transient $\ldots \ldots \ldots \ldots \ldots \ldots \ldots \ldots$

2.38 Photograph of a central segment of PTSE-2 fracture surfaces $\ldots \ldots \ldots \ldots \ldots$

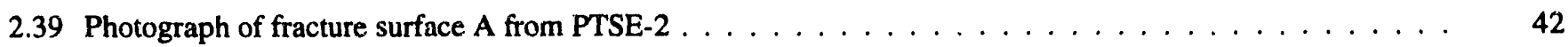

2.40 Experimental facility at AEA-Risley that applies centrifugal loads through high-speed spinning and thermal-shock loads through spraying of inner surface of thick-wall test cylinders . . . . . . . . .

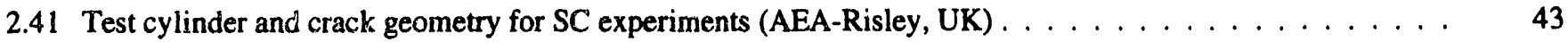

2.42 Instrumentation layout for first spinning cylinder experiment $(\mathrm{SC}-\mathrm{I}) \ldots \ldots \ldots \ldots$

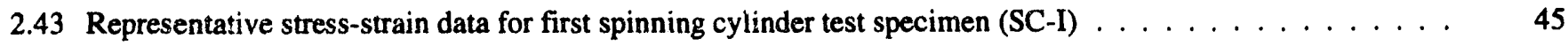

2.44 Loading and material data for first spinning cylinder test $(\mathrm{SC}-\mathrm{I}) \ldots \ldots \ldots \ldots$

2.45 (a) Identification of initiation from alternating current potential drop (ACPD) data (SC-I);

(b) crack profile in first spinning cylinder test $\ldots \ldots \ldots \ldots \ldots \ldots$

2.46 (a) Angular velocity vs crack extension data from three ACPD measurement stations utilized to develop crack time curve for the analysis of SC-I; $(b)$ corrected COD vs speed for the first spinning cylinder test $(\mathrm{SC}-\mathrm{I}) \ldots \ldots \ldots \ldots \ldots \ldots \ldots \ldots \ldots \ldots \ldots \ldots$

2.47 Instrumentation layout for second spinning cylinder experiment $(\mathrm{SC}-\mathrm{II}) \ldots \ldots \ldots \ldots$

2.48 Small- and large-specimen fracture toughness curves for the $\mathrm{SC}$ experiments . . . . . . . . . . . 57

2.49 Loading data for the $\mathrm{SC}-\mathrm{II}$ experiment $\ldots \ldots \ldots \ldots \ldots \ldots \ldots \ldots$

2.50 (a) Comparison of measured and computed temperature histories for the second spinning cylinder test (upper thermocouple array, SC-II); (b) crack profile in the second spinning cylinder test (SC-II); (c) COD vs time for SC-II; and $(d)$ hoop strains vs time for SC-II . . . . . . . . . . . . . . . . 
2.51 Specimen and crack geometry for the Step B test (JAPEIC, Japan) $\ldots \ldots \ldots \ldots$

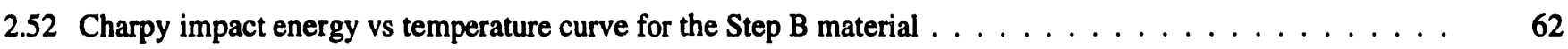

$2.53 \mathrm{~K}_{\mathrm{Ic}}$ vs temperature curve for the Step B material $\ldots \ldots \ldots \ldots \ldots \ldots$

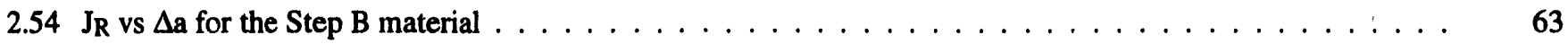

2.55 Thermal/mechanical loading and material characteristics for Step B test material characteristics _ . . . . . 64

2.56 Time history of temperature at discrete points in the Step B test specimen $\ldots \ldots \ldots \ldots$

2.57 Time history of convective heat transfer coefficient for Step B test $\ldots \ldots \ldots \ldots$

2.58 Time history of surface strain near initial crack for Step B test $\ldots \ldots \ldots \ldots$

2.59 Time history of deformation at center of Step B test specimen $\ldots \ldots \ldots \ldots$

2.60 Initial crack and measured stable crack extension in Step B test $\ldots \ldots \ldots \ldots \ldots$

4.1 CMOD vs time for NKS-3 experiment $\ldots \ldots \ldots \ldots \ldots \ldots \ldots \ldots$

4.2 Axial strains at inner surface $184 \mathrm{~mm}$ above crack ligament vs time for NKS-3 experiment . . . . . . . 80

$4.3 \mathrm{~J}$-integral vs time for $\mathrm{NKS}-3$ experiment $\ldots \ldots \ldots \ldots \ldots \ldots$

4.4 Effective stresses on ligament $t=0 \mathrm{~s}$ (NKS-3 experiment) $\ldots \ldots \ldots \ldots \ldots \ldots$

4.5 Effective stresses on ligament $t=60 \mathrm{~s}(\mathrm{NKS}-3$ experiment $) \ldots \ldots \ldots \ldots$

4.6 Effective stresses pn ligament $t=300 \mathrm{~s}$ (NKS-3 experiment) $\ldots \ldots \ldots \ldots \ldots \ldots$

4.7 Effective stresses on ligament $t=600$ s $($ NKS-3 experiment $) \ldots \ldots \ldots \ldots \ldots$

4.8 Effective stresses on ligament $t=1200 \mathrm{~s}$ (NKS-3 experiment) $\ldots \ldots \ldots \ldots \ldots$

4.9 Stress triaxiality on ligament $\mathrm{t}=0 \mathrm{~s}(\mathrm{NKS}-3$ experiment $) \ldots \ldots \ldots \ldots$

4.10 Stress triaxiality on ligament $t=60 \mathrm{~s}$ (NKK-3 experiment) $\ldots \ldots \ldots \ldots \ldots \ldots$

4.11 Stress triaxiality on ligament $t=300 \mathrm{~s}$ (NKS-3 experiment) $\ldots \ldots \ldots \ldots$

4.12 Stress triaxiality on ligament $t=600 \mathrm{~s}$ (NKS-3 experiment) $\ldots \ldots \ldots \ldots$

4.13 Stress triaxiality on ligament $t=1200 \mathrm{~s}$ (NKS-3 experiment) $\ldots \ldots \ldots \ldots$

4.14 CMOD vs time for $\mathbf{N K S}-4$ experiment $\ldots \ldots \ldots \ldots \ldots \ldots \ldots \ldots \ldots \ldots \ldots$

4.15 Axial strains at inner surface $184 \mathrm{~mm}$ above crack ligament vs time for NKS-4 experiment $\ldots \ldots \ldots 8$

$4.16 \mathrm{~J}$-integral vs time for $\mathrm{NKS}-4$ experiment $\ldots \ldots \ldots \ldots \ldots \ldots$

4.17 Effective stresses on ligament $t=0 \min ($ NKS-4 experiment $) \ldots \ldots \ldots 1$

4.18 Effective stresses on ligament $t=1 \min ($ NKS-4 experiment $) \ldots \ldots \ldots \ldots$

4.19 Effective stresses on ligament $t=5 \min ($ NKS-4 experiment $) \ldots \ldots \ldots \ldots 2$ 
4.20 Effective stresses on ligament $t=10 \min ($ NKS- -4 experiment $) \ldots \ldots \ldots \ldots \ldots$

4.21 Stress triaxiality on ligament $\mathrm{t}=0 \mathrm{~min}(\mathrm{NKS}-4$ experiment $) \ldots \ldots \ldots \ldots$

4.22 Stress triaxiality on ligament $t=1 \min (\mathrm{NKS}-4$ experiment $) \ldots \ldots \ldots \ldots$

4.23 Stress triaxiality on ligament $t=5$ min $(\mathrm{NKS}-4$ experiment $\ldots \ldots \ldots \ldots \ldots \ldots$

4.24 Stress triaxiality on ligament $\mathrm{t}=10 \mathrm{~min}(\mathrm{NKS}-4$ experiment $) \ldots \ldots \ldots \ldots \ldots$

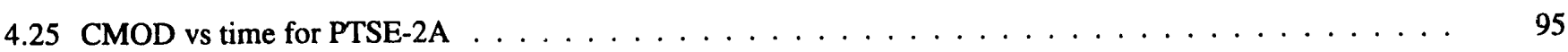

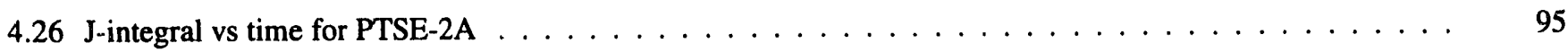

4.27 Effective stresses on ligament $\mathrm{t}=0 \mathrm{~s}$ (PTSE-2A experiment) $\ldots \ldots \ldots \ldots \ldots$

4.28 Effective stresses on ligament $\mathrm{t}=30 \mathrm{~s}$ (PTSE-2A experiment) $\ldots \ldots \ldots \ldots \ldots \ldots$

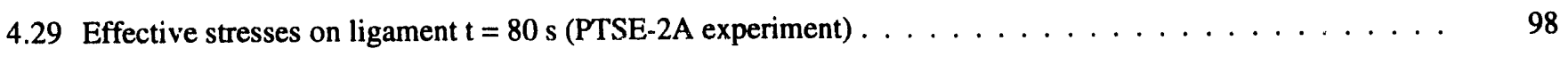

4.30 Effective stresses on ligament $\mathrm{t}=190 \mathrm{~s}$ (PTSE-2A experiment) $\ldots \ldots \ldots \ldots$

4.31 Stress triaxiality on ligament $\mathrm{t}=0 \mathrm{~s}(\mathrm{PTSE}-2 \mathrm{~A}$ experiment $\ldots \ldots \ldots \ldots \ldots$

4.32 Stress triaxiality on ligament $\mathrm{t}=30 \mathrm{~s}$ (PTSE-2A experiment) $\ldots \ldots \ldots \ldots$

4.33 Stress triaxiality on ligament $\mathrm{t}=80 \mathrm{~s}$ (PTSE-2A experiment) $\ldots \ldots \ldots \ldots$

4.34 Stress triaxiality on ligament $\mathrm{t}=190 \mathrm{~s}$ (PTSE-2A experiment) $\ldots \ldots \ldots \ldots$

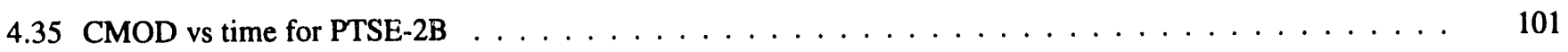

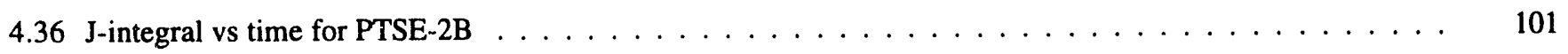

4.37 Effective stresses on ligament $\mathrm{t}=45 \mathrm{~s}$ (PTSE-2B experiment) $\ldots \ldots \ldots \ldots$

4.38 Effective stresses on ligament $\mathrm{t}=145 \mathrm{~s}$ (PTSE-2R experiment) $\ldots \ldots \ldots \ldots$

4.39 Effective stresses on ligament $t=345 \mathrm{~s}$ (PTSE-2B experiment) $\ldots \ldots \ldots \ldots$

4.40 Hoop stresses vs wall thickness for PTSE-2B $\ldots \ldots \ldots \ldots \ldots \ldots$

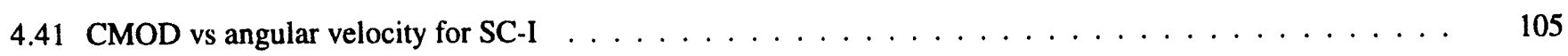

$4.42 \mathrm{~J}$-integral vs angular velocity for SC-I $\ldots \ldots \ldots \ldots \ldots \ldots \ldots$

4.43 Hoop stresses vs wall thickness for SC-I $\ldots \ldots \ldots \ldots \ldots \ldots$

$4.44 \mathrm{~J}$-integral vs time for SC-II $\ldots \ldots \ldots \ldots \ldots \ldots \ldots \ldots \ldots$

4.45 Results of 3-D elastic plastic analysis (analysis 17 ) for $\mathrm{SC}-\mathrm{II} \quad \ldots \ldots \ldots \ldots$

B.1 Axial stresses vs wall thickness $t=420 \mathrm{~s}(\mathrm{NK} \mathrm{s}-3$ experiment $) \ldots \ldots \ldots$

B.2 Axial stresses vs wall thickness $t=300 \mathrm{~s}$ (NKS-4 experiment) $\ldots \ldots \ldots \ldots$

B.3 Effective stresses on the ligament $t=0,30,80$, and 190 s (PTSE-2A experiment) $\ldots \ldots \ldots 138$ 
B.4 Hoop stresses vs wall thickness for PTSE-2A $\ldots \ldots \ldots \ldots \ldots \ldots \ldots \ldots$

B.5 Effective stresses on ligament $t=45,145$, and $345 \mathrm{~s}$ (PTSE-2B experiment) $\ldots \ldots \ldots 139$

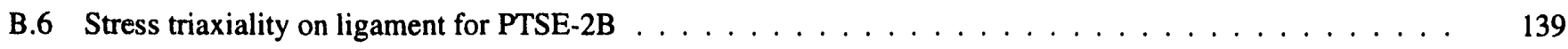

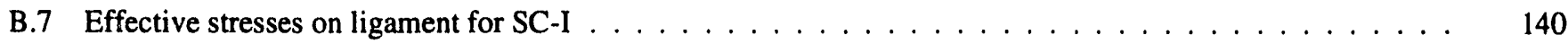

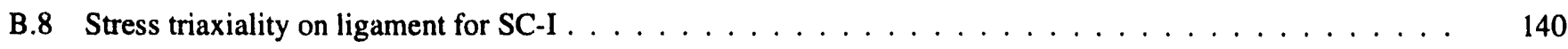

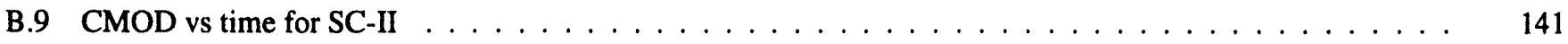

B.10 Effective stresses on ligament $($ SC-II experiment) $\ldots \ldots \ldots \ldots \ldots \ldots \ldots \ldots$

B.11 Effective stresses vs wall thickness (SC-II experiment) $\ldots \ldots \ldots \ldots \ldots \ldots$

B.12 SC-II, hoop stresses vs wall thickness (SC-II experiment) $\ldots \ldots \ldots \ldots \ldots \ldots$ 


\section{List of Tables}

Table

Page

1.1 Large-scale fracture experiments analyzed in CSNIFAG Project FALSIRE $\ldots \ldots \ldots \ldots \ldots$

1.2 Organizations participating in the Project FALSIRE Workshop, Boston, May $1990 \ldots \ldots$. . . . . . . 2

1.3 Summary of test objectives of large-scale experiments used in Project FALSIRE . . . . . . . . . . . 3

1.4 Summary of Project FALSIRE reference experiments $\ldots \ldots \ldots \ldots \ldots \ldots \ldots$

1.5 Summary of Project FALSIRE analysis techniques $\ldots \ldots \ldots \ldots \ldots \ldots$

2.1 Temperature-dependent material data for NKS-3 specimen $\ldots \ldots \ldots \ldots \ldots$

2.2 Thermal material data for $\mathrm{NKS}-3$ specimen $\ldots \ldots \ldots \ldots \ldots \ldots$

2.3 Temperature-dependent material data for NKS-4 specimen $\ldots \ldots \ldots \ldots \ldots$

2.4 Summary of $J_{R}$ curve test of $\mathrm{CT}$ specimen from NKS-4 material at $160^{\circ} \mathrm{C} \ldots \ldots \ldots$

2.5 Initial conditions and loading parameters for the two transients in the NKS-4 experiment $\ldots \ldots \ldots$

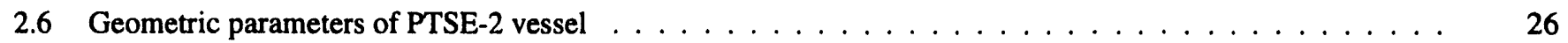

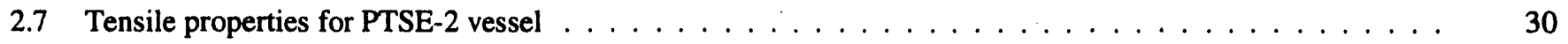

2.8 Physical properties for PTSE-2 vessel $\ldots \ldots \ldots \ldots \ldots \ldots \ldots$

2.9 Fracture properties for PTSE-2 material $\ldots \ldots \ldots \ldots \ldots \ldots$

2.10 Updated ductile-shelf fracture-toughness results for PTSE-2 2 1/4 Cr-1 Mo

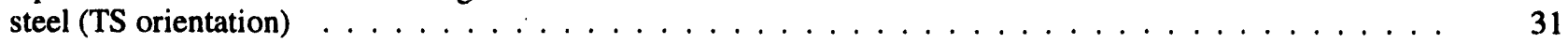

2.11 Experimental pressure vs time values for PTSE-2A and $-2 \mathrm{~B}$ at selected time steps $\ldots \ldots \ldots$

2.12 Events identified by transient data in PTSE-2A and -2 B $\ldots \ldots \ldots \ldots \ldots$

2.13 Fracture features shown in Fig. $2.38 \ldots \ldots \ldots \ldots \ldots \ldots \ldots \ldots$

2.14 Dimensions of fracture features of the PTSE-2 flaw $\ldots \ldots \ldots \ldots \ldots$

2.15 Tensile data at $290^{\circ} \mathrm{C}$ for first spinning cylinder test material $\ldots \ldots \ldots \ldots \ldots \ldots$

$2.16 \mathrm{SC}-\mathrm{I} \mathrm{J}$ vs $\Delta \mathrm{a}$ values from unloading compliance tests with physical measurements of final crack

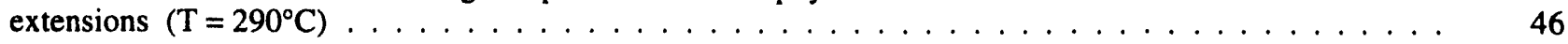

2.17 Regression coefficients for power-law curve fit to J vs $\Delta$ a data for SC-I

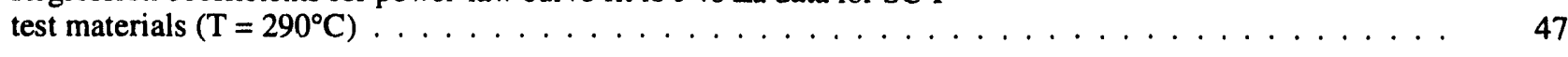

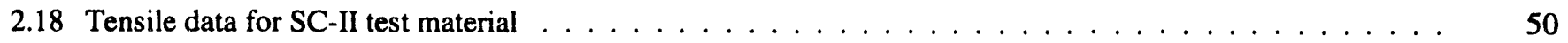

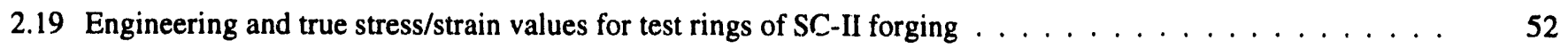

2.20 Physical properties for SC-II test material $\ldots \ldots \ldots \ldots \ldots \ldots \ldots \ldots \ldots$ 
Contents

Table

Page

$2.21 \mathrm{~J}$ vs $\Delta \mathrm{a}$ values from unloading compliance tests with physical measurements of final crack extension

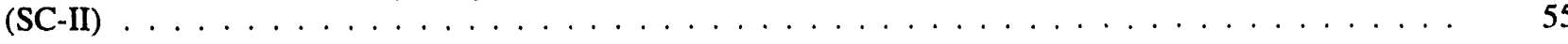

2.22 Regression coefficients in the expression $\mathrm{J}=\mathrm{A}(\Delta \mathrm{a})^{\mathrm{B}}(\mathrm{SC}-\mathrm{II}) \ldots \ldots$

2.23 Summary of ductile tearing in SC-I and -II under mechanical and/or thermal shock loading conditions . . . . . . . . . . . . . . . . . . . . . 60

2.24 Young's modulus and coefficient of thermal expansion for Step B test material . . . . . . . . . . . . . 61

2.25 True stress vs true strain data for Step B test material . . . . . . . . . . . . . . . . . . .

3.1 Summary of finite-element applications to analysis of Project FALSIRE reference experiments . . . . . . . . 70

3.2 Summary of estimation scheme applications to analysis of Project FALSIRE reference experiments . . . . 73

4.1 NKS-3- selected characteristics of FE analyses $\ldots \ldots \ldots$

4.2 NKS-4- selected characteristics of FE analyses $\ldots \ldots \ldots$

4.3 PTSE-2A - selected characteristics of FE analyses . . . . . . . . . . . . . . . . . . 96

4.4 PTSE-2B - selected characteristics of FE analyses $\ldots \ldots \ldots 102$

5.1 Comparative assessment of structural behavior in Project FALSIRE reference experiments . . . . . . . . . 109

5.2 Comparative assessment of fracture behavior in Project FALSIRE reference experiments . . . . . . . . . . 110 


\section{EXECUTIVE SUMMARY}

This report summarizes the recently completed Phase I of the Project for Fracture Analysis of Large-Scale International Reference Experiments (Project FALSIRE). Project FALSIRE was created by the Fracture Assessment Group (FAG) of Principal Working Group No. 3 (PWG/3) of the Organization for Economic Cooperation and Development/Nuclear Energy Agency's Committee on the Safety of Nuclear Installations (CSNI). Motivation for the project was derived from recognition by the CSNI-PWG/3 that inconsistencies were being revealed in predictive capabilities of a variety of fracture assessmemt methods, especially in ductile fracture applications. As a consequence, the CSNI/FAG was formed to evaluate fracture prediction capabilities currently used in safety assessments of nuclear components. Members are from laboratories and research organizations in Western Europe, Japan, and the United States (U.S.A.). On behalf of the CSNI/FAG, the U.S. Nuclear Regulatory Commission's Heavy-Seition Steel Technology Program at the Oak Ridge National Laboratory (ORNL) and the Gesellschaft für Anlagen - und Reaktorsicherheit (GRS), Köln, Federal Republic of Germany (FRG), had responsibility for organization arrangements related to Project FALSIRE. The group is chaired by H. Schulz from GRS, Köln, FRG.

To meet its objectives, the CSNI/FAG planned an international project to assess various fracture methodologies through interpretive analyses of selected large-scale fracture experiments. A survey of large-scale experiments and related analyses was give, at the first meeting of the group in May 1988 at Stuttgart (FRG). Priority was given to thermal-shock experiments to include combinations of mechanical and thermal loads. Reference experiments were selected by the CSNI/FAG at their second meeting in August 1989 at Monterey, California (U.S.A.), for detailed analysis and interpretation. Before the 1989 Monterey meeting, the CSNI/FAG established a common format for comprehensive statements of these experiments, including supporting information and available analysis results. These statements formed the basis for evaluations of the experiments that were performed by an international group of analysts using a variety of structural and fracture mechanics techniques. A 3-d workshop was held in Boston, Massachusetts (U.S.A.), during May 1990, at which all participating analysts examined these evaluations in detail.

The experiments used in Project FALSIRE were designed to examine various aspects of crack growth in reactor pressure vessel steels under pressurized-thermal-shock (PTS) loading conditions. These conditions were achieved in three of the experiments by internally pressurizing a heated cylindrical vessel containing a sharp crack and thermally shocking it with a coolant on the inner (NKS-3 and -4 , from Materialprüfungsanstalt, Stuttgart, FRG) or outer (PTSE-2, from ORNL, U.S.A.) surface. In a series of spinning cylinder (SC) experiments (from Atomic Energy Authority Technology, U.K.), a thick cylinder with a deep crack on the inner surface was rotated about its axis in a specially constructed rig (SC-I) and was thermally shocked with a water spray (SC-II). A Japanese (Step B, from Japan Power and Engineering Inspection Corporation, Japan) test used a large surface-cracked plate subjected to combined mechanical loading of tension and bending, coordinated with a thermal shock of the cracked surface to model PTS loading conditions. Data from the experiments provided in the CSNI/FAG problem statements included pretest material characterization, geometric parameters, loading histories, instrumentation and measured data [e.g., temperature and strains, crack-mouth-opening .displacements (CMODs), and crack-extension histories].

Based on the CSNI/FAG problem statements, 37 participants representing 19 organizations performed a total of 39 analyses of the experiments. The analysis techniques employed by the participants included engineering methods [R6, General Electric/Electric Power Research Institute estimation scheme, deformation plasticity failure assessment diagram] and finite-element methods; these techniques were combined with applications of $J_{R}$ methodology and the French local approach. The finite-element applications included both two- and three-dimensional (2-and 3-D) models, as well as deformation plasticity and incremental thermo-elastic-plastic constitutive formulations. Crack-growth models based on nodal release techniques were used to generate both application- and generation-mode solutions for several of the experiments. For each of the experiments, analysis results provided estimates of variables including crack growth, CMOD, temperatures, strains, stresses, and applied $\mathrm{J}$ and $\mathrm{K}$ values. Conditions of crack stability and instability were identified in the experiments. Where possible, computed values were compared with measured data.

Based on results from the Project FALSIRE Workshop, several observations can be made concerning predictive capabilities of current fracture assessment methodologies as reflected in the large-scale experiments. Generally, these experiments were designed to examine fracture methodologies under prototypical combinations of geometry, constraint, and loading conditions. However, because complexities of the experiments do not permit a clear separation of the effects of the many variables involved, it has proved difficult to interpret the aralyses of those transients for which expected results were: not achieved. Modeling requirements for the experiments incorporate history-dependent mechanical, thermal, and body force loadings; temperature-dependent material and fracture toughness properties; specially designed materials; 
residual stress states; and 3-D effects. Interactions of both cleavage and ductile modes of fracture must be modeled for certain transients. For these reasons, it could be anticipated that comparisons of analysis predictions with available structural data from the experiments would yield results that vary significantly. Many observations from the comparative assessment of the analysis results have not yet been explained, but Chap. 4 and Appendix B of this report contain a data base of analysis results available for further studies on separate effects. The analysis results highlight the importance of obtaining high-quality material properties and structural response data (CMOD, strains, etc.) from the experiments and accurately calculating structural behavior of the specimen before performing fracture mechanics evaluations. In particular, variables must be carefully selected and reliably measured to provide a minimum set of data for validating these structural models. This requirement was not uniformly achieved in all of the large-scale experiments examined in the Project FALSIRE Workshop.

In applications of $J_{\mathbf{R}}$ methodology based on small specimen data, all analyses correctly distinguished between stable c.ack growth and ductile instability conditions for each experiment. These analyses include both estimation schemes and detailed finite-element analyses. However, as a technique to predict crack extension, $J_{R}$ methodology was partially successful in some cases (NKS experiments) but not in others (PTSE-2, SC experiments). Fracture assessments based on compact-tension (CT) specimens overestimated stable crack growth in the cases of NKS-4, SC-I and -II, and Step B PTS because the crack resistance in large-scale test specimens is bigger than pr edicted by small conventional specimens (e.g., Ci-25). SC-I and -II fracture results show that crack growth can be described quite well with the J-integral and the $J_{R}$ curves of the large-scale test specimen. Therefore, future work has to be concentrated on extension of the $J_{R}$ methodology by a parameter that controls the geometry dependence of the crack resistance. In PTSE-2, the first phase; of stable crack extension is underestimated because the crack loading also represented in CMOD is underestimated. Furthermore, differences between pretest characterization data and posttest in situ data for material and fracture toughness properties gave rise to questions concerning whether $J_{R}$ curves from CT specimens were representative of the flawed region of the vessel. None of these temperature-dependent $J_{R}$ curves were consistent with all phases of ductile tearing,observed in PTSE-2. It should be pointed out that the PTSE-2 transient included load-history (i.e., warm-prestressing) effects that were not incorporated into the $J_{R}$ methodology.

The substantial differences between fracture toughness curves generated from the SCs and from CT specimens focused attention on other factors, which include the possibility that crack-tip behavior in the SC is not characterized by a single correlation parameter. Alternative criveria under consideration include two-parameter models in which $\mathrm{K}$ or $\mathrm{J}$ is augmented by the next higher-order term $\mathrm{T}$ or $\mathrm{Q}$ in the series expansion of the stresses around the crack tip. Other measures considered in dealing with the transfer of small specimen data to large structures include the stress triaxiality parameter $q$, which is proportional to the ratio of hydrostatic to effective stress. The temperature dependence of the crack resistance measured with CT specimens shows a decrease with increasing temperature for PTSE-2, NKS-3, and Step B PTS but shows an increase for NKS-4 material. Also, the French local approach has been applied as an alternative to $J_{R}$ methodology for performing fracture toughness evaluations but only in the case of NKS-3. For the SCs, clarification of the initial stress state in front of the crack tip (due to cyclic fatiguing) may be an important consideration.

Organizations involved in Phase I of the FALSIRE Project desire to proceed with this type of work regarding the evaluation of fracture mechanics analysis methods for combined mechanical thermal loading conditions in Phase II. Stimulated by the somewhat unfavorable results of the analyses for PTSE-2, the main objective of Phase II should be to investigate cracks of a limited depth, preferably' showing two stages of crack extension. An example would be limited stable crack extension followed by limited unstable crack extension. Furthermore, special attention should be given to the behavior of shorter cracks. Investigation of crack extension in connection with cladded surfaces is of special interest.

Experimental research programs are being performed in this subject area in France, the FRG, Japan, the U.K., and in the Russian Republic. Contacts with the different organizations involved in these tests have been established. Reference documents that could be used to document the information available are under preparation. Two or three tests that would fulfill the outlined goals will be selected in the coming months. A call for participation in Phase II is foreseen in the second half of 1993. 


\section{INTRODUCTION}

This report summarizes the recently completed Phase I of the Project for Fracture Analysis of Large-Scale International Reference Experiments (Project FALSIRE). Project FALSIRE was created by the Fracture Assessment Group (FAG) of Principal Working Group No. 3 (PWG/3) of the Organization for Economic Cooperation and Development (OECD)/Nuclear Energy Agency's (NEA's) Committee on the Safety of Nuclear Installations (CSNI). Motivation for the project was derived from recognition by the CSNI-PWG/3 that inconsistencies were being revealed in predictive capabilities of a variety of fracture assessment methods, especially in ductile fracture applications. As a consequence, the CSNI/FAG was formed to evaluate fracture prediction capabilities currently used in safety assessments of nuclear components. Members are from laboratories and research organizations in Western Europe, Japan, and the United States of America (U.S.A.). On behalf of the CSNI/FAG, the U.S. Nuclear Regulatory Commission's (NRC's) Heavy-Section Steel Technology (HSST) Program at the Oak Ridge National Laboratory (ORNL) and the Gesellschaft für Anlagen-und Reaktorsicherheit (GRS), Köln, Federal Republic of Germany (FRG) had responsibility for organization arrangements related to Project FALSIRE. The group is chaired by H. Schulz from GRS, Köln, FRG.

To meet its objectives, the CSNI/FAG planned an international project to assess various fracture methodologies through interpretive analyses of selected large-scale fracture experiments. A number of large-scale fracture tests have been performed in recent years in several countries, and an even larger number of organizations have become cognizant of them and employed test results in attempts to verify analytical methods. A survey of large-scale experiments and related analyses was given at the first meeting of the group in May 1988 at Stuttgart (FRG). Priority was given to thermal-shock experiments to include combinations of mechanical and thermal loads. The reference experiments that were selected by the CSNI/FAG at their second meeting in August 1989 at Monterey, California (U.S.A.), for detailed analysis and interpretation are given in Table 1.1. Detailed descriptions of the conditions and results for each of the large-scale experiments studied in Project FALSIRE are given in Chap. 2 of this report.

Before the 1989 Monterey meeting, the CSNI/FAG established a common format for comprehensive statements of these experiments, including supporting information and available analysis results (see Appendix A). These statements formed the basis for evaluations that were performed by an international group of analysts using a variety of structural and fracture mechanics techniques (see Chap. 3). A 3-d workshop was held in Boston, Massachusetts (U.S.A.), during May 1990, at which all participating analysts examined these evaluations in detail. Organizations that participated in the workshop are listed in Table 1.2.

Table 1.1 Large-scale fracture experiments analyzed in CSNI/FAG Project FALSIRE

\begin{tabular}{lll}
\hline Experiment & \multicolumn{1}{c}{ Organization } & $\begin{array}{c}\text { Testing } \\
\text { country }\end{array}$ \\
\hline iNKS-3 & $\begin{array}{l}\text { Materialprufüngsanstalt (MPA), } \\
\text { Universität Stuttgart }\end{array}$ & FRG \\
NKS-4 & MPA, Universität Stuttgart & FRG \\
PTSE-2A & ORNL & U.S.A. \\
PTSE-2B & ORNL & U.S.A. \\
SC-I & $\begin{array}{l}\text { Atomic Energy Authority (AEA), } \\
\text { Risley }\end{array}$ & U.K. \\
SC-II & AEA, Risley & U.K. \\
Step B PTS & Japan Pov:er and Engineering & Japan \\
\hline
\end{tabular}


Introduction

Table 1.2 Organizations participating in the Project FALSIRE Workshop, Boston, May 1990

\begin{tabular}{ll}
\hline \multicolumn{1}{c}{ Organization } & Country \\
\hline AEA & U.K. \\
AZ/Electric Power Research Institute (EPRI) & U.S.A. \\
Babcock and Wilcox (B\&W) Nuclear Services & U.S.A. \\
Battelle Columbus Division & U.S.A. \\
Central Research Institute of Electric & Japan \\
Power Industry (CRIEPI) & \\
Centre D'Etudes Nucleaires de Saclay & France \\
Combustion Engineering (CE) & U.S.A. \\
Electricite de France (EDF) & France \\
Fraunhofer Institut fur Werkstoffmechanik (IWM) & FRG \\
GRS & FRG \\
JAPEIC & Japan \\
Korea Institute of Nuclear Safety & Korea \\
MPA, Universität Stuttgart & FRG \\
Mitsubishi Heavy Industries (MHI) & Japan \\
National Committee for Nuclear and & Italy \\
Alternative Energies (ENEA-DISP) & \\
Nuclear Electric & U.K. \\
OECD/NEA & France \\
Nuclear Installations Inspectorate & U.K. \\
NRC & U.S.A. \\
ORNL & U.S.A. \\
Paul Scherrer Institut & Switzerland \\
Southwest Research Institute (SWRI) & U.S.A. \\
Technical Research Centre of Finland (VTT) & Finland \\
University of Maryland & U.S.A. \\
University of Tennessee & U.S.A. \\
University of Tokyo & Japan \\
Participants: U.S.A. 17, FRG 5, France 4, U.K. 3, Japan 3, & \\
Finland 2, Switzerland 1, Korea 1, Italy 1; Total 37 & \\
\hline & \\
\hline
\end{tabular}

The experiments used in Project FALSIRE were designed to examine various aspects of crack growth in reactor pressure vessel (RPV) steels under pressurized-thermalshock (PTS) loading conditions. These conditions were achieved in three of the experiments by internally pressurizing a heated cylindrical vessel containing a sharp crack and thermally shocking it with a coolant on the inner (NKS-3 and -4) or outer [PTSE Experiment (PTSE)-2] surface. In the series of spinning cylinder (SC) experiments, a thick cylinder with a deep crack on the inner surface was thermally shocked with a water spray while simultaneously spinning the cylinder about its axis in a specially constructed rig. The Japanese Step B test used a large surface-cracked plate subjected to combined mechanical loading of tension and bending, coordinated with a thermal shock of the cracked surface to model PTS loading conditions. Data from the experiments provided in the CSNI/FAG problem statements included pretest material characterization, geometric parameters, loading histories, instrumentation and measured data [e.g., temperature and strains, crack-mouth opening displacements (CMODs), and crack-growth histories]. A summary of the objectives and of the material toughness, loading conditions, crack geometry, and crack growth for each experiment are listed in Tables 1.3 and 1.4, respectively. The analyses have concentrated on the phases of ductile crack growth having a range of $\sim 1$ to $6 \%$ of the initial crack depth in the NKS, SC, and Step B tests. In case of PTSE-2A, the first phase of ductile crack growth was $\sim 35 \%$ of the initial depth; in PTSE-2B, the corresponding crack growth was $9 \%$ of the initial depth. 
Table 1.3 Summary of test objectives of large-scale experiments used in Project FALSIRE

\begin{tabular}{|c|c|}
\hline $\begin{array}{c}\text { Experiment } \\
\text { (place) }\end{array}$ & Objective \\
\hline $\begin{array}{l}\text { NKS-3 } \\
\text { (MPA, FRG) }\end{array}$ & $\begin{array}{l}\text { Determine potential for crack initiation and stable } \\
\text { growth under PTS loading conditions; validate } \\
\text { analysis techniques based on J-integral }\end{array}$ \\
\hline $\begin{array}{l}\text { NKS-4 } \\
\text { (MPA, FRG) }\end{array}$ & $\begin{array}{l}\text { Determine potential for crack initiation and stable } \\
\text { extension of surface crack in low-toughness material } \\
\text { under PTS loading conditions; validate analyses } \\
\text { techniques }\end{array}$ \\
\hline $\begin{array}{l}\text { PTSE-2A/B } \\
\text { (ORNL/U.S.A.) }\end{array}$ & $\begin{array}{l}\text { Inves igate transitional crack behavior in a steel } \\
\text { with low tearing resistance under PTS loading } \\
\text { conditions and the effects of warm prestressing on } \\
\text { crack initiation }\end{array}$ \\
\hline $\begin{array}{l}\text { SĊ-I } \\
\text { (AEA, U.K.) }\end{array}$ & $\begin{array}{l}\text { Investigate stable ductile crack growth in contained } \\
\text { yield for a thick-section low-alloy steel;;provide } \\
\text { experimental data for construction of J-resistance } \\
\text { curve }\end{array}$ \\
\hline $\begin{array}{l}\text { SC-II } \\
\text { (AEA, U.K.) }\end{array}$ & $\begin{array}{l}\text { Investigate stable crack growth in a thick section } \\
\text { plane strain specimen under severe thermal shock } \\
\text { loading conditions }\end{array}$ \\
\hline $\begin{array}{l}\text { Step B PTS } \\
\text { (JAPEIC, Japan) }\end{array}$ & $\begin{array}{l}\text { Determine potential for crack initiation and stable } \\
\text { growth in a thick-section plate under PTS loading } \\
\text { conditions; validate analysis techniques }\end{array}$ \\
\hline
\end{tabular}


Introduction

Table 1.4 Summary of Project FALSIRE reference experiments

\begin{tabular}{|c|c|c|c|c|}
\hline $\begin{array}{l}\text { Experiment } \\
\text { (place) }\end{array}$ & $\begin{array}{l}\text { Material }^{a} \\
\text { toughness }\end{array}$ & Loading & $\begin{array}{c}\text { Crack } \\
\text { geometry }\end{array}$ & $\begin{array}{l}\text { Crack } \\
\text { growth }\end{array}$ \\
\hline $\begin{array}{l}\text { NKS-3 } \\
\text { (MPA, FRG) }\end{array}$ & $\begin{aligned} A_{\mathrm{v}}^{\text {us }} & =95 \mathrm{~J} \\
T_{\text {NDT }} & =60^{\circ} \mathrm{C}\end{aligned}$ & $\begin{array}{l}\text { Thermal-shock } \\
\text { axial tension, } \\
\text { internal } \\
\text { pressure } \\
\text { (constant) }\end{array}$ & $\begin{array}{l}\text { Circumferential } \\
(\mathrm{a} / \mathrm{t}=0.3)\end{array}$ & $\begin{array}{l}\text { Ductile } 3.6 \mathrm{~mm} \\
\text { (average) } \\
\Delta \mathrm{a} / \mathrm{a}=0.06\end{array}$ \\
\hline $\begin{array}{l}\text { NKS-4 } \\
\text { (MPA, FRG) }\end{array}$ & $\begin{aligned} A_{v}^{u s} & =60 \mathrm{~J} \\
T_{\text {NDT }} & =120^{\circ} \mathrm{C}\end{aligned}$ & $\begin{array}{l}\text { Thermal-shock } \\
\text { axial tension, } \\
\text { internal } \\
\text { pressure } \\
\text { (constant) }\end{array}$ & $\begin{array}{l}\text { Partly } \\
\text { circumferential } \\
(\mathrm{a} / \mathrm{t}=0.15)\end{array}$ & $\begin{array}{l}\text { Ductile } 1.5 \mathrm{~mm} \\
\quad \text { (center) } \\
\Delta \mathrm{a} / \mathrm{a}=0.05\end{array}$ \\
\hline $\begin{array}{l}\text { PTSE 2AlB } \\
\text { (ORNL, U.S.A.) }\end{array}$ & $\begin{aligned} \mathrm{A}_{\mathrm{v}}^{\mathrm{us}} & =60 \mathrm{~J} \\
\mathrm{~T}_{\mathrm{NDT}} & =49^{\circ} \mathrm{C}^{b} \\
& =75^{\circ} \mathrm{C}^{c}\end{aligned}$ & $\begin{array}{l}\text { Thermal-shock, } \\
\text { internal } \\
\text { pressure } \\
\text { (transient) }\end{array}$ & $\begin{array}{l}\text { Axial } \\
(a / t=0.110 .29)\end{array}$ & $\begin{array}{l}\text { Ductile } 11.113 .7 \mathrm{~mm} \\
\text { Brittle } 16.8132 .7 \mathrm{~mm} \\
\text { Unstable }-168.8 \mathrm{~mm} \\
\Delta \mathrm{a} / \mathrm{a}=0.3510 .09 \\
\text { (first phase of } \mathrm{AlB} \text { ) }\end{array}$ \\
\hline $\begin{array}{l}\text { SC-I } \\
\text { (AEA, U.K.) }\end{array}$ & $A_{v}^{u s}=90 \mathrm{~J}$ & $\begin{array}{r}\text { Rotation of } \\
\text { specimen }\end{array}$ & $\begin{array}{l}\text { Axial } \\
(a / t=0.54)\end{array}$ & $\begin{array}{l}\text { Ductile } 2.8 \mathrm{~mm} \\
\text { (average) } \\
\Delta \mathrm{a} / \mathrm{a}=0.03\end{array}$ \\
\hline $\begin{array}{l}\text { SC-II } \\
\text { (AEA, U.K.) }\end{array}$ & $A_{v}^{u s}=110 J$ & Thermal shock & $\begin{array}{l}\text { Axial } \\
(\mathrm{a} / \mathrm{t}=0.52)\end{array}$ & $\begin{array}{l}\text { Ductile } 0.0-0.75 \mathrm{~mm} \\
\Delta \mathrm{a} / \mathrm{a}=0.01(\mathrm{max})\end{array}$ \\
\hline $\begin{array}{l}\text { Step B PTS } \\
\text { (JAPEIC, } \\
\text { Japan) }\end{array}$ & $\begin{aligned} A_{v}^{u s} & =100 \mathrm{~J} \\
T_{N D T} & =139^{\circ} \mathrm{C}\end{aligned}$ & $\begin{array}{l}\text { Thermal-shock } \\
\text { tension and } \\
\text { bending }\end{array}$ & $\begin{array}{l}\text { Surface crack } \\
(\mathrm{a} / \mathrm{t}=0.14)\end{array}$ & $\begin{array}{l}\text { Ductile } 0.3-1.0 \mathrm{~mm} \\
\Delta \mathrm{a} / \mathrm{a}=0.04(\max )\end{array}$ \\
\hline
\end{tabular}

${ }^{a} \mathrm{~A}_{\mathrm{v}}^{u s}=$ Charpy V-notch $(\mathrm{CVN})$ upper-shelf energy; $\mathrm{T}_{\mathrm{NDT}}=$ nil-ductility transition temperature.

${ }^{b}$ Pretest.

${ }^{c}$ Posttest. 
Based on the CSNI/FAG problem statements, 37 participants representing 19 organizations performed a total of 39 analyses of the experiments. A breakdown of the number of analyses contributed by the participating institutions and of the arialysis methods applied to each experiment is given in Table 1.5. The analysis techniques employed by the participants included engineering methods (R6, GE/EPRI estimation scheme, DPFAD) and finite-element methods. These techniques were combined with applications of $J_{R}$ methodology and the French local approach. The finite-element applications included both two- and three-dimensional models, as well as deformation plasticity and incremental thermo-elastic-plastic constitutive formulations. Crack-growth models based on nodal release techniques were used to generate both application- and generation-mode solutions for several of the experiments. Additional details concerning the structural and fracture mechanics analysis techniques employed by the participants are provided in Chap. 3 .

For each of the experiments, analysis results provided estimates of variables including crack growth, CMOD, temperatures, strains, stresses, and applied $\mathrm{J}$ and $\mathrm{K}$ values. Conditions of crack stability and instability were identified in the experiments. Where possible, computed values were compared with measured data. A comparative assessment and discussion of the analysis results is presented in
Chap. 4. (Additional results from the data base are summarized in Appendix B.) Based on this assessment, some conclusions concerning the predictive capabilities of current state-of-the-art fracture methodologies as applied to pressure vessels are given in Chap. 5. Recommendations for future development of fracture methodologies to improve these predictive capabilities are addressed also. Furthermore, proposals for future work in the context of a Phase II of Project FALSIRE are provided in Chap. 6.

The present status of the project was presented at the MPA Seminar in Stuttgart in October $1990^{1}$ and at the Eleventh International Conference on Structural Mechanics in Reactor Technology (SMiRT) in Tokyo in August $1991 .^{2}$

\section{REFERENCES}

1. B. R. Bass et al., "Fracture Mechanics Analyses of Large Scale Experiments in International Comparison," Proceedings of 16th Materialprifungsanstalt Seminar, Stuttgart, Federal Republic of Germany, 1990.

2. B. R. Bass et al., "Assessment of Ductile Fracture Methodology Based on Applications to Large Scale Experiments," pp. 25-36 in Proceedings of 11th International Conference on Structural Mechanics in Reactor Technology, Vol. G1, 1991.

Table 1.5 Summary of Project FALSIRE analysis techniques ${ }^{a}$

\begin{tabular}{lccccc}
\hline $\begin{array}{c}\text { NKS-3 } \\
\text { (10 analyses) }\end{array}$ & $\begin{array}{c}\text { NKS-4 } \\
\text { (6 analyses) }\end{array}$ & $\begin{array}{c}\text { PTSE-2 } \\
\text { (8 analyses) }\end{array}$ & $\begin{array}{c}\text { SC-I } \\
\text { (6 analyses) }\end{array}$ & $\begin{array}{c}\text { SC-II } \\
\text { (8 analyses) }\end{array}$ & $\begin{array}{c}\text { STEP B PTS } \\
\text { (1 analysis) }\end{array}$ \\
\hline FE, JR & FE, JR & FE, JR & FE, JR & FE, JR & FE, JR \\
FE; JR, LA & FE, JR & FE, JR & FE, JR & FE, JR & \\
FE, JR & FE, JR & FE, JR & FE, JR & FE, ES & \\
FE; JR, LA & FE, JR & FE, JR & ES & FE, ES \\
FE, JR & ES, J/T & FE, JR & ES & ES & \\
FE, JR & ES, R6/1 & FE, JR & ES, WF & ES, R6/1 \\
FE, JR & & ES, J/T & & ES & \\
FE, JR & & ES & & & \\
ES, J/T & & & & \\
ES, R6/1 & & & & & \\
\hline
\end{tabular}

\footnotetext{
${ }^{a} \mathrm{FE}=$ finite-element method

$\mathrm{ES}=$ estimation scheme

$A 1=$ analytic solution with numerical integration

$\mathrm{A} 2$ = handbook analysis of statically indeterminate model

$\mathrm{JR}=\mathrm{R}$-curve approach

$\mathrm{J} / \mathrm{T}=\mathrm{J} /$ tearing modulus approach

LA $=$ local approach

$R 6 / 1=R 6$ method/option 1

$\mathrm{WF}=$ weight function method
} 


\section{Description of Reference Experiments}

The objectives of the tests were to evaluate fracture analysis methods, as well as to demonstrate special effects, such as warm prestressing. Generally, the materials tested are not commercial pressure vessel steels but were subjected to special heat treatment to simulate embrittlement. The experimental results were accepted from the analyzing organizations without qualifying the data. A consistent set of data was not available for all reference experiments. The materials, loadings, and the specimen/crack geometry have been designed to obtain the desired results in the presence of financial and technical limitations. The test transients were not intended to simulate real transients in nuclear plants, but the problems modeled by the reference experiments should contribute to understanding the loading of postulated cracks in RPVs in the case of overcooling accidents.

\subsection{NKS PTS Experiments}

\subsubsection{NKS-3}

The NKS-3 PTS experiment ${ }^{1}$ was performed with a thick-walled hollow cylinder (thickness, $200 \mathrm{~mm}$; inner diameter, $400 \mathrm{~mm}$ ) containing a $360^{\circ}$ circumferential flaw on the inner surface having an average depth of $-62.8 \mathrm{~mm}$ (Fig. 2.1). The test piece was first loaded with an axial tensile load of $100 \mathrm{MN}$ and by internal pressure using water $\left(30 \mathrm{MPa}, 330^{\circ} \mathrm{C}\right)$ in the cylinder volume.

Thermal-shock cooling of the inner cylinder surface was performed by means of two high-pressure pumps spraying cold water $\left(20^{\circ} \mathrm{C}\right)$ through evenly distributed nozzles toward the inner cylinder surface over the whole test length of the cylinder (Fig. 2.2). These loading conditions produced a stress field on the circumferential plane of the test vessel that approximates the stress field on a longitudinal plane of an RPV.

The instrumentation of the test piece with strain gages, thermocouples, and clip gages is illustrated in the instrumentation plan in Figs. 2.3 and 2.4. The temperatures in the wall thickness were recorded by thermocouples mounted in drill holes of varying depths from the outer surface. Additional temperature measurement points were located on the inner and outer surfaces of the specimen together with strain gages. The notch opening was recorded by means of crack-opening displacement (COD) sensors. The location of the measurement points permitted a check on the rotational symmetry of the specimen loading and its variation along the specimen length. The latter was also intended to be as low as possible.

The test vessel was fabricated from $22 \mathrm{Ni} \mathrm{Mo} \mathrm{Cr} 37$ steel. Temperature-dependent mechanical properties for the test vessel material are given in Table 2.1 and the thermal properties in Table 2.2. Figure 2.5 depicts the Charpy-V-notch (CVN) impact energy vs temperature and indicates an upper-shelf toughness of $\sim 95 \mathrm{~J}$ (RTNDT $\sim 60^{\circ} \mathrm{C}$ ) in the temperature range of the experiment. Fracture-toughness data for the test material are given in Figs. 2.6 and 2.7. The $J_{R}$ curves in Fig. 2.7 were generated from compact-tension (CT) specimens having thicknesses of 25 (CT-25) and $50 \mathrm{~mm}$ (CT-50) at temperatures of 160 and $220^{\circ} \mathrm{C}$.

Internal pressure, axial load, and through-wall temperature distribution in the NKS-3 experiment are given in

. Figs. 2.8 -2.10 as functions of time relative to initiation of the thermal shock. At the beginning of the thermal shock, the average wall temperature was $332^{\circ} \mathrm{C}$. Results from measurements of stable crack extension on the fracture surface of the NKS-3 specimen are shown in Fig. 2.11. Fractographic crack-depth measurement indicates an average measured crack extension of $-3.6 \mathrm{~mm}$ around the circumference of the flaw. Additional details concerning the NKS-3 experiment are given in Ref. 1 .

\subsubsection{NKS-4}

The PTS experiment NKS-4 (Ref. 2) examined crack-growth behavior of two symmetrically opposed semielliptical surface cracks in a low-toughness material. Figure 2.12 shows the geometry of the test cylinder and the two circumferential cracks located on the inner surface. Each crack has a ratio of length to depth of 6:1 and a maximum depth of $-30 \mathrm{~mm}$. The cracks were produced by means of spark erosion and fatiguing procedures.

The test rig and loading procedures used to test the NKS-4 specimen were essentially the same as those described in the previous section for NKS-3 (Fig. 2.13). The instrumentation of the test piece with strain gages, thermocouples, and clip gages is given in the diagram of Fig. 2.14.

Temperature-dependent material data for the NKS-4 specimen are given in Table 2.3 and in Fig. 2.15. The CVN energy vs temperature data in Fig. 2.16 indicates an upper-shelf toughness of $-60 \mathrm{~J}$ and an NDT temperature of $\sim 120^{\circ} \mathrm{C}$ for the NKS-4 test specimen. Fracture-toughness data for the NKS-4 material are summarized in Fig. 2.17. Detailed test results from CT tests at $160^{\circ} \mathrm{C}$ are given in Table 2.4 and in Fig. 2.17(a).

The NKS-4 experiment was performed using two thermal-shock transients, the first of which produced a reduced thermal loading caused by mechanical problems with the cooling water flow. The two transients, identified 

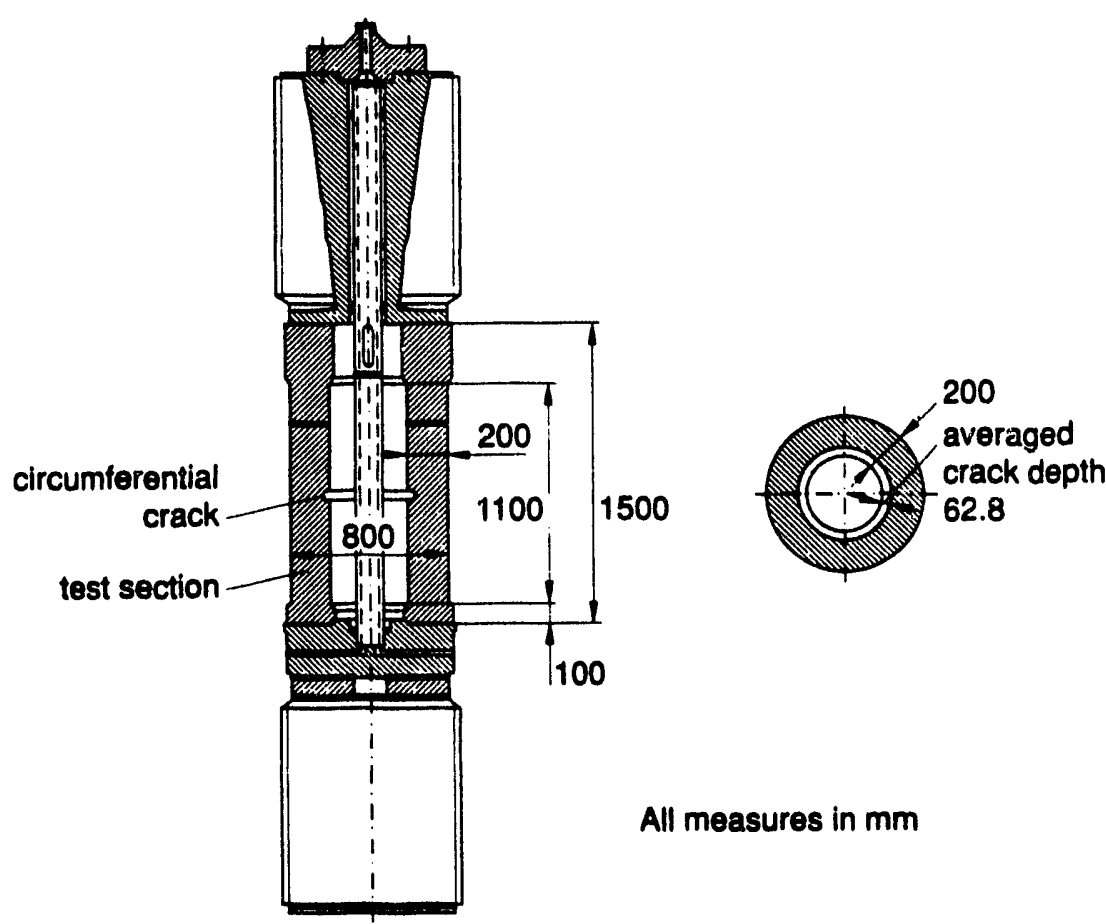

Fig. 2.1. Test cylinder and crack geometry used in NKS-3 experiment (MPA-Stuttgart, FRG).

OANL-OWG 23-2228 ETD

\section{Thermal and mechanical} loading

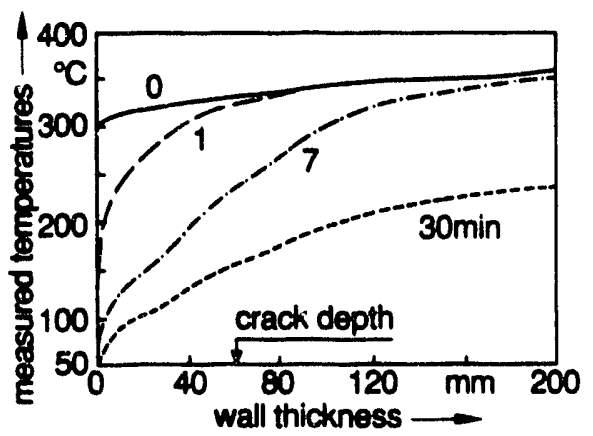

inner
Material characterization of the test section 22 NI Mo Cr 37

\begin{tabular}{|l|c|}
\hline $\begin{array}{l}\text { yield/ultimate } \\
\text { stress at RT }\end{array}$ & $563 / 723 \mathrm{MPa}$ \\
\hline $\begin{array}{l}\text { charpy energy } \\
\text { for upper shelf }\end{array}$ & $95 \mathrm{~J}$ \\
\hline NDT & $60^{\circ} \mathrm{C}$ \\
\hline
\end{tabular}

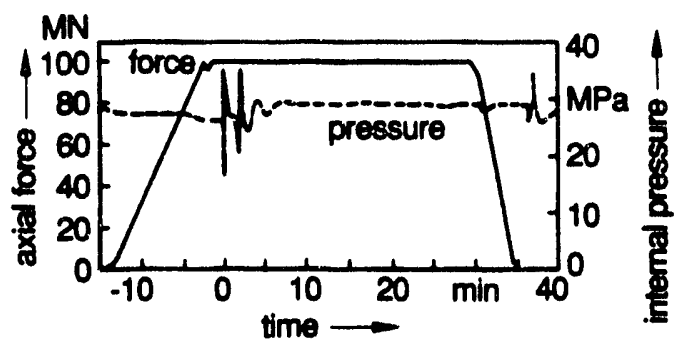

Fig. 2.2. Loading and test material data (NKS-3 specimen). 


\section{Longitudinal Section of the Specimen}

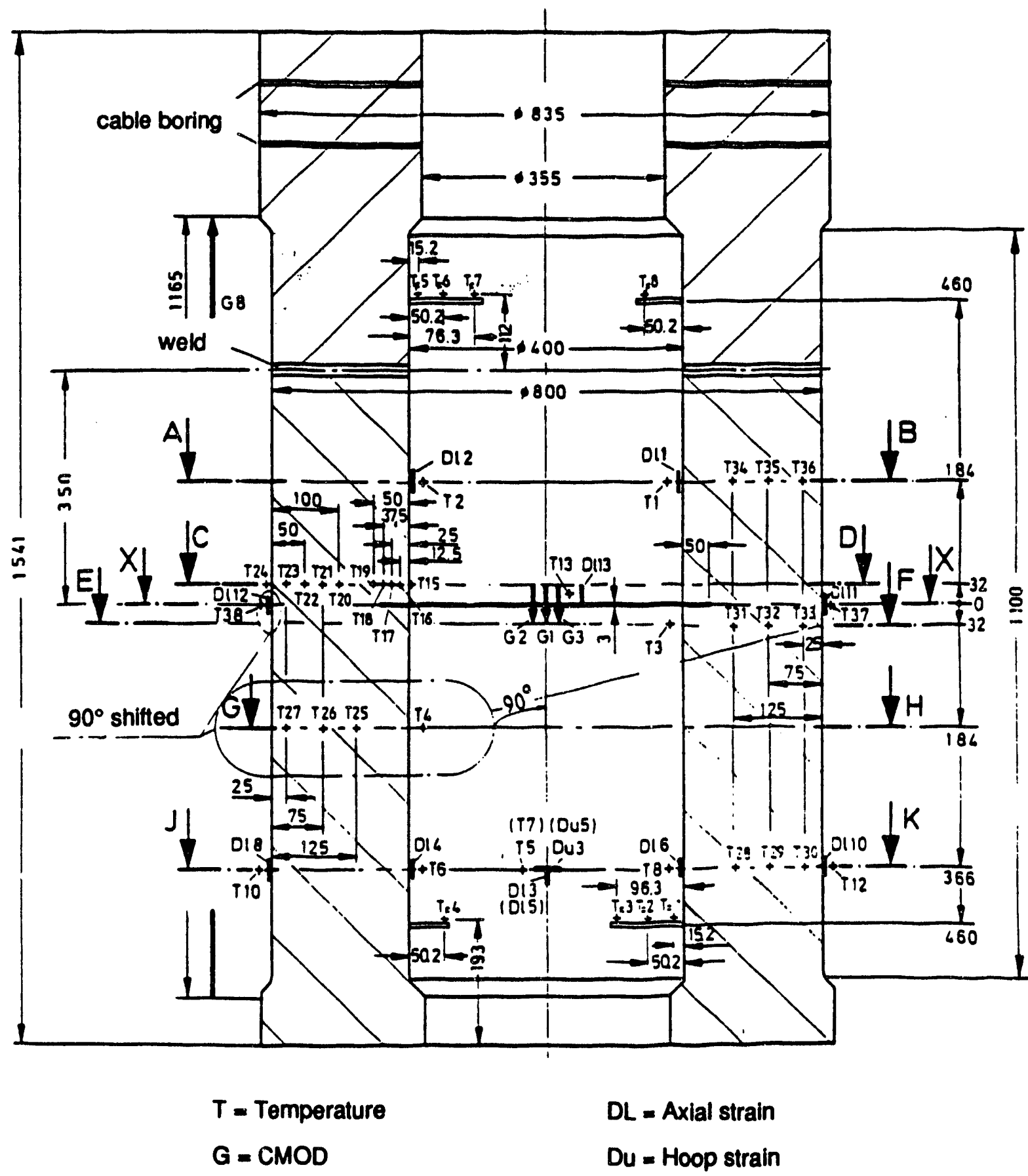

Fig. 2.3. Measurement positions in thermal shock specimen NKS-3 $(D L=$ longitudinal strain, $D u=$ circumferential strain, $\mathbf{T}=$ temperature, and $\mathbf{G}=\mathbf{C M O D})$. 
Description

ORNL-DWG 93-2230 ETD

Cross Sections of the Specimen

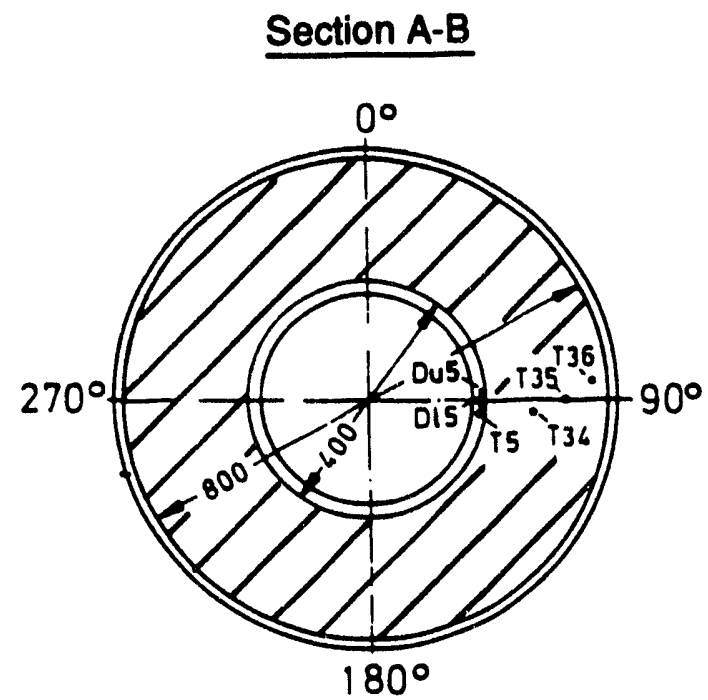

Section E-F
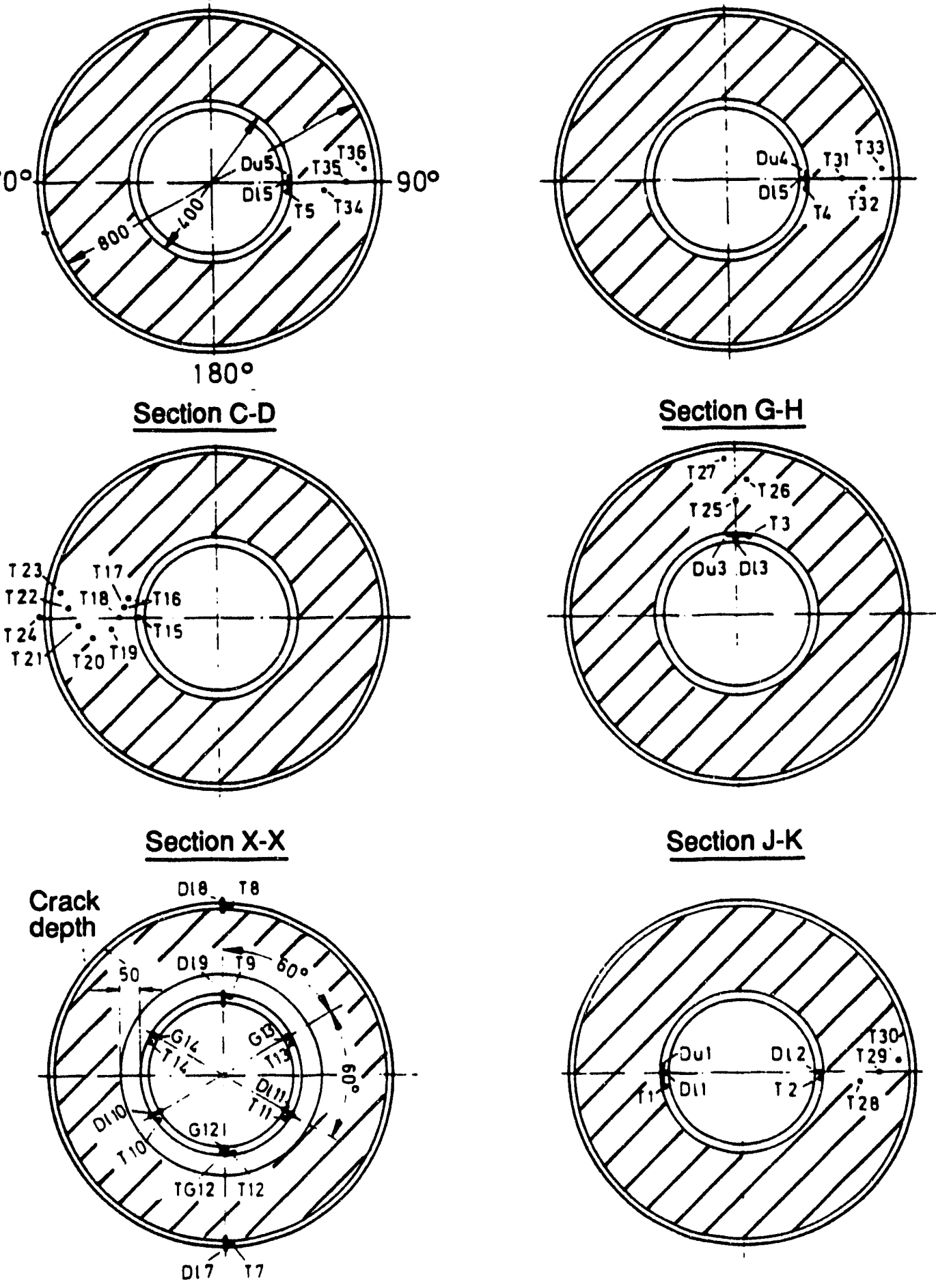

Fig. 2.4. Measurement positions in thermal shock specimen NKS-3. 
Table 2.1 Temperature-dependent material data for NKS-3 specimen

\begin{tabular}{cccc}
\hline $\begin{array}{c}\text { Temperature } \\
\left({ }^{\circ} \mathbf{C}\right)\end{array}$ & $\begin{array}{c}\text { E-modulus } \\
(\mathbf{M P a})^{\prime}\end{array}$ & $\begin{array}{c}\boldsymbol{\sigma}_{\mathbf{0 . 2}} \\
(\mathbf{M P a})\end{array}$ & $\begin{array}{c}\boldsymbol{\sigma}_{\mathbf{u}} \\
(\mathbf{M P a})\end{array}$ \\
\hline 20 & 210,000 & 563 & 723 \\
160 & 200,000 & 519 & 672 \\
260 & 190,300 & 536 & 699 \\
320 & 184,400 & 523 & 702 \\
\hline
\end{tabular}

Table 2.2 Thermal material data for NKS-3 specimen

Thermal conductivity, $\lambda=40 \mathrm{~W} / \mathrm{mK}$

Specific heat conductivity, $\mathrm{cp}=0.55 \mathrm{~kJ} / \mathrm{kg} \mathrm{K}$

Thermal expansion coefficient, $\alpha=14.4 \times 10^{-6} 1 / \mathrm{K}$

Heat convection coefficient (inner surface, time dependent)

Time, $s \quad 0-300$

$\mathrm{h}, \mathrm{W} / \mathrm{m}^{2} \mathrm{~K} \quad 1500 .-3000 . \quad 3000$.

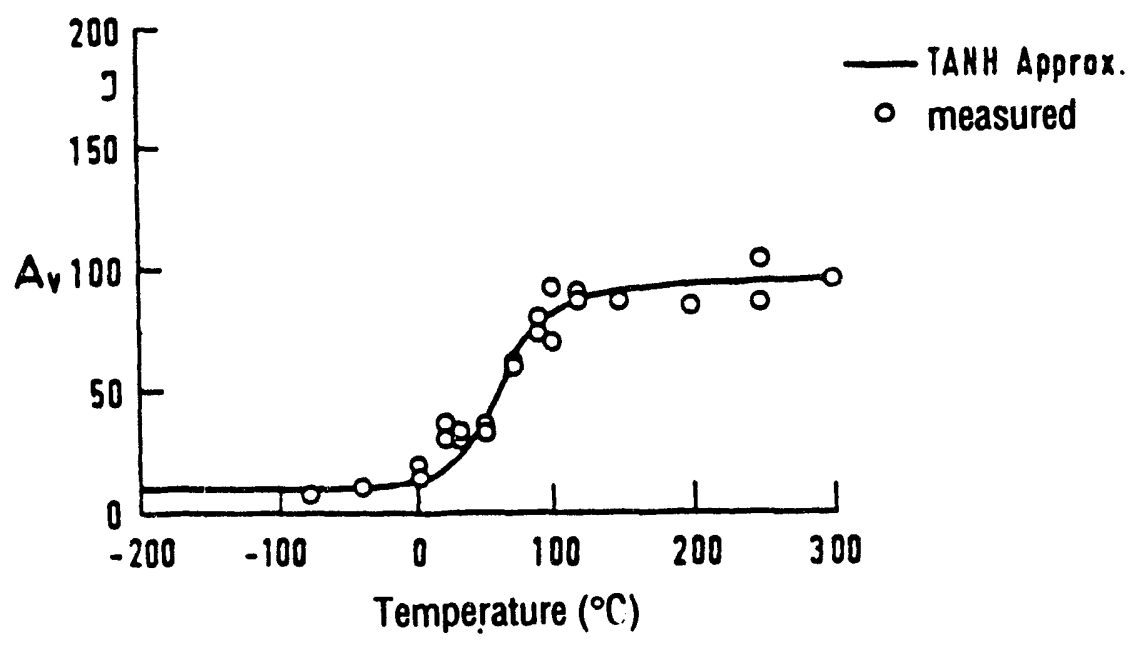

Fig. 2.5. Charpy V-notch impact energy vs temperature for NKS-3 material.

ORNL-DWG 93-2232 ETD

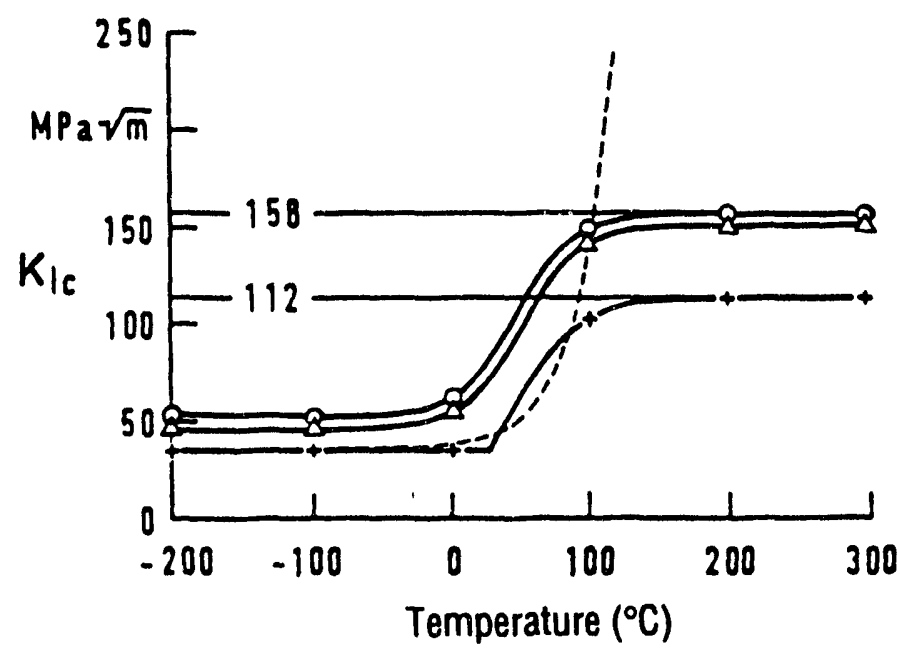

- average

$\Delta 99 \%$ limit of confidence

+ 99 \% limit of tolerance

ASME Sect. XI curve

$R T_{\text {HOT }}=60^{\circ} \mathrm{C}$

Fig. 2.6. Fracture toughness vs temperature for NKS-3 material. 
Description
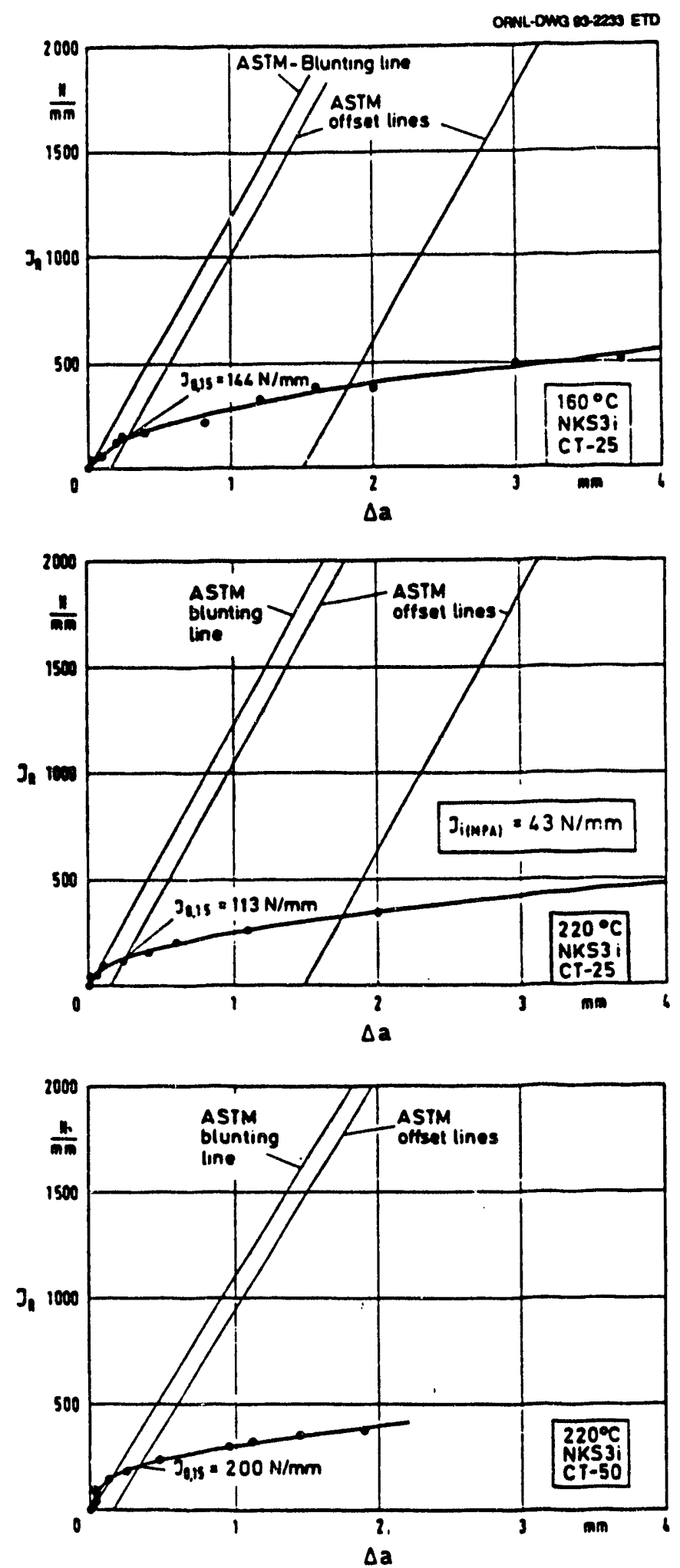

Fig. 2.7. Crack resistance for NKS-3 material. 


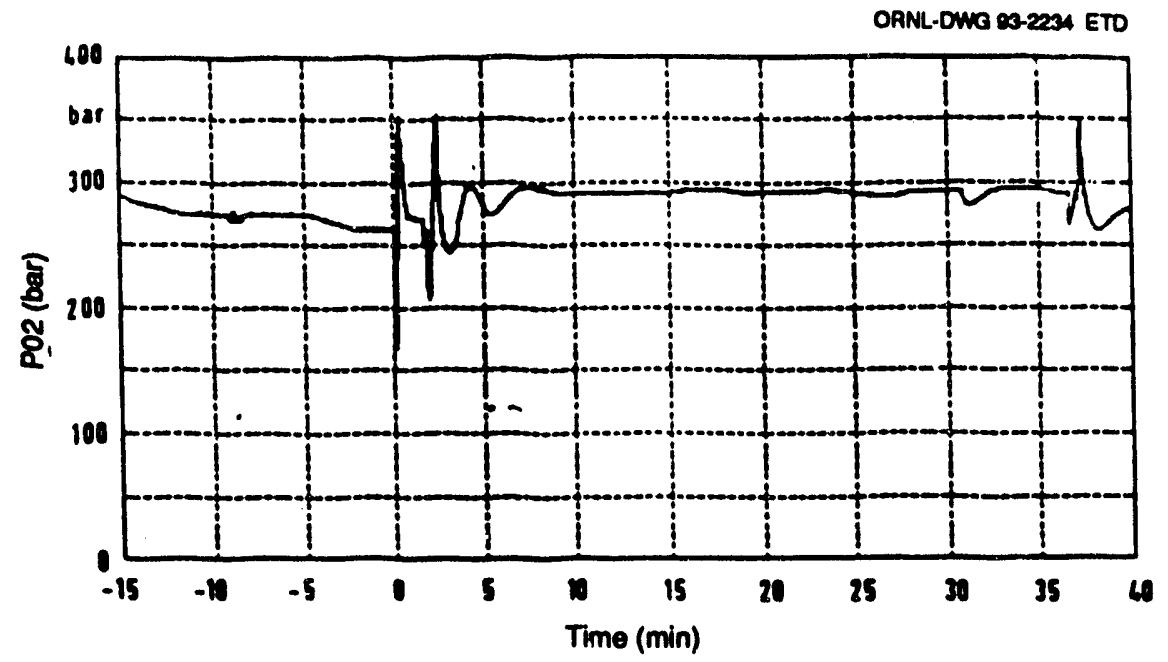

Fig. 2.8. Internal pressure vs time in NKS-3 experiment.

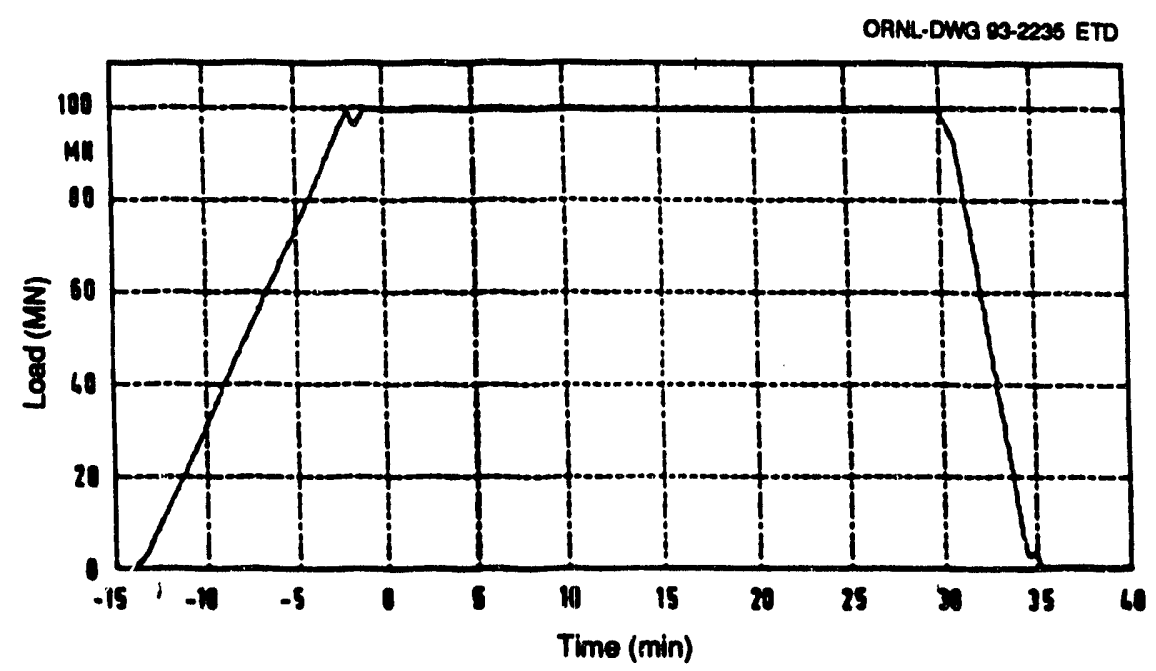

Fig. 2.9. Axial load vs time in NKS-3 experiment. 


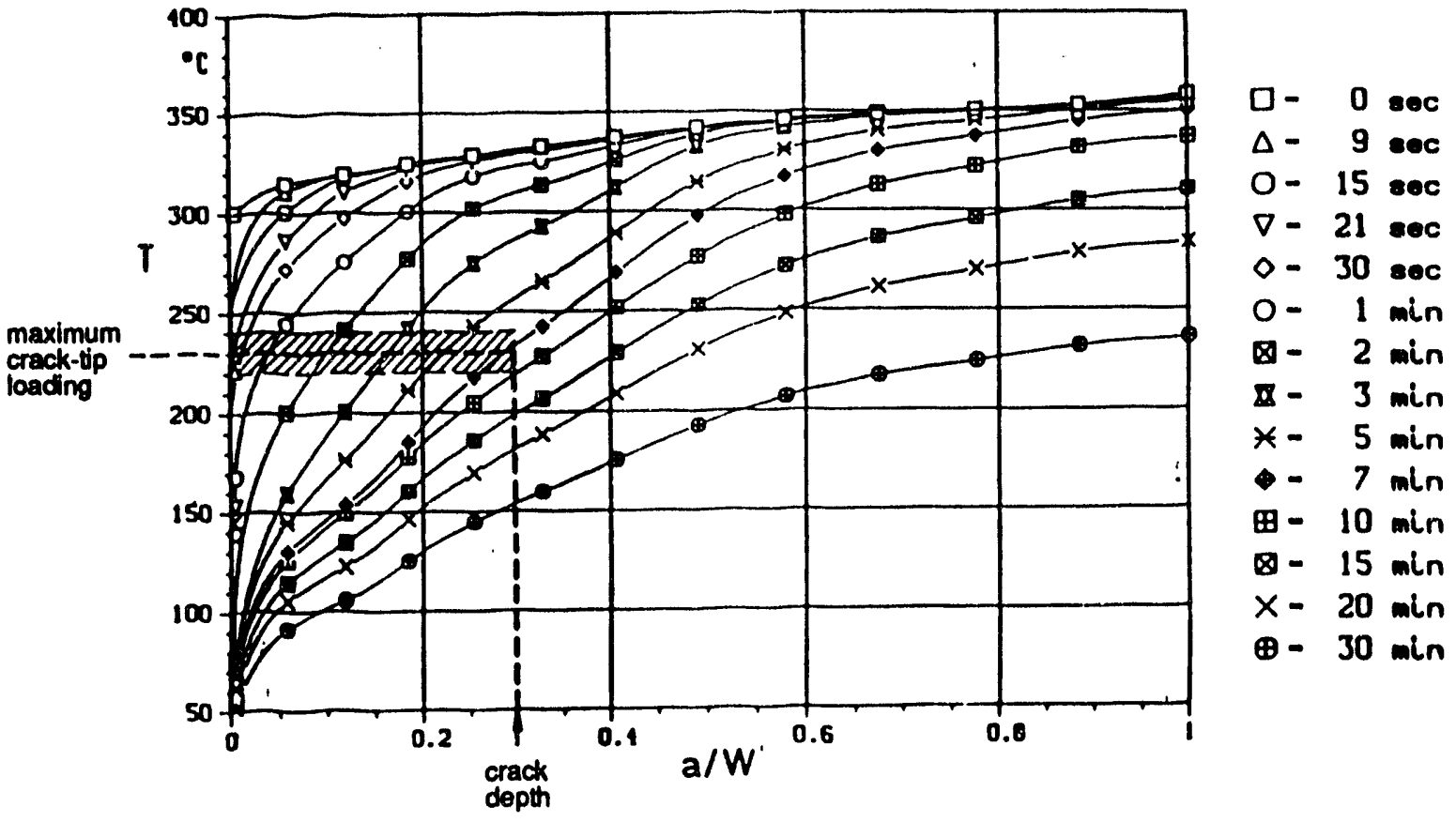

Fig. 2.10. Measured temperature profiles across wall thickness as function of time (NKS-3 experiment).

ORNL.OWO 93-2237 ETD

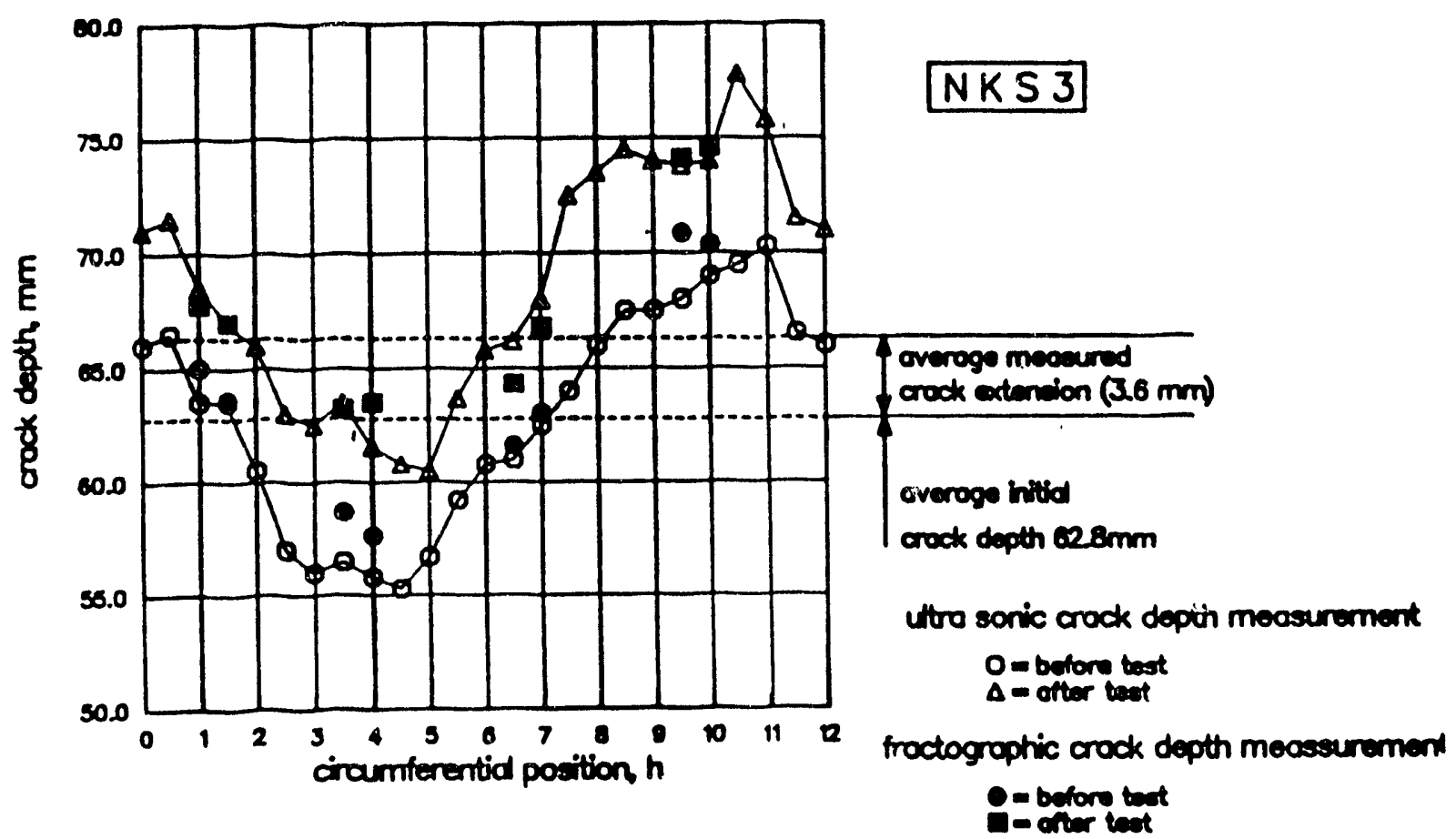

Fig. 2.11. Results from crack extension measurement on fracture surface of NKS-3 specimen. 


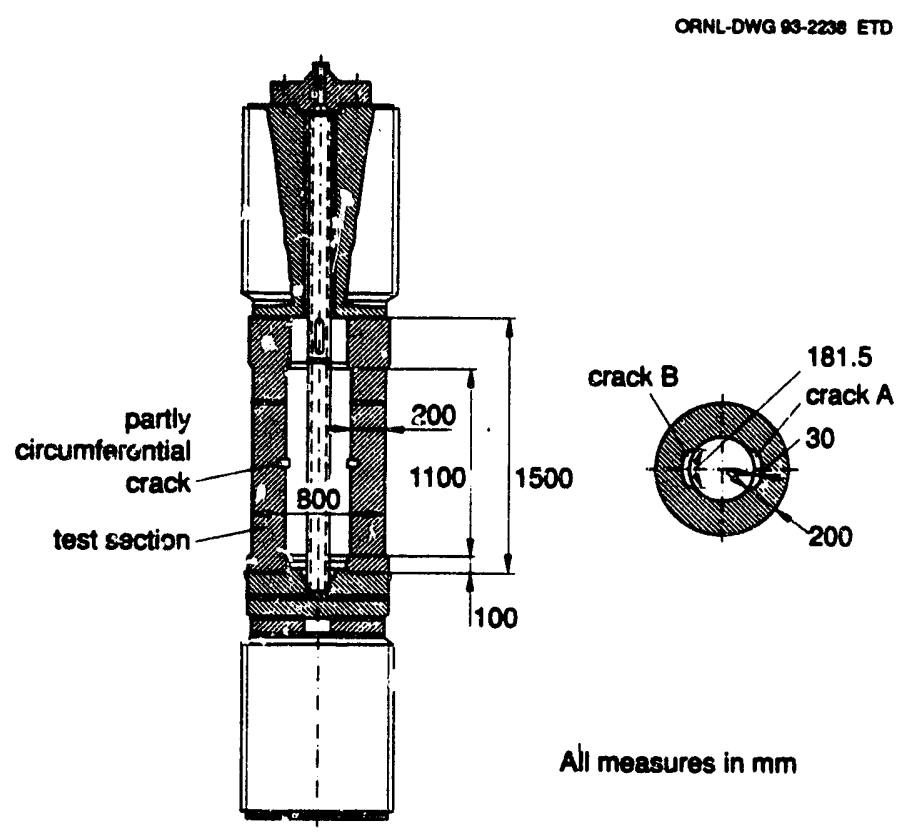

Fig. 2.12. Test cylinder and crac: geometry used in NKS-4 experiment (MPA-Stuttgart, FRG).

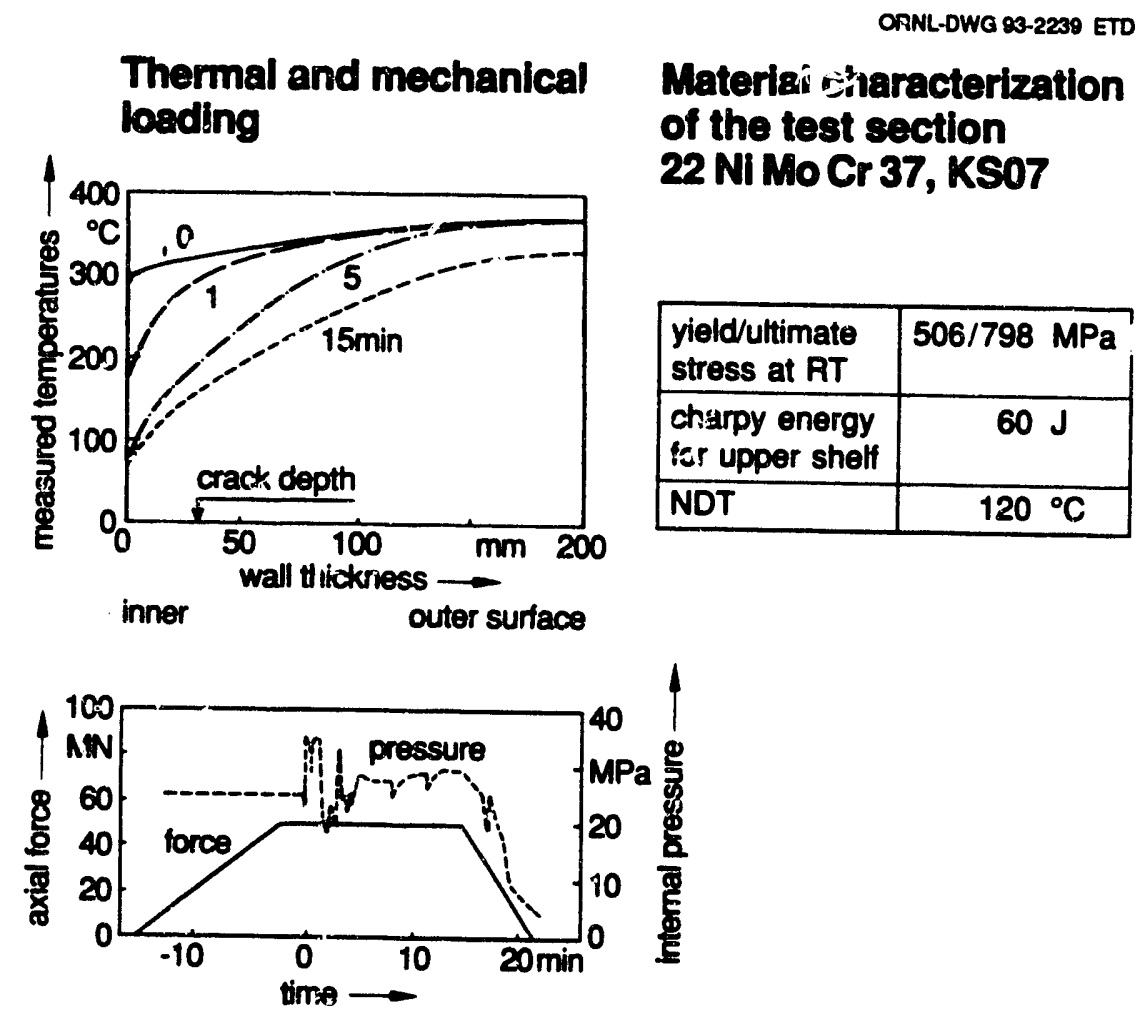

Fig. 2.13. Loading and material data (NKS-4 specimen). 


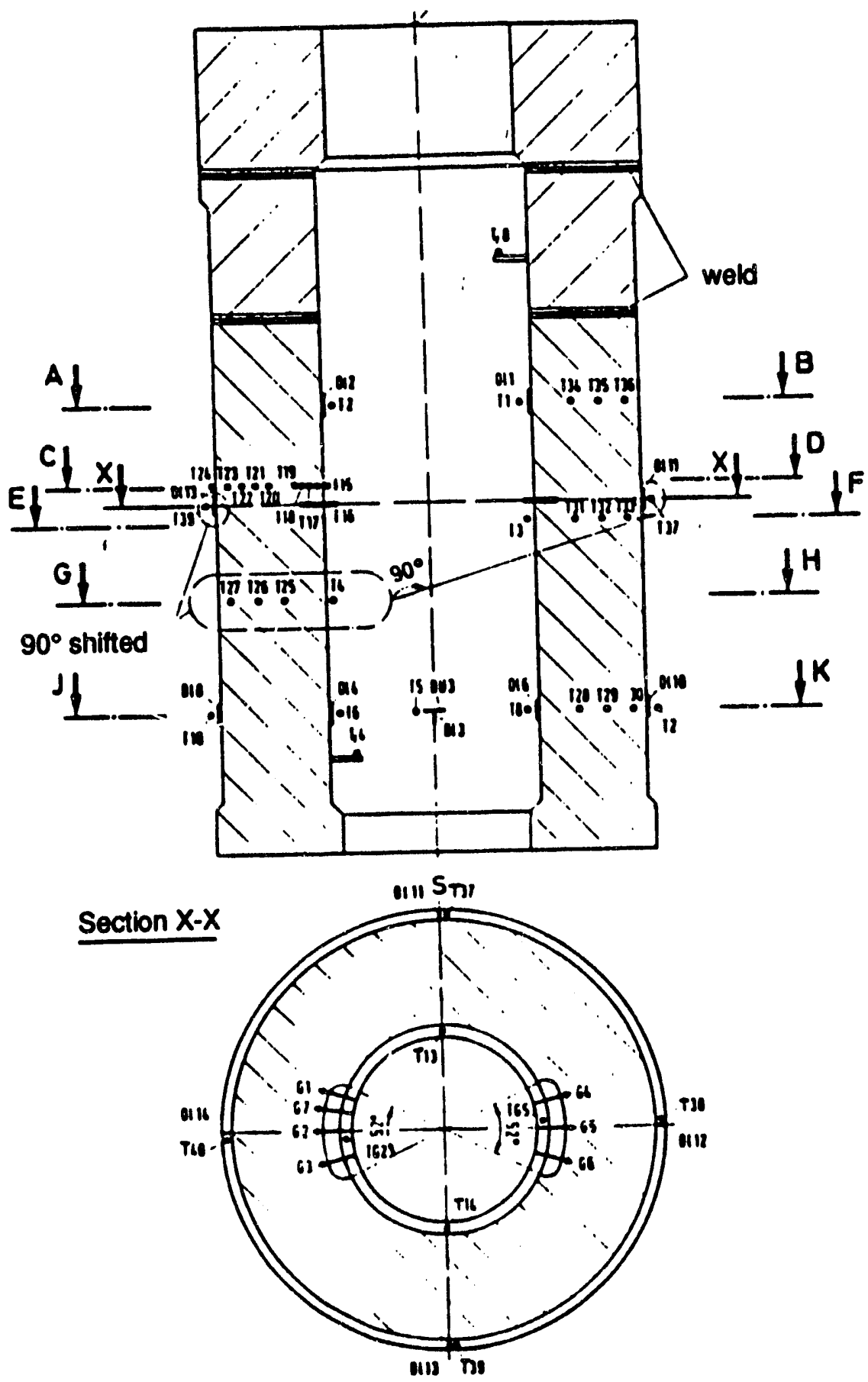

Fig. 2.14. Measurement positions in thermal shock specimen NKS-4 (DL = longitudinal strain, Du = circumferential strain, $\mathbf{T}=$ temperature, and $\mathbf{G}=\mathbf{C M O D}$ ). 
Table 2.3 Temperature-dependent material data for NKS-4 specimen: Material 22 Ni Mo Cr 37

\begin{tabular}{cccccc}
\hline $\begin{array}{c}\text { Temperature } \\
\left({ }^{\circ} \mathbf{C}\right)\end{array}$ & $\begin{array}{c}\text { E-Modulus } \\
(\mathbf{M P a})\end{array}$ & $\begin{array}{c}\boldsymbol{\sigma o . 2} \\
(\mathbf{M P a})\end{array}$ & $\begin{array}{c}\sigma_{\mathbf{u}} \\
(\mathbf{M P a})\end{array}$ & $\begin{array}{c}\mathbf{A s} \\
(\mathbf{\%})\end{array}$ & $\begin{array}{c}\mathbf{Z} \\
(\mathbf{\%})\end{array}$ \\
\hline 20 & 210,000 & 506 & 798 & 16 & 44 \\
120 & 204,000 & 503 & 770 & 14.2 & 41 \\
160 & 189,000 & 473 & 742 & 13 & 37.5 \\
280 & 178,000 & 492 & 813 & 13.8 & 31 \\
320 & 173,000 & 452 & 793 & 16.6 & 37.5 \\
\hline
\end{tabular}

Note: Upper-shelf toughness: $60 \mathrm{~J}$

Upper-shelf temperature: $220^{\circ} \mathrm{C}$

NDT-temperature: $120^{\circ} \mathrm{C}$, inner region of cylinder; $140^{\circ} \mathrm{C}$, outer region of cylinder

ORNL-DWG 93-2241 ETD

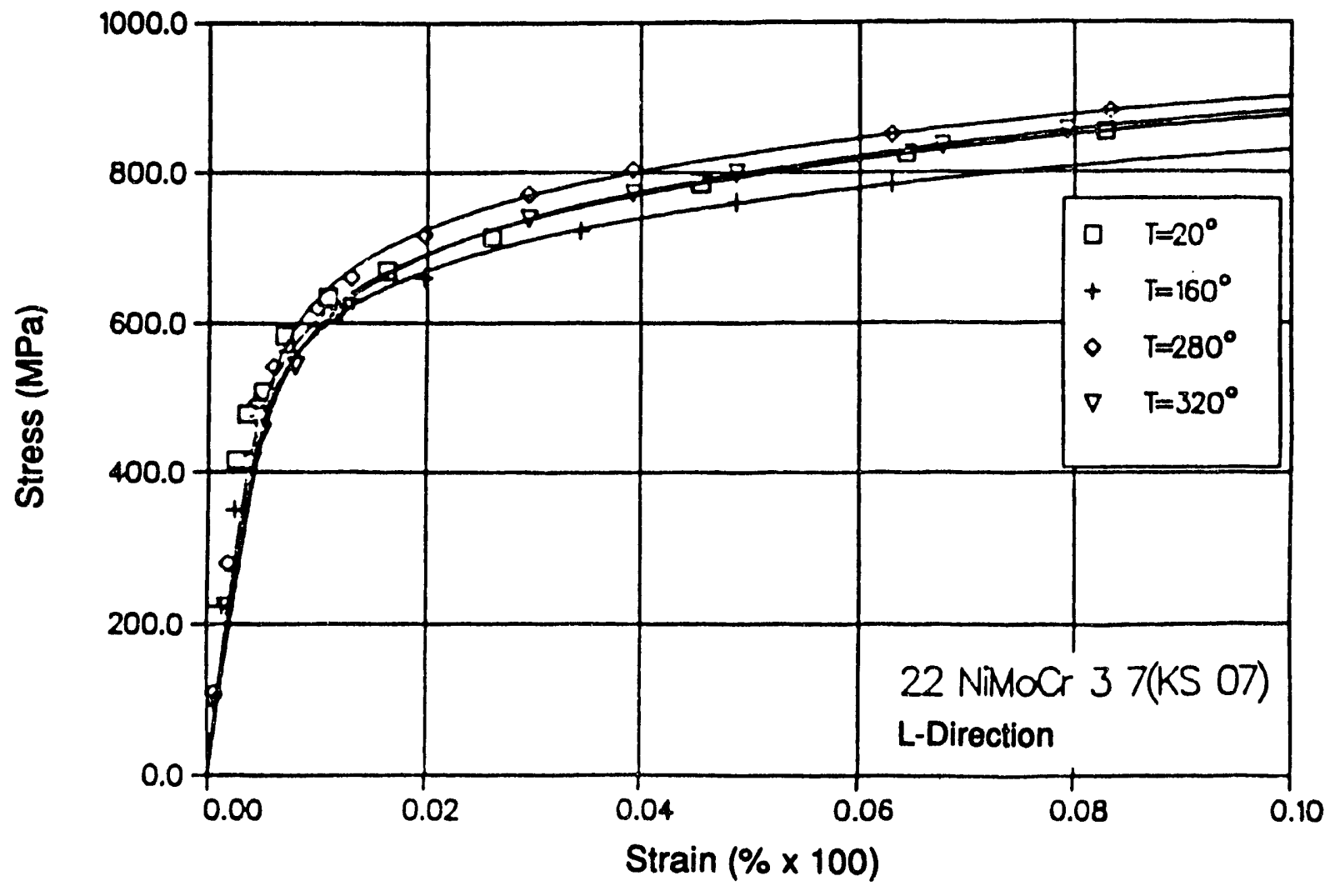

Fig. 2.15. Temperature-dependent true stress-true strain curves for NKS-4 specimen. 


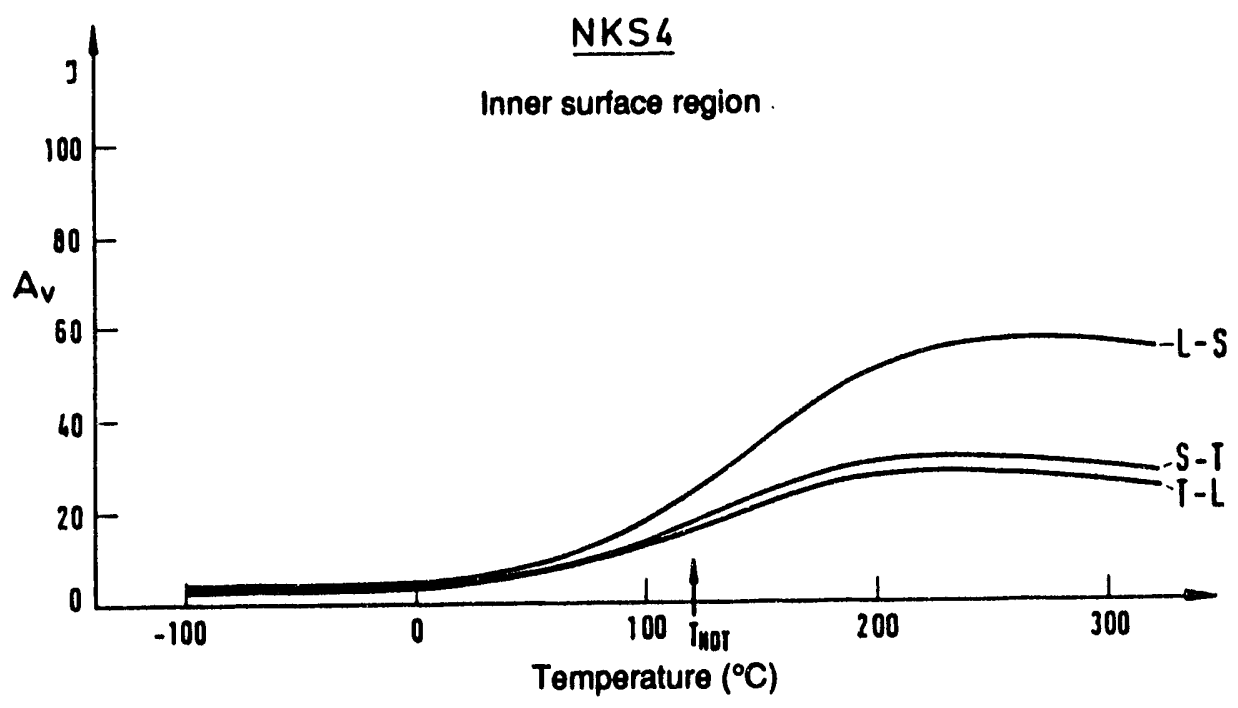

Fig. 2.16. Charpy V-notch impact energy vs temperature for NKS-4 material.

in this discussion as NKS-4/1 and NKS-4/2, are summarized in Table 2.5 and in Figs. 2.18-2.21. The target values for constant internal pressure and axial load for the transients were $30 \mathrm{MPa}$ and $50 \mathrm{~N}$, respectively. The time histories of these loadings achieved during the two transients are depicted in Fig. 2.18 for internal pressure and in Fig. 2.19 for axial load. The temperature profiles measured across the wall thickness as a function of time are given in Fig. 2.20 for the two transients. The heat transfer coefficients vs time were determined for the two transients in Ref. 2 and are shown in Fig. 2.21. The latter results clearl $j^{\prime}$ indicate that the flow velocities of the cooling water along the inner surface of the test specimen produced different heat transfer coefficients for the two transients.

The arnount of stable crack extension measured in fractographic studies of the test specimen is given in Fig. 2.22 for the two transients. These results indicate that crack growth for crack A was $\sim 50 \%$ greater than that for crack B. In Ref. 2, these differences are attributed to inhomogeneities in material properties. The NKS-4/1 transient produced a maximum crack extension of $\sim 1.5 \mathrm{~mm}$ for crack $A$ in the radial direction. The NKS-4/2 transient resulted in a maximum radial growth of $3.1 \mathrm{~mm}$ for crack A. Additional discussion of results for the NKS-4 experiment are given in Ref. 2.

\subsection{PTSE-2}

\subsubsection{PTSE-2A}

The details of the PTSE-2 test vessel and the initial flaw geometry 3,4 are given in Fig. 2.23 and in Table 2.6. An HSST intermediate test vessel was prepared with a plug of specially heat-treated test steel welded into the vessel. The 1-m-long sharp flaw was implanted in the outside surface of the plug by cracking a shallow electron-beam weld under the influence of hydrogen charging. For the test, the vessel was extensively instrumented (e.g., Figs. 2.24 and 2.25) to give direct measurements of CMOD, temperature profiles through the vessel wall, and internal pressure during the transient.

In the experiment, the flawed vessel was enclosed in an outer test vessel (OTV), as is shown schematically in Fig. 2.26. The OTV is electrically heated to bring the flawed test vessel to the desired uniform initial temperature of $\sim 290^{\circ} \mathrm{C}$. A thermal transient is initiated by suddenly injecting a chilled methanol-water mixture through an annulus between the test vessel and the other vessel. The annulus between the vessel surfaces was designed to permit coolant velocities that would produce the appropriate convection heat transfer from the test vessel for a period of 
ORNL-DWG $93-2243$ ETD

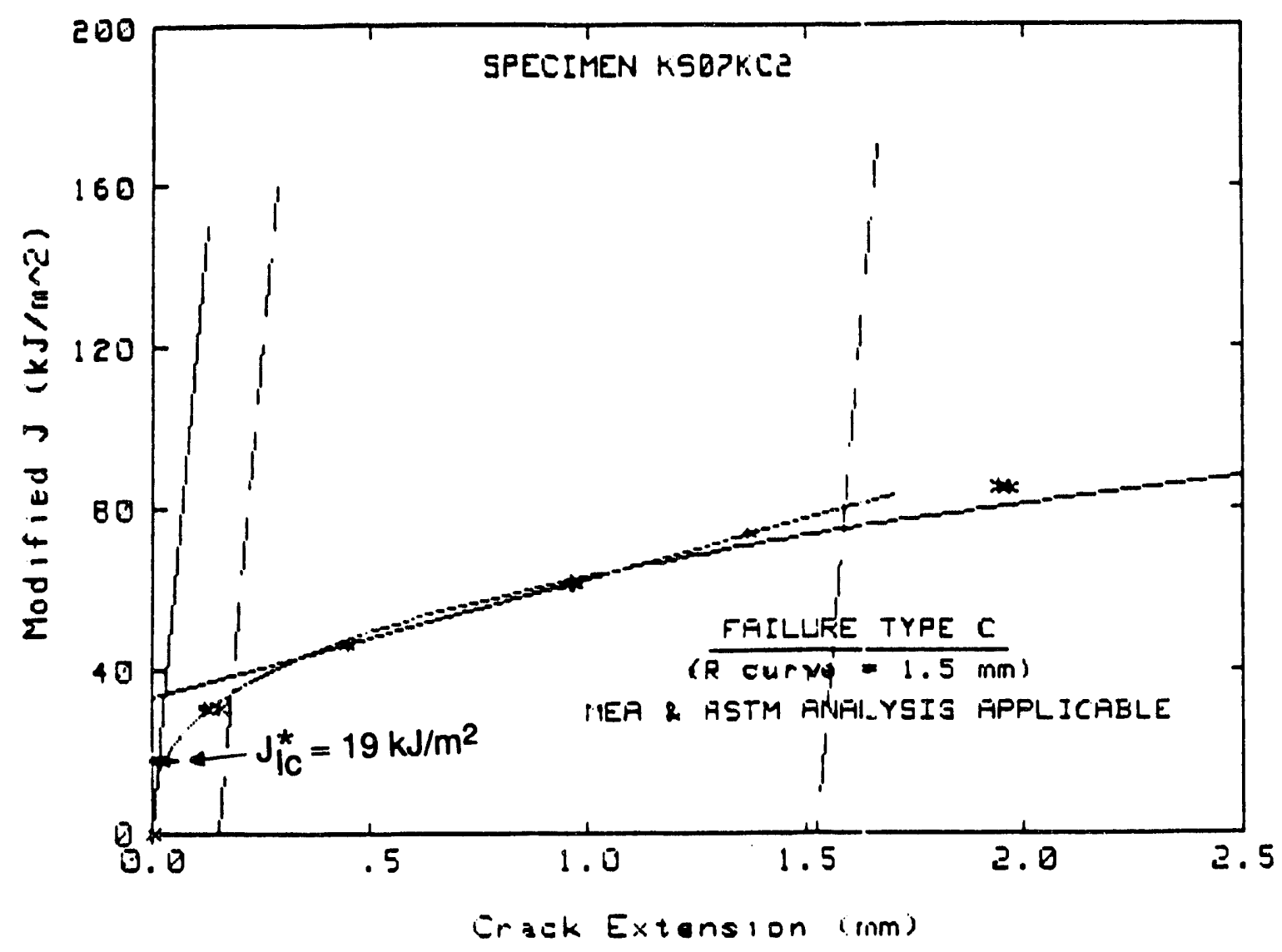

(a)

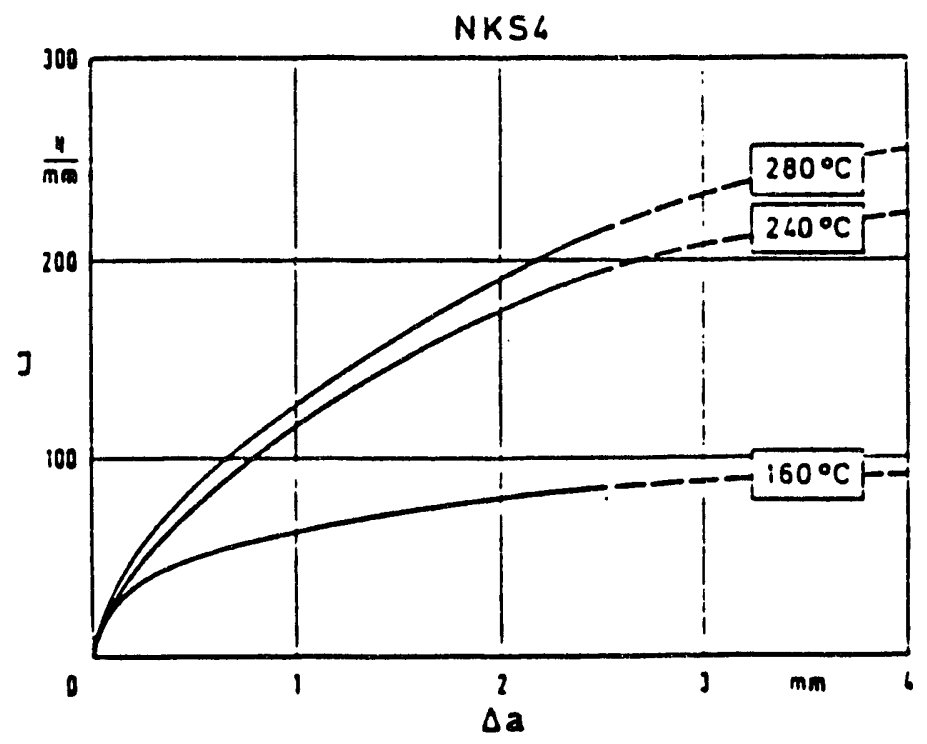

(b)

Fig. 2.17. Crack resistance of NKS-4 material: $(a)$ detailed plot of $\mathrm{JR}_{\mathrm{R}}$ curve at $160^{\circ} \mathrm{C}_{;}$(b) summary of $\mathrm{J}_{\mathrm{R}}$ curves at 160,240 , and $280^{\circ} \mathrm{C}$. 
Description

Table 2.4 Summary of $J_{R}$ curve test of CT specimen from NKS-4 material at $160^{\circ} \mathrm{C}$

\begin{tabular}{|c|c|c|}
\hline \multicolumn{3}{|c|}{ Test specimen data } \\
\hline $\begin{array}{l}\text { Material type } \\
\text { Test temperature } \\
\text { Percent side groove } \\
\text { Specimen thickness } \\
\text { Initial crack length } \\
\text { Final crack length } \\
\text { Flow stress } \\
\text { Young's modulus }\end{array}$ & $\begin{array}{l}22 \mathrm{Ni} \mathrm{Mo} \mathrm{Cr} 37 \\
160^{\circ} \mathrm{C} \\
20 \% \\
24.91 \mathrm{~mm} \\
29.35 \mathrm{~mm} \\
31.2 \mathrm{~mm} \\
615 \mathrm{MPa} \\
200,000 \mathrm{MPa}\end{array}$ & $\begin{array}{l}\text { Initial a/W }=0.585 \\
\text { Final a/W }=0.622 \\
\text { (Estimated value) } \\
\text { (Estimated value) }\end{array}$ \\
\hline \multicolumn{3}{|c|}{ Power law data $J=C(\Delta a)^{N}$} \\
\hline $\begin{array}{l}\mathrm{J}_{\mathrm{Ic}} \\
\mathrm{K}_{\mathrm{Jc}} \\
\mathrm{J}(@ \mathrm{~J} / \mathrm{T}=8.8) \\
\text { Exponent } \mathrm{N} \\
\text { Coefficient } \mathrm{C} \\
\mathrm{T} \text { (average) }\end{array}$ & $\begin{array}{l}34.4 \mathrm{~kJ} / \mathrm{m}^{2} \\
87 \mathrm{MPa} \cdot \sqrt{\mathrm{m}} \\
75.9 \mathrm{~kJ} / \mathrm{m}^{2} \\
0.3574 \\
63.5 \mathrm{~kJ} / \mathrm{m}^{2} \\
14\end{array}$ & $K_{\mathrm{lc}}(\beta=72.4 \mathrm{MPa} \cdot \sqrt{\mathrm{m}})$ \\
\hline \multicolumn{3}{|c|}{ Least-suluares linear line (ASTM) $J=M(\Delta \&)+B$} \\
\hline 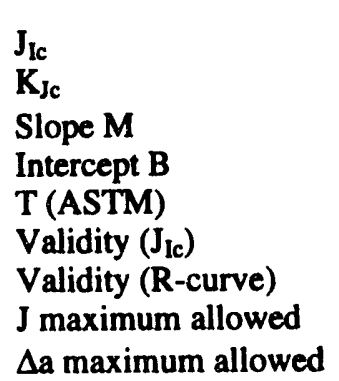 & $\begin{array}{l}34.2 \mathrm{~kJ} / \mathrm{m}^{2} \\
86.6 \mathrm{MPa} \cdot \sqrt{\mathrm{m}} \\
29,576.1 \mathrm{~kJ} / \mathrm{m}^{3} \\
33.3 \mathrm{~kJ} / \mathrm{m}^{2} \\
16 \\
\text { Valid } \\
\text { Invalid-2 } \\
0 \mathrm{~kJ} / \mathrm{m}^{2} \\
2.08 \mathrm{~mm}\end{array}$ & $\begin{array}{l}\left(\mathrm{J}_{\max }=\mathrm{B}_{\text {net }}+\text { flow stress } / 20\right) \\
(\Delta \mathrm{a} \max =0.1+\beta \mathrm{O})\end{array}$ \\
\hline
\end{tabular}

Table 2.5 Initial conditions and loading parameters for the two transients in the NKS-4 experiment

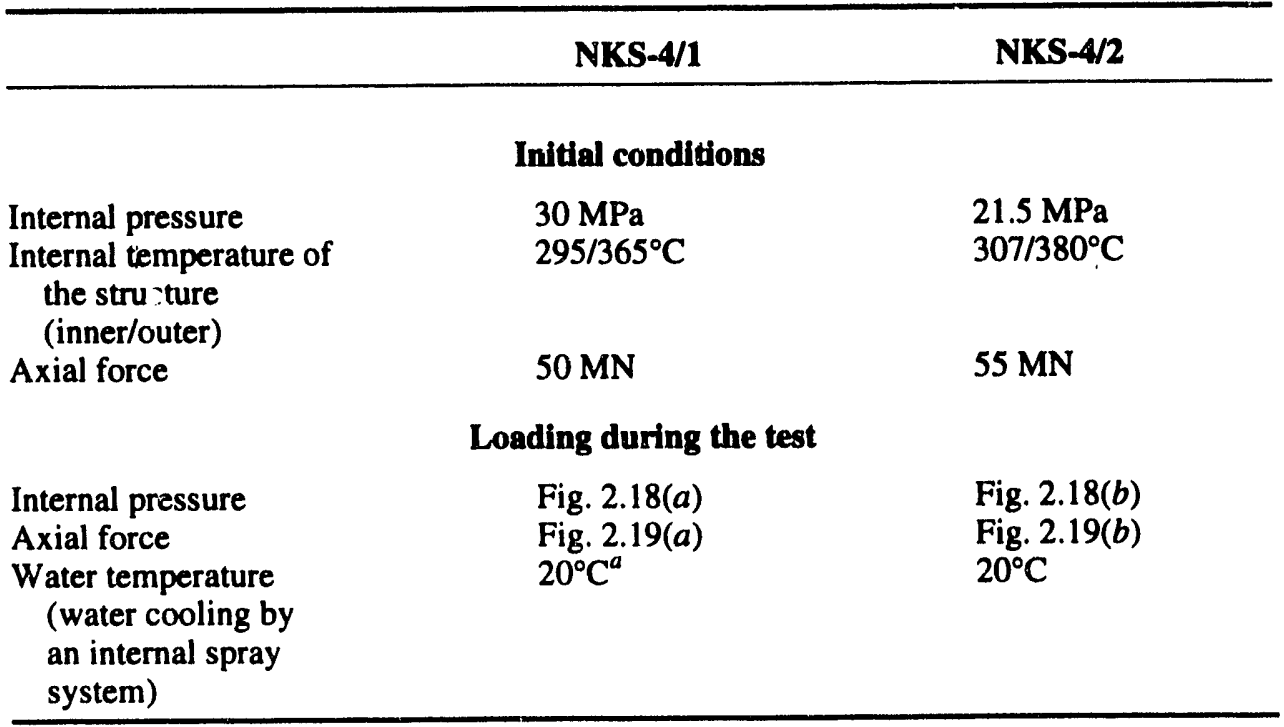

${ }^{a}$ Because of problems with valves, the cooling water flow was severely restricted; therefore, the test was stopped afier $12 \mathrm{~min}$. 

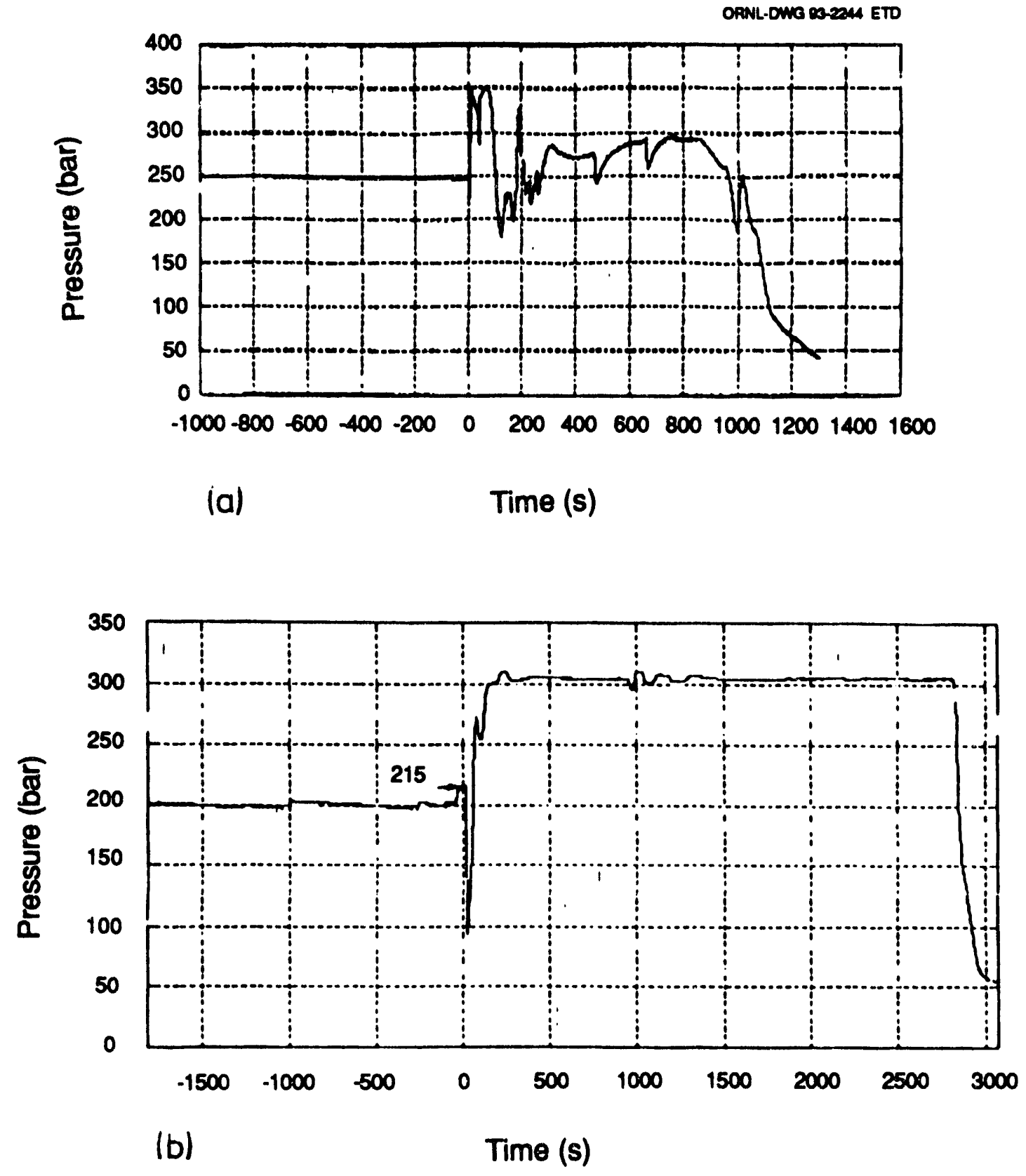

Fig. 2.18. Internal pressure vs time in NKS-4 experiment: (a) NKS-4/1; (b) NKS-4/2. 


\section{Description}

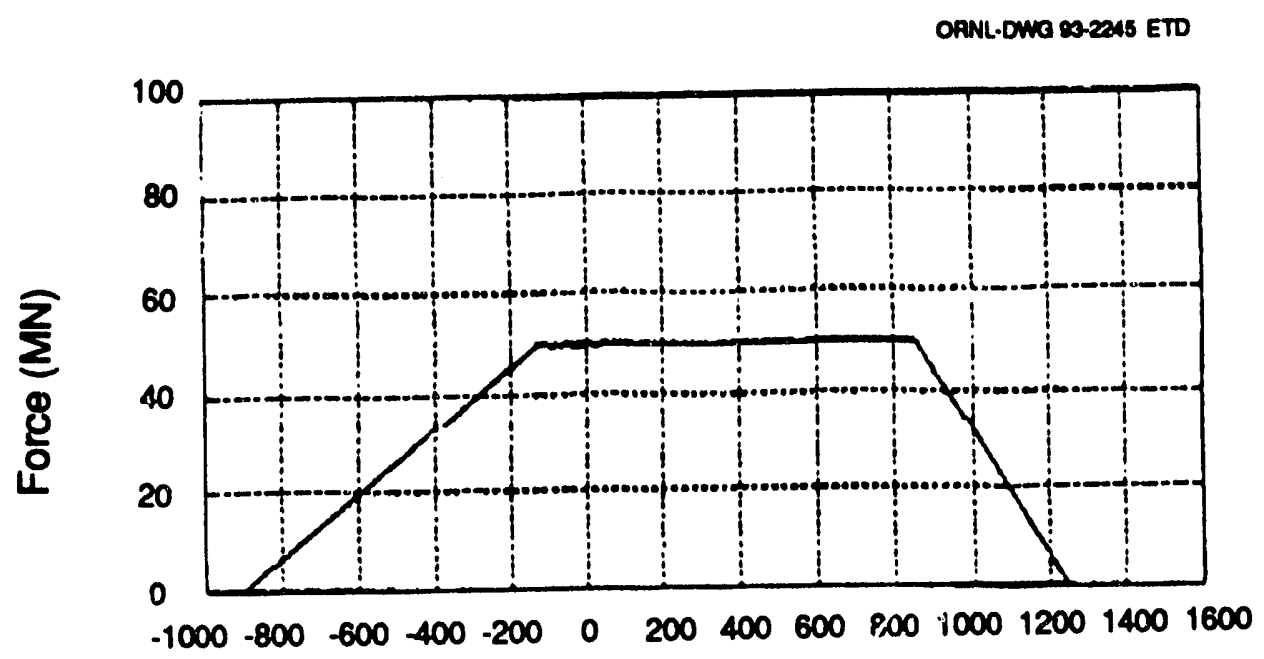

(a)

$\operatorname{Tim} \theta(\mathbf{s})$

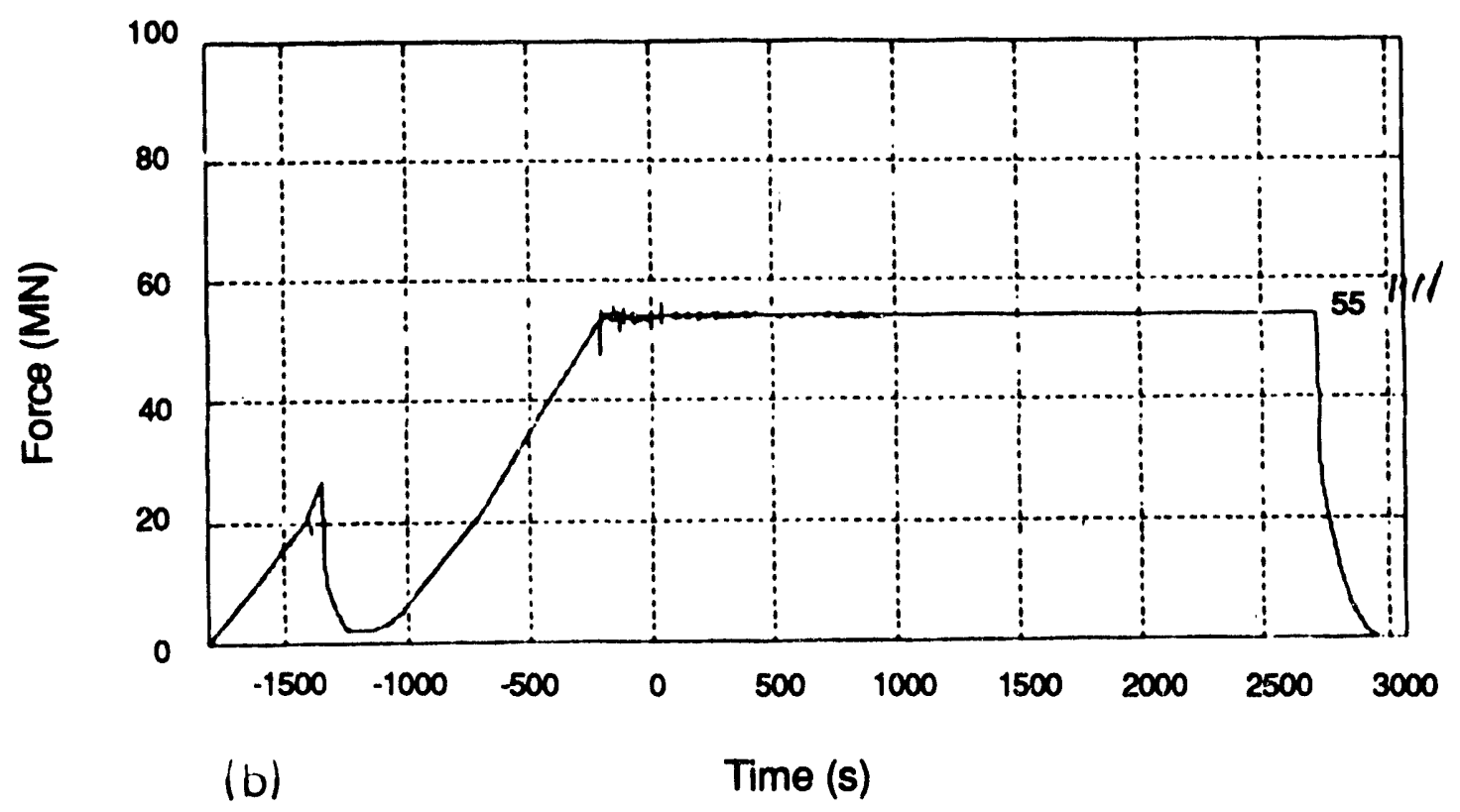

Fig. 2.19. Axial load vs time in NKS-4 experiment: (a) NKS-4/1; (b) KNS-4/2. 


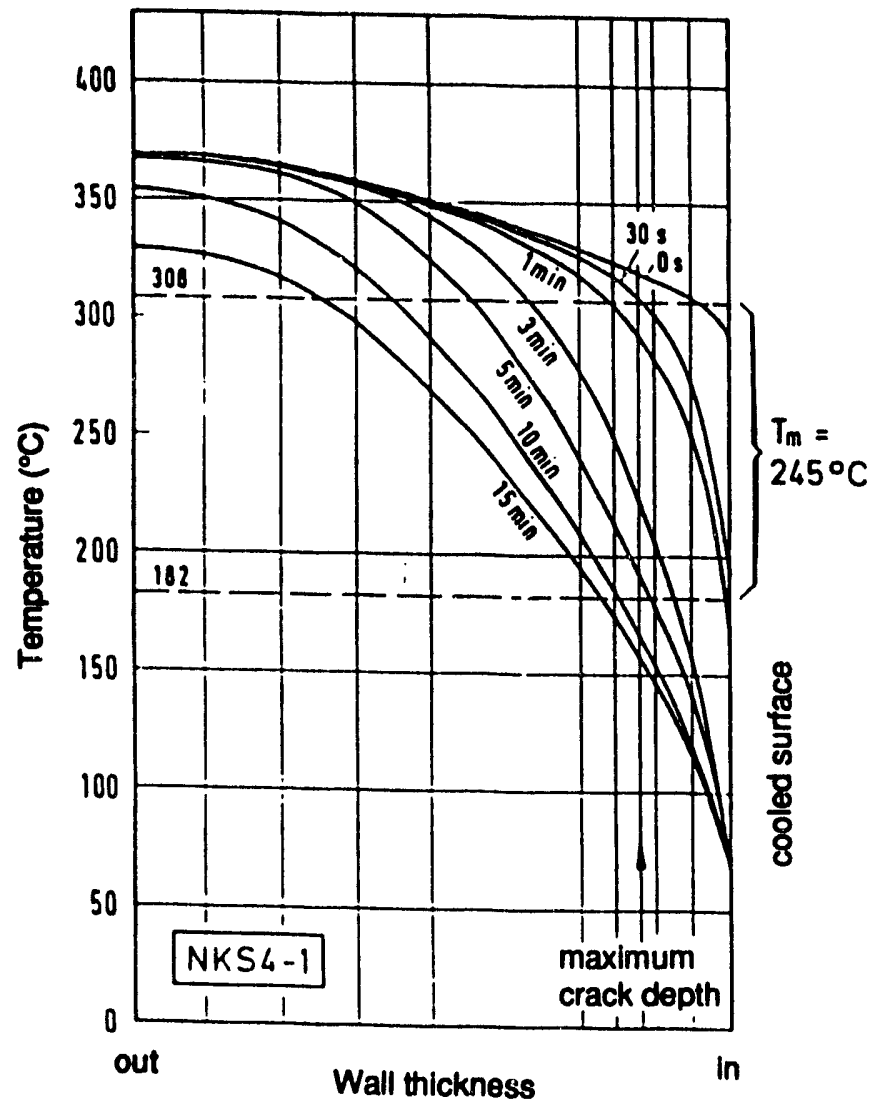

(a)

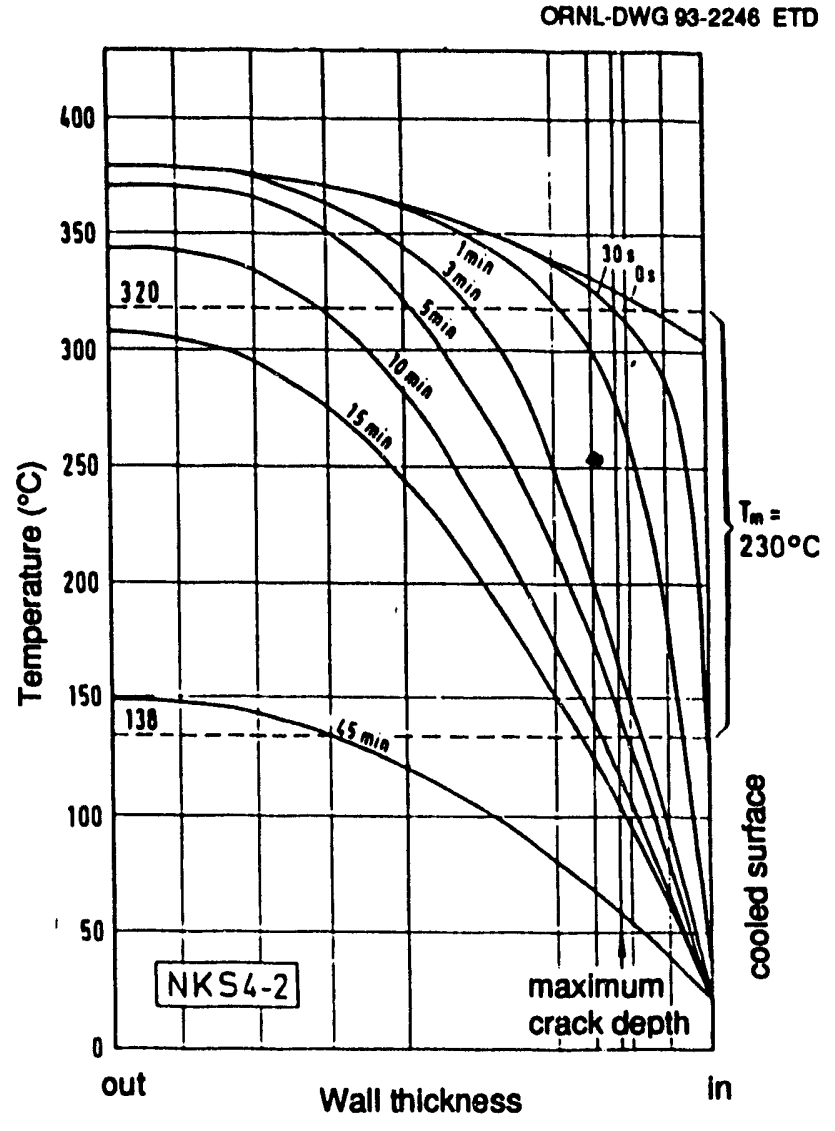

(b)

Fig. 2.20. Measured temperature profiles across wall thickness as function of time in NKS-4 experiments: (a) NKS-4/1; (b) NKS-4/2.

$\sim 10 \mathrm{~min}$. Pressurization of the test vessel is controlled independently by a system capable of pressures up to $\sim 100 \mathrm{MPa}$. A detailed description of the ORNL PTS test facility, including the main coolant and pressurization systems, as well as the computer-controlled data acquisition systems, is given in Refs. 3 and 4 .

In PTSE-2, the insert (test) material was taken from a $21 / 4$ $\mathrm{Cr}-1$ iNo plate, meeting SA-387 grade 22 specifications. The two pieces used for the insert and for properties characterization were subjected to the same heat treatment following welding of the insert into the vessel. The heat treatment was intended to provide the tensile and toughness characteristics desired for the experiment. The tensile strengths were undesirably low, but other properties, although somewhat uncertain, were satisfactory. True stress-strain tensile data are shown in Fig. 2.27 for the low upper-shelf (LUS) test material (A) and the tough carrier vessel material (B). [Concerning Fig. 2.27, note that the LUS material (A) set-5 data were from the properties characterization piece and were used in pretest analyses; however, the set-7 data were obtained from actual vessel insert material after completion of PTSE-2.] Tensile and physical properties for the test vessel are given in Tables 2.7 and 2.8. Additional data characterizing the fracture properties of the PTSE-2 material are given in Tables 2.9 and 2.10 and in Figs. 2.28 and 2.29. Side-grooved specimens from the vessel insert and from the pretest characterization piece (PTC1) were tested at 175 and $250^{\circ} \mathrm{C}$ to obtain full $J_{R}$ curves (Fig. 2.29). These unloading-compliance characterization tests were analyzed using procedures described in American Society for Testing and Materials (ASTM) E1 152, and the power-law curve fit parameters are given in Table 2.10.

Pretest crack arrest $\left(\mathrm{K}_{\mathrm{Ia}}\right)$ and crack initiation fracture toughness ( $\mathrm{K}_{\mathrm{Ic}}$ and $\mathrm{KJ}_{\mathrm{J}}$ ) data are shown in Fig. 2.28. The $\mathrm{K}_{\text {Ia }}$ data were obtained from tests of 33-and 51-mm-thick specimens. $\mathrm{K}_{\mathrm{Ic}}$ and $\mathrm{K}_{\mathrm{J}}$ data are from tests of 25 -mm-thick specimens. The upper- and lower- $\mathrm{K}_{\mathrm{Ia}}$ curves shown in Fig. 2.28 $(a)$ were determined by least-squares fits to the raw data and to $\beta$-adjusted data, ${ }^{5}$ respectively. The curves representing $\mathrm{K}_{\mathrm{Ic}}$ at high transitional temperatures were presumed, in the absence of reliable data, to be positioned 
Description

ORNL-DWG 93-2247 ETD

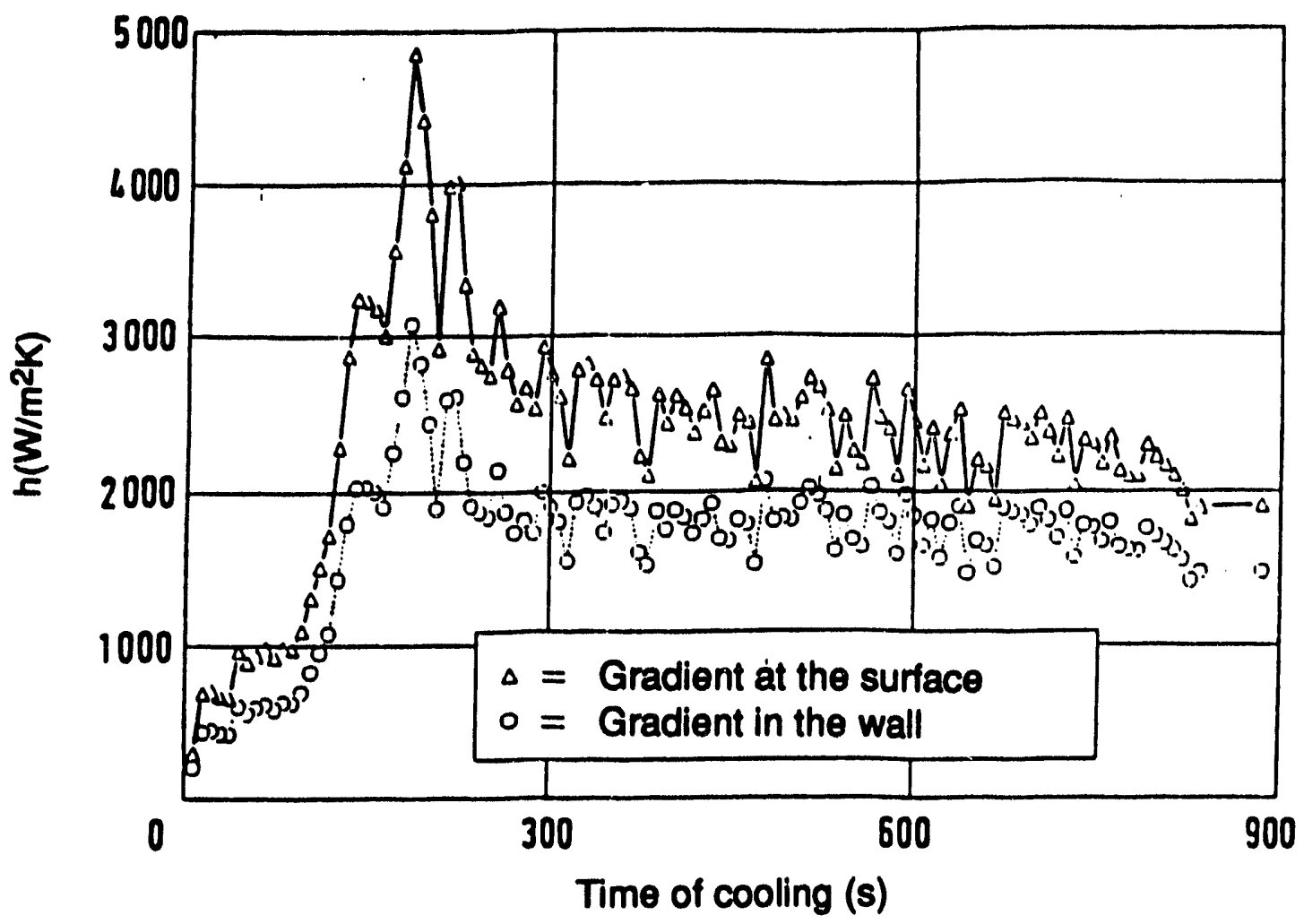

(a)

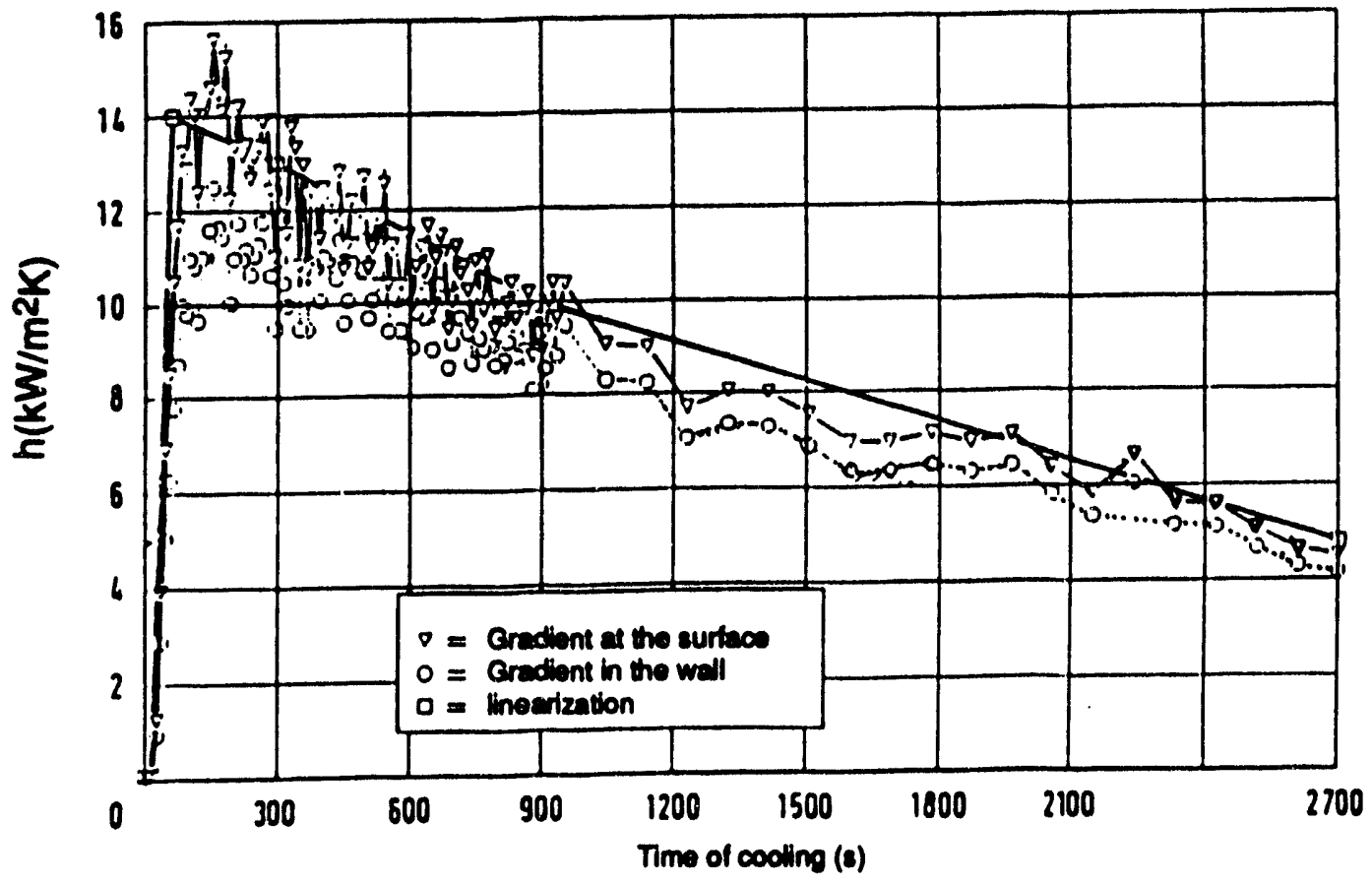

(b)

Fig. 2.21. Heat transfer coeffcients vs time for NKS-4 experiments: (a) NKS-4/1; (b) NKS-4/2. 
Description

OARL-OWO Da-2ane ETO

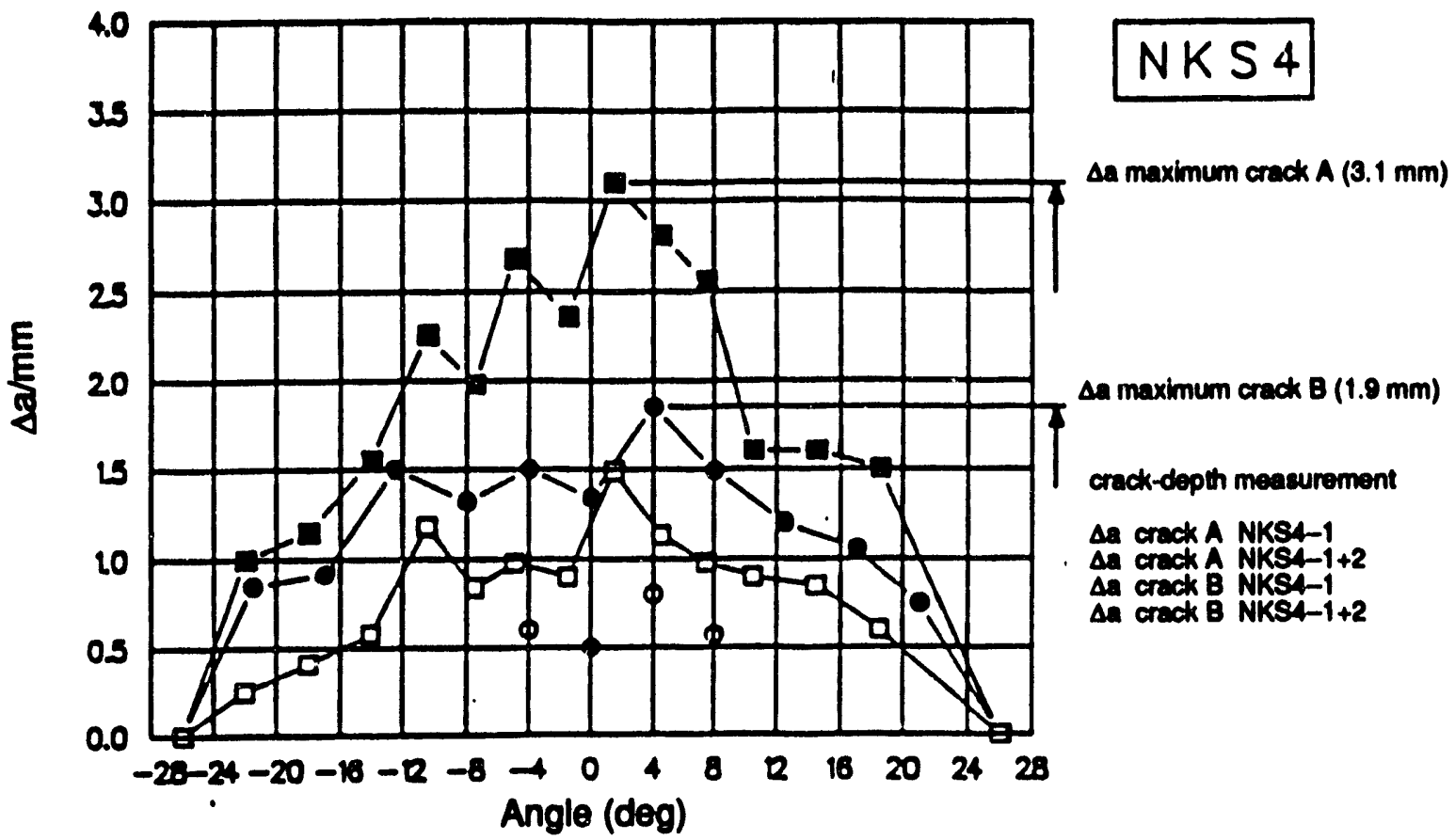

Fig. 2.22. Fractographic results for NKS-4 experiments.
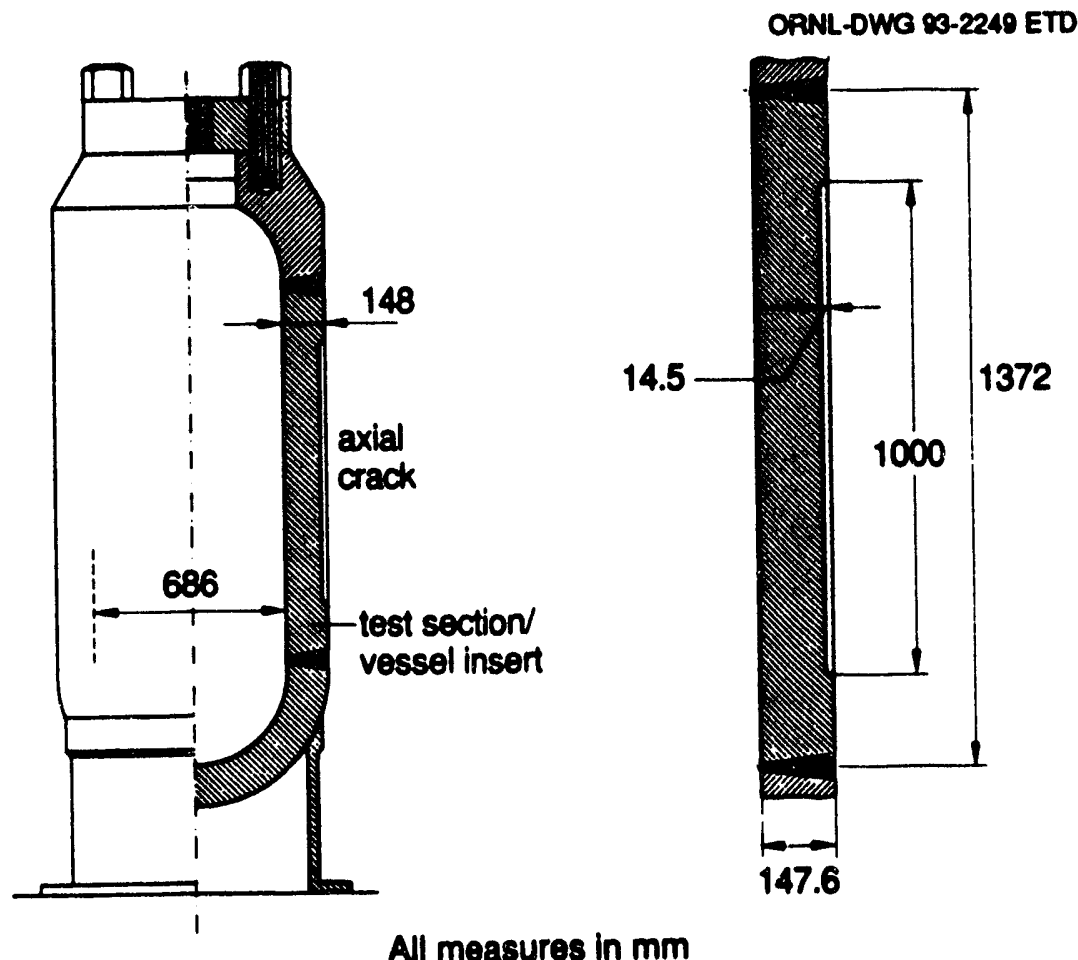

Fig. 2.23. Test vessel and crack geometry for PTSE-2A, transient A (ORNL, U.S.A.). 
Table 2.6 Geometric parameters of PTSE-2 vessel

\begin{tabular}{ll}
\hline \multicolumn{1}{c}{ Parameter } & Value \\
\hline Inside radius, $\mathrm{mm}$ & 343.0 \\
Wall thickness $(\mathrm{w}), \mathrm{mm}$ & 147.6 \\
Flaw length, $\mathrm{mm}$ & 1000.0 \\
Flaw length $\mathrm{a}, \mathrm{mm}$ & 14.5 \\
$\mathrm{a} / \mathrm{W}$ & 0.098 \\
\hline
\end{tabular}

$-30^{\circ} \mathrm{K}$ lower in temperature than the respective $\mathrm{K}_{\mathrm{la}}$ curves. It transpired that a $K_{I c}$ curve determined by the low-temperature $K_{I c}$ points and by the remaining $\beta$ and rate-adjusted $K_{J}$ data ${ }^{4}$ in the transition region was suitably related to the upper $\mathrm{K}_{\mathrm{Ia}}$ curve. This fitted $\mathrm{K}_{\mathrm{Ic}}$ curve and a lower $\mathrm{K}_{\text {Ic }}$ curve, displaced upward by $30^{\circ} \mathrm{K}$ from the former [Fig. 2.28(b)], were adopted for planning PTSE-2.

The experiment was planned to consist of two transients, of which the first would induce warm prestressing $\left(\dot{K}_{1}>0\right)$ followed by reloading $\left(\dot{K}_{1}<0\right)$ until the crack propagated by cleavage and arrested. The second transient was planned to produce a deep cleavage crack jump with an arrest occurring only after conditions conducive to subsequent unstable tearing were attained. The second transient was also necessary to provide a measurement of $K_{\mathrm{Ic}}$ that was not strongly affected by warm prestressing so that the effects of warm prestressing in the first transient could be evaluated. The experimentally determined temperature profile and pressure data for transient $\mathrm{A}$, as well as some material characterization of the test section, are shown in Fig. 2.30 (see also Fig. 2.31 and Table 2.11).

The time dependence of the heat transfer coefficient for transient $A$ is given in Fig. 2.32. The thermal shock in the PTSE-2A transient started $-112 \mathrm{~s}$ after the initiation of the data scan. Subsequently and sequentially, the flaw experienced ductile tearing while $K_{I}$ was increasing; tearing ceased, presumably when $K_{I}$ first decreased; tearing resumed at about the time $K_{I}$ increased again; cleavage crack propagation and arrest occurred; and, finally, ductile tearing resumed after crack arrest until pressure was reduced. The succession of events identifiable from recorded transient data is summarized in Table 2.12. The most probable times of events were determined by detailed evaluation of all relevant data.

CMOD behavior for the entire PTSE-2A transient is typified by the plot shown in Fig. 2.33. More detail for the period of initial tearing that preceded the initial maximum $\mathrm{K}_{\mathrm{I}}$ is represented by two typical CMOD measurements vs time, shown in Fig. 2.34. The first maximum $K_{I}$ was reached at point $A$, when $C M O D$ reached a maximum. Examination of the fracture surface showed that ductile tearing enlarged the flaw depthwise with no significant axial tearing.

The second episode of ductile tearing transpired when CMOD again increased (from point $B$ to $C$ in Figs. 2.33 and 2.35 ). The crack propagated by cleavage, causing the rapid change in CMOD from $C$ to $\mathrm{C}^{\prime}$. The final ductile tearing in PTSE-2A occurred while pressure and CMOD were increasing (from point $C^{\prime}$ to $D$ in Figs. 2.33 and 2.35).

\subsubsection{PTSE-2B}

The arrested crack from transient $A$ was the initial crack geometry for transient B. Data describing the thermal and mechanical loading conditions in transient $B$ are provided in Fig. 2.36 (see also Fig. 2.31 and Table 2.11). The thermal shock in PTSE-2B started at $-155 \mathrm{~s}$ after initiation of the data scan. Here, $K_{I}$ increased monotonically until about the time of the rapid cleavage crack propagation. The extended crack that had developed during the PTSE-2A first tore depthwise and then converted to cleavage. The propagating cleavage crack arrested and then propagated by ductile tearing until the vessel ruptured. The events in this transient are summarized in Table 2.12. The CMOD behavior typical of the time before cleavage is shown by the CMOD at the center of the flaw in Fig. 2.37. The time of the start of the cleavage event is reasonably well defined by all of the active CMOD and strain gages.

The PTSE-2 experiment produced two fast crack jumps. The final crack propagation led to rapid ductile tearing that penetrated the vessel wall. Prominent features of the flaw are identified in Fig. 2.38 and in Tables 2.13 and 2.14. The entire fracture surface ( $A$ side) is shown in Fig. 2.39. The average depth of the flaw at several stages is given in Table 2.14. The experimental records of CMOD vs time in conjunction with finite-element calculations of displacements for a range of crack depths and times were 


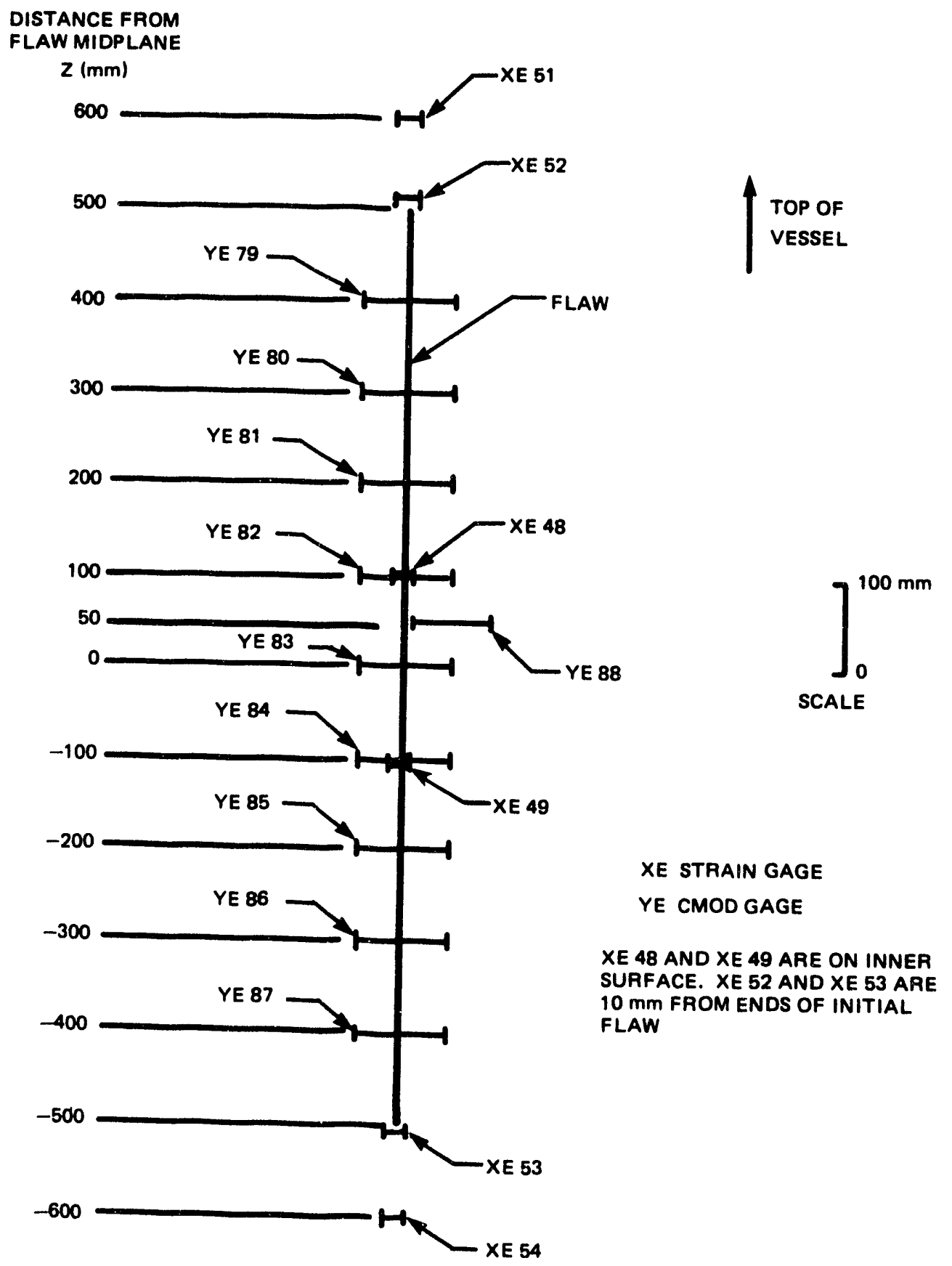

Fig. 2.24. Locations of CMOD gages and strain gages near flaw on PTSE-2 vessel. 


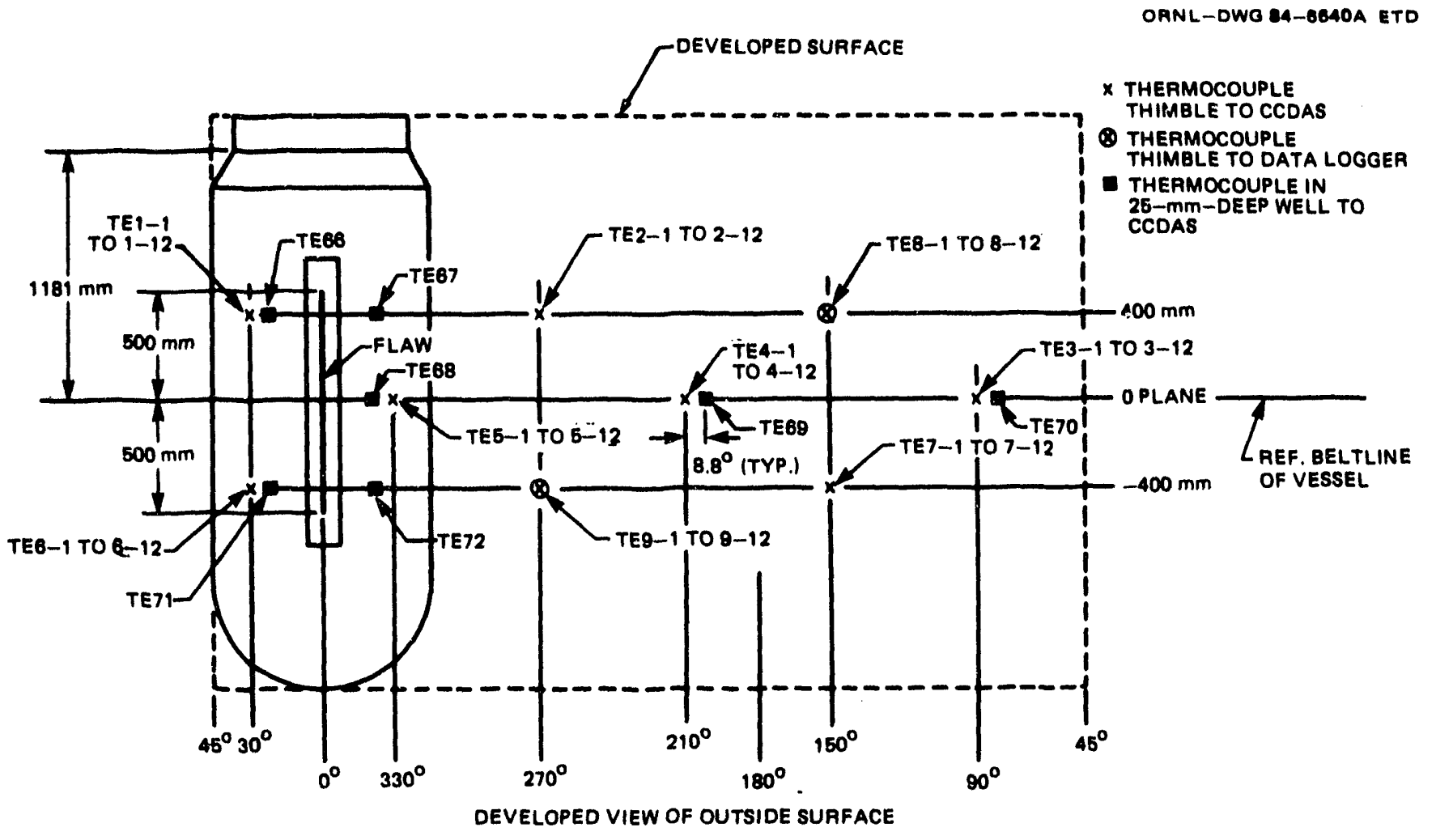

Fig. 2.25. Thermocouple thimble and near-surface thermocouple locations in PTSE-2 vessel.

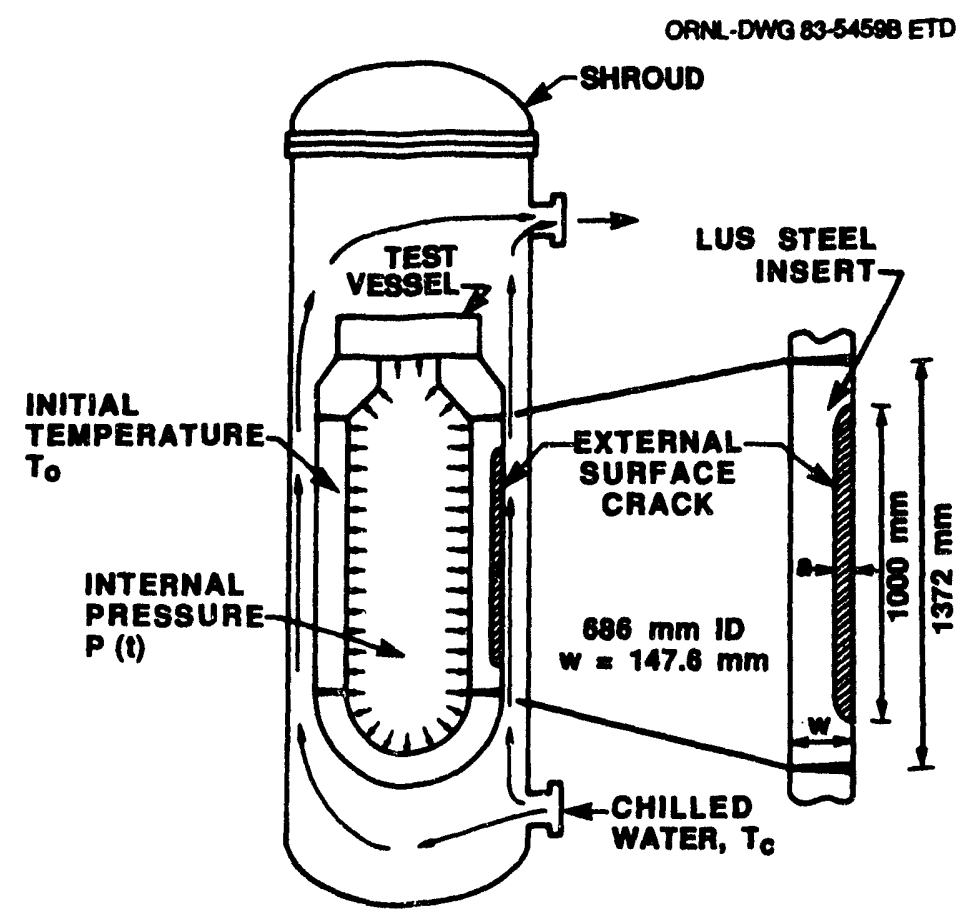

Fig. 2.26. Schematic view of pressurized-thermal-shock (PTSE-2) vessel inside shroud. 


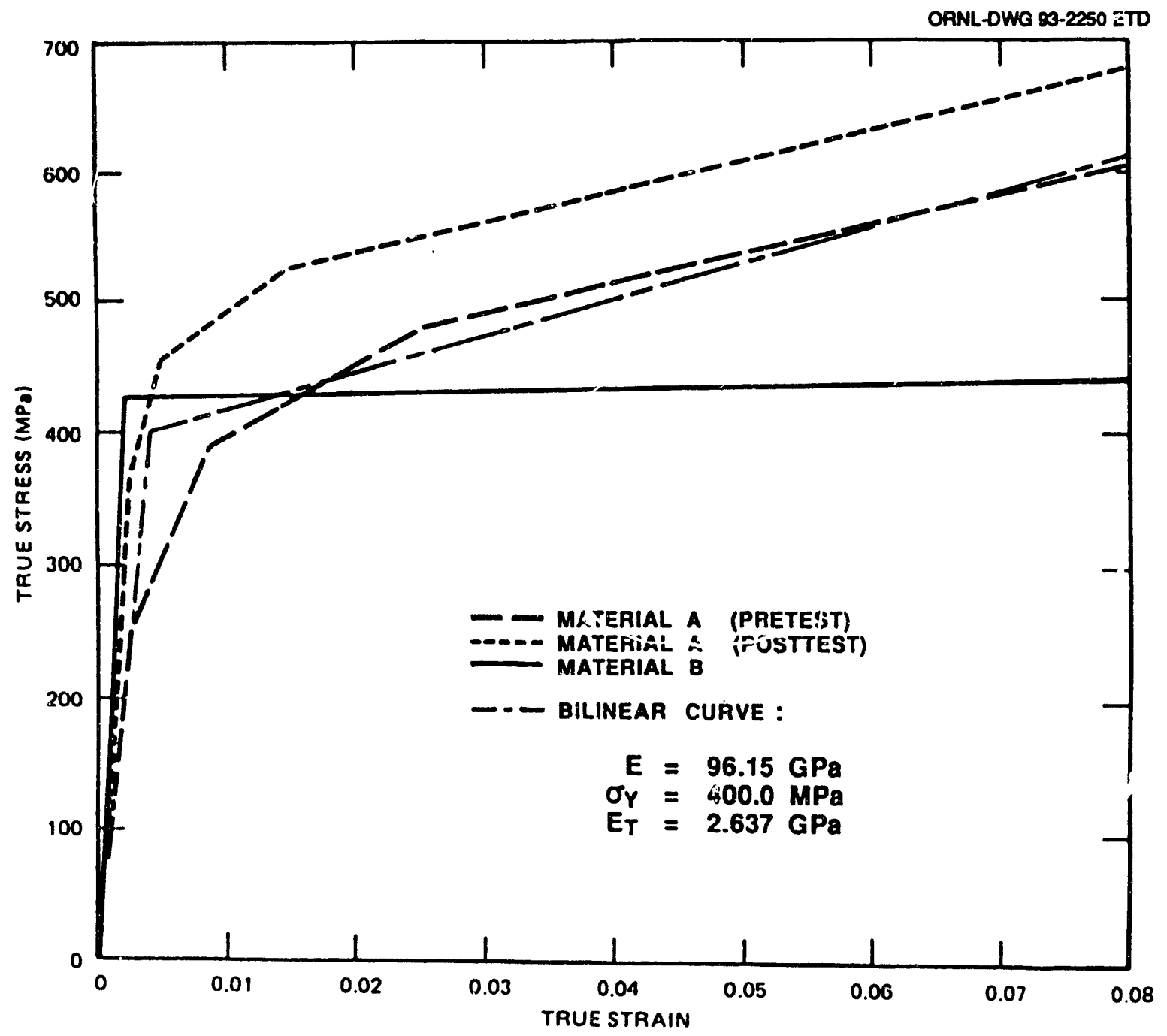

Fig. 2.27. S3ress-strain curves used in analyses of the PTSE-2 experiment. 
Table 2.7 Tensile properties for PTSE-2 vessel

\begin{tabular}{llll}
\hline & $\begin{array}{c}\text { Material A } \\
\text { (set 5) }\end{array}$ & $\begin{array}{c}\text { Material A } \\
\text { (set 7) }\end{array}$ & ${\text { Material } \mathbf{B}^{b}}^{a}$ \\
\hline Elastic modulus E, MPa & $2.111 \times 10^{5}$ & $1.98 \times 10^{5}$ & $2.023 \times 10^{5}$ \\
Poisson's ratio v & 0.3 & 0.3 & 0.3 \\
RT $^{c}$ yield stress $\sigma_{\mathrm{y}}, \mathrm{MPa}$ & 255 & 375 & 430 \\
${\text { RT ultimate stress } \sigma_{\mathrm{u}}, \mathrm{MPa}}$ & 518 & $?$ & $?$ \\
\hline
\end{tabular}

${ }^{a}$ LUS test material.

bCarrier vessel material.

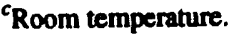

Table 2.8 Physical properties for PTSE-2 vessel

Heat convection coefficient

Thermal conductivity

Specific heat

Density

Coefficient of thermal expansion
(Fig. 2.32)

$\mathrm{k}=41.54 \mathrm{~W} \cdot \mathrm{m}^{-1} \cdot \mathrm{K}^{-1}$

$\mathrm{c}=502.4 \mathrm{~J} \cdot \mathrm{kg}-1 \cdot \mathrm{K}^{-1}$

$\rho=7833 \mathrm{~kg} \cdot \mathrm{m}^{-3}$

$\alpha=14.4 \times 10^{-6} \mathrm{~K}^{-1}$

Table 2.9 Fracture properties for'PTSE-2 material

\begin{tabular}{lc}
\hline \multicolumn{1}{c}{ Property } & Value \\
\hline NDT temperature, ${ }^{\circ} \mathrm{C}$ & 49 \\
Onset of Charpy upper shelf & 150 \\
$\quad\left(100 \%\right.$ shear fracture appearance), ${ }^{\circ} \mathrm{C}$ & \\
Charpy upper-shelf energy, J & $\sim 50-75^{a}$ \\
Charpy transition temperature, ${ }^{\circ} \mathrm{C}$ & \\
At 50\% shear fracture appearance & 90 \\
At 0.89-mm lateral expansion & 98 \\
\hline
\end{tabular}

a Range for all depths in plate. The average at 1/4 depth is $-68 \mathrm{~J}$. 


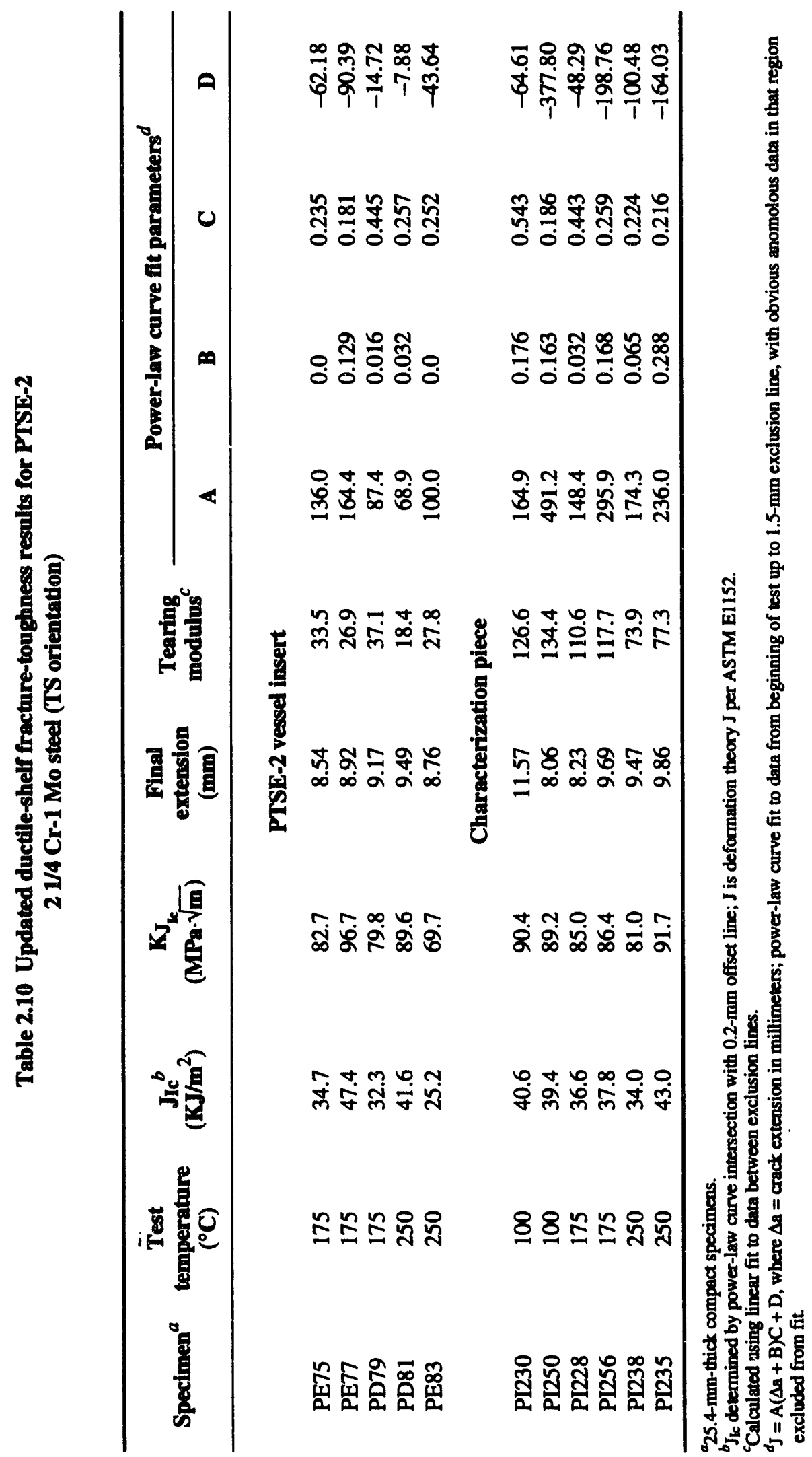




\section{Description}

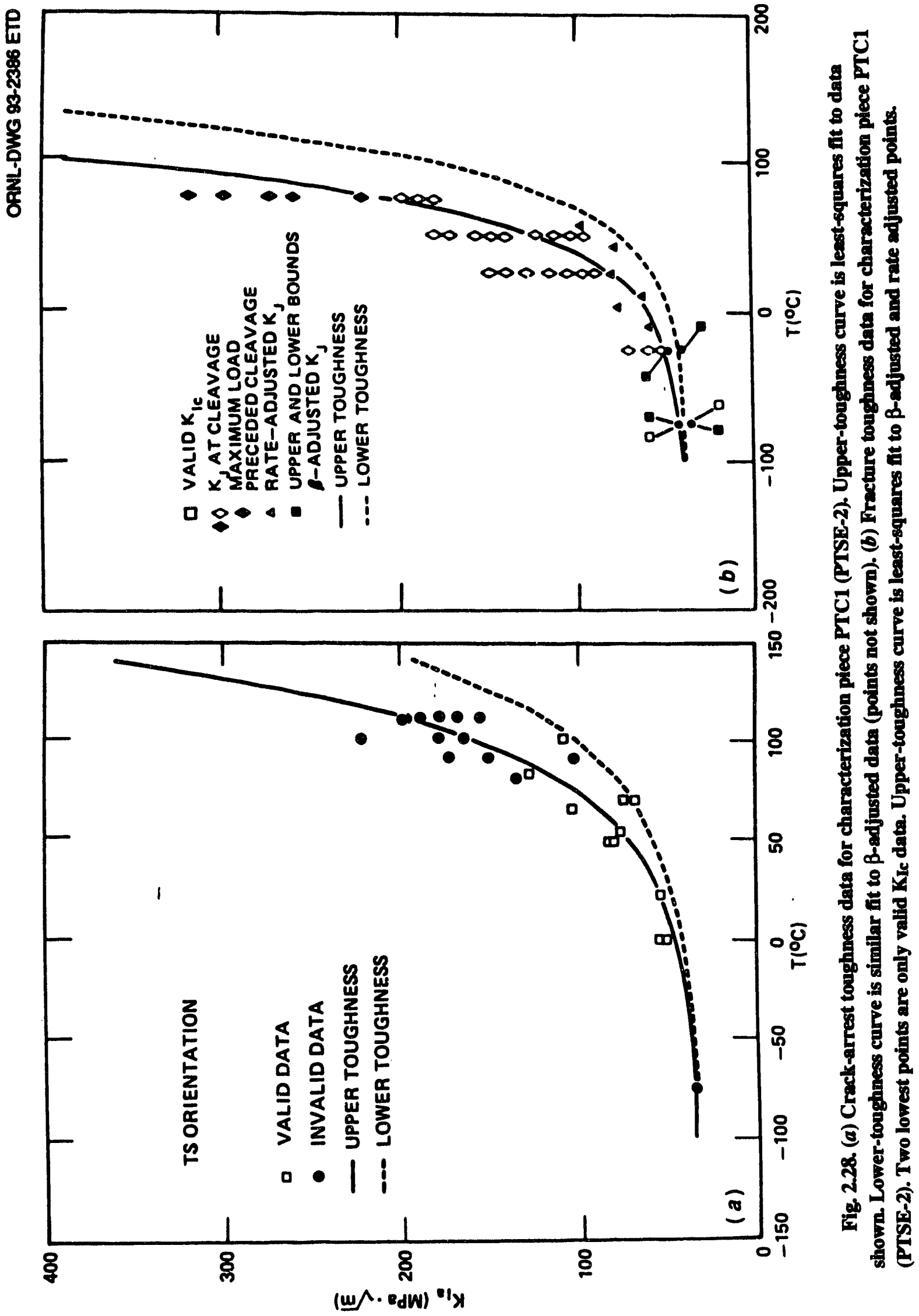




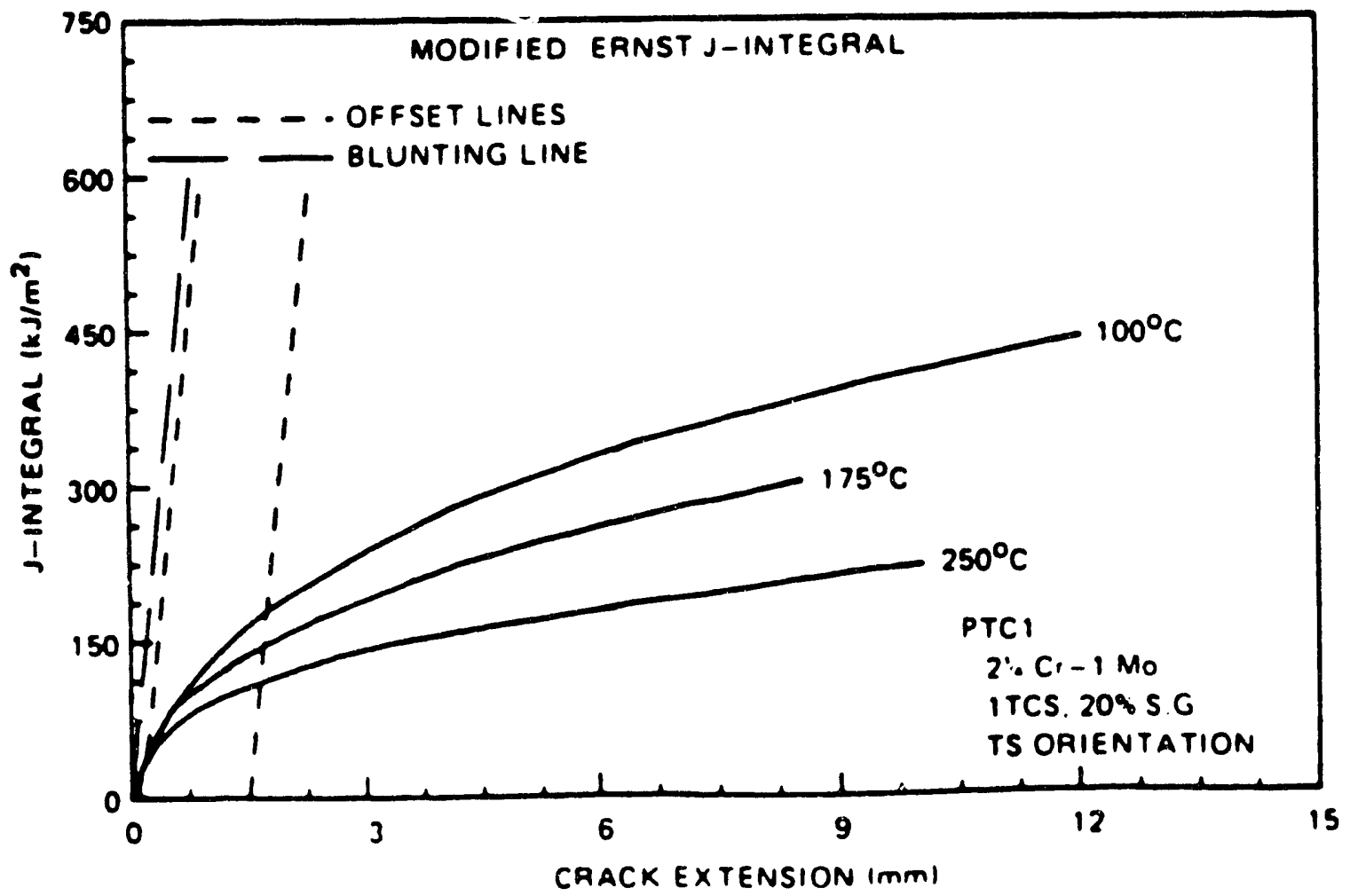

Fig. 2.29. Comparison of $\mathrm{J}$-integral $\left(\mathrm{J}_{\mathrm{m}}\right)$ resistance curves at three test temperatures for PTSE-2 (TS orientation) near plate surface of characterization block PTC5.

Thermal and mechanical loading
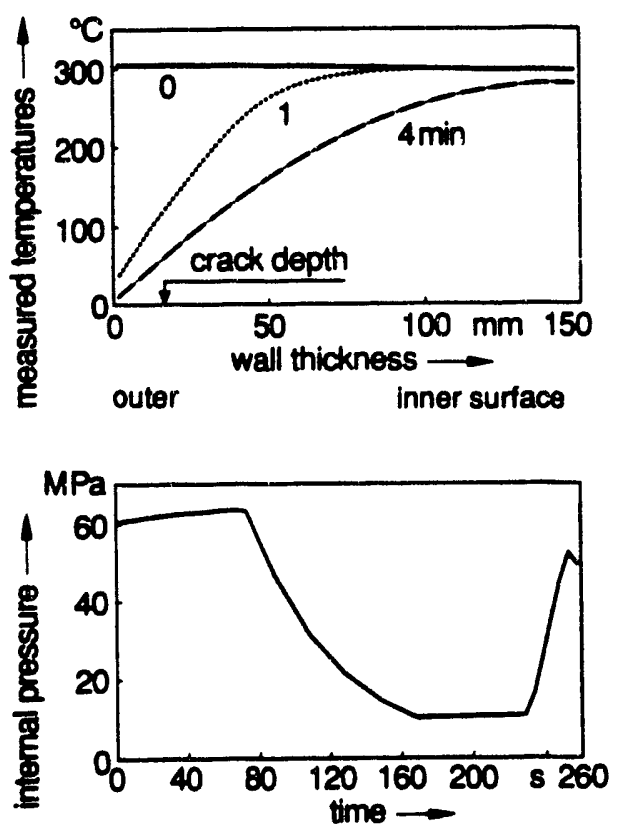

OANL-DWG 93-2251 ETD

Material characterization of 21/4 Cr-1 Mo (SA-387 grade 22) (test section/vessel insert)

\begin{tabular}{|l|c|}
\hline $\begin{array}{l}\text { yield/ultimate } \\
\text { stress at RT }\end{array}$ & $\begin{array}{r}255 / 518 \mathrm{MPa} \\
\text { (pretest) } \\
\text { ? MPa } \\
\text { (posttest) }\end{array}$ \\
\hline $\begin{array}{l}\text { charpy energy } \\
\text { for upper shelf }\end{array}$ & $50-75 \mathrm{~J}$ \\
\hline NDT & $\begin{array}{l}49^{\circ} \mathrm{C} \\
\text { (pretest) } \\
7^{\circ} \mathrm{C} \\
\text { (posttest) }\end{array}$ \\
\hline
\end{tabular}

Fig. 2.30. Loading data for PTSE-2A (transient A) and material data of test section. 


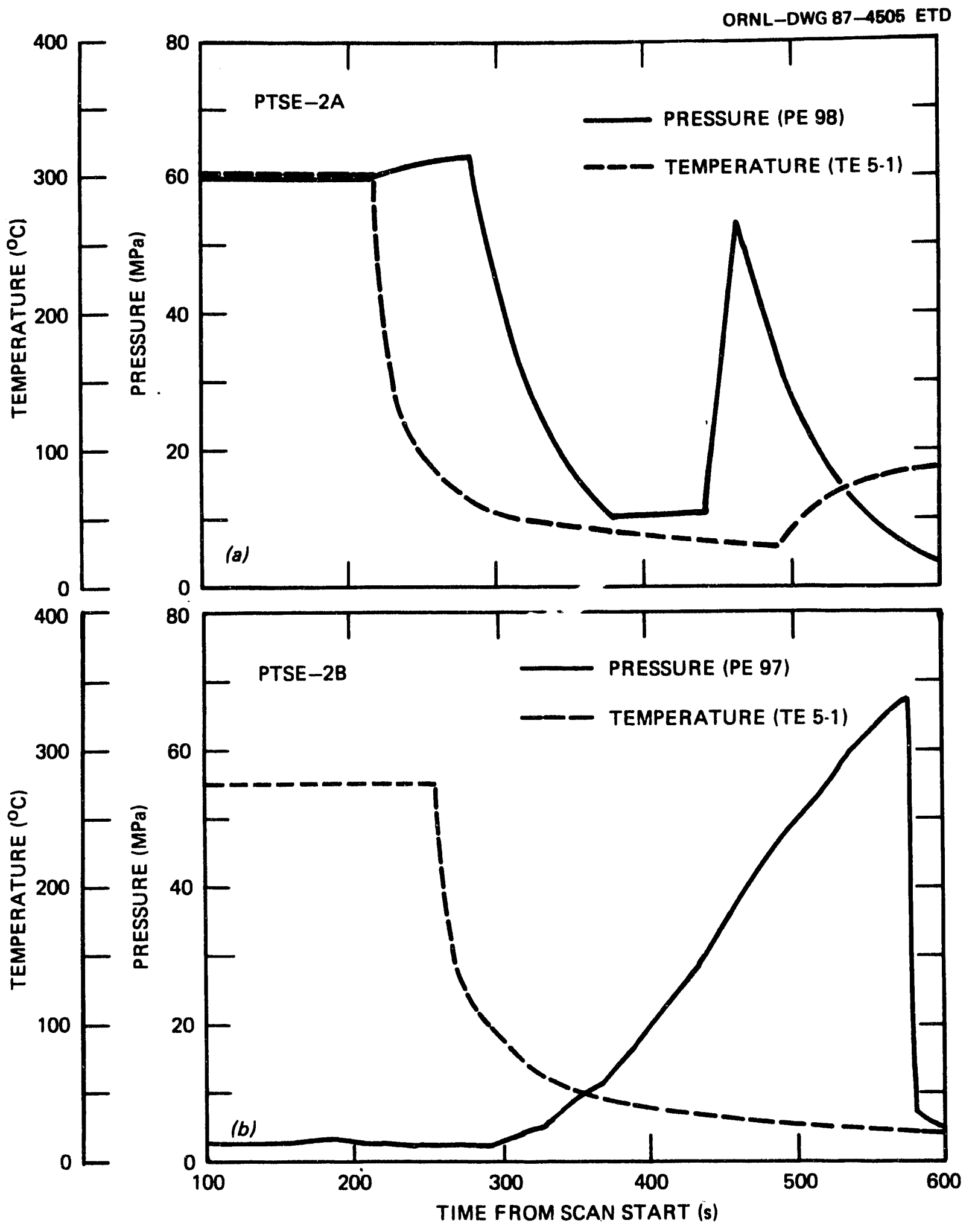

Fig. 2.31. Temperature and pressure vs time data recorded for PTSE-2 transients: (a) PTSE-2A and (b) PTSE-2B. 
Table 2.11 Experimental pressure vs time values for PTSE-2A and -2B at selected time steps ${ }^{a}$

\begin{tabular}{ccccc}
\hline & PTSE-2A & & \multicolumn{2}{c}{ PTSE-2B } \\
\cline { 4 - 5 } Time & $\begin{array}{c}\text { Pressure } \\
\text { (s) }\end{array}$ & TPa) & (s) & $\begin{array}{c}\text { Pressure } \\
\text { (MPa) }\end{array}$ \\
\hline 110 & 60.0 & 157.2 & 2.7 \\
120 & 60.5 & 159.6 & 2.9 \\
130 & 61.2 & 161.9 & 3.0 \\
140 & 61.8 & 164.3 & 3.0 \\
150 & 62.2 & 167.9 & 3.1 \\
160 & 62.6 & 171.5 & 3.1 \\
170 & 63.0 & 178.7 & 3.2 \\
180 & 63.2 & 185.8 & 3.4 \\
185 & 62.8 & 193.0 & 3.2 \\
200 & 46.5 & 200.2 & 2.9 \\
220 & 31.5 & 214.5 & 2.5 \\
240 & 21.5 & 228.8 & 2.5 \\
260 & 14.8 & 243.2 & 2.6 \\
280 & 10.4 & 271.8 & 2.4 \\
310 & 10.8 & 300.5 & 3.1 \\
340 & 11.1 & 329.2 & 5.5 \\
345 & 16.7 & 350.7 & 9.3 \\
350 & 26.5 & 365.0 & 11.2 \\
355 & 36.5 & 386.5 & 16.3 \\
360 & 45.8 & 400.8 & 20.1 \\
365 & 52.5 & 451.0 & 34.9 \\
370 & 49.4 & 501.2 & 50.0 \\
& & 551.3 & 62.9 \\
& & 572.8 & 66.9 \\
& & 575.7 & 67.3 \\
& & 576.0 & 65.1 \\
& & 576.7 & 62.3 \\
\hline
\end{tabular}

${ }^{a}$ Time $\mathrm{t}=112 \mathrm{~s}$ and $155 \mathrm{~s}$ at start of thermal transient for PTSE-2A and $-2 \mathrm{~B}$, respectively.

the basis for identifying fracture events. The time of vessel rupture is marked by a sharp drop in pressure and by abrupt changes in CMOD and strain gage outputs. Times of all events are given relative to the time of initiation of the computer-controlled data scans.

\subsection{SC Experiments}

\subsubsection{SC-I}

The first SC experiment ${ }^{6,7}$ was an investigation of stable ductile crack growth in contained yield for a thick-section low-alloy steel structure. Crack growth was generated by progressively increasing the rotational speed of a cylindrical specimen maintained at a uniform temperature of $290^{\circ} \mathrm{C}$

The general arrangement of the $\mathrm{SC}$ apparatus ${ }^{6}$ is shown in Fig. 2.40, where the central feature is an 8-ton cylindrical test specimen ( $1.3 \mathrm{~m}$ long, $1.4-\mathrm{m}$ OD, $200-\mathrm{mm}$ wall thickness as shown in Fig. 2.41) suspended by a flexible shaft from a single pivoted bearing so that it is free to rotate about the vertical axis.

The driving power is provided by a $375-\mathrm{kW}$ dc motor that is capable of a maximum design speed of $3500 \mathrm{rpm}$ at the rotor. A damping device (not shown) is attached to the bearing pivot to stabilize the rotor against aerodynamically induced precessional motion. Eight 3-kW heaters mounted vertically within the cylinder enclosure provide the 


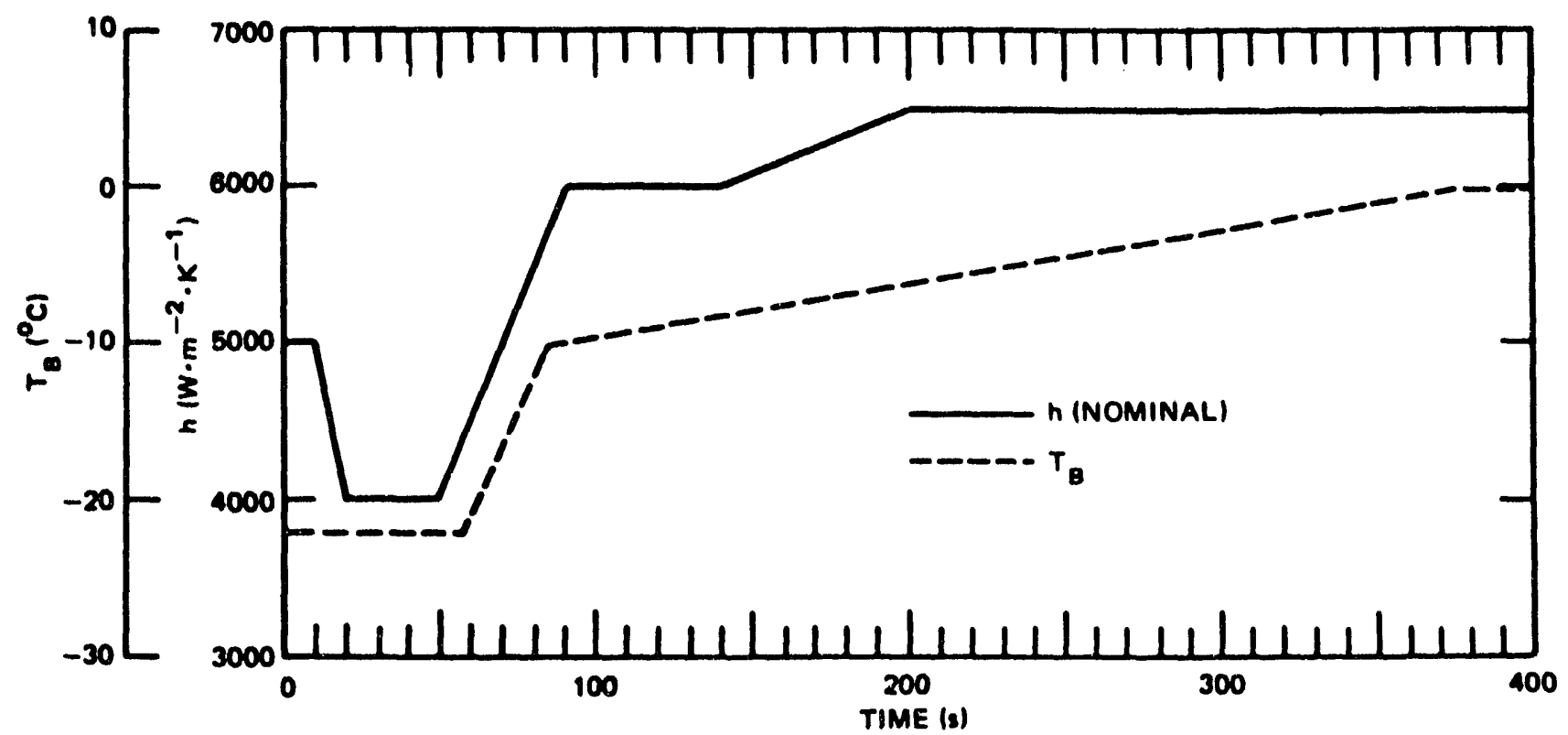

Fig. 2.32. Time-dependent values of $h$ (heat convection coeficient) and $T_{B}$ (bulk coolant temperature) established from pretest thermo-hydraulic measurement and heat transfer analyses for PTSE-2A. Final ORNL pretest analyses included variants of $h \mathbf{~} 10 \%$ above and below normal.

Table 2.12 Events identified by transient data in PTSE-2A and -2B

\begin{tabular}{|c|c|c|}
\hline Event & $\begin{array}{c}\text { Time } \\
\text { (s) }\end{array}$ & Evidence of event \\
\hline \multicolumn{3}{|c|}{ PTSE-2A } \\
\hline Initiation of thermal shock & $\sim 112$ & Outside surface temperature \\
\hline Initial tearing & $112-184.6$ & Analysis and CMOD \\
\hline First maximum $\mathrm{K}_{\mathbf{1}}$ & 184.6 & Calculated $\mathrm{K}_{1} ; \mathrm{CMOD}$, pressure \\
\hline Minimum $K_{\mathbf{l}}$ & 341.8 & Calculated $\mathrm{K}_{1} ; \mathrm{CMOD}$, pressure \\
\hline Precleavage tearing & $341.8-361.4$ & Analysis and CMOD \\
\hline Initial cleavage propagation & 361.4 & CMOD \\
\hline Crack arrest & $361.4^{b}$ & CMOD \\
\hline Axial crack propagation & 361.4 & $\begin{array}{l}\text { Strain and CMOD gages beyond } \\
\text { ends of initial flaw }\end{array}$ \\
\hline Postcleavage tearing & $361.4-365.6$ & Analysis and CMOD \\
\hline Final maximum $\mathrm{K}_{\mathrm{l}}$ & 365.6 & Calculated $\mathrm{K}_{\mathrm{l}}, \mathrm{CMOD}$, pressure \\
\hline \multicolumn{3}{|c|}{ PTSE-2B } \\
\hline Initiation of thermal shock & $\sim 155$ & Outside surface temperature \\
\hline Precleavage tearing & $155-575.8$ & Analysis and CMOD \\
\hline Cleavage propagation & 575.82 & CMOD \\
\hline Crack arrest & $575.82^{b}$ & CMOD \\
\hline Postcleavage tearing & $576.2-576.7$ & Analysis and $\mathrm{CMOD}$ \\
\hline Rupture of vessel wall & 576.7 & Pressure, CMOD, strain \\
\hline
\end{tabular}

${ }^{a}$ Time after start of scanning by the data acquisition system.

${ }^{b}$ Time intervals $<10 \mathrm{~ms}$ cannot be resolved by the data acquisition system. 


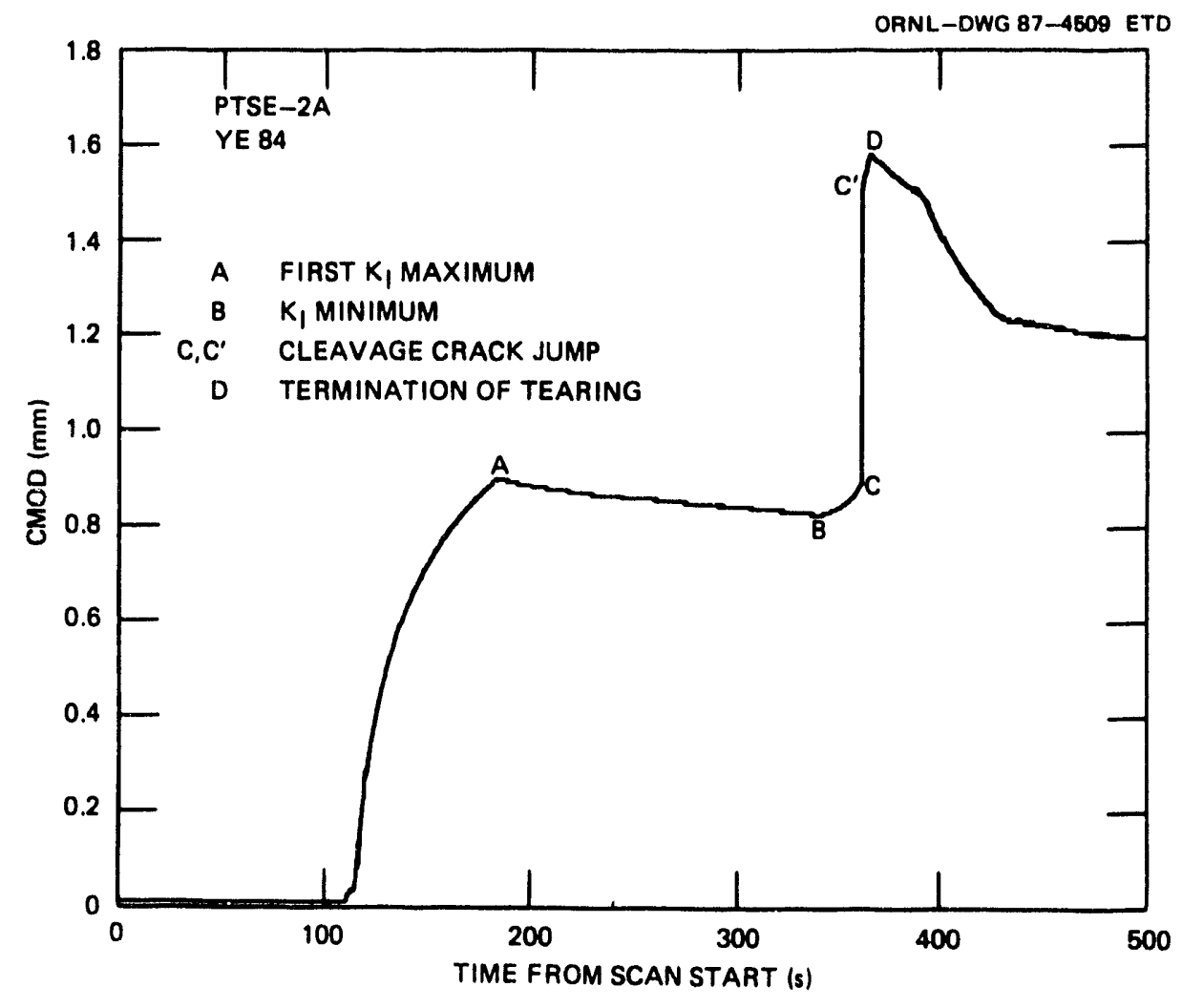

Description

Fig. 2.33. CMOD vs time at center of flaw for PTSE-2A transient.

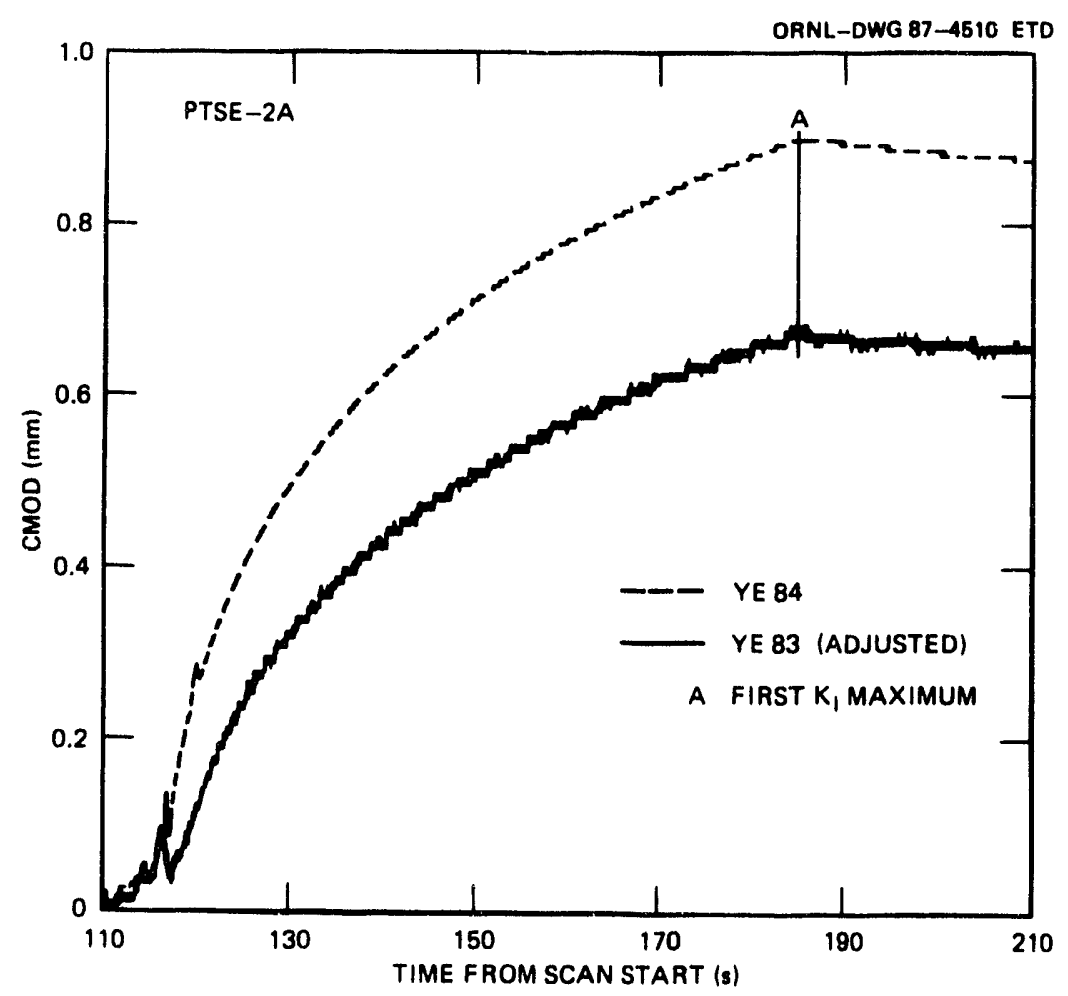

Fig. 2.34. CMOD vs time during early phase of PTSE-2A measured at center of flaw $(z=0)$ and $100 \mathrm{~mm}$ below center $(z=-100 \mathrm{~mm})$ by gages YE84 and YE83, respectively (see Fig. 2.24). The YE84 output was naturally biased by incorporation of dummy gage in bridge circuit. The YE83 output has been adjusted by subtracting output of dummy gage (YE56). 


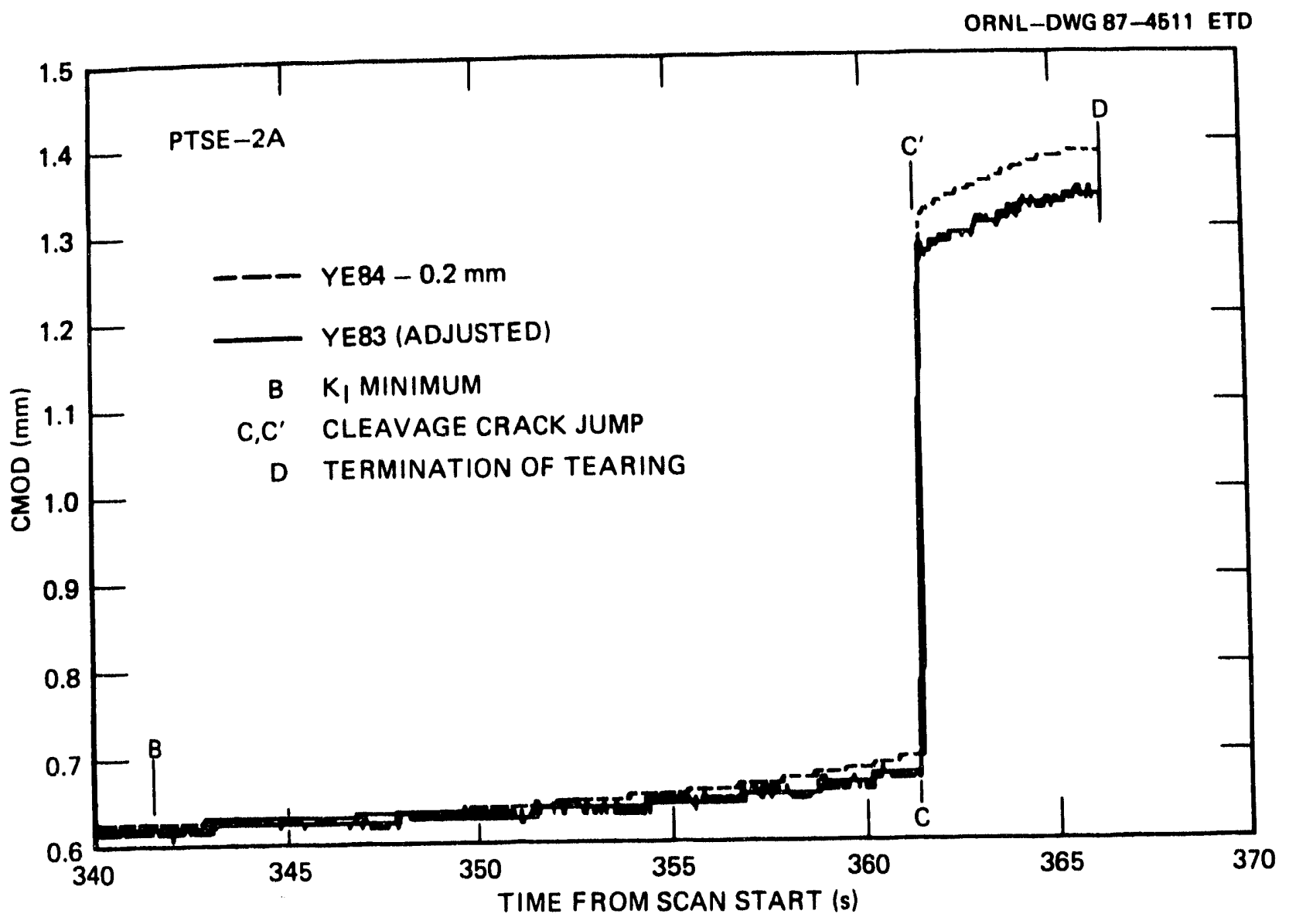

Fig. 2.35. CMOD vs time for final phase of PTSE-2A. The effects of precleavage tearing, cleavage crack propagation, and postcleavage tearing are shown. The output of gage YE84 has been shifted by $0.2 \mathrm{~mm}$ to facilitate comparision of changes in CMOD at two proximal points while crack was growing.

necessary heat to raise the specimen to the required test temperature of $290^{\circ} \mathrm{C}$. A stationary water spray system within the cylinder provides the mechanism for thermally shocking the rotating inner surface (used in SC-II).

Most of the instrumentation was mounted directly on the rotating specimen, and signals were extracted via a 100 -way slip ring unit mounted directly above the gearbox. The arrangement of the crack-measuring instrument for the SC-I test is shown in Fig. 2.42. Three sets of alternating current potential drop (ACPD) probes were situated $25 \mathrm{~mm}$ above the bottom of the machined slot in different axial locations. The connections for the constant ac driving current $(0.4 \mathrm{~A}$ at $1 \mathrm{kHz})$ were on opposite sides of the slot so that the current between them passed around the crack tip. Additional instrumentation comprised five back-face strain gages, three pairs of clip gages to monitor changes in the slot gap closely adjacent to the ACPD stations, and an array of thermocouples to measure the cylinder temperature variations.

A fatigue crack was generated at the bottom of the machined slot by subjecting the cylinder to cyclic diametral loading in the plane of the slot using a 500-ton hydraulic actuator. The specimen was maintained at $-90^{\circ} \mathrm{C}$, and some 80,000 cycles were applied using a maximum load of 420 tons to generate a reasonably uniform fatigue crack to a mean depth of $10 \mathrm{~mm}$ over the central meter of the slot.

Pretest material properties were determined from a prolongation of the test cylinder used in the first experiment. Values of $0.2 \%$ proof stress $\left(\sigma_{0.2}\right)$, ultimate tensile strength $\left(\sigma_{u}\right)$, percentage elongation, and reduction of area from six tensile tests are presented in Table 2.15. (The proof stress $\sigma_{0.2}$ corresponds to a permanent strain of 0.002 as determined from a stress-strain curve.) Additional 


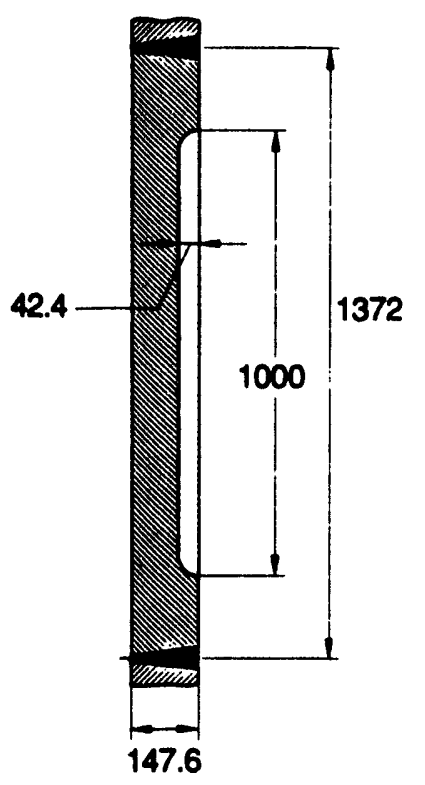

All measures in $\mathrm{mm}$

Fig. 2.36. Crack geometry and loading data for PTSE-2B, transient B.

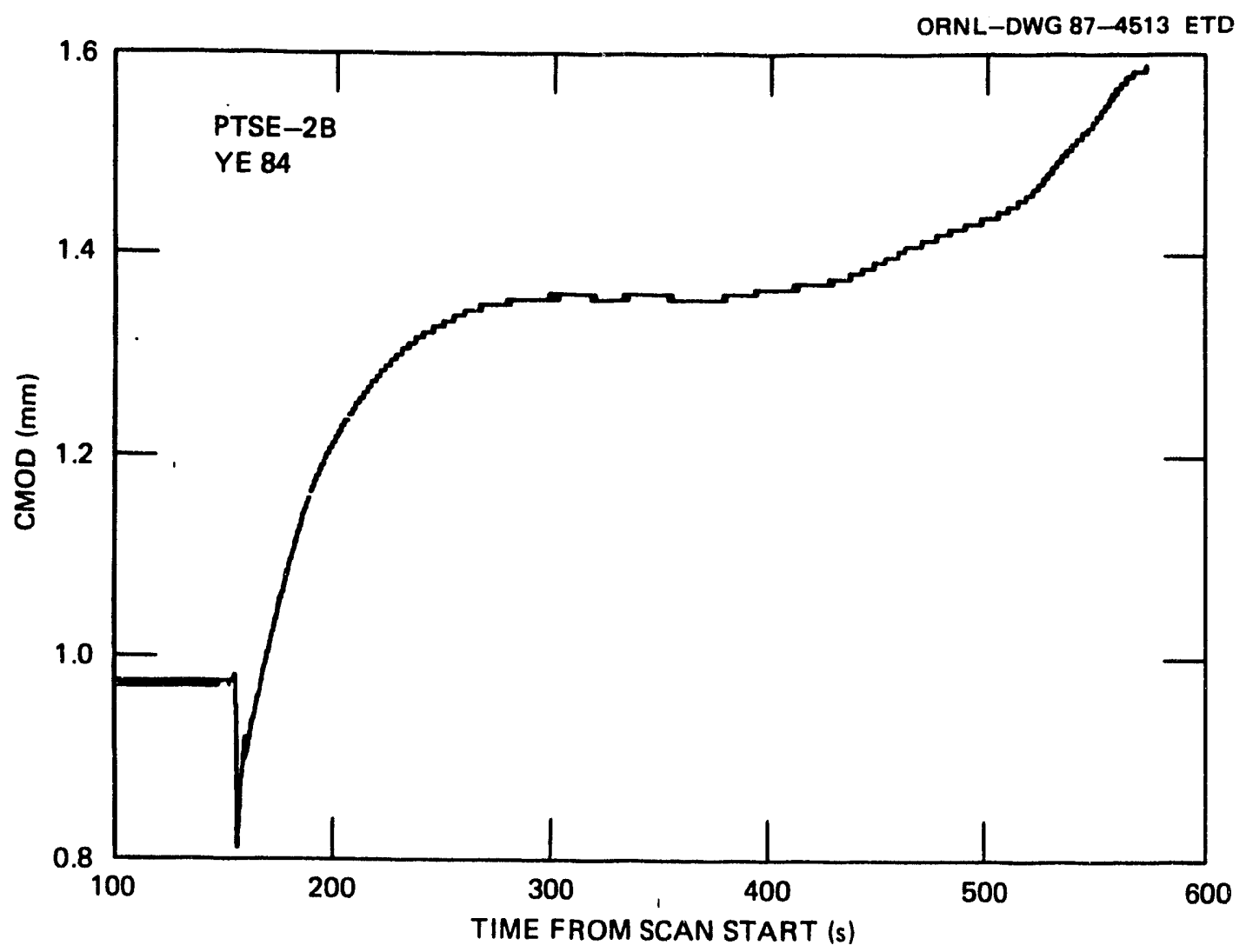

Fig. 2.37. Typical CMOD behavior during PTSE-2B transient. CMOD gage YE84 is at center of the flaw. 
INSIDE

SURFACE
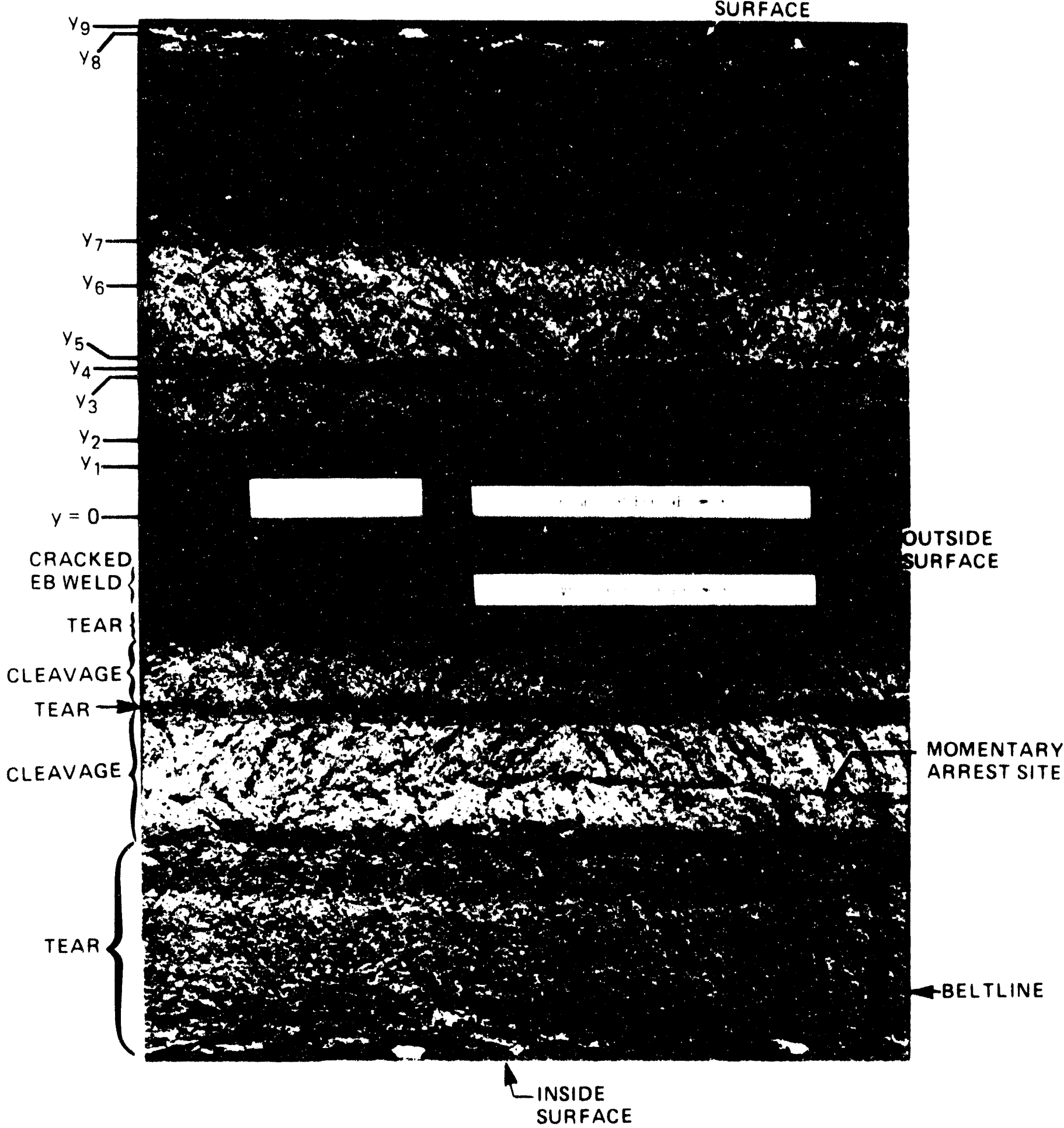

Fig. 2.38. Photograph of central segment of PTSE-2 fracture surfaces. Depths (y) are described in Table 2.13. 
Table 2.13 Fracture features shown in Fig. 2.38

\begin{tabular}{|c|c|c|}
\hline Area & $\begin{array}{l}\text { Deeper } \\
\text { boundary }\end{array}$ & Description \\
\hline A & $y_{1}$ & $\begin{array}{l}\text { Cracked electron-beam weld, smooth } \\
\text { dark gray }\end{array}$ \\
\hline B & $y_{2}$ & $\begin{array}{l}\text { Precleavage ductile tear in PTSE-2A, } \\
\text { dark gray, rough }\end{array}$ \\
\hline C & $y_{3}$ & $\begin{array}{l}\text { Cleavage fracture in PTSE-2A, light } \\
\text { gray }\end{array}$ \\
\hline $\mathrm{D}$ & $y_{4}$ & $\begin{array}{l}\text { Postcleavage ductile tear in PTSE-2A, } \\
\text { brown or gray band }\end{array}$ \\
\hline $\mathrm{E}$ & $y_{5}$ & $\begin{array}{l}\text { Precleavage ductile tear in PTSE-2B, } \\
\text { medium gray }\end{array}$ \\
\hline $\mathrm{F}$ & $y_{6}$ & $\begin{array}{l}\text { Cleavage fracture in PTSE-2B, } \\
\text { light gray }\end{array}$ \\
\hline G & $y_{6}$ & $\begin{array}{l}\text { Narrow band of ductile tearing, } \\
\text { medium gray }\end{array}$ \\
\hline $\mathrm{H}$ & $y_{7}$ & Same as F \\
\hline I & $\mathrm{y}_{8}$ & Postcleavage ductile tear in PTSE-2B \\
\hline J & $\mathrm{y}_{9}$ & $\begin{array}{l}\text { Light-gray shear lip in ruptured } \\
\text { portion; unbroken ligament, very } \\
\text { light gray, near both ends of flaw }\end{array}$ \\
\hline
\end{tabular}

Table 2.14 Dimensions of fracture features of the PTSE-2 flaw

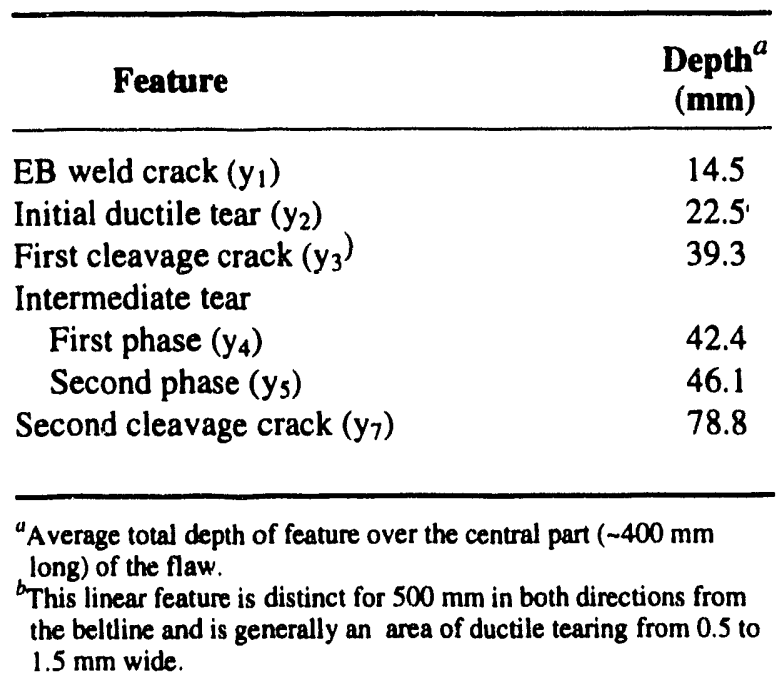




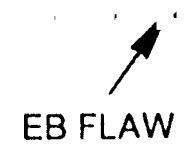

Fig. 2.39. Photograph of fracture surface $A$ from PTSE-2. The fracture surface was reassembled after being cut

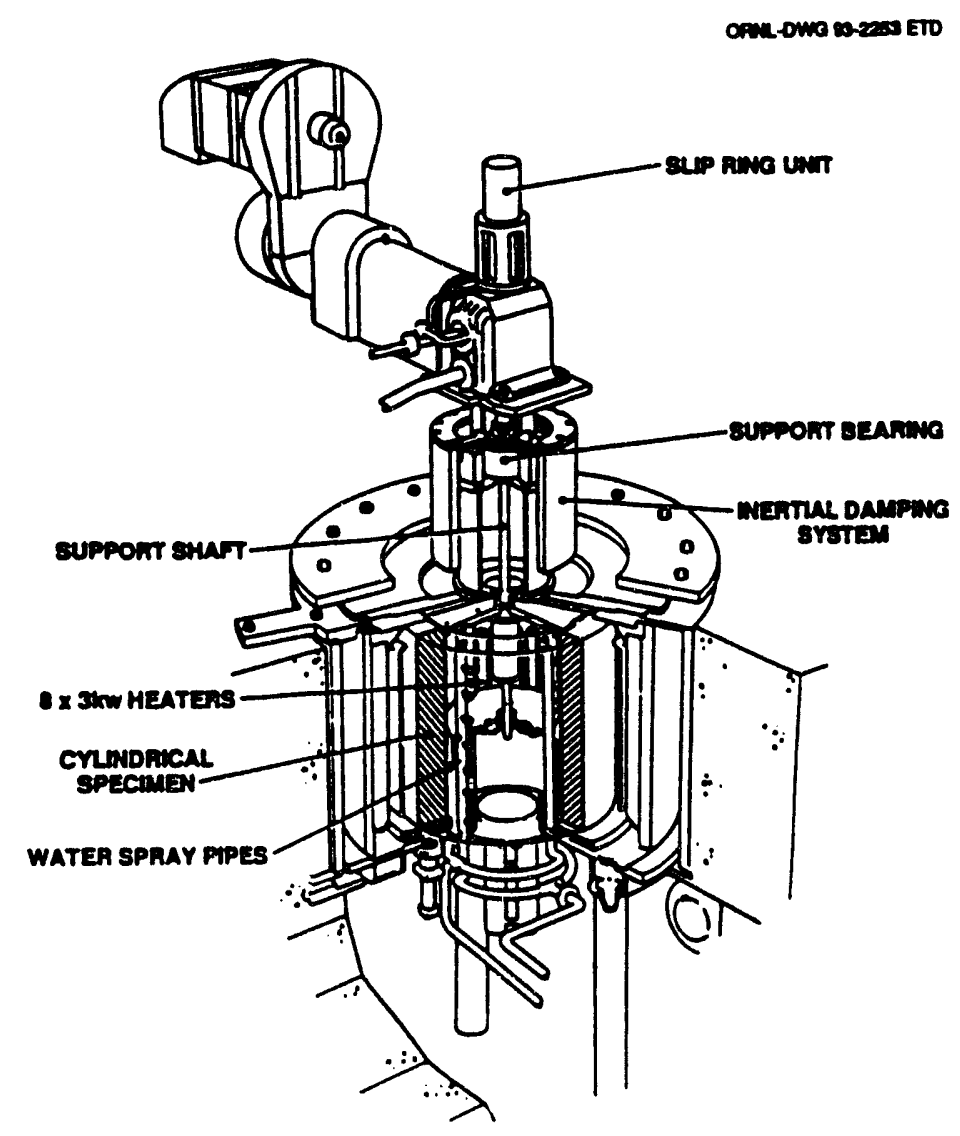

Fig. 2.40. Experimental facility at AEA-Risley that applies centrifugal loads through high-speed spinning and thermal-shock loads through spraying of inner surface of thick-wall test cylinders. 


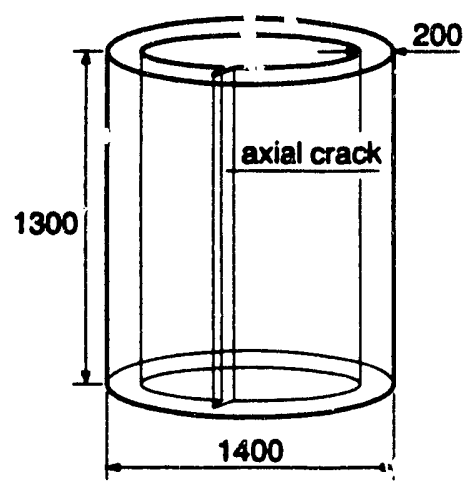

All moasures in $\mathrm{mm}$
OPNL-DWG 93-2254 ETD

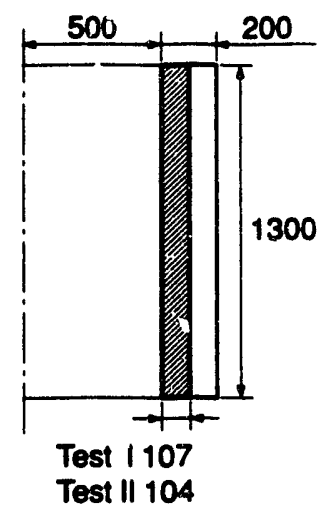

Fig. 2.41. Test cylinder and crack geometry for SC experiments (AEA-Risley, UK).

engineering stress-strain data are given in Fig. 2.43. The loading and material characterization data for SC-I are summarized in Fig. 2.44.

A total of six 35-mm compact specimens were tested at $290^{\circ} \mathrm{C}$, and values of crack len th, crack growth, and corresponding values of $\mathrm{J}$ are presented in Table 2.16. Individual unloading conipliance $\mathrm{J}_{\mathrm{R}}$ curves have been characterized using a power curve fit of the form

$$
\mathrm{J}=\mathrm{A}(\Delta \mathrm{a})^{\mathrm{B}}
$$

where values of the regression coefficients $A$ and $B$ are given in Table 2.17. A "composite" $J_{R}$ curve for the material as a whole has also been included.

The plan for the SC-I test was to proceed directly to a target speed at which a useful minimum crack extension would be anticipated without incurring the risk of catastrophic failure and then to proceed beyond that point as circumstances allowed. In the actual expeiment, three speed increments beyond the planned target speed of $2285 \mathrm{rpm}$ were required to reach the intended crack growth $(3$ to $5 \mathrm{~mm}$ ) at an eventual terminal speed of $26 \mathrm{~W}$. $\mathrm{pm}$.

Initiation of crack growth in the experiment was related to a pronounced change in the rate of increase of the ACPD signal at about $2250 \mathrm{rpm}$ [Fig. 2.45(a)]. An unexpected feature of the ACPD behavior was the absence of the characteristic minimum in the region of crack initiation as normally observed in tests with CT specimens. The reason for the divergence from CT behavior is partly explicable in terms of the absence of pronounced end effects, but further work is required to establish whether a more fundamental source of difference can be identified. An axial block containing the slot was subsequently cut from the cylinder and broken open to reveal the actual extent of crack growth. The growth at the ACPD stations varied from 2.4 to $3.1 \mathrm{~mm}$, with a mean of $2.75 \mathrm{~mm}$. The crack profile is shown in Fig. 2.45(b). Data from three ACPD stations were used to develop the angular velocity vs crack growth curves shown in Fig. 2.46(a). Figure 2.46(b) depicts measured CODs (Fig. 2.42) vs angular velocity at gages 2 and 6. These results were made available after evaluation of the analysis results of the Project FALSIRE workshop and, consequently, are not included in comparative assessments described in Chap. 4 of this report.

\subsubsection{SC-II}

The second SC experiment was an investigation of stable crack extension in contained yield for a thick-section low-alloy steel structure subjected to a severe thermal shock. The crack-tip temperature was always consistent with upper-shelf fracture behavior. The configuration of the cylindrical specimen used in the second test is shown in Fig. 2.41. The instrumentation layout for the experiment is shown in Fig. 2.47.

Tensile specimens taken from different positions across the cylinder wall thickness were tested at temperatures spanning the complete (anticipated) temperature range of thermal trarisient (i.e., 20 to $350^{\circ} \mathrm{C}$ ). Individual exponential expressions of the form

$$
\sigma=\alpha \operatorname{EXP}(\beta T),
$$

where $\sigma$ is either $\sigma_{u}$ or $\sigma_{0.2}$, and $T$ is the temperature, were fitted to the data via linear regression analysis. Circumferential and axial test results were included in the analyses, resulting in the expressions in Table 2.18. Values 


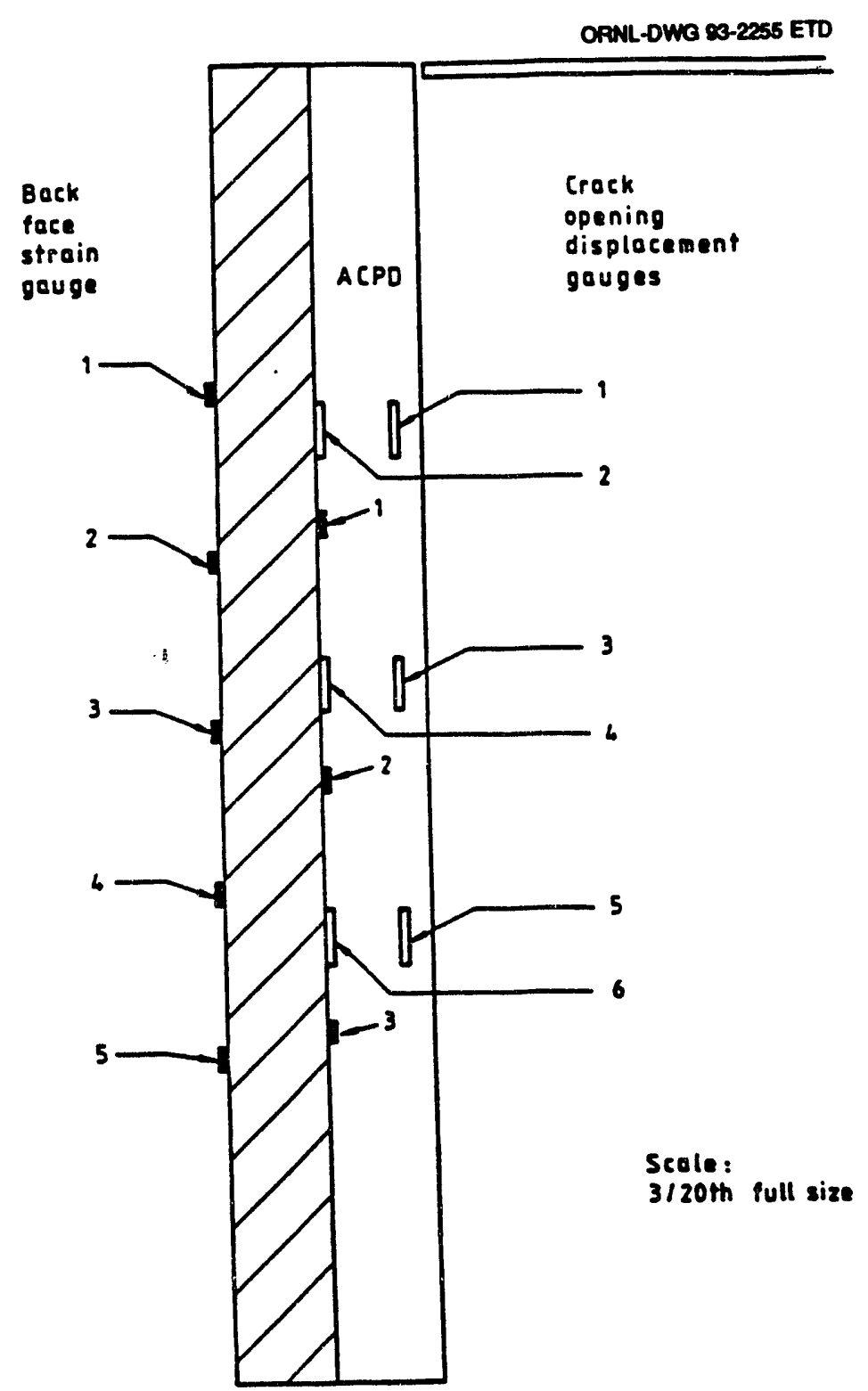

Fig. 2.42. Instrumentation layout for first spinning cylinder experiment (SC-I). 
Table 2.15 Tensile data at $290^{\circ} \mathrm{C}$ for SC-I test material

\begin{tabular}{|c|c|c|c|c|c|c|}
\hline $\begin{array}{c}\text { Specimen } \\
\text { Identification }\end{array}$ & $\begin{array}{l}\text { Prolon- } \\
\text { gation }\end{array}$ & Orientation $^{a}$ & $\begin{array}{c}\text { 0.2\% Proof } \\
\text { stress } \\
\sigma_{0.2} \\
(\mathrm{MPa})\end{array}$ & $\begin{array}{c}\text { Ultimate } \\
\text { stress } \\
\sigma_{u} \\
(\mathbf{M P a})\end{array}$ & $\begin{array}{c}\text { Elongation } \\
(\%)\end{array}$ & $\begin{array}{c}\text { Reduction } \\
\text { of area } \\
\text { (\%) }\end{array}$ \\
\hline HU1 & Top & C & 540 & 728 & 18 & 51 \\
\hline HU3 & Top & $\mathbf{R}$ & 548 & 709 & 17 & 49 \\
\hline HU5 & Top & $\mathrm{L}$ & 540 & 703 & 18 & 66 \\
\hline HW1 & Bottom & $\mathrm{C}$ & 529 & 702 & 16 & 52 \\
\hline HW3 & bottom & $\mathbf{R}$ & 533 & 703 & 13 & 35 \\
\hline HW5 & Bottom & L & 543 & 711 & 17 & 59 \\
\hline
\end{tabular}

${ }^{a} \mathrm{C}=$ circumferential

$\mathbf{R}=$ radial

$\mathrm{L}=$ longitudinal

${ }^{b}$ None of the specimens failed within the middle third of the gage length.

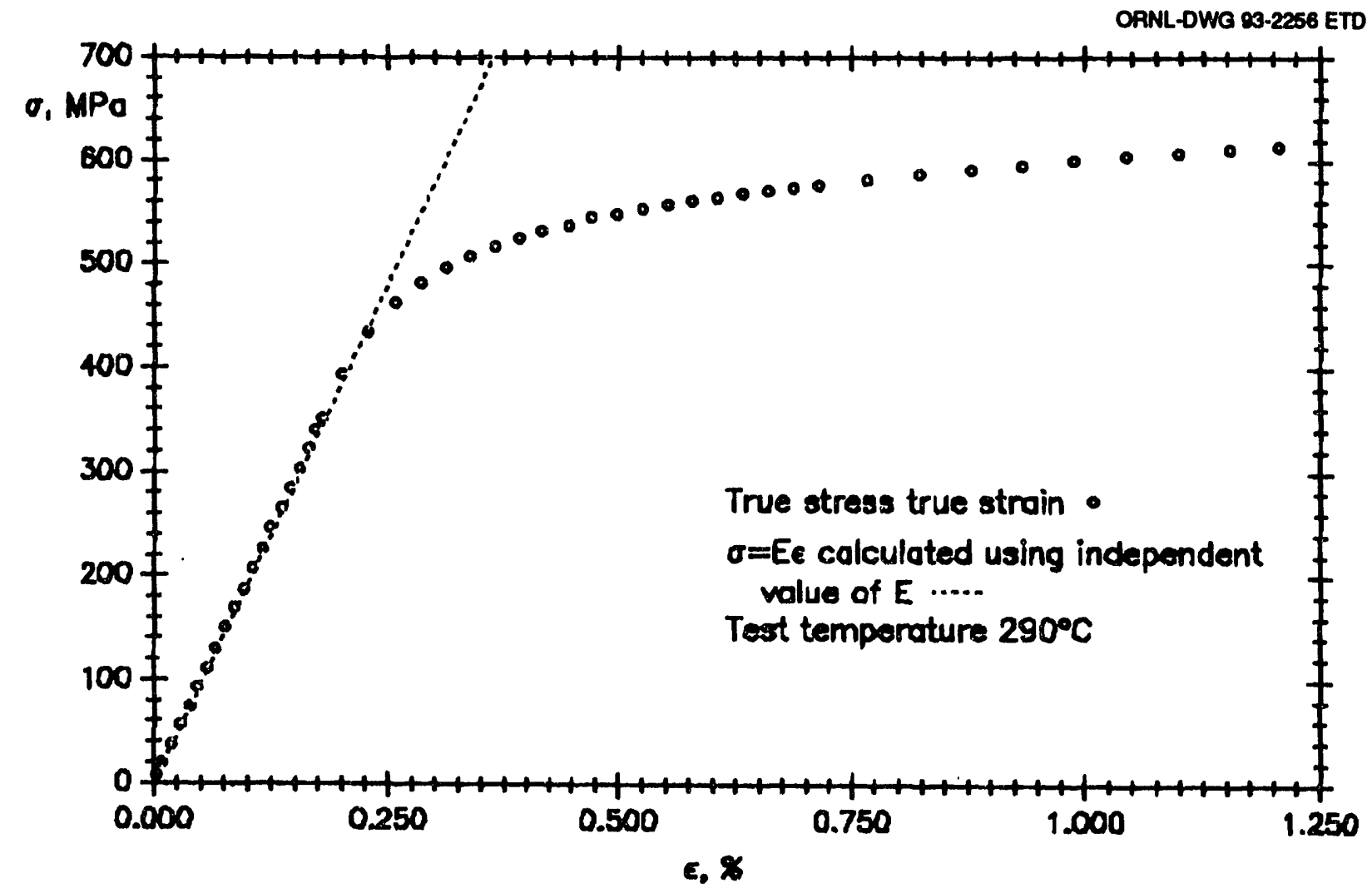

Fig, 2,43, Representative stress-strain data for first spinning cylinder test specimen (SC-I). 
Description

Table 2.16 SC-I J vs $\Delta \mathrm{a}$ values from unloading compliance tests with physical measurements of final crack extensions $\left(\mathrm{T}=290^{\circ} \mathrm{C}\right)$

\begin{tabular}{|c|c|c|c|}
\hline $\begin{array}{l}\text { Crack growth } \\
\text { (mm) }\end{array}$ & $\underset{\left(\mathbf{M J} / \mathbf{m}^{2}\right)}{\mathbf{J}}$ & $\begin{array}{c}\text { Crack growth } \\
(\mathbf{m m})\end{array}$ & $\underset{\left(\mathbf{M J} / \mathbf{m}^{2}\right)}{\mathbf{J}}$ \\
\hline \multicolumn{2}{|c|}{ Specimen HV1 (top ring) } & \multicolumn{2}{|c|}{ Specimen HV2 (top ring) } \\
\hline 0.0 & 0.012 & 0.0 & 0.012 \\
\hline 0.02 & 0.047 & 0.03 & 0.047 \\
\hline 0.08 & 0.071 & 0.09 & 0.071 \\
\hline 0.11 & 0.099 & 0.16 & 0.099 \\
\hline 0.27 & 0.13 & 0.23 & 0.131 \\
\hline 0.43 & 0.161 & 0.4 & 0.164 \\
\hline 0.66 & 0.192 & 0.72 & 0.196 \\
\hline 0.99 & 0.227 & 1.24 & 0.227 \\
\hline 1.9 & 0.256 & 2.0 & 0.266 \\
\hline 2.64 & 0.292 & $2.82(2.44)$ & 0.306 \\
\hline $3.62(3.34)$ & 0.327 & & \\
\hline \multicolumn{2}{|c|}{ Specimen HV3 (top ring) } & \multicolumn{2}{|c|}{ Specimen HV4 (top ring) } \\
\hline 0.0 & 0.012 & $0.55^{a}$ & 0.183 \\
\hline 0.07 & 0.047 & & \\
\hline 0.1 & 0.068 & & \\
\hline 0.15 & 0.087 & & \\
\hline 0.23 & 0.108 & & \\
\hline 0.3 & 0.134 & & \\
\hline 0.46 & 0.161 & & \\
\hline 0.7 & 0.19 & & \\
\hline 1.22 & 0.216 & & \\
\hline 1.73 & 0.243 & & \\
\hline $2.78(2.79)$ & 0.277 & & \\
\hline \multicolumn{2}{|c|}{ Specimen HX1 (bottom ring) } & \multicolumn{2}{|c|}{ Specimen HX2 (bottom ring) } \\
\hline 0.0 & 0.012 & 0.0 & 0.012 \\
\hline 0.05 & 0.047 & -0.01 & 0.046 \\
\hline 0.08 & 0.072 & 0.04 & 0.069 \\
\hline 0.15 & 0.099 & 0.09 & 0.098 \\
\hline 0.24 & 0.131 & 0.23 & 0.129 \\
\hline 0.47 & 0.162 & 0.44 & 0.161 \\
\hline 0.77 & 0.196 & 0.68 & 0.195 \\
\hline 1.12 & 0.227 & 1.43 & 0.225 \\
\hline 2.22 & 0.258 & 2.21 & 0.264 \\
\hline 2.88 & 0.288 & 2.89 & 0.302 \\
\hline $4.52(4.32)$ & 0.323 & $3.92(3.74)$ & 0.316 \\
\hline
\end{tabular}

${ }^{a}$ Measured final crack growth.

Note: ()$=$ measured value. 


\section{Thermal and mechanical loading}

ORNL-DWG 93-2257 ETD

Material characterization of A 508 class 3 type steel (nonstandard quenched and tempered)

Teat l:

rotational speed:

$\omega=0-2600 \mathrm{pm}$ at $\mathrm{T}=290^{\circ} \mathrm{C}$

\begin{tabular}{|l|c|}
\hline $\begin{array}{l}\text { yield/ultimate } \\
\text { stress at } 290^{\circ} \mathrm{C}\end{array}$ & $540 / 710 \mathrm{MPa}$ \\
\hline $\begin{array}{l}\text { charpy energy } \\
\text { for upper shelf }\end{array}$ & $90 \mathrm{~J}$ \\
\hline NDT & $?$ \\
\hline
\end{tabular}

Fig. 2.44. Loading and material data for first spinning cylinder test (SC-1).

Table 2.17 Regression coefficients for power-law curve fit to J vs $\Delta a$ data for SC-I test materials ${ }^{a}\left(\mathrm{~T}=290^{\circ} \mathrm{C}\right)$

\begin{tabular}{lccc}
\hline & \multicolumn{3}{c}{ Coefincients } \\
\cline { 2 - 4 } & Specimen & B & $\mathbf{r}^{2 b}$ \\
\hline HV1 & 0.213 & 0.339 & 0.985 \\
HV2 & 0.215 & 0.326 & 0.996 \\
HV3 & 0.201 & 0.356 & 0.970 \\
HX1 & 0.207 & 0.306 & 0.991 \\
HX2 & 0.209 & 0.314 & 0.990 \\
Composite & 0.208 & 0.329 & 0.976 \\
$\quad$ curve & & & \\
\hline
\end{tabular}

$a_{J}=A(\Delta a)^{B}$, where units of $J$ and $\Delta \mathrm{a}$ are $\mathrm{MJ} / \mathrm{m}^{2}$ and $\mathrm{mm}$.

${ }^{b}$ Square of regression correlation coefficient $(r)$. 

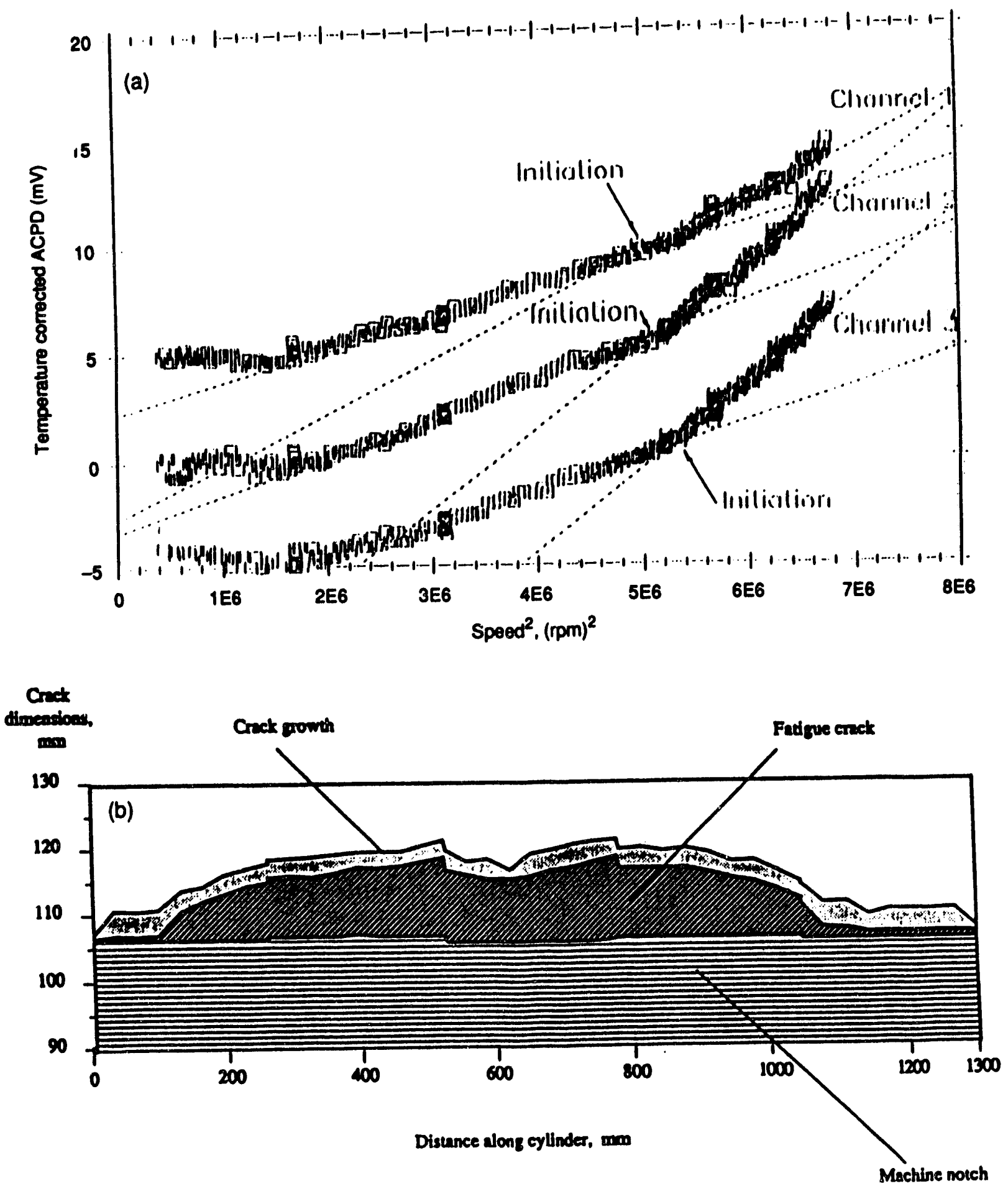

Fig. 2.45. (a) Identincation of initiation from alternating current potential drop (ACPD) data (SC-I); (b) crack profile in first spinning cylinder test. 
ORNL-DWG 93-2259 ETD
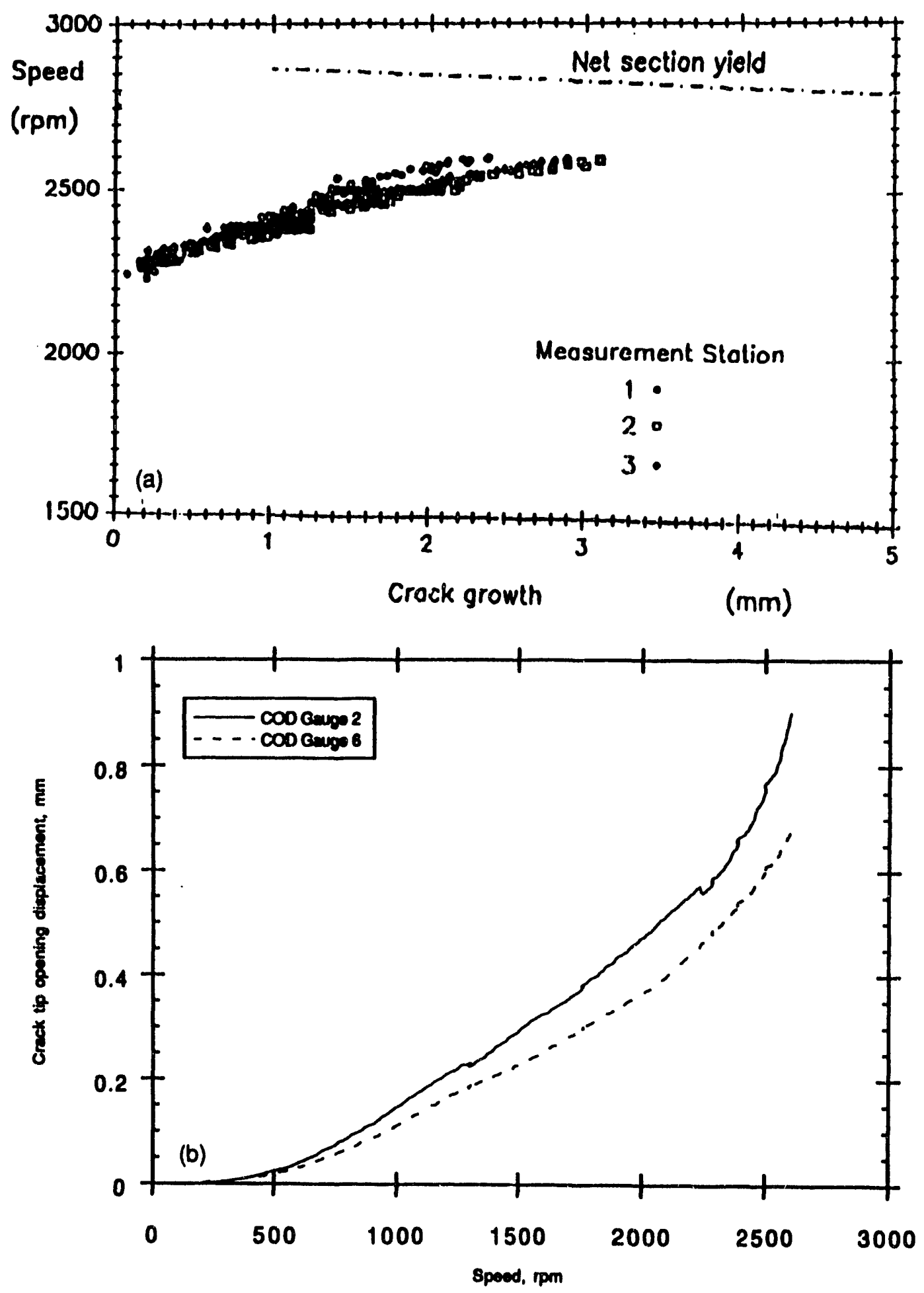

Fig. 2.46. (a) Angular velocity vs crack extension data from three ACPD measurement stations utilized to develop crack time curve for the analysis of SC-I; $(b)$ corrected crack vs speed for the first spinning cylinder test (SC-I). 


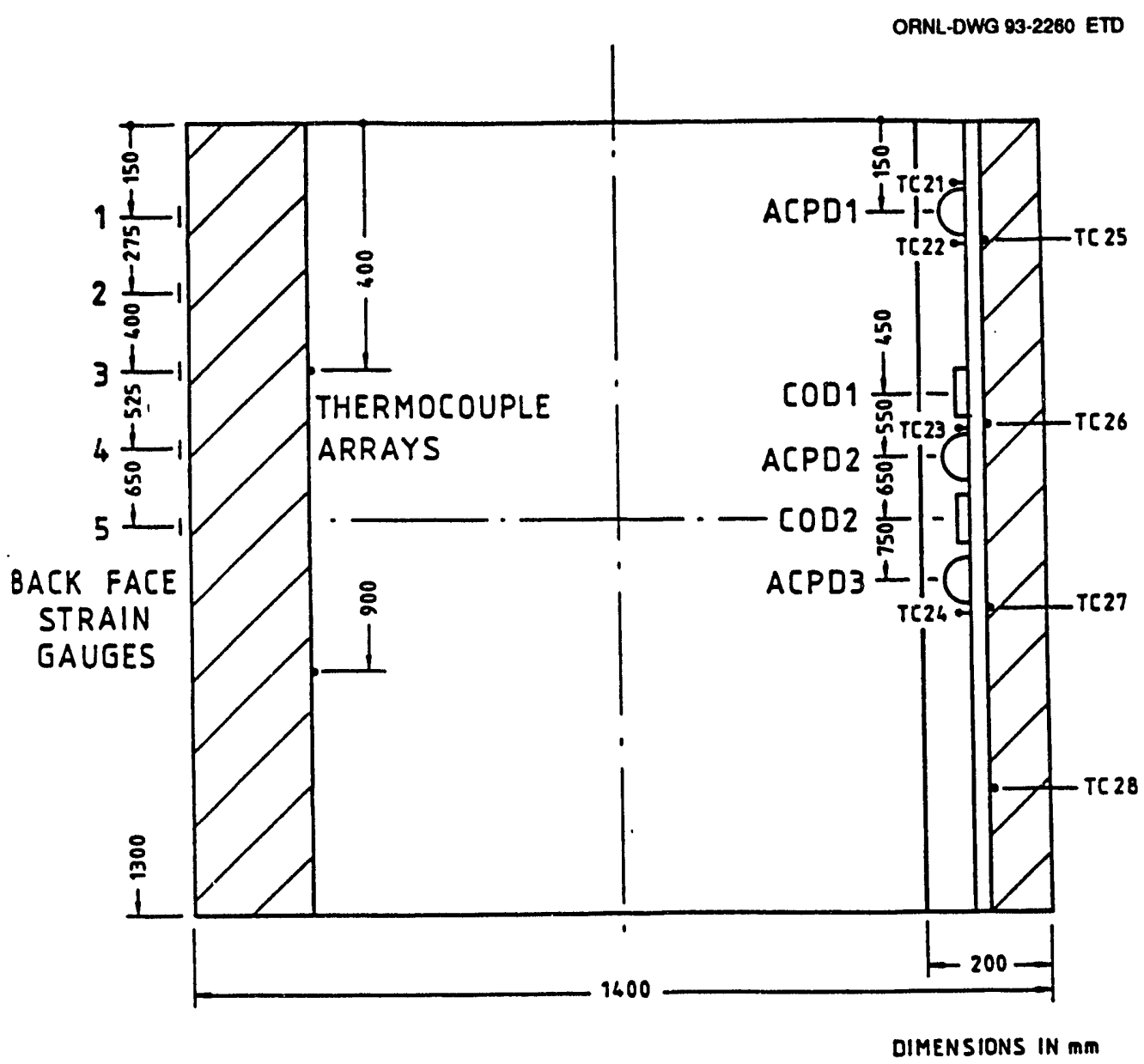

Fig. 2.47. Instrumentation layout for second spinning cylinder experiment (SC-II).

Table 2.18 Tensile data for SC-II test material ${ }^{a}$

\begin{tabular}{ll}
\hline Young's modulus E, GPa & $212.35-0.0063 \mathrm{~T}$ \\
$0.2 \%$ proof stress $\sigma_{0.2}, \mathrm{MPa}$ & $560.3 \exp \left(-3.356 \times 10^{-4} \mathrm{~T}\right)$ \\
Ultimate stress $\sigma_{\mathrm{u}}, \mathrm{MPa}$ & $708.5 \exp \left(-1.889 \times 10^{-4} \mathrm{~T}\right)$ \\
Poisson's ratio, $v$ & 0.275 \\
\hline
\end{tabular}

${ }^{a}$ Temperature $\mathrm{T}$ has units of ${ }^{\circ} \mathrm{C}$. 
of engineering stress strain and true stress-strain data from these tensile tests are presented in Table 2.19. Physical properties characterizing the behavior of the test material under thermal-shock conditions are given in Table 2.20.

A total of eight 35-mm-thick compact fracture toughness specimens were tested at temperatures of 150 and $290^{\circ} \mathrm{C}$. Values of crack length $\left(\mathrm{a}_{0}\right)$ and ductile crack extension $(\Delta a)$ were estimated both from unloading compliance measurements made during the test and from fracture surface measurements. As Table 2.21 shows, good agreement (to within 16\%) was obtained between unloading compliance predictions and measured values of final crack extension ( $\Delta \mathrm{af})$.

For each test, the data have been characterized using a power curve to fit the form given by $\mathrm{Eq}$. (2.1), where values of the regression coefficients $A$ and $B$ are given in Table 2.22. Composite $J_{R}$ curves for the different test rings are included (Fig. 2.48).

In the SC-II test, the cylinder was stabilized at a mean temperature of $312^{\circ} \mathrm{C}$. The cylinder was then rotated to $530 \mathrm{rpm}$ to provide for uniform cooling of the inner surface. The inner surface of the rotating cylinder was spray cooled with water at a temperature of $15^{\circ} \mathrm{C}$ and a flow rate of $269 \mathrm{gal} / \mathrm{min}$ to produce an effective heat transfer coefficient in excess of $20 \mathrm{~kW} / \mathrm{m}^{2} \cdot{ }^{\circ} \mathrm{C}$ and thermal gradient in the wall (Fig. 2.49).

Temperature data from the test are depicted graphically in Fig. 2.50(a), in which the measured temperatures are compared with the results of a one-dimensional finite-difference analysis using a heat transfer coefficient of $22,750 \mathrm{~W} / \mathrm{m} 2 \cdot{ }^{\circ} \mathrm{C}$. Ductile crack extension was variable along the length of the crack, achieving a maximum of $\sim 0.75 \mathrm{~mm}$ at the midplane [Fig. 2.50(b)]. Time histories of COD and hoop strain at gage locations identified in Fig. 2.47 are shown in Fig. 2.50(c) and (d), respectively. The results in Fig. 2.50(c) and $(d)$ were made available after evaluation of the analysis results of the Project FALSIRE workshop and, consequently, are not included in comparative assessments described in Chap. 4 of this report. The loading conditions and the fracture results for tests I and II are summarized in Table 2.23.

\subsection{Step B PTSE}

The Japanese series of tests ${ }^{8,9}$ were planned to investigate crack behavior under PTS conditions, using a flat plate specimen with a thickness equal to that of an actual vessel. The tests are designed to produce an evolution of stress through the thickness of the specimen that is comparable to that in the wall of an RPV. The PTS loading conditions are applied to the plate specimen shown in Fig. 2.51 as follows: internal pressure is simulated by mechanical tensile load; thermal bending stress induced by thermal moment is simulated by mechanical bending load; and local thermal stress is simulated by thermal shock of the cracked surface. The Step B test was designed to study crack extension at upper-shelf temperatures and applications of elastic-plastic fracture mechanics methodologies to these conditions.

The dimensions and details of the test specimen are shown in Fig. 2.51. An initial semielliptical surface crack was prepared by electric discharge machining and cyclic bending load. The crack depth and length are 23.1 and $118.4 \mathrm{~mm}$, respectively (see Fig. 2.51). The test material for the Step B test was a modified A 533 grade B class 1 steel having the mechanical and physical properties given in Tables 2.24 and 2.25 (Young's modulus, coefficient of thermal expansion, and stress-strain data) and in Figs. 2.52-2.54 (temperature dependence of Charpy energy and fracture toughness as well as crack resistance curves of $20 \%$ side-grooved CT-25 specimens). For the material, the upper-shelf Charpy energy and the RTNDT are $\sim 100 \mathrm{~J}$ and $139^{\circ} \mathrm{C}$, respectively. Fracture toughness data for the test material were generated from 25.4-mm-thick compact specimens for the range of temperatures encountered in the test. Results of these tests in terms of $\mathrm{K}_{\mathrm{Ic}}$ and $\mathrm{J}_{\mathrm{R}}$ curves are presented in Figs. 2.53 and 2.54, respectively.

In the Step B test, the insulated specimen was initially heated to a uniform temperature of $322^{\circ} \mathrm{C}$, and a tensile load of $17.87 \mathrm{MN}$ was applied and kept constant during the test. Then the specimen surface with the initial crack was thermally shocked using a coolant at $91^{\circ} \mathrm{C}$, and a four-point bending load was applied to the specimen simultaneously. The time history of the mechanical loads and the evolution of the temperature distribution through the plate thickness, as well as some test material characteristics, are given in Fig. 2.55 (see also measured temperatures in Fig. 2.56 and heat convection coefficient in Fig. 2.57). Measured time histories of surface strains near the initial crack and of the deflection at the center of the beam are shown in Figs. 2.58 and 2.59 , respectively. Ductile stable crack extension measured at the deepest point of the initial crack is $\sim 0.9 \mathrm{~mm}$, which is indicated in Fig. 2.60. 
Description

Table 2.19 Engineering and true stress-strain values for test rings of SC-II forging

\begin{tabular}{|c|c|c|c|c|c|c|c|}
\hline \multicolumn{4}{|c|}{ JU21/JU3 $\left(20^{\circ} \mathrm{C}\right)$} & \multicolumn{4}{|c|}{ JU22/JU4 $\left(20^{\circ} \mathrm{C}\right)$} \\
\hline Strain & $\begin{array}{l}\text { Stress } \\
\text { (MPa) }\end{array}$ & $\begin{array}{l}\text { True } \\
\text { strain }\end{array}$ & $\begin{array}{l}\text { True } \\
\text { stress } \\
\text { (MPa) }\end{array}$ & Strain & $\begin{array}{l}\text { Stress } \\
\text { (MPa) }\end{array}$ & $\begin{array}{c}\text { True } \\
\text { strain }\end{array}$ & $\begin{array}{c}\text { True } \\
\text { stress } \\
\text { (MPa) }\end{array}$ \\
\hline JU21 & & & & JU22 & & & \\
\hline 0.0002 & 67.0 & 0.0003 & 67.1 & 0.0002 & 50.9 & 0.0002 & 50.9 \\
\hline 0.0006 & 129.4 & 0.0006 & 129.5 & 0.0005 & 115.3 & 0.0005 & 115.3 \\
\hline 0.0009 & 191.1 & 0.0009 & 191.3 & 0.0008 & 177.3 & 0.0008 & 177.4 \\
\hline 0.0012 & 252.0 & 0.0012 & 252.3 & 0.0011 & 237.8 & 0.0011 & 238.1 \\
\hline 0.0015 & 311.7 & 0.0015 & 312.2 & 0.0014 & 297.9 & 0.0014 & 298.3 \\
\hline 0.0018 & 371.8 & 0.0018 & 372.5 & 0.0017 & 358.8 & 0.0017 & 359.4 \\
\hline JU3 & & & & JU4 & & & \\
\hline 0.0024 & 503.1 & 0.0024 & 504.3 & 0.0021 & 455.3 & 0.0021 & 456.3 \\
\hline 0.0033 & 546.0 & 0.0033 & 547.8 & 0.0030 & 548.3 & 0.0030 & 550.0 \\
\hline 0.0041 & 551.4 & 0.0041 & 553.6 & 0.0038 & 552.9 & 0.0038 & 555.0 \\
\hline 0.0049 & 557.1 & 0.0049 & 559.8 & 0.0045 & 558.7 & 0.0046 & 561.4 \\
\hline 0.0070 & 586.8 & 0.0070 & 590.9 & 0.0082 & 598.8 & 0.0082 & 603.7 \\
\hline 0.0138 & 615.7 & 0.0137 & 624.1 & 0.0150 & 620.5 & 0.0149 & 629.8 \\
\hline 0.0202 & 637.4 & 0.0200 & 650.3 & 0.0217 & 642.2 & 0.0215 & 656.2 \\
\hline 0.0261 & 657.8 & 0.0258 & 675.0 & 0.0281 & 662.0 & 0.0277 & 681.4 \\
\hline 0.0325 & 675.3 & 0.0320 & 697.3 & 0.0349 & 674.9 & 0.0343 & 698.5 \\
\hline 0.0389 & 687.2 & 0.0382 & 714.0 & 0.0417 & 686.9 & 0.0408 & 715.5 \\
\hline 0.0453 & 698.0 & 0.0443 & 729.6 & 0.0480 & 699.2 & 0.0469 & 732.8 \\
\hline 0.9521 & 707.7 & 0.0508 & 744.6 & 0.0552 & 706.9 & 0.0537 & 746.0 \\
\hline 0.0584 & 715.6 & 0.0658 & 757.5 & 0.0624 & 713.3 & 0.0605 & 757.8 \\
\hline 0.0652 & 720.1 & 0.0632 & 767.0 & 0.0696 & 715.6 & 0.0672 & 765.4 \\
\hline 0.0728 & 724.4 & 0.0703 & 777.1 & 0.0771 & 719.7 & 0.0743 & 775.3 \\
\hline 0.0800 & 724.6 & 0.0769 & 782.5 & 0.0847 & 719.1 & 0.0813 & 780.0 \\
\hline 0.0871 & 728.3 & 0.0835 & 791.7 & 0.0926 & 719.7 & 0.0886 & 786.4 \\
\hline 0.0947 & 728.7 & 0.0905 & 797.7 & & & & \\
\hline
\end{tabular}


Table 2.19 (continued)

\begin{tabular}{|c|c|c|c|c|c|c|c|}
\hline \multicolumn{4}{|c|}{$\mathrm{JU5}\left(150^{\circ} \mathrm{C}\right)^{a}$} & \multicolumn{4}{|c|}{ JU'24/JU6 $\left(150^{\circ} \mathrm{C}\right)$} \\
\hline Strain & $\begin{array}{l}\text { Stress } \\
\text { (MPa) }\end{array}$ & $\begin{array}{c}\text { True } \\
\text { strain }\end{array}$ & $\begin{array}{l}\text { True } \\
\text { stress } \\
\text { (MPa) }\end{array}$ & Strain & $\begin{array}{l}\text { Stress } \\
\text { (MPa) }\end{array}$ & $\begin{array}{c}\text { True } \\
\text { strain }\end{array}$ & $\begin{array}{r}\text { True } \\
\text { stress } \\
(\mathbf{M P a})\end{array}$ \\
\hline JU5 & & & & JU24 & & & \\
\hline 0.0024 & 456.4 & 0.0024 & 457.5 & 0.0003 & 59.4 & 0.0003 & 59.4 \\
\hline 0.0033 & 503.1 & 0.0033 & 504.8 & 0.0006 & 115.6 & 0.0006 & 115.7 \\
\hline 0.0041 & 514.6 & 0.0041 & 516.7 & 0.0009 & 173.5 & 0.0009 & 173.6 \\
\hline 0.0049 & 523.1 & 0.0049 & 525.6 & 0.0012 & 231.7 & 0.0012 & 232.0 \\
\hline 0.0082 & 552.9 & 0.0081 & 557.4 & 0.0015 & 286.0 & 0.0015 & 286.5 \\
\hline 0.0142 & 581.7 & 0.0141 & 590.0 & 0.0018 & 338.9 & 0.0018 & 339.5 \\
\hline 0.0205 & 602.3 & 0.0203 & 614.7 & & & & \\
\hline 0.0265 & 618.8 & 0.0262 & 635.2 & JU6 & & & \\
\hline 0.0325 & 639.3 & 0.0320 & 660.1 & & & & \\
\hline 0.0389 & 650.5 & 0.0382 & 675.8 & 0.0024 & 466.5 & 0.0024 & 467.6 \\
\hline 0.0453 & 662.7 & 0.0443 & 692.7 & 0.0033 & 504.2 & 0.0033 & 505.0 \\
\hline 0.0516 & 670.7 & 0.0504 & 705.3 & 0.0041 & 617.7 & 0.0041 & 519.8 \\
\hline 0.0584 & 675.0 & 0.0568 & 714.5 & 0.0049 & 526.6 & 0.0049 & 529.2 \\
\hline 0.0652 & 680.4 & 0.0632 & 724.8 & 0.0101 & 558.0 & 0.0101 & 563.6 \\
\hline 0.0720 & 684.6 & 0.0695 & 733.9 & 0.0167 & 576.7 & 0.0166 & 586.3 \\
\hline 0.0791 & 688.7 & 0.0762 & 743.3 & 0.0229 & 603.1 & 0.0227 & 617.0 \\
\hline 0.0859 & 689.7 & 0.0824 & 748.9 & 0.0291 & 619.9 & 0.0287 & 638.9 \\
\hline 0.0935 & 694.0 & 0.0894 & 758.9 & 0.0357 & 632.4 & 0.0351 & 655.0 \\
\hline \multirow[t]{10}{*}{0.1007} & 688.7 & 0.0959 & 758.1 & 0.0423 & 646.2 & 0.0415 & 673.6 \\
\hline & & & & 0.0485 & 656.1 & 0.0474 & 687.9 \\
\hline & & & & 0.0551 & 665.8 & 0.0537 & 702.5 \\
\hline & & & & 0.0621 & 674.2 & 0.0603 & 716.1 \\
\hline & & & & 0.0692 & 678.4 & 0.0669 & 725.3 \\
\hline & & & & 0.0766 & 681.1 & 0.0738 & 733.3 \\
\hline & & & & 0.0836 & 685.3 & 0.0803 & 742.6 \\
\hline & & & & 0.0910 & 687.5 & 0.0871 & 750.1 \\
\hline & & & & 0.0989 & 686.7 & 0.0943 & 754.6 \\
\hline & & & & 0.1051 & 690.3 & 0.0999 & 762.8 \\
\hline
\end{tabular}


Table 2.19 (continued)

\begin{tabular}{|c|c|c|c|c|c|c|c|}
\hline \multicolumn{4}{|c|}{ JU25/JU7 $\left(350^{\circ} \mathrm{C}\right)$} & \multicolumn{4}{|c|}{$\mathrm{JU} 14\left(350^{\circ} \mathrm{C}\right)^{a}$} \\
\hline Strain & $\begin{array}{l}\text { Stress } \\
\text { (MPa) }\end{array}$ & $\begin{array}{l}\text { True } \\
\text { strain }\end{array}$ & $\begin{array}{c}\text { True } \\
\text { stress } \\
(\mathbf{M P a}) \\
\end{array}$ & Strain & $\begin{array}{l}\text { Stress } \\
(\mathbf{M P a})\end{array}$ & $\begin{array}{l}\text { True } \\
\text { strain }\end{array}$ & $\begin{array}{c}\text { True } \\
\text { stress } \\
(\mathbf{M P a})\end{array}$ \\
\hline \multirow[t]{2}{*}{ JU25 } & & & & JU14 & & & \\
\hline & & & & 0.0029 & 470.2 & $\quad 0.0029$ & 471.6 \\
\hline 0.0000 & 8.1 & 0.0000 & 8.1 & 0.0037 & 498.9 & 0.0037 & 500.8 \\
\hline 0.0003 & 59.2 & 0.0003 & 59.3 & 0.0045 & 617.7 & 0.0045 & 520.0 \\
\hline 0.0006 & 113.1 & 0.0006 & 113.1 & 0.0102 & 548.7 & 0.0101 & 554.3 \\
\hline 0.0009 & 169.2 & 0.0009 & 169.4 & 0.0157 & 574.7 & 0.0156 & 583.8 \\
\hline 0.0012 & 226.5 & 0.0012 & 236.8 & 0.0221 & 597.7 & 0.0219 & 611.2 \\
\hline 0.0015 & 283.1 & 0.0015 & 283.5 & 0.0289 & 614.3 & 0.0285 & 632.1 \\
\hline \multirow[t]{2}{*}{0.0018} & 338.1 & 0.0018 & 338.7 & 0.0353 & 634.2 & 0.0347 & 656.5 \\
\hline & & & & 0.0416 & 643.0 & 0.0408 & 669.5 \\
\hline \multirow[t]{2}{*}{ JU7 } & & & & 0.0484 & 651.2 & 0.0473 & 682.7 \\
\hline & & & & 0.0556 & 655.3 & 0.0541 & 691.7 \\
\hline 0.0024 & 431.5 & 0.0024 & 432.6 & 0.0627 & 660.7 & 0.0609 & 702.2 \\
\hline 0.0033 & 480.0 & 0.0033 & 482.4 & 0.0703 & 663.5 & 0.0679 & 710.1 \\
\hline 0.0041 & 507.3 & 0.0041 & 509.4 & 0.0779 & 667.5 & 0.0750 & 719.5 \\
\hline 0.0049 & 524.2 & 0.0049 & 526.8 & 0.0858 & 669.5 & 0.0823 & 726.9 \\
\hline 0.0130 & 559.9 & 0.0129 & 567.1 & $0.0947^{\prime}$ & 668.9 & 0.0900 & 731.9 \\
\hline 0.0193 & 588.4 & 0.0191 & 599.8 & & & & \\
\hline 0.0265 & 608.8 & 0.0262 & 624.9 & & & & \\
\hline 0.0357 & 627.2 & 0.0350 & 649.5 & & & & \\
\hline 0.0444 & 642.1 & 0.0435 & 670.6 & & & & \\
\hline 0.0532 & 653.9 & 0.0518 & 688.7 & & & & \\
\hline 0.0731 & 660.3 & 0.0705 & 708.5 & & & & \\
\hline 0.0930 & 665.8 & 0.0889 & 727.8 & & & & \\
\hline
\end{tabular}

${ }^{a}$ Small specimen data omitted-alignment errors.

Notes: 1 . Data up to strains of $0.2 \%$ taken from small specimens; data from $0.02 \%$ to $10.0 \%$ taken from large specimens.

2. Elastic data from JU24/JU6 exhibit a discontinuity. This will lead to some errors in E values determined from this data.

Table 2.20 Physical properties for SC-II test material

Heat convection coefficient $h, W / m^{2} K$

Thermal conductivity $\lambda, \mathrm{W} / \mathrm{m} \cdot \mathrm{K}$

Specific heat capacity $c_{p}, \mathrm{~kJ} / \mathrm{kg} \mathrm{K}$

Density $\rho, \mathrm{kg} / \mathrm{m}^{3}$

Coefficient of thermal expansion $\alpha, 1 / \mathrm{K}$
22,750 (during time relevant to crack growth)

$38.6-2.2 \times 10^{-2} \mathrm{~T}+1.67 \times 10^{-5} \mathrm{~T}^{2}$

$4.1 \times 10^{-4} \mathrm{~T}+0.432$

7757 at $290^{\circ} \mathrm{C}$

Instantaneous: $(11.46+0.0105 \mathrm{~T}) \times 10^{-6}$

Mean $(20-\mathrm{T}):\left(11.59+5.161 \times 10^{-3} \mathrm{~T}\right) \times 10^{-6}$

where $\mathrm{T}$ is temperature in ${ }^{\circ} \mathrm{C}$ 
Table 2.21 J vs $\Delta a$ values from unloading compliance tests with physical measurements of final crack extension (SC-II)

\begin{tabular}{|c|c|c|c|}
\hline$\underset{(\mathbf{m m})}{\Delta \mathrm{a}}$ & $\underset{\left(\mathbf{M J} / \mathbf{m}^{2}\right)}{\mathbf{J}}$ & $\underset{(\mathbf{m m})}{\Delta \mathbf{a}}$ & $\begin{array}{c}\mathbf{J} \\
\left(\mathbf{M} / \mathbf{m}^{2}\right)\end{array}$ \\
\hline \multicolumn{2}{|c|}{ Specimen JT1 (bottom $290^{\circ} \mathrm{C}$ ) } & \multicolumn{2}{|c|}{ Specimen JT3 (bottom $290^{\circ} \mathrm{C}$ ) } \\
\hline 0.03 & 0.100 & 0.00 & 0.040 \\
\hline 0.09 & 0.135 & 0.08 & 0.069 \\
\hline 0.19 & 0.173 & 0.11 & 0.102 \\
\hline 0.34 & -0.216 & 0.24 & 0.138 \\
\hline $0.55\left(\mathrm{P}_{\max }\right)$ & 0.264 & 0.33 & 0.176 \\
\hline 0.86 & 0.314 & $0.57\left(P_{\max }\right)$ & 0.216 \\
\hline 1.49 & 0.364 & 0.74 & 0.257 \\
\hline 2.10 & 0.409 & 1.21 & 0.291 \\
\hline $2.98^{a}$ & 0.437 & $1.35^{a}$ & 0.330 \\
\hline 3.67 & 0.473 & $2.54^{a}$ & 0.373 \\
\hline $5.44^{a}$ & 0.493 & 3.73 & 0.406 \\
\hline \multirow[t]{3}{*}{$6.34^{a}(6.23)$} & 0.518 & 4.27 & 0.436 \\
\hline & & 4.66 & 0.467 \\
\hline & & $5.92(5.72)$ & 0.487 \\
\hline \multicolumn{2}{|c|}{ Specimen JT4 (middle $150^{\circ} \mathrm{C}$ ) } & \multicolumn{2}{|c|}{ Specimen JT5 (middle $150^{\circ} \mathrm{C}$ ) } \\
\hline 0.01 & 0.019 & 0.03 & 0.019 \\
\hline 0.01 & 0.032 & 0.03 & 0.032 \\
\hline 0.03 & 0.049 & 0.03 & 0.049 \\
\hline 0.09 & 0.068 & 0.09 & 0.068 \\
\hline 0.16 & 0.085 & 0.13 & 0.099 \\
\hline 0.16 & 0.113 & 0.21 & 0.134 \\
\hline 0.23 & 0.136 & 0.32 & 0.173 \\
\hline 0.28 & 0.162 & 0.46 & 0.212 \\
\hline 0.37 & 0.193 & 0.69 & 0.249 \\
\hline 0.54 & 0.228 & 0.96 & 0.287 \\
\hline 0.73 & 0.258 & 1.24 & 0.321 \\
\hline 0.95 & 0.294 & 1.52 & 0.362 \\
\hline 1.19 & 0.329 & 1.95 & 0.394 \\
\hline 1.58 & 0.363 & 2.23 & 0.428 \\
\hline 1.98 & 0.395 & 2.66 & 0.459 \\
\hline 2.57 & 0.425 & 3.21 & 0.491 \\
\hline 3.16 & 0.450 & $3.81(3.27)$ & 0.511 \\
\hline 3.61 & 0.473 & & \\
\hline $4.09(4.04)$ & 0.501 & & \\
\hline
\end{tabular}


Description

Table 2.21 (continued)

\begin{tabular}{|c|c|c|c|}
\hline $\begin{array}{c}\Delta \mathrm{a} \\
(\mathrm{mm})\end{array}$ & $\left(\mathbf{M J} / \mathrm{m}^{2}\right)$ & $\begin{array}{c}\Delta \mathrm{a} \\
(\mathbf{m m})\end{array}$ & $\left(\mathbf{M J} / \mathbf{m}^{2}\right)$ \\
\hline \multicolumn{2}{|c|}{ Specimen JT7 (middle $290^{\circ} \mathrm{C}$ ) } & \multicolumn{2}{|c|}{ Specimen JT8 (middle $290^{\circ} \mathrm{C}$ ) } \\
\hline 0.08 & 0.090 & 0.01 & 0.050 \\
\hline 0.12 & 0.126 & 0.02 & 0.071 \\
\hline 0.26 & 0.168 & 0.03 & 0.092 \\
\hline 0.40 & 0.213 & 0.11 & 0.114 \\
\hline 0.65 & 0.265 & 0.24 & 0.151 \\
\hline $0.90\left(\mathrm{P}_{\max }\right)$ & 0.317 & 0.35 & 0.191 \\
\hline $1.73^{a}$ & 0.371 & 0.49 & 0.233 \\
\hline $2.71^{a}$ & 0.414 & $0.79\left(\mathrm{P}_{\max }\right)$ & 0.275 \\
\hline 3.22 & 0.459 & 1.11 & 0.313 \\
\hline 3.85 & 0.493 & 1.60 & 0.351 \\
\hline 4.52 & 0.524 & 2.22 & 0.391 \\
\hline \multirow[t]{4}{*}{$b(5.79)$} & 0.568 & 2.76 & 0.429 \\
\hline & & 3.48 & 0.463 \\
\hline & & 4.33 & 0.496 \\
\hline & & $5.64^{a}(5.58)$ & 0.521 \\
\hline \multicolumn{2}{|c|}{ Specimen JT10 (top $290^{\circ} \mathrm{C}$ ) } & \multicolumn{2}{|c|}{ Specimen JT11 (top $290^{\circ} \mathrm{C}$ ) } \\
\hline 0.04 & 0.023 & 0.02 & 0.041 \\
\hline 0.04 & 0.040 & 0.03 & 0.060 \\
\hline 0.02 & 0.058 & 0.06 & 0.082 \\
\hline 0.05 & 0.080 & 0.11 & 0.105 \\
\hline 0.06 & 0.105 & 0.29 & 0.131 \\
\hline 0.10 & 0.130 & 0.37 & 0.161 \\
\hline 0.22 & 0.157 & 0.56 & 0.195 \\
\hline 0.33 & 0.188 & 0.84 & 0.231 \\
\hline $0.58\left(P_{\max }\right)$ & 0.225 & 1.07 & 0.270 \\
\hline $0.85^{a}$ & 0.264 & $1.31\left(\mathrm{P}_{\max }\right)$ & 0.313 \\
\hline $1.75^{a}$ & 0.302 & $2.58^{a}$ & 0.350 \\
\hline $2.36^{a}$ & 0.335 & $3.60^{a}$ & 0.374 \\
\hline $3.36^{a}$ & 0.360 & $5.15^{a}$ & 0.403 \\
\hline $4.65^{a}$ & 0.384 & 5.93 & 0.434 \\
\hline $5.51^{a}$ & 0.404 & $6.70^{a}(6.23)$ & 0.461 \\
\hline $6.31^{a}$ & 0.553 & & \\
\hline $6.88^{a}(6.71)$ & 0.534 & & \\
\hline
\end{tabular}

Notes: () 9 pt. average measured values.

${ }^{a}$ Plastic instubility.

bast unloading line not recorded. 
Table 2.22 Regression coeficients in the expression $J=A(\Delta a)^{B}$

(SC-II) $)^{a}$

\begin{tabular}{|c|c|c|c|c|c|c|c|c|}
\hline \multirow{2}{*}{ Specimen } & \multirow{2}{*}{$\begin{array}{c}\text { Temperature } \\
\left({ }^{\circ} \mathrm{C}\right)\end{array}$} & \multirow{2}{*}{ Ring } & \multicolumn{3}{|c|}{ Individual coefîicients } & \multicolumn{3}{|c|}{ Composite coeficients } \\
\hline & & & $\mathbf{A}$ & B & $\mathbf{r}^{2}$ & $\mathbf{A}$ & B & $\mathbf{r}^{2}$ \\
\hline JT1 & 290 & Bottom & 0.317 & 0.320 & 0.991 & & & \\
\hline JT3 & 290 & Bottom & 0.265 & 0.376 & 0.968 & & & \\
\hline JT4 & 150 & Middle & 0.286 & 0.429 & 0.985 & & & \\
\hline JT5 & 150 & Middle & 0.291 & 0.458 & 0.996 & & & \\
\hline JT7 & 290 & Middle & 0.300 & 0.375 & 0.981 & & & \\
\hline JT8 & 290 & Middle & 0.289 & 0.392 & 0.988 & & & \\
\hline JT10 & 290 & Top & 0.259 & 0.323 & 0.984 & & & \\
\hline JT11 & 290 & Top & 0.248 & 0.385 & 0.969 & & & \\
\hline
\end{tabular}

${ }^{a}$ Notes: 1. J has units $\mathrm{MJ} / \mathrm{m}^{2}$, and $\Delta \mathrm{a}$ has units $\mathrm{mm}$.

2. Power curves performed using data within the limits $0.2 \mathrm{~mm} \leq \Delta \mathrm{a} \leq 4.5 \mathrm{~mm}$ only.

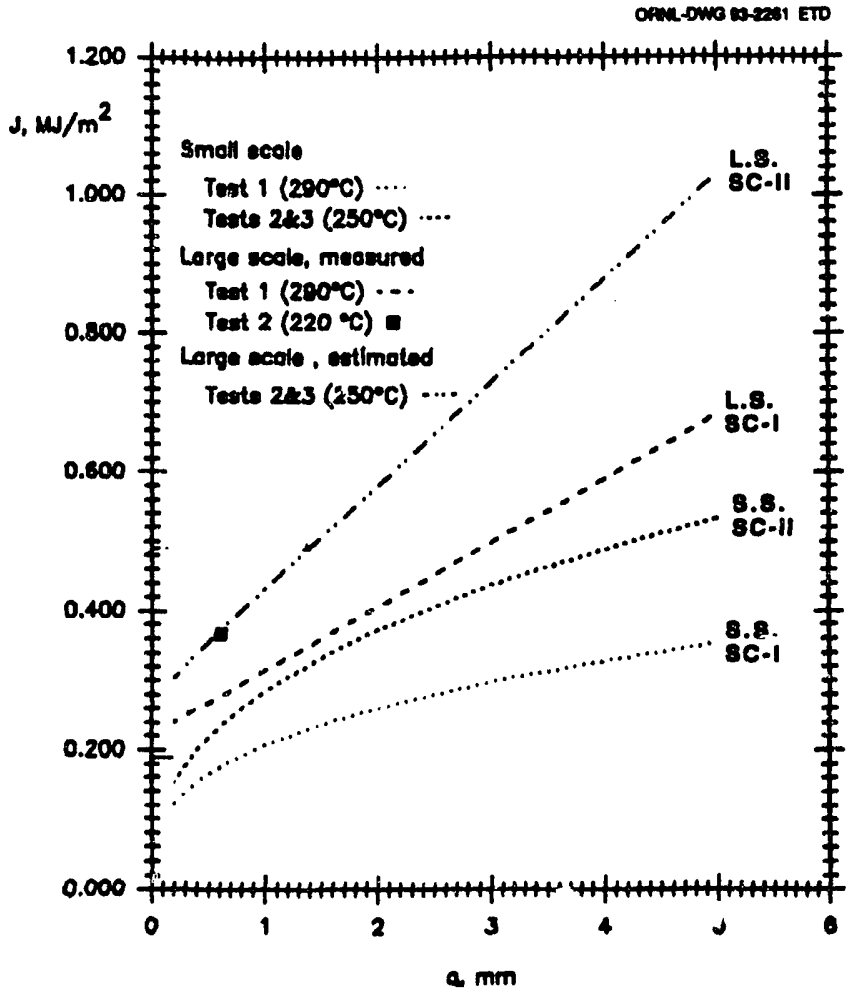

Fig. 2.48. Small- and large-specimen fracture toughness curves for the $\mathrm{SC}$ experiments.
OANL-DWG 93-2262 ETO

Teet In: rotational speed: $\omega=530 \mathrm{rpm}$ at $\mathrm{T}=312^{\circ} \mathrm{C}$

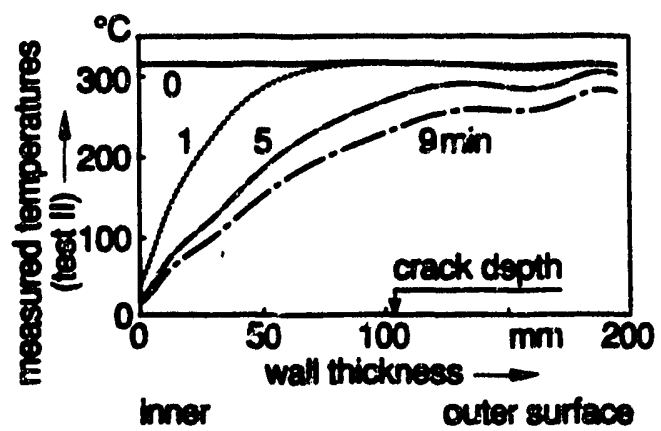

Fig. 2.49. Loading data for the SC-II experiment. 
Description

ORNL-DWG 93-2263(PARTA) ETD
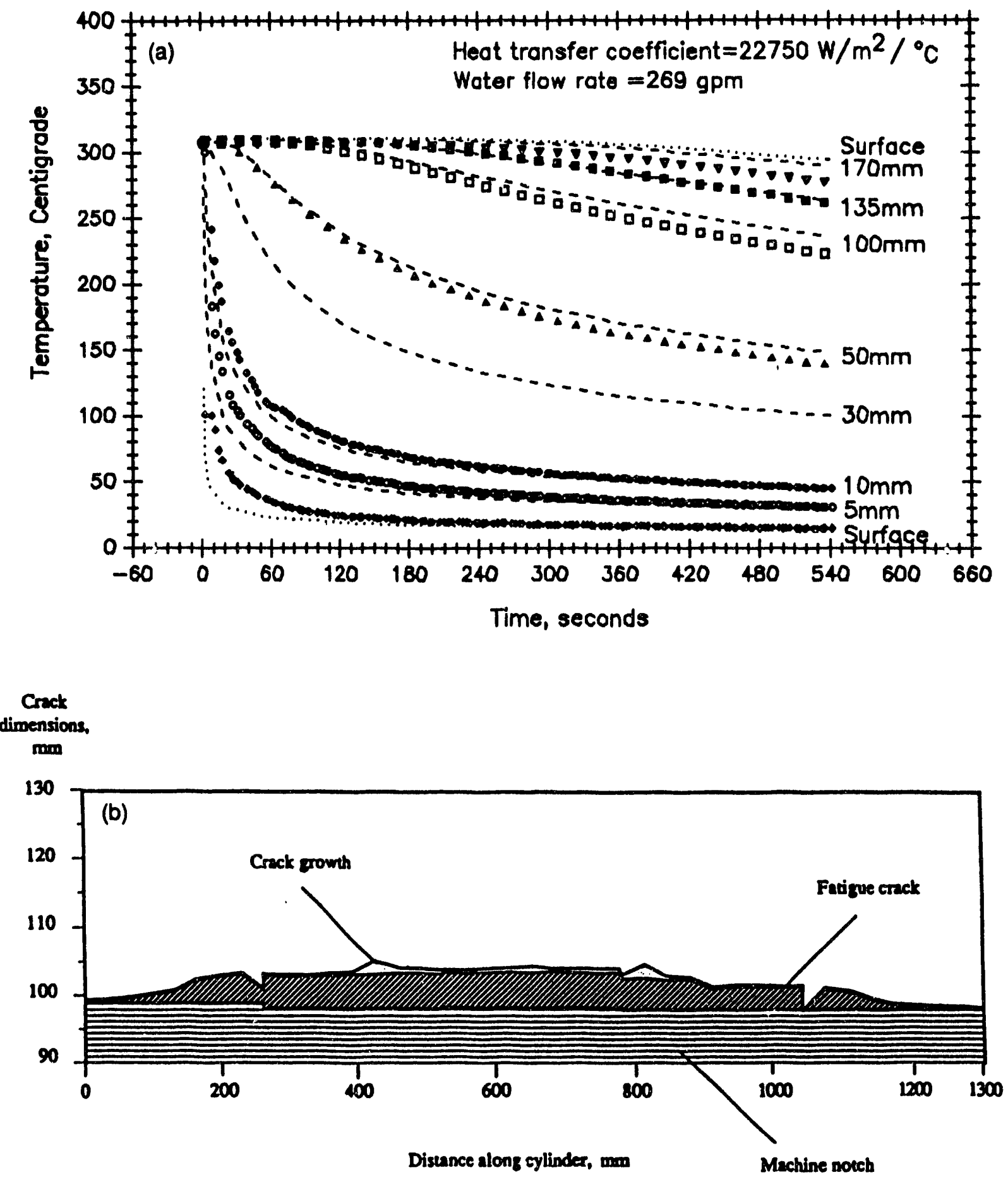

Fig. 2.50. (a) Comparison of measured and computed temperature histories for the second spinning cylinder test (upper thermocouple array, SC-II); (b) crack profile in the second spinning cylinder test (SC-II); (c) COD vs time for SC-II; and (d) hoop strains vs time for SC-II. 
ORNL-DWG 93-2263(PARTB) ETD
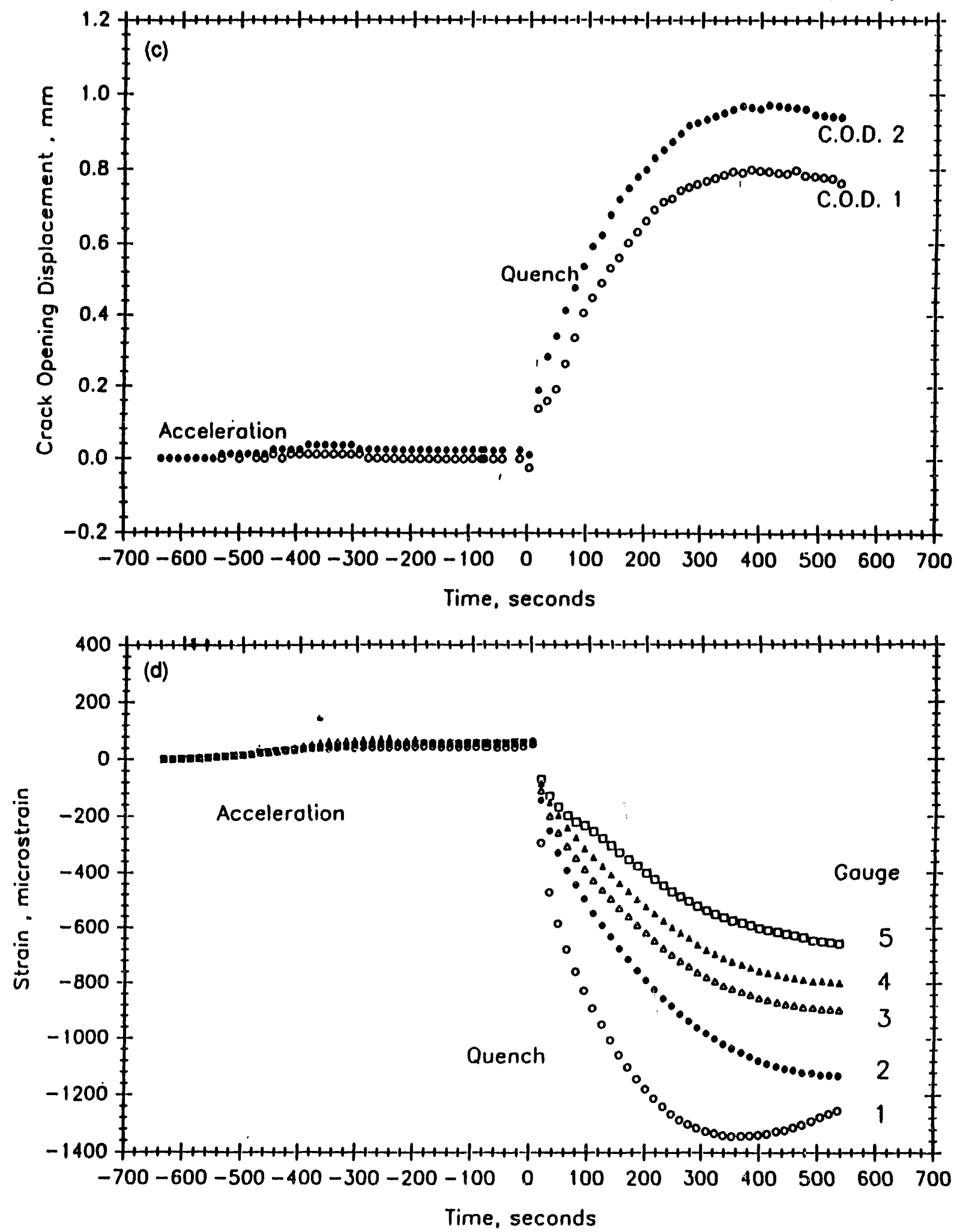

Fig. 2.50 (continued) 
Description

Table 2.23 Summary of ductile tearing in SC-I and -II under mechanical and/or thermal shock loading conditions

\begin{tabular}{|c|c|c|c|c|c|}
\hline \multirow{2}{*}{$\begin{array}{l}\text { Test } \\
\text { No. }\end{array}$} & $\begin{array}{c}\text { Initial } \\
\text { naw }\end{array}$ & $\begin{array}{c}\text { Mechanical } \\
\text { loading }\end{array}$ & $\begin{array}{l}\text { Thermal } \\
\text { loading }\end{array}$ & \multirow{2}{*}{$\begin{array}{c}\text { Coolant } \\
\text { temperature } \\
\left({ }^{\circ} \mathbf{C}\right)\end{array}$} & \multirow{2}{*}{$\begin{array}{c}\text { Maximum } \\
\text { crack } \\
\text { growth } \\
\text { (mm) }\end{array}$} \\
\hline & $(\mathbf{a} / \mathbf{t})$ & $\begin{array}{c}\text { Maxdmum } \\
\text { velocity } \\
(\mathbf{r p m})\end{array}$ & $\begin{array}{c}\text { Initial } \\
\text { temperature } \\
\left({ }^{\circ} \mathrm{C}\right) \\
\end{array}$ & & \\
\hline SC-I & 0.58 & 2600 & 290 & $\begin{array}{l}\text { No thermal } \\
\text { shock }\end{array}$ & $\sim 3$ \\
\hline SC-II & 0.52 & 530 & 312 & 15 & $\sim 0.75$ \\
\hline
\end{tabular}

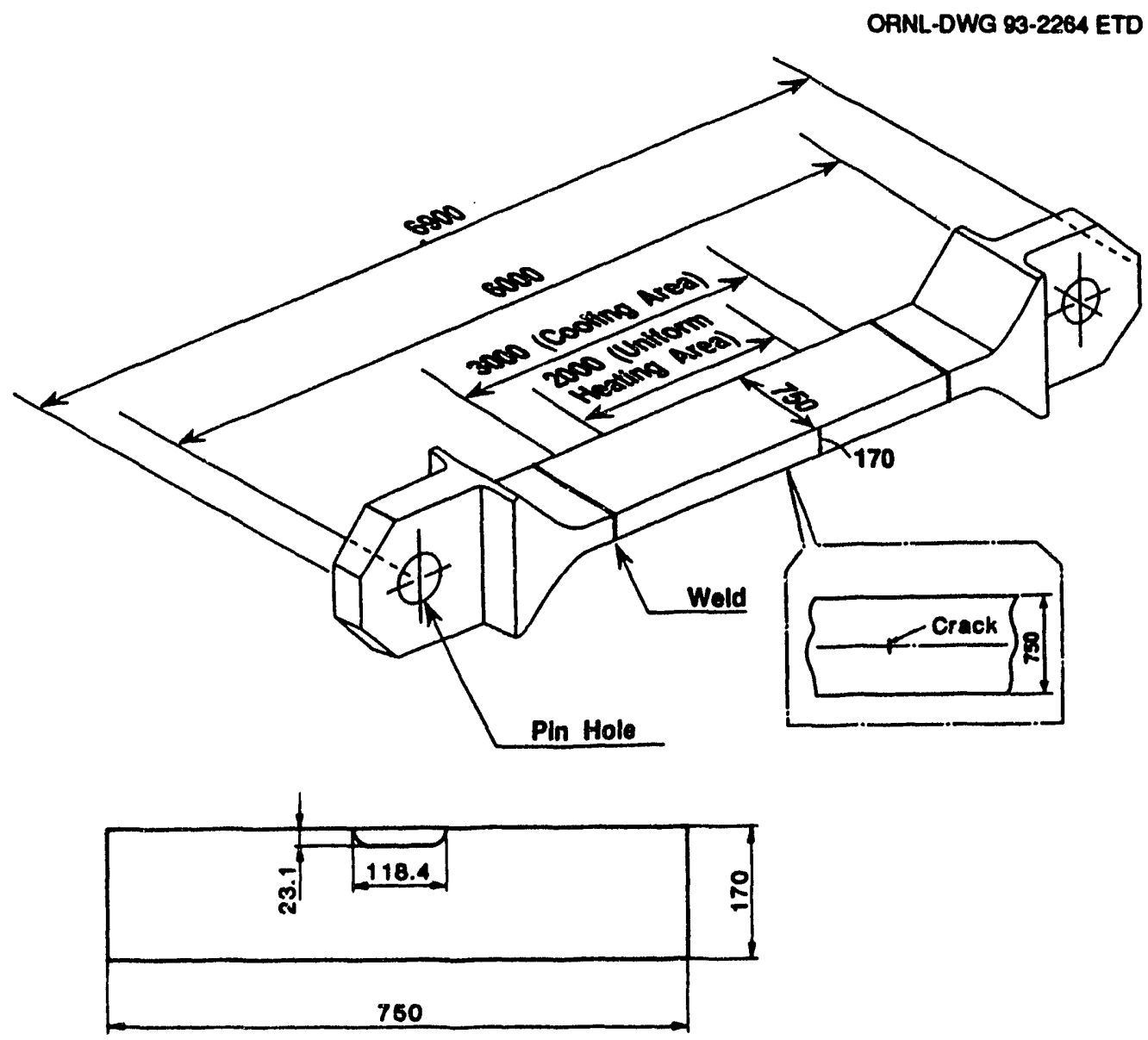

Fig. 2.51. Specimen and crack geometry for the Step I tegt (IAPEIC, Japan). 
Table 2.24 Young's modulus and coeficient of thermal expansion for Step B test material ${ }^{a}$

\begin{tabular}{ccc}
\hline $\begin{array}{c}\text { Temperature } \\
\left({ }^{\circ} \mathbf{C}\right)\end{array}$ & $\begin{array}{c}\text { Young's Modulus } \\
(\mathbf{M P a})\end{array}$ & $\begin{array}{c}\text { Coemcient of } \\
\text { thermal expansion } \\
\left(\mathbf{1} /{ }^{\circ} \mathbf{C}\right) \times \mathbf{1 0}^{-5}\end{array}$ \\
\hline 30 & 205900 & 1.106 \\
75 & 204000 & 1.178 \\
100 & 203000 & 1.210 \\
150 & 200000 & 1.280 \\
200 & 197100 & 1.351 \\
250 & 194200 & 1.420 \\
300 & 190300 & 1.484 \\
\hline
\end{tabular}

${ }^{a}$ Poisson's ratio $v=0.3$.

Table 2.25 True stress vs true strain data for Step B test material

\begin{tabular}{|c|c|c|c|c|c|}
\hline $\begin{array}{c}\text { Temperature } \\
\left({ }^{\circ} \mathbf{C}\right) \\
\end{array}$ & $\begin{array}{l}\text { Plastic } \\
\text { strain }\end{array}$ & $\begin{array}{l}\text { Stress } \\
(\mathbf{M P a}) \\
\end{array}$ & $\begin{array}{c}\text { Temperature } \\
\left({ }^{\circ} \mathbf{C}\right)\end{array}$ & $\begin{array}{l}\text { Plastic } \\
\text { strain } \\
\end{array}$ & $\begin{array}{l}\text { Stress } \\
(\mathbf{M P a}) \\
\end{array}$ \\
\hline 30 & $\begin{array}{l}0.0 \\
0.0025 \\
0.005 \\
0.001 \\
0.02 \\
0.04 \\
0.06 \\
0.10\end{array}$ & $\begin{array}{r}677 \\
780 \\
809 \\
843 \\
885 \\
929 \\
981 \\
1035\end{array}$ & 200 & $\begin{array}{l}0.0 \\
0.0025 \\
0.005 \\
0.01 \\
0.02 \\
0.04 \\
0.06 \\
0.10\end{array}$ & $\begin{array}{l}598 \\
736 \\
760 \\
792 \\
836 \\
897 \\
939 \\
990\end{array}$ \\
\hline 75 & $\begin{array}{l}0.0 \\
0.0025 \\
0.005 \\
0.01 \\
0.02 \\
0.04 \\
0.06 \\
0.10\end{array}$ & $\begin{array}{r}647 \\
760 \\
789 \\
814 \\
863 \\
932 \\
971 \\
1013\end{array}$ & 250 & $\begin{array}{l}0.0 \\
0.0025 \\
0.005 \\
0.01 \\
0.02 \\
0.04 \\
0.06 \\
0.10\end{array}$ & $\begin{array}{l}598 \\
736 \\
780 \\
814 \\
858 \\
912 \\
951 \\
990\end{array}$ \\
\hline 100 & $\begin{array}{l}0.0 \\
0.0025 \\
0.005 \\
0.01 \\
0.02 \\
0.04 \\
0.06 \\
0.10\end{array}$ & $\begin{array}{r}628 \\
755 \\
780 \\
809 \\
858 \\
922 \\
961 \\
1000\end{array}$ & 300 & $\begin{array}{l}0.0 \\
0.0025 \\
0.005 \\
0.01 \\
0.02 \\
0.04 \\
0.06 \\
0.10\end{array}$ & $\begin{array}{l}579 \\
726 \\
765 \\
814 \\
873 \\
929 \\
964 \\
990\end{array}$ \\
\hline 150 & $\begin{array}{l}0.0 \\
0.0025 \\
0.005 \\
0.01 \\
0.02 \\
0.04 \\
0.06 \\
0.10\end{array}$ & $\begin{array}{l}598 \\
740 \\
770 \\
794 \\
843 \\
902 \\
941 \\
983\end{array}$ & & & \\
\hline
\end{tabular}


Description

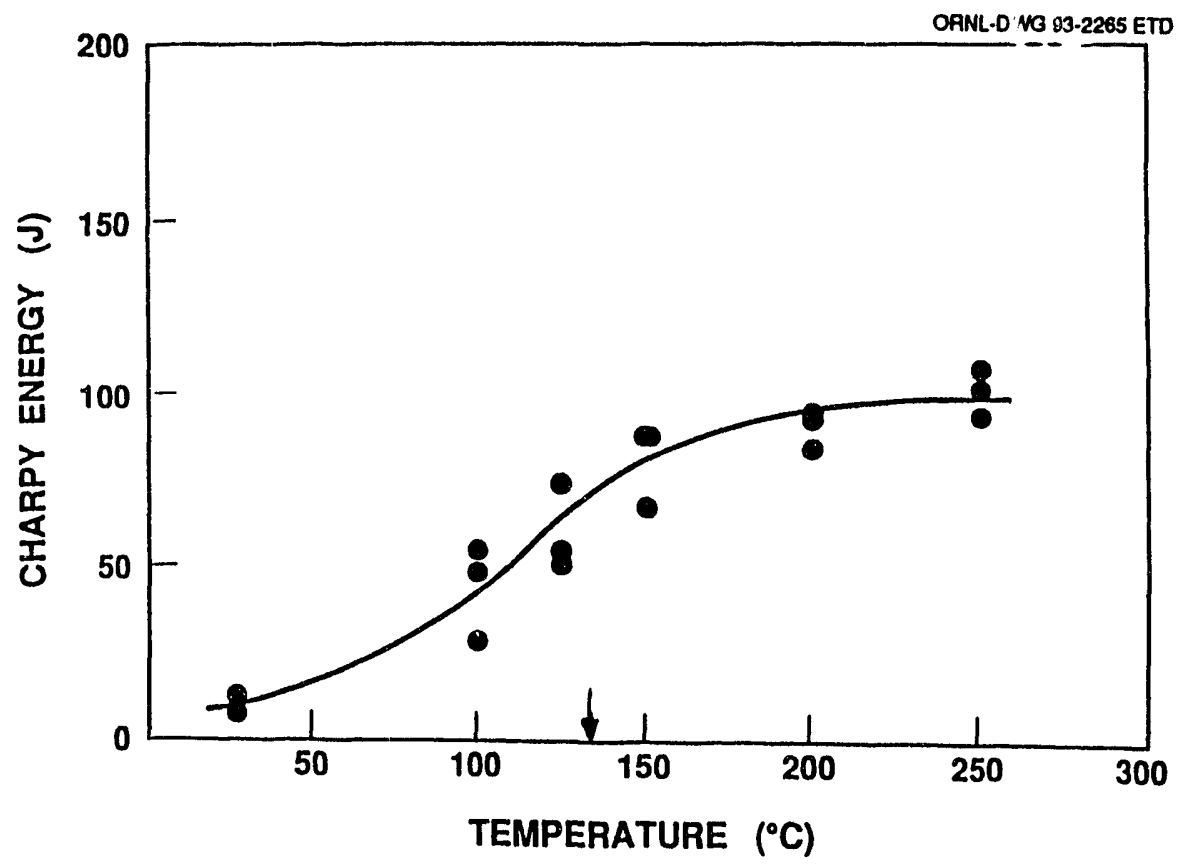

Fig. 2.52. Charpy impact energy vs temperature curve for the Step B material.

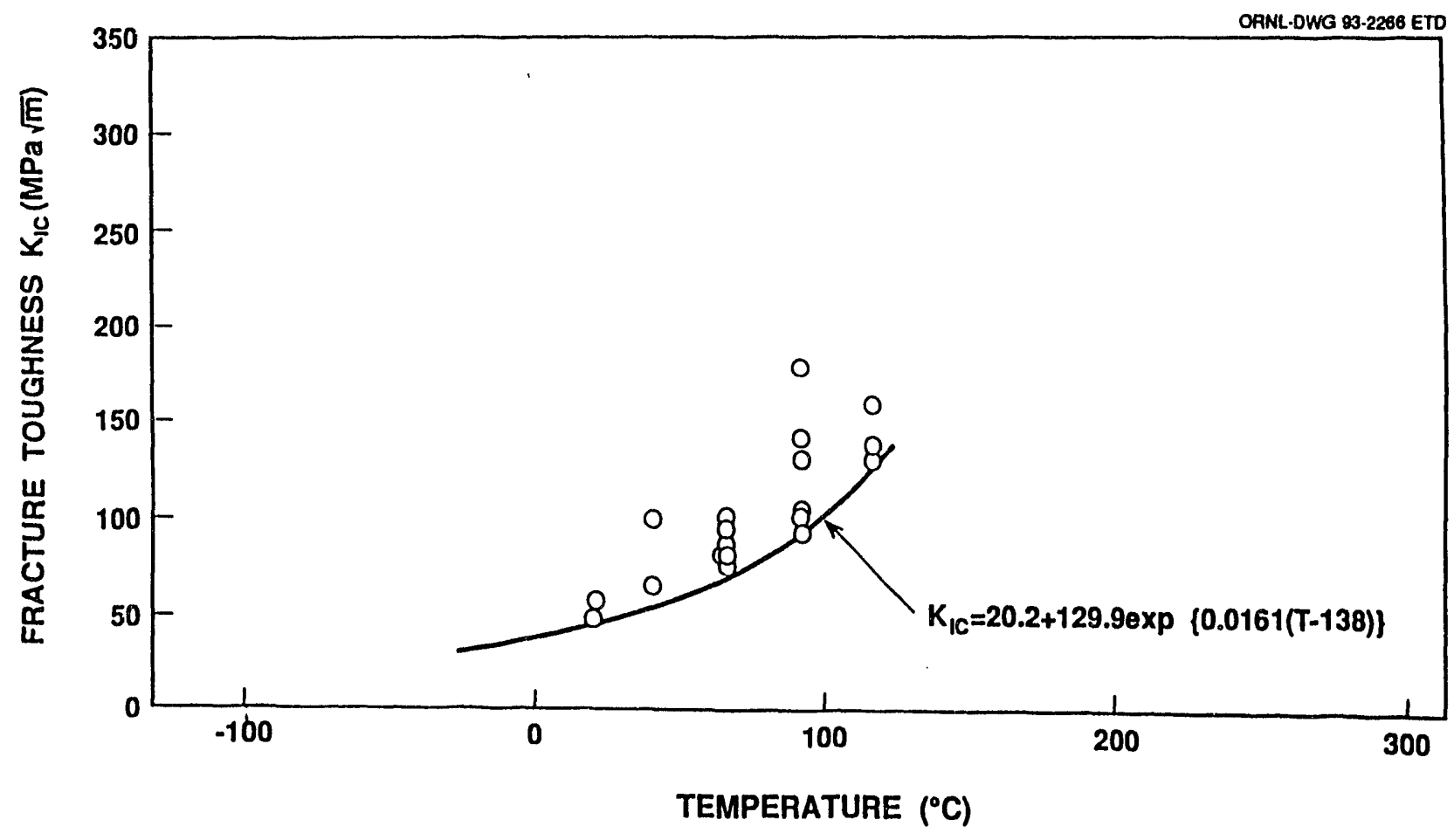

Fig. 2.53. KIc vs temperature curve for the Step B material. 

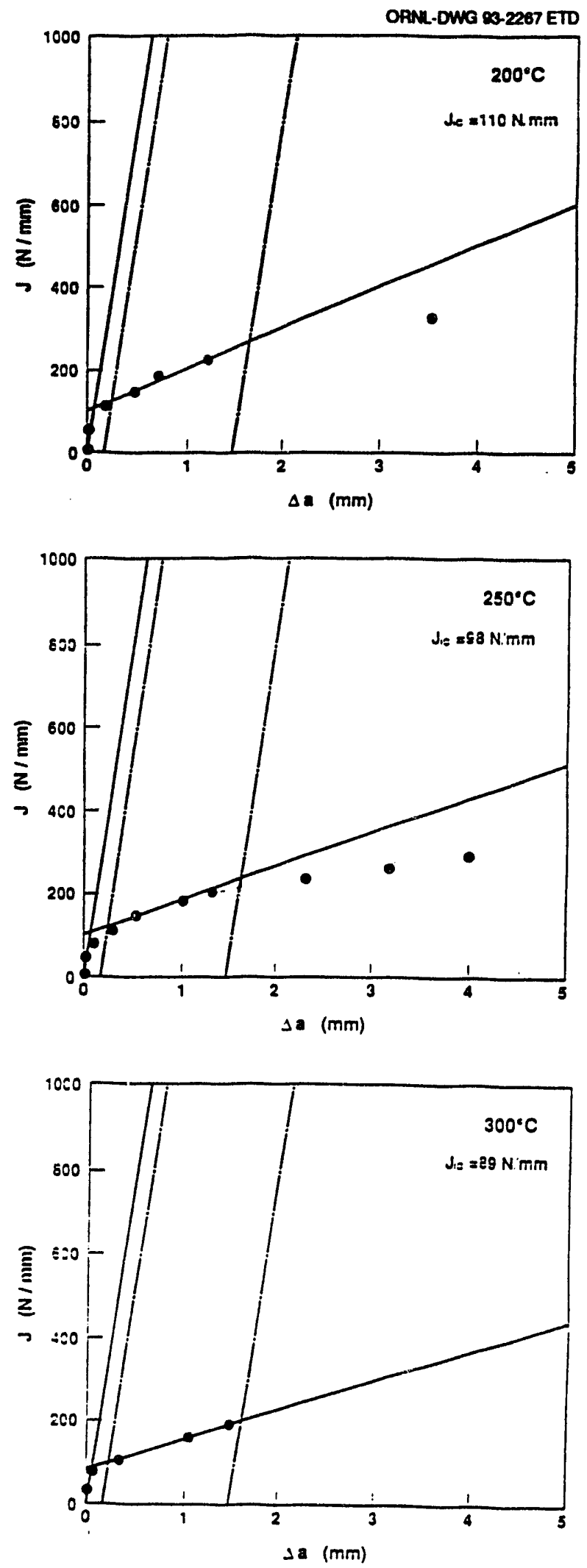

Fig. 2.54. JR vs $\Delta a$ for the Step B material. 
Description

ORNL-DWG 93-2268 ETD

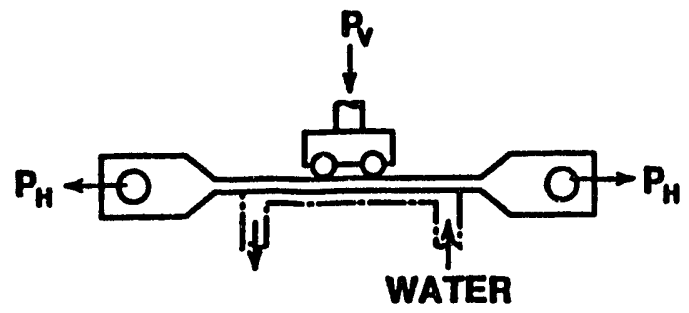

\begin{tabular}{|l|l|}
\hline yleld strese at RT & $677 \mathrm{MPa}$ \\
\hline $\begin{array}{l}\text { charpy energy for } \\
\text { upper shelf }\end{array}$ & $101 \mathrm{~J}$ \\
\hline NDT & $139^{\circ} \mathrm{C}$ \\
\hline
\end{tabular}
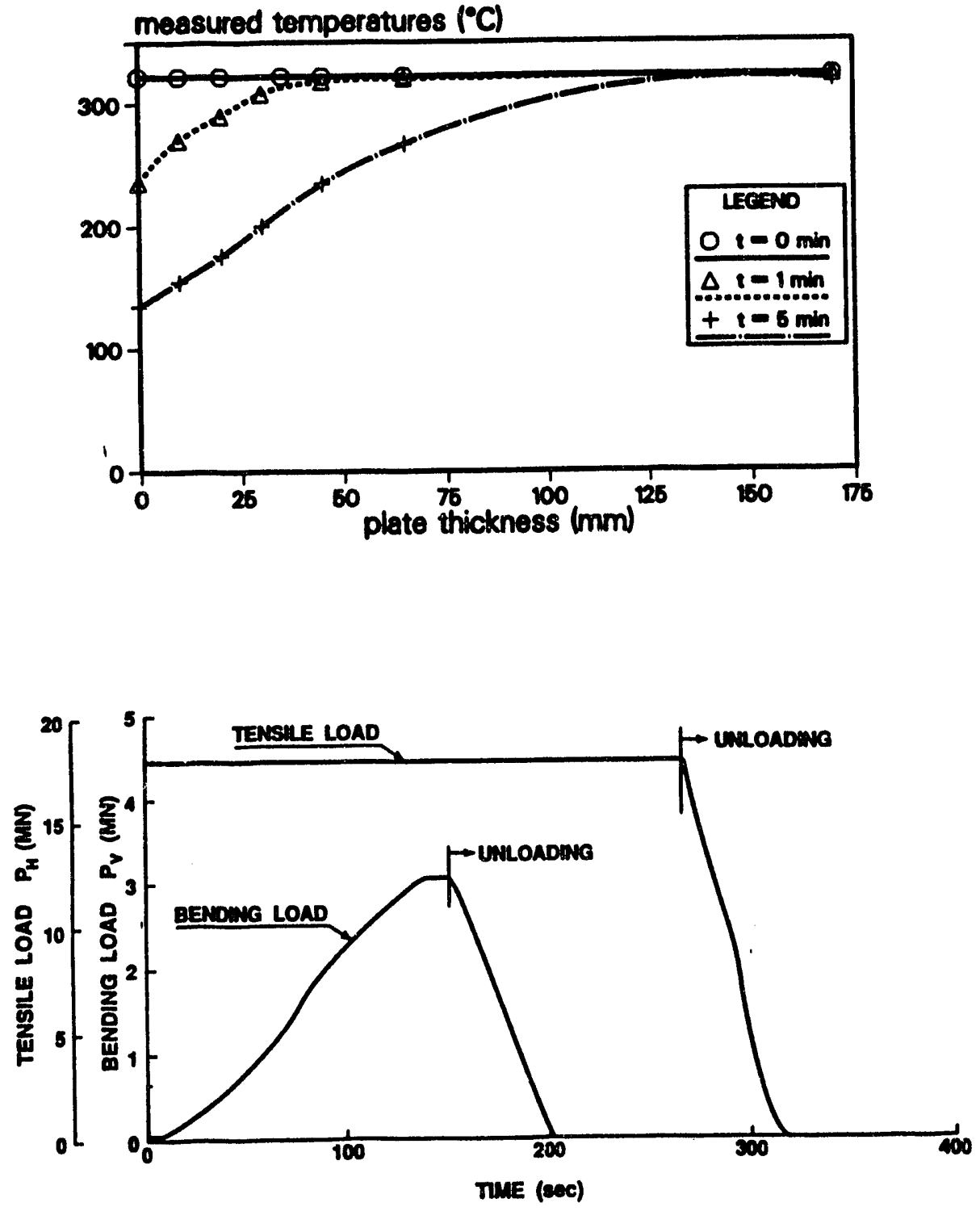

Fig. 2.55. Thermal/mechanical loading and material chargeteristics for Step B test material characteristics. 

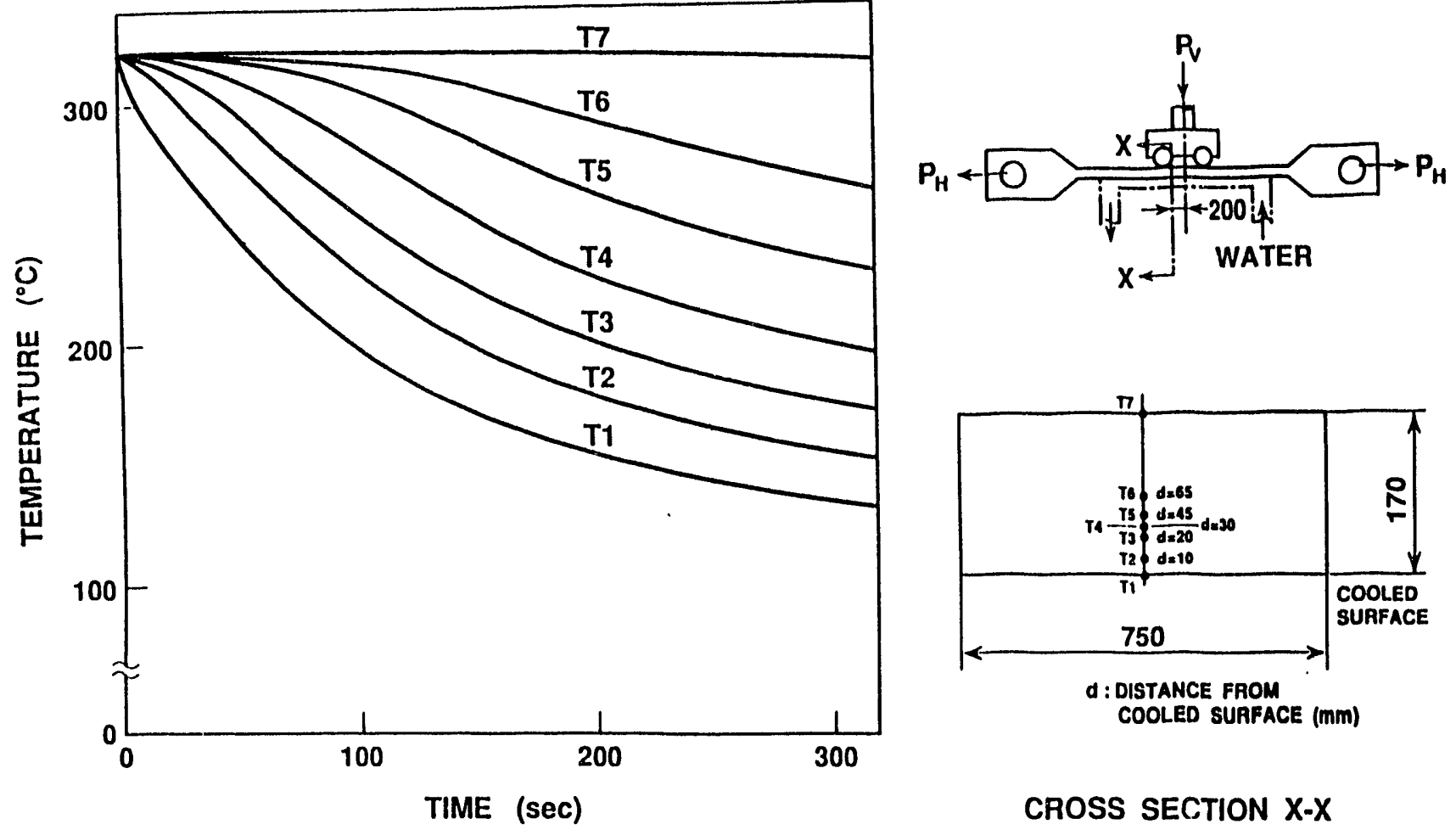

CROSS SECTION $X-X$

Fig. 2.56. Time history of temperature at discrete points in the Step B test specimen.

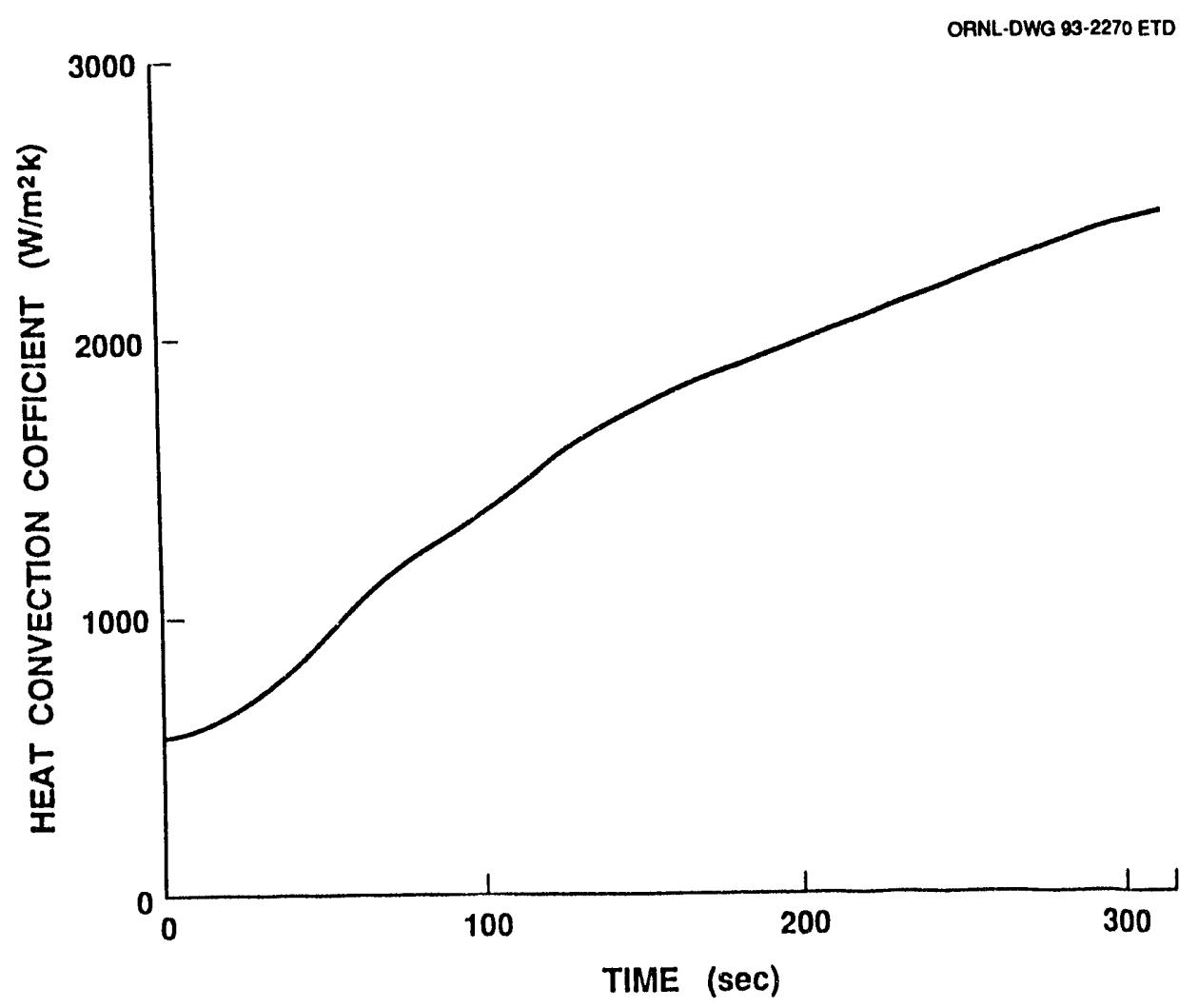

Fig. 2.57. Time history of convective heat transfer coefficient for Step B test. 
Description

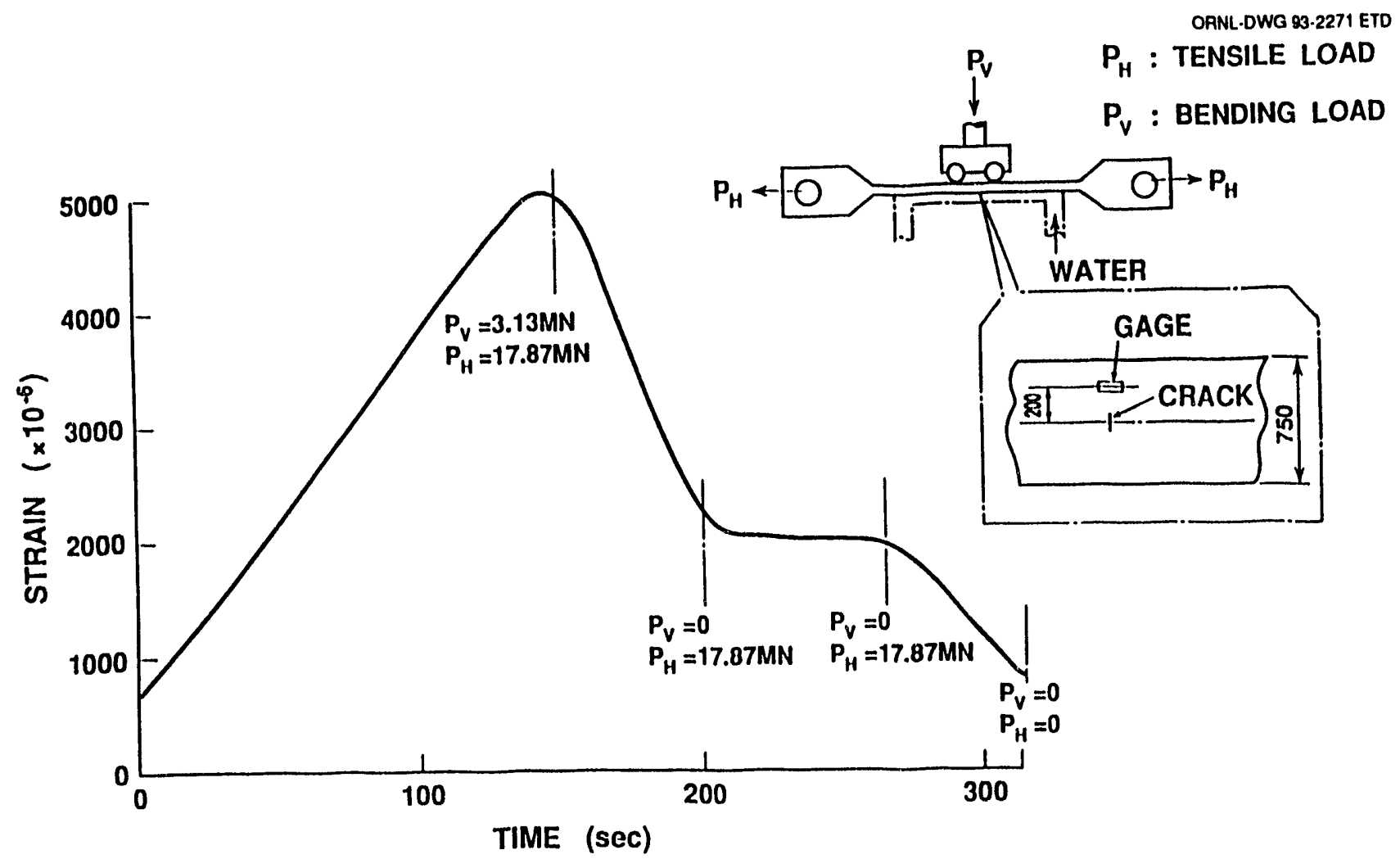

Fig. 2.58. Time history of surface strain near initial crack for Step B test.

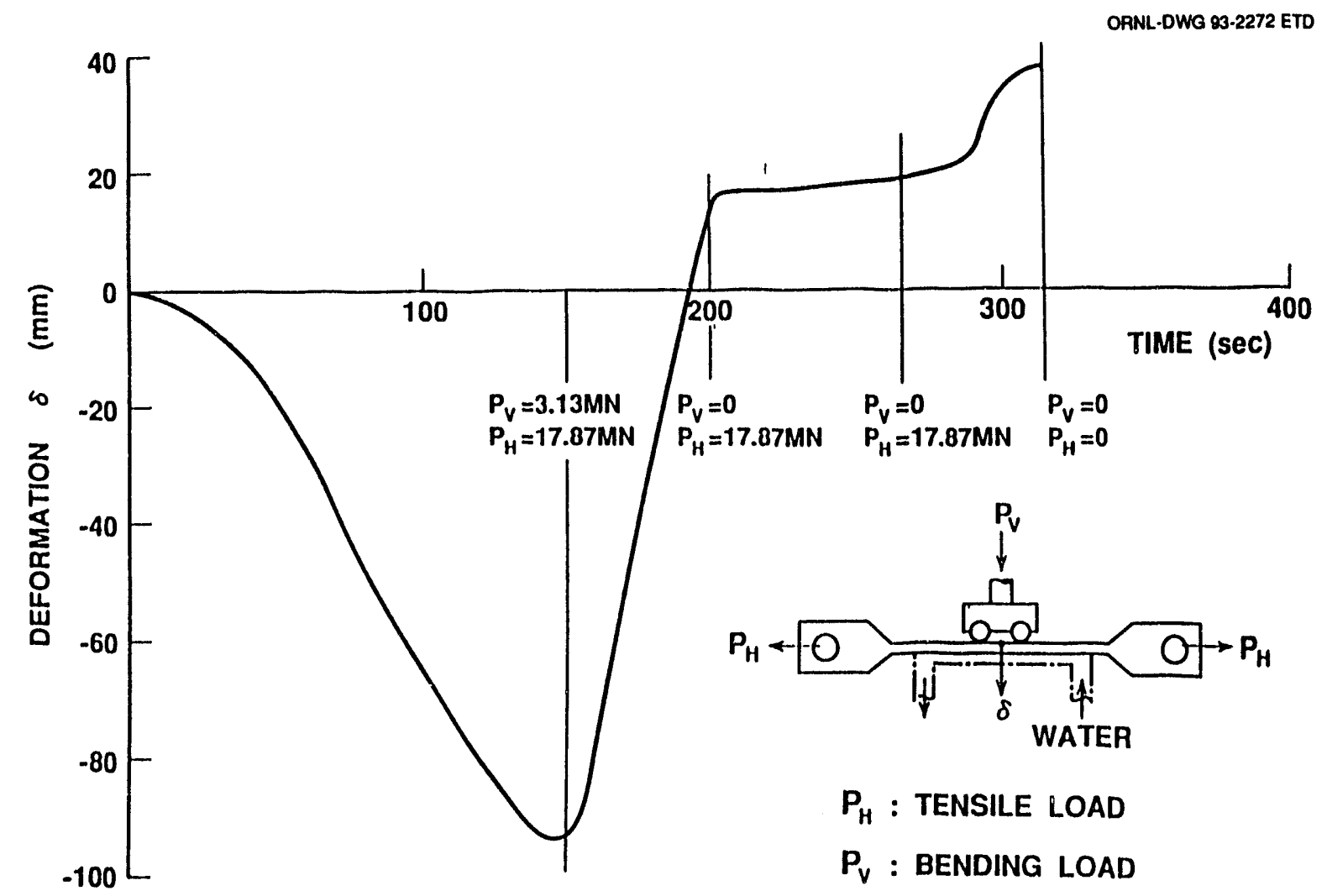

Fig. 2.59. Time history of deformation at center of Step B test speciman. 
DISTANCE FROM CENTER ( $\mathrm{mm})$

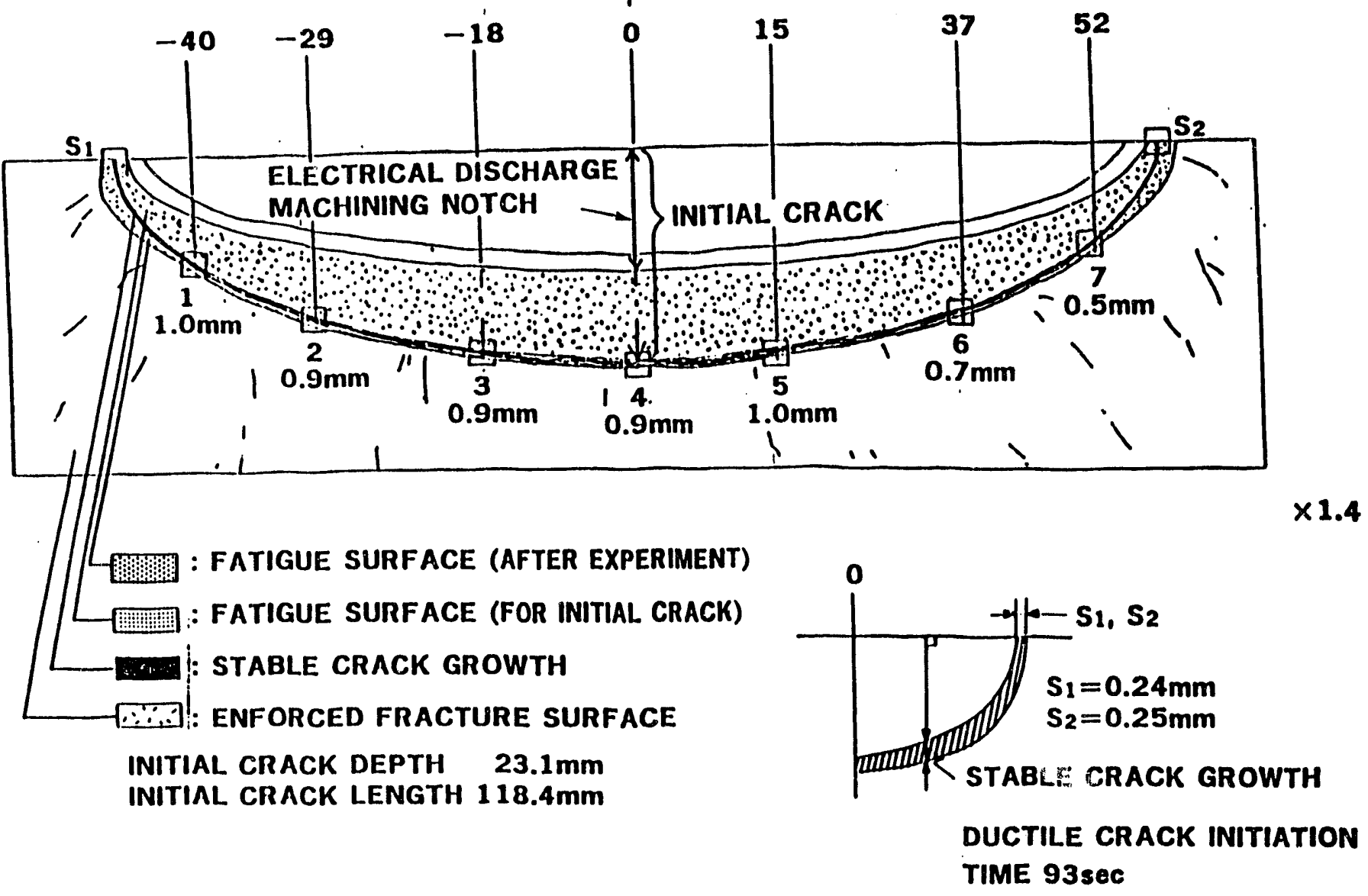

Fig. 2.60. Initial crack and measured stable crack extension in Step B test. 


\section{REFERENCES}

1. A. Sauter, "Recent Progress in PTS Research at MPA Stuttgart,"' French-German Seminar, Technical Presentation 1.4, Electricite de France, Moret sur Loing, France, 1987.

2. A. Sauter et al., "Behavior of Surface Flaws under Thermal-Mechanical Loading," 14th Materialprüfungsanstalt Seminar, Stuttgart, FRG, 1988.

3. R. H. Bryan et al., Martin Marietta Energy Systems, Inc., Oak Ridge Natl. Lab., "Pressurized-Thermal-Shock Test of 6-in.-Thick Pressure Vessels, PTSE-1: Investigations of Warm Prestressing and Upper-Shelf Arrest," USNRC Report NUREG/CR-4106 (ORNL-6135), April 1985.*

4. R. H. Bryan et al., Martin Marietta Energy Systems, Inc., Oak Ridge Natl. Lab., "Pressurized-Thermal Shock Test of 6-in.-Thick Pressure Vessels, PTSE-2: Investigation of Low Tearing Resistance and Warm Prestressing," USNRC Report NUREG/CR-4888 (ORNL-6377), December 1987."

5. J. G. Merkle, Union Carbide Corp. Nuclear Div., Oak Ridge Natl. Lab., "An Examination of the Size Effects and Data Scatter Observed in Small-Specimen Cleavage Fracture Toughness Testing," USNRC Report NUREG/CR-3672 (ORNL/TM-9088), April 1984.*

6. A. M. Clayton et al., "A Spinning Cylinder Tensile Test Facility for Pressure Vessel Steels," in Proceedings of Eighth International Conference on Structural Mechanics in Reactor Technology, Brussels, Belgium, Aug. 19-23, 1985.

7. D. J. Lacey and R. E. Leckenby, "Determination of Upper Shelf Fracture Resistance in the Spinning Cylinder Test Facility," pp. 1-6 in Tenth International Conference on Structural Mechanics in Reactor Technology, Vol. F, 1989.

8. H. Okamura et al., "PTS Integrity Study in Japan," pp. 395-400 in Ninth International Conference on Structural Mechanics in Reactor Technology, Vol. G, 1987.

9. H. Okamura et al., "PTS Integrity Study in Japan (Part 2)," pp. 7-12 in Tenth International Conference on Structural Mechanics in Reactor Technology, Vol. F, 1989. 


\section{Description of Applied Analysis Methods}

\subsection{Structural Mechanics Analysis Methods}

\begin{abstract}
The summary of analysis techniques for Project FALSIRE provided in Table 1.4 indicates that the predominant structural analysis tool was the finite-element method. Some additional details concerning applications of finite-element techniques to each of the reference experiments by the participating analysts are given in Table 3.1. The data in Table 3.1 identify the finite-element program used in each analysis, the number of dimensions and size (i.e., number of equations) of the finite-element model, the constitutive relation, material model and stress-strain approximation, and the solution scheme (integration rule and equilibrium iteration method) employed in the analysis of the model.
\end{abstract}

A typical analysis in Table 3.1 used an elastic-plastic or thermo-elastic-plastic constitutive model, combined with one of several possible equilibrium iteration schemes, to achieve convergence of the nonlinear solution. (Two solutions of the SC-II experiment, submitted by analysts 11 and 16 , were based on linear thermo-elastic constitutive models.) A bilinear or multilinear representation of the material stress-strain curve was employed, depending on the capabilities of the finite-element program applied to the problem. Table 3.1 indicates that, for a given reference experiment and dimensional representation of the geometry [i.e., two dimensional (2D) or three dimensional (3D)], the mesh refinement varied considerably among the different solutions, as measured by the number of equations defining the finite-element model.

Capabilities of the finite-element programs used in the Project FALSIRE analyses and identified in Table 3.1 are available in Refs. 1-7. Detailed discussions of the various finite-element solution strategies outlined in Table 3.1, including the constitutive models appropriate for thermo-elastic-plastic applications and the equilibrium iteration schemes for achieving convergent solutions, can be found in many references (e.g., Refs. 8-10).

Several participating analysts in Project FALSIRE elected to perform structural analyses of the reference experiments using engineering estimation schemes to determine stress fields. These approaches are summarized in Table 3.2 for analyses 11 through 16 . In the methodology employed by analyst 12 , the stress distribution through the vessel wall ' s calculated using the principles of linear elasticity. closed-form solutions for stresses caused by pressure and thermal-shock loadings were obtained from the published literature. ${ }^{11-13}$ These solutions were based on material properties at the mean temperature of the transient under consideration. The total elastic stress distribution was then constructed by superposing the pressure and thermal stress solutions. The total stress distribution was fitted by a fourth-order polynomial for use in calculating stress intensity factors $\mathrm{K}_{\mathrm{I}}$. When the total elastic stress distribution gave stresses above the flow stress (defined as one-half the sum of yield and ultimate strengths), the stress distribution was modified by a simple procedure. ${ }^{14}$ The procedure consisted of the following three elements: (1) the peak stress in the modified stress distribution was taken as the flow stress, and the stress gradient $d \sigma / d x$ was set to zero at this location, where $x$ is the distance into the vessel wall; (2) the stress and do/dx at the location farthest from the peak stress location was taken to be the same as that in the linear elastic distribution; and (3) the modified stress distribution represented the same equivalent force across the vessel section as that in the linear elastic stress distribution. The modified stress distribution so obtained was fitted to a fourth-order polynomial for use in fracture mechanics analyses.

In Table 3.2 analyst 14 employed a statically indeterminate method for analyses of reference experiments PTSE- 2 and $\mathrm{SC}-\mathrm{I}$. This technique is used to determine the circumferential force $(\mathrm{P})$ and bending moment $(\mathrm{M})$ acting on the end surface of a cylindrical shell containing a slit. (No reference was provided for the method applied in this solution.) Analyst 15 derived a stress distribution for the PTSE-2 experiment corresponding to the temperature data provided in the problem statement. Polynomial best-fit formulas describing the temperature distribution through the wall were devised for each time in the transient using a least-squares method. These distributions were then used in an analytical solution ${ }^{15}$ to obtain the linear thermo-elastic stress field. The hoop stress distribution in the first SC experiment (SC-I) was determined by analyst 16 from an analytic solution for a rotating cylinder taken from Ref. 15. For experiment SC-II, which was subjected primarily to thermal-shock loading, analyst 11 used an analytic solution from Ref. 15 for stresses in a cylinder subjected to thermal gradient loading.

\subsection{Fracture Mechanics Analysis Methods}

All of the finite-element analyses summarized in Table 3.1 employed a J-resistance curve methodology for modeling stable ductile crack extension. This methodology is based on the existence of equilibrium during crack extension between the crack driving force $J(P, a)$ and the resistance of 


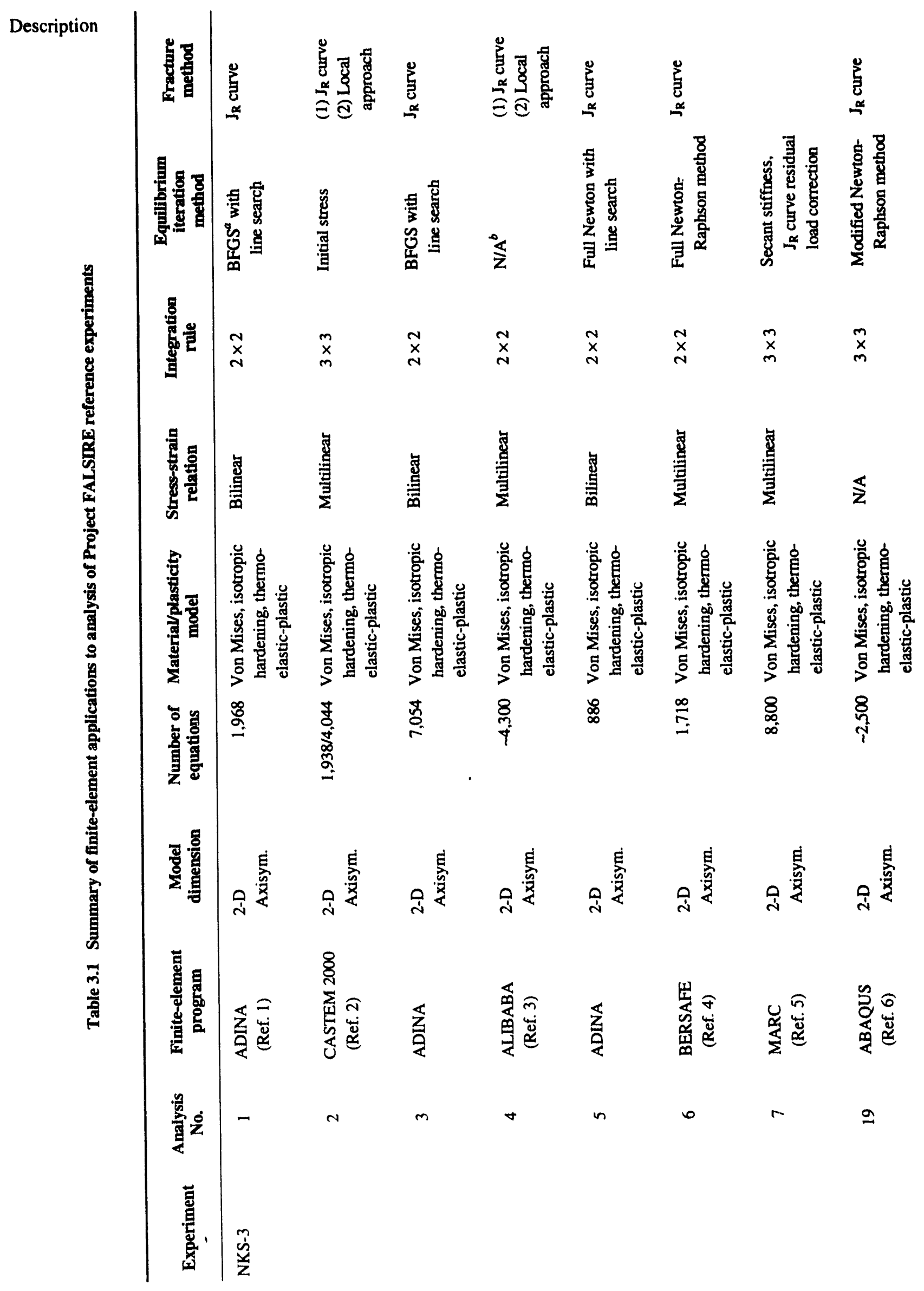




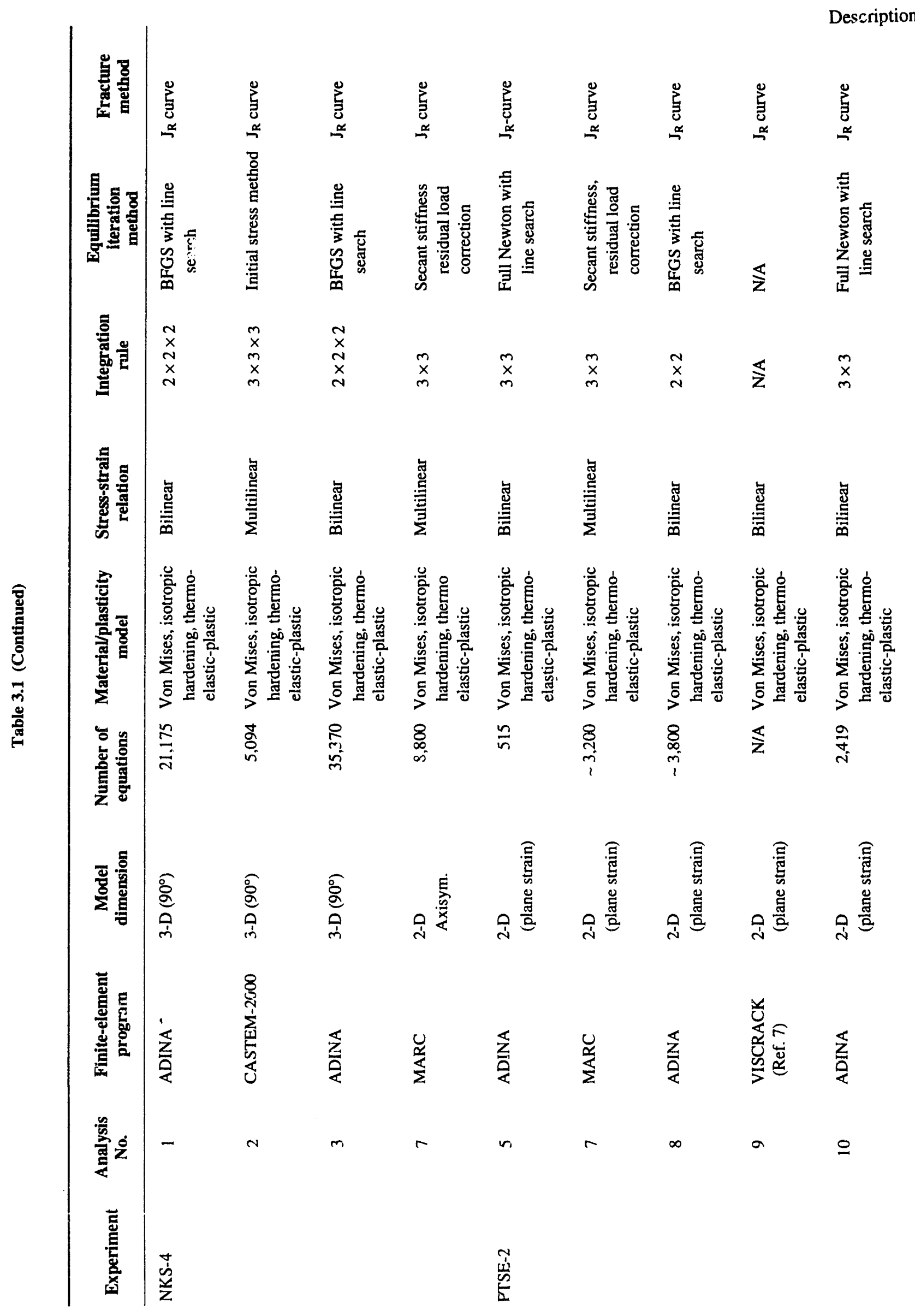




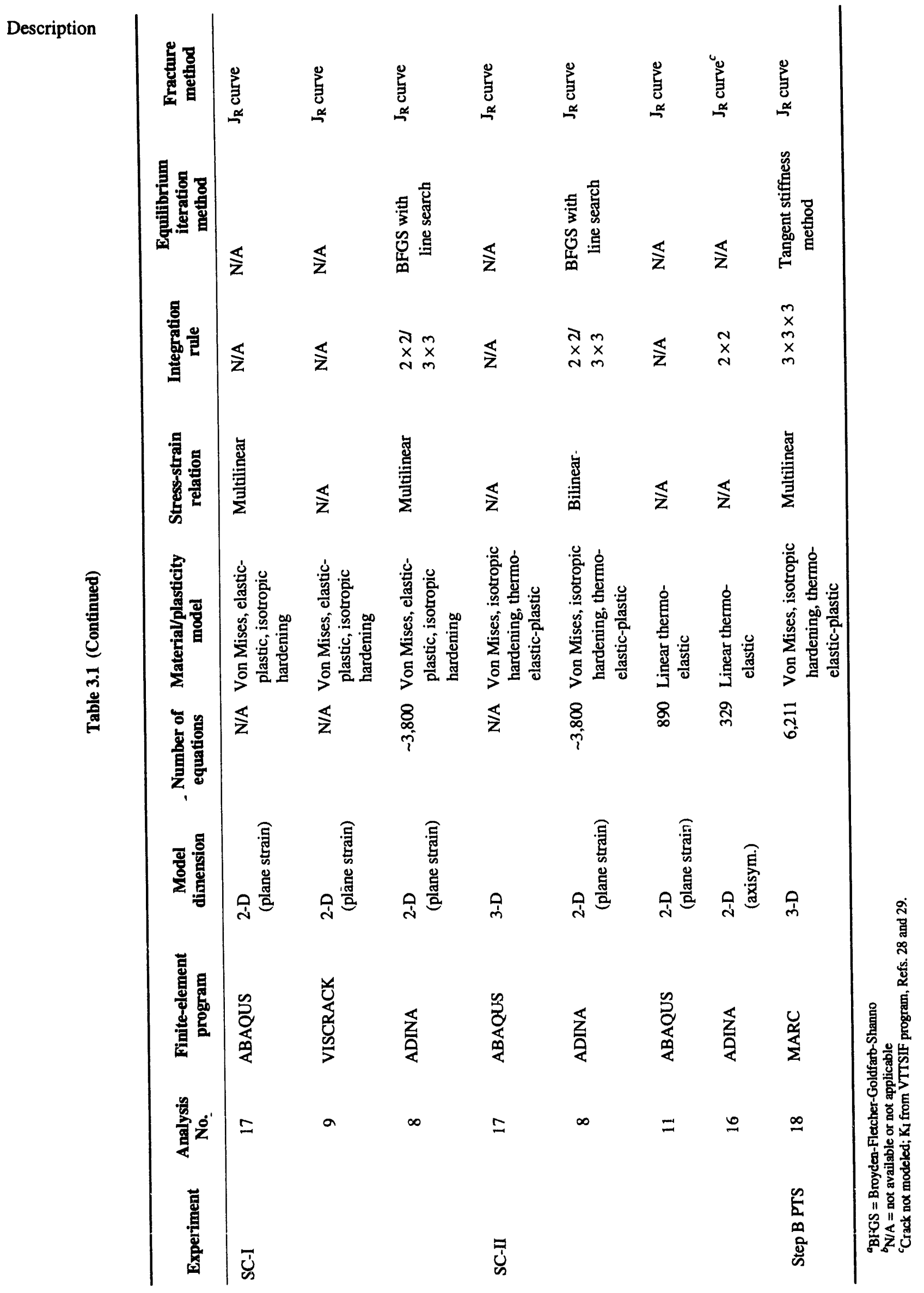


Table 3.2 Summary of estimation scheme applications to analysis of Project FALSIRE reference experiments

\begin{tabular}{|c|c|c|c|}
\hline Experiment & $\begin{array}{c}\text { Analysis } \\
\text { No. } \\
\end{array}$ & $\begin{array}{l}\text { Stress analysis } \\
\text { methodology }\end{array}$ & $\begin{array}{c}\text { Fracture } \\
\text { methodology }\end{array}$ \\
\hline \multirow[t]{2}{*}{ NKS-3 } & 12 & $\begin{array}{l}\text { Superposition of closed form } \\
\text { solutions for stresses caused by } \\
\text { pressure and thermal loading } \\
\text { (Refs. 11-13) }\end{array}$ & $\begin{array}{l}\mathrm{J}_{\mathrm{R}} \text { curve; } \\
\mathrm{J} \text { from handbook } \\
\text { (Ref. 31) }\end{array}$ \\
\hline & 13 & $\begin{array}{l}\text { Thermal stresses calculated } \\
\text { analytically from LOTUS } 1,2,3\end{array}$ & $\begin{array}{l}\text { R6, Option } 1 \\
\text { (Refs. } 37 \text { and 38) }\end{array}$ \\
\hline \multirow[t]{2}{*}{ NKS-4 } & 12 & $\begin{array}{l}\text { Superposition of closed form } \\
\text { solutions for stresses caused by } \\
\text { pressure and thermal loading } \\
\text { (Refs. 11-13) }\end{array}$ & $\begin{array}{l}\mathrm{J}_{\mathrm{R}} \text { curve; } \\
\mathrm{J} \text { from handbook } \\
\text { (Ref. 31) }\end{array}$ \\
\hline & 13 & $\begin{array}{l}\text { Thermal stresses calculated } \\
\text { analytically from LOTUS } 1,2,3\end{array}$ & $\begin{array}{l}\text { R6, Option } 1 \\
\text { (Refs. } 37 \text { and 38) }\end{array}$ \\
\hline \multirow[t]{3}{*}{ PTSE-2 } & 12 & $\begin{array}{l}\text { Superposition of closed form } \\
\text { solutions for stresses caused by } \\
\text { pressure and thermal loading } \\
\text { (Refs. 11-13) }\end{array}$ & $\begin{array}{l}\mathrm{J}_{\mathrm{R}} \text { curve; } \\
\mathrm{J} \text { from handbook } \\
\text { (Ref. 31) }\end{array}$ \\
\hline & 14 & $\begin{array}{l}\text { Statically indeterminate } \\
\text { solutions for circumferential } \\
\text { force and bending moment } \\
\text { on end surface of cracked } \\
\text { cylindrical shell }\end{array}$ & $\begin{array}{l}\mathrm{J}_{\mathrm{R}} \text { curve; } \\
\mathrm{J} \text { from elastic } \\
\text { and fully plastic } \\
\text { solutions } \\
\text { (Refs. } 32 \text { and } 33 \text { ) }\end{array}$ \\
\hline & 15 & $\begin{array}{l}\text { Stress distribution from } \\
\text { analytical solution obtained } \\
\text { from integration of temperature } \\
\text { distribution (Ref. 15) }\end{array}$ & $\begin{array}{l}\mathrm{J}_{\mathrm{R}} \text { curve; } \\
\mathrm{J} \text { from influence } \\
\text { coefficients } \\
\text { (Refs. } 34 \text { and } 35 \text { ) }\end{array}$ \\
\hline \multirow[t]{3}{*}{ SC-I } & 12 & $\begin{array}{l}\text { Analytic solution for } \\
\text { hoop stress distribution } \\
\text { in rotating cylinder } \\
\text { (Ref. 15) }\end{array}$ & $\begin{array}{l}\mathrm{J}_{\mathrm{R}} \text { curve; } \\
\mathrm{J} \text { from handbook } \\
\text { (Ref. 31) }\end{array}$ \\
\hline & 14 & $\begin{array}{l}\text { Statically indeterminate } \\
\text { solution for circumferential } \\
\text { force and bending moment } \\
\text { on end surface of cracked } \\
\text { cylindrical shell }\end{array}$ & $\begin{array}{l}\mathrm{J}_{\mathrm{R}} \text { curve; } \\
\mathrm{J} \text { from elastic } \\
\text { and fully plastic } \\
\text { solutions } \\
\text { (Refs. } 32 \text { and } 33 \text { ) }\end{array}$ \\
\hline & 16 & $\begin{array}{l}\text { Analytic solution for hoop } \\
\text { stress distribution in } \\
\text { rotating cylinder } \\
\text { (Ref. 15) }\end{array}$ & $\begin{array}{l}\mathrm{J}_{\mathrm{R}} \text { curve; } \\
\mathrm{J} \text { from weight } \\
\text { function method } \\
\text { (VTTSIF, Refs. } 28 \text { and 29) }\end{array}$ \\
\hline
\end{tabular}




\section{Description}

Table 3.2 (continued)

\begin{tabular}{|c|c|c|c|}
\hline Experiment & $\begin{array}{l}\text { Analysis } \\
\text { No. }\end{array}$ & $\begin{array}{l}\text { Stress analysis } \\
\text { methodology }\end{array}$ & $\begin{array}{l}\text { Fracture } \\
\text { methodology }\end{array}$ \\
\hline \multirow[t]{5}{*}{ SC-II } & 12 & $\begin{array}{l}\text { Superposition of closed form } \\
\text { solutions for stress caused by } \\
\text { pressure and thermal loading } \\
\text { (Refs. 11-13) }\end{array}$ & $\begin{array}{l}\mathrm{J}_{\mathrm{R}} \text { curve; } \\
\mathrm{J} \text { from handbook } \\
\text { (Ref. 31) }\end{array}$ \\
\hline & 13 & $\begin{array}{l}\text { Thermal stresses calculated } \\
\text { analytically from LOTUS } 1,2,3\end{array}$ & $\begin{array}{l}\text { R6, Option } 1 \\
\text { (Refs. } 37 \text { and 38) }\end{array}$ \\
\hline & 14 & $\begin{array}{l}\text { Statically indeterminate } \\
\text { solutions for circumferential } \\
\text { force and bending moment } \\
\text { on end surface of cracked } \\
\text { cylindrical shell }\end{array}$ & $\begin{array}{l}\mathrm{J}_{\mathrm{R}} \text { curve; } \\
\mathrm{J} \text { from elastic and } \\
\text { fully plastic solutions } \\
\text { (Refs. } 33 \text { and } 33 \text { ) }\end{array}$ \\
\hline & 11 & $\begin{array}{l}\text { Analytic solution for } \\
\text { stress in a cylinder } \\
\text { subjected to thermal } \\
\text { gradient loading } \\
\text { (Ref. 15) }\end{array}$ & $\begin{array}{l}\mathrm{J}_{\mathrm{R}} \text { curve; } \mathrm{J} \text { from } \\
\text { influence functions } \\
\text { (Ref. 34) }\end{array}$ \\
\hline & 16 & $\begin{array}{l}\text { Analytic and finite-element } \\
\text { solutions for stress in a } \\
\text { cylinder subjected to } \\
\text { thermal gradient loading }\end{array}$ & $\begin{array}{l}J_{R} \text { curve; } \mathrm{J} \text { from } \\
\text { weight function method } \\
\text { (VTTSIF, Refs. } 28 \text { and 29) }\end{array}$ \\
\hline
\end{tabular}

the material to ductile fracture $J_{R}(\Delta a)$ as required by the relation

$$
\mathrm{J}(\mathrm{P}, \mathrm{a})=\mathrm{J}_{\mathrm{R}}\left(\mathrm{a}-\mathrm{a}_{0}\right)=\mathrm{J}_{\mathrm{R}}(\Delta \mathrm{a})
$$

The parameter $\mathrm{J}$ is a function of the applied load $\mathrm{P}$, the crack length $\mathrm{a}$, and the geometry of the body. Under loading conditions for which Eq. (3.1) cannot be satisfied, the crack is assumed to experience ductile instability. The basis of elastic-plastic fracture mechanics is the interpretation of $\mathrm{J}$ as a measure of the intensity of the Hutchinson, Rice, and Rosengren ${ }^{16,17}$ singular crack-tip fields and of the J-resistance curve $J_{R}(\Delta a)$ as a unique property of the material when cohditions for J-controlled crack extension are satisfied. Conditions for J-dominance and $\mathrm{J}$-controlled crack extension are detailed in numerous texts, including Chap. 5 of Ref. 18.

In the finite-element applications of Table 3.1, the parameter $\mathrm{J}$ is typically calculated from a path-area integral or domain integral expression (e.g., Refs. 19 and 20) con- taining terms appropriate for the applied loading conditions (i.e., mechanical loads, thermal gradient, centrifugal loading). The J-resistance curve data were provided to the participating analysts in the problem statements describing the reference experiments. These data were generated from small laboratory specimens for the purpose of characterizing the large-scale test material. Most analysts computed the J-parameter as a function of the applied loading conditions for one or more fixed crack depths. Three analyses (PTSE-2, No. 8; SC-I, No. 8; and SC-II, No. 8) employed a node-release technique ${ }^{21}$ to perform both generation- and application-mode analyses of the ductile tearing process. In a generation-mode analysis, the crack tip is propagated through the model by systematically releasing crack-plane nodes according to a prescribed relation between crack depth and applied load (or time) determined from measured data. An application-mode analysis is performed by propagating the crack tip such that the equiiibrium condition [Eq. (3.1)] is satisfied in each load (or time) step of the analysis. In analysis 5 (Table 3.1) of the NKS-3 experiment, crack extension was modeled using a node shift and fixity release technique. ${ }^{22}$ 
For some experiments, a parameter (q) characterizing the stress triaxiality on the ligament is evaluated and presented in Appendix B. The parameter is defined as

$$
q=\frac{\sigma_{x x}+\sigma_{y y}+\sigma_{z z}}{\sigma_{e f f}}
$$

where $\sigma_{\text {eff }}$ is the von Mises effective stress. This parameter has the following limit values:

$q=1$, if $\sigma_{x x} \neq 0$ and all other components have value 0 ;

$q=2$, if $\sigma_{y y}=\sigma_{z z}$ and all other components have value 0 ;

$q=\infty$, if $\sigma_{x x}=\sigma_{y y}=\sigma_{z z}$ and all other components have value 0 .

Plane strain calculations of a CT-25 specimen show q-values of $\sim 6$ on the ligament in front of the crack tip (see Ref. 23).

Two analyses of the NKS- 3 experiment (analyses 2 and 4 in Table 3.1) used a local approach to fracture mechanics. Analyst 4 investigated crack extension in NKS-3 using a continuum damage mechanics model developed by Rousselier ${ }^{24}$ The evolution of damage in the structure, related to the nucleation and growth of cavities, is characterized in terms of damage parameters that appear in the material constitutive relations. These parameters are calculated from near crack-tip stress and strain fields (local values). When these values are applied to the material constitutive relation, crack initiation and propagation can be simulated without the use of numerical techniques such as crack plane node release (as described in the previous paragraph). Predictions of crack extension were derived from this local approach methodology and were compared with predictions based on calculated J-integral values and the experimentally determined $\mathrm{J}_{-}$resistance curve for the test specimen. Analyst 2 presented two solutions for NKS-3, one of which employed the Rice and Tracey model ${ }^{25}$ for cavity growth in a local approach methodology. For this analysis, cavity growth was calibrated on notched specimens of NKS-3 material that were tested at $220^{\circ} \mathrm{C}$ and are described in Ref. 26. The calibrated model was then used to determine when crack initiation occurred in the NKS experiment.

The only finite-element solution in Table 3.1 that did not incorporate a crack in the model was submitted by analyst 16 for the SC-II experiment. In this case, the stress field obtained from the solution for the uncracked cylinder was used to calculate stress-intensity factors from the VTTSIF Program, 27,* which is based on the weight function method, ${ }^{28,29}$ The $\mathrm{K}$ values were thus calculated by integrating the unflawed cylinder stresses at the crack-face location using geometry-dependent weight functions. A plastic correction ${ }^{30}$ was then applied to the stress-intensity factors according to

$$
K_{\text {eff }}=K \sqrt{1+r_{p} / a},
$$

where $r_{p}$ is the radius of plastic zone calculated as

$$
r_{p}=\frac{1}{6 \pi}\left(\frac{K}{\sigma_{y}}\right)^{2} .
$$

The corrected $\mathrm{K}_{\mathrm{I}}$ values were finally transformed to $\mathrm{J}$ using the formula

$$
J=\frac{K_{\text {eff }}^{2}\left(1-v^{2}\right)}{E}
$$

The fracture analysis methodologies employed in the estimation scheme applications listed in Table 3.2 were based primarily on the J-resistance curve approach, with the J parameter determined from a variety of published sources. Analyst 12 used $K_{1}$ solutions from Ref. 31, which were then modified using the Irwin plastic zone correction [Eq. (3.4)]. The modified $\mathrm{K}_{I}$ values were subsequently converted to equivalent J values using Eq. (3.5). The applied tearing modulus was calculated using the procedure given in Ref. 31 . Analyst 14 employed results from a statically indeterminate solution for a cylindrical shell to evaluate the J parameter by defining it as the sum of elastic and fully plastic components. The elastic and plastic solutions are taken from Refs. 32 and 33, respectively. Analyst 15 calculated stress-intensity factors based on superposition methods using analytical stress solutions for a cylinder subjected to PTS conditions. The influence coefficients for longitudinal continuous cracks (2-D) and longitudinal surface cracks (3-D) were taken from Refs. 34 and 35, respectively. Similarly, analyst 11 determined $\mathrm{K}_{\mathrm{I}}$ values from influence coefficients presented in Ref. 36 for a vessel having a wall thickness to inner radius $(t / R)$ ratio of 0.1 ; the corresponding ratio for the $S C$-II cylinder was $t / R=0.4$. Analyst 16 also used an analytic solution for the hoop stress distribution in a rotating cylinder ${ }^{15}$ to determine $J$ from the weight function method incorporated into the VTTSIF Program. ${ }^{27, *}$

Solutions in Table 3.2 provided by analyst 13 were based on option 1 of the R6 method described in Refs. 37 and 38. In the R6 methodology, a failure assessment diagram (FAD) is constructed that represents the failure locus of the structure. The two extremes of failure mechanisms for a cracked structure (i.e., brittle fracture and plastic collapse)

\footnotetext{
*T. P. J. Mikkola and H. Raiko, "Development of an Automated Fracture Assessment System for Nuclear Structures," paper submitted for publication in Pressure Versels and Piping.
} 
are represented in the diagram, along with an interpolating function that represents tie interaction between the two mechanisms. Integrity of the structure is then evaluated on the basis of whether the assessment points for a loading condition fall inside or outside the failure locus in the FAD.

\section{REFERENCES}

1. ADINA-A Finite Element Program for Automatic Dynamic Incremental'Nonlinear Analysis, Theory and Modeling Guide, Report ARD 87-8, ADINA R\&D, Inc., 1987.

2. J. Rastoin, A. Hoffmann, and R. Roche, "CASTEM: A System of Finite Element Computer Programs for Elastic and Inelastic Analysis of Mechanical Structures and Reactors," pp. 725-739 in Proceedings of the Conference on Structural Analysis, Design and Construction in Nuclear Power Plants, Porto Alegre, Brazil, April 18-20, 1978, Vol. 2.*

3. D. Esping and J. Bjorn, "ALIBABA Non-Linear Optimization Package," Comput. Struct. 24(2), 323-345 (1986). ${ }^{\dagger}$

4. BERSAFE (Berkeley Structural Analysis by Finite Elements), Finite Element News 3, 4-10 (June 1991). ${ }^{\dagger}$

5. MARC-ABB Computer Program, Proprietary Version of MARC-CDC Non-linear Finite Element Analysis Program Developed by MARC Analysis Research Corporation, Rev. 20, Windsor, Conn., 1990.

6. ABAQUS Theory Manual, Version 4-8, Hibbitt, Karlsson and Sorensen, Inc., Providence, R.I., 1989.

7. R. J. Dexter, User's Manual for VISCRK: A Finite Element Program for Dynamic Fracture in Viscoplastic Materials, Southwest Research Institute, San Antonio, Texas, 1988.

8. O. C. Zienkiewicz, The Finite Element Method, 3rd ed., McGraw-Hill Book Company (U.K.) Limited, Maidenhead, Berkshire, England, 1977.

9. K. J. Bathe, Finite Element Procedures in Engineering Analysis, Prentice-Hall, Inc., Englewood Cliffs, N.J., 1982.

10. D. R. J. Owen and E. Hinton, Finite Elements in Plasticity: Theory and Practice, Pineridge Press Limited, Swansea, U.K., 1980.

11. R. C. Young, Roark's Formulas for Stress and Strain, 6th ed., McGraw Hill, Inc., New York, 1989.

NUREG/CR-5997
12. R. C. Juvinall, Stress, Strain and Strength, 1st ed., McGraw Hill, Inc., New York, 1967.

13. H. H. Bedner, Pressure Component Construction, Van Nostrand, Reinhold and Co., New York, 1981.

14. A. Zahooi, Ductile Tearing Resistance of Flawed Pipes, Electric Power Research Institute Report No. TR-100374, 1992.

15. S. P. Timoshenko and J. N. Goodier, Theory of Elasticity, 3rd ed., McGraw Hill, Inc., New York, 1987.

16. J. W. Hutchinson, "Singular Behavior at the End of a Tensile Crack in a Hardening Material," J. Mech. Phys. Solids 16, 13-31 (1968). ${ }^{\dagger}$

17. J. R. Rice and G. F. Rosengren, "Plane Strain Deformation Near a Crack Tip in a Power-Law Hardening Material," J. Mech. Phys. Solids 16, 1-12 (1968). ${ }^{\dagger}$

18. M. F. Kanninen and C. H. Popelar, Advanced Fracture Mechanics, Oxford University Press, New York, 1985.

19. B. Moran and C. F. Shih, Office of Naval Research, "Crack Tip and Associated Domain Integrals from Momentum and Energy Balance," ONR0365/2, May 1986.

20. H. G. DeLorenzi, "Energy Release Rate Calculations by Finite Element Method," Engineering Fractional Mechanics 21(1), 129-143 (1985). ${ }^{\dagger}$

21. J. Jung and M. F. Kanninen, "An Analysis of Dynamic Crack Propagation and Arrest in a Nuclear Pressure Vessel Under Thermal Shock Conditions," Journal of Pressure Vessel Technology 105, 111-116 (May 1983). ${ }^{\dagger}$

22. H. G. DeLorenzi, "J-Integral and Crack Growth Calculations with ADINA," Electric Power Research Institute contract RP601-2 (1978).

23. J. Sievers, "Ductile Fracture Mechanical Analyses of Large-Scale Thermal Shock Experiments," Nucl. Eng. Des. 130, 13-20 (1991).

24. G. Rousselier et al., "A Methodology for Ductile Fracture Analysis Based on Damage Mechanics: An Illustration of a Local Approach of Fracture," pp. 332-354 in Nonlinear Fracture Mechanics, Voi. II-Elastic-Plastic Fraciure, ASTIM STP 995 , American Society Testing and Materials, Philadelphia, 1989. ${ }^{\dagger}$ 
25. J. R. Rice and D. M. Tracey, "On the Ductile Enlargement of Voids in Triaxial Stress Fields," $J$. Mech. Phys. Solids 17, 201-217 (1969). ${ }^{\dagger}$

26. M. Bethmont, G. Devesa, and G. Rousselier, "A Methodology for Ductile Fracture Analysis Based on Damage Mechanics: An Application of Local Approach to Fracture to the NKS-3 Thermal Shock Experiment," presented at 5th MPA Seminar, Stuttgart, October 5-6, 1988.

27. K. Kantola, Technical Research Centre of Finland, Helsinki, Nuclear Engineering Laboratory, "Calculation of Stress Intensity Factors Using the Influence Function Method," Research Notes YRT-2/86, p. 35 (in Finnish).

28. P. M. Besuner, "Influence Function Method for Fracture Mechanics and Residual Fatigue Life Analysis of Crack Components under Complex Stress Fields," Nucl. Eng. Des. 43, 115-154 (1977). ${ }^{\dagger}$

29. H. J. Petroski and J. D. Achenbach, " Computation of the Weight Function from a Stress Intensity Factor," Eng. Fract. Mech. 10, 257-266 (1978). ${ }^{\dagger}$

30. C. E. Turner, "Methods for Post-Yield Fracture Safety Assessment," Post Yield Fracture Mechanics, pp. 25-221, Elsevier Applied Science Publishers, 2nd ed. England, 1984.
31. A. Zahoor, Ductile Fracture Handbook, Vols. 2 and 3, EPRI NP-6301-D, Electric Power Research Institute, Palo Alto, Calif., 1990 and 1991.

32. H. Tada, P. C. Paris, and G. R. Irwin, The Stress Analysis of Cracks Handbook, Del Research Corporation, Hellertown, Pa., 1973.

33. C. F. Shih and A. Needleman, J. Appl. Mech. 51, 48-64 (1984). ${ }^{\dagger}$

34. Y. Murakami, Stress Intensity Factors Handbook, 1st ed., Pergamon Press, Oxford, 1987.

35. J. C. Newman and I. S. Raju, "Stress Intensity Factor Influence Coefficients for Internal and External Surface Cracks in Cylindrical Vessels," Pressure Vessels and Piping $58 .^{\dagger}$

36. C. B. Buchalet and W. H. Bamford, "Stress Intensity Factor Solutions for Continuous Surface Flaws in Reactor Pressure Vessels," pp. 385-402 in Mechanics of Crack Growth, ASTM STP 590, American Society for Testing and Materials, Philadelphia, $1979 .^{\dagger}$

37. I. Milne et al., "Assessment of the Integrity of Structures Containing Defects," The International Journal of Pressure Vessels and Piping 32, 3-104. ${ }^{\dagger}$

38. I. Milne et al., "Background to and Validation of CEGB Report R/H/R6-Revision 3," The International Journal of Pressure Vessels and Piping 32,105-196. ${ }^{\dagger}$

\footnotetext{
*Available for purchase from the National Technical Information Service Springfield, VA 22161.

${ }^{\dagger}$ Available in public technical libraries.
} 


\section{Comparative Assessments and Discussion of the Analysis Results}

In this chapter, the results of the finite-element (FE) and the estimation scheme (ES) analyses presented at the workshop in Boston in May 1990 are discussed. Note that most of the analyses were done in a short period of time and with limits on the use of computer time. Therefore, parametric studies could not be done, and in certain cases, the FE models are not as refined as desired. There are some restrictions concerning the input data to certain older FE program versions (e.g., option of multilinear approximation of stress-strain data) used in the round robin. For the different analyses, a set of quantities have been selected for comparison that approximate the structural behavior of the test specimens and the fracture behavior of the cracks. A data base of the results has been established, and the available plots are given in this chapter and in Appendix B. The following discussion concentrates on reasons for the discrepancies among the various analyses of the reference experiments.

\subsection{NKS-3}

Figures 4.1-4.3 show the time history of CMOD, axial strain at the inner surface $184 \mathrm{~mm}$ above the crack ligament (measurement positions DL 1/2, Fig. 2.3), and the J-integral. Analyses 1-7 used FE methods, and analyses 12 and 13 used ES methods. The difference between the results from FE methods are quite small. Table 4.1 summarizes some selected characteristics of the FE analyses. Because of restrictions of the FE-code versions, the approximations of the stress-strain data are different. Multilinear temperature-dependent approximations with plasticity above $\sigma_{y}$ are used in analysis 4 and above $\sigma_{0.2}$ in analysis 6 . The bilinear approximations in analyses 1 and 5 are very similar, as are the calculated results. The FE models differ in the number of degrees of freedom by a factor of 10 . This number ranges between 886 (analysis 5) and 8800 (analysis 7). Therefore, the results in this case do not depend very much on the model size. The J-integral results of the ES analyses are in the scatterband of the FE results. In Figs. 4.4-4.8, the von Mises effective stresses on the ligament of the crack are given for the times $0,1,5,10$, and $20 \mathrm{~min}$ after the start of the thermal-shock transient. The stress distribution is strongly dependent on the approximation of the stress-strain data. In analysis 2 , a very low yield stress results in lower stresses on the ligament during the transient. In Figs. 4.9-4.13, a parameter (q) characterizing the stress triaxiality (Sect. 3.2) in front of the crack tip has been evaluated over $\sim 15 \mathrm{~mm}$ of the ligament. The $q$ values shown in Figs. 4.9-4.13 are close to plane strain values. Thus, crack extension can be evaluated with crack resistance curves of CT-25 specimens, giving values of -3 to $4.8 \mathrm{~mm}$ (average measured: $3.6 \mathrm{~mm}$, i.e., $-6 \%$ of the initial crack depth) because of the scatterband of the analyses results. The uncertainty of the calculated crack extension is $-3 \%$ of the initial crack depth. Therefore, these analysis results show a scatterband that is acceptable in comparison with the experimental data. The necessary material properties to calculate the structure mechanics behavior were available. The $J_{R}$ methodology based on small specimens gives suitable results for the analyses.

\subsection{NKS-4}

In this chapter, the analyses of the first transient in NKS-4 are discussed. Comparisons of CMOD, axial strain at measurement position DL 1/2 (Fig. 2.14), and the J-integral at the center of the partially circumferential crack vs time are shown in Figs. 4.14-4.16. Selected characteristics of the FE analyses are summarized in Table 4.2. Analysis 1 fits the experimental data best. Analysis 2 used a temperature-independent stress-strain curve with a very low yield stress and a higher thermal expansion coefficient that produces higher CMOD. The J values of small evaluation regions show $\sim 30 \%$ lower values than presented in Fig. 4.16 (very recent results). Analysis 3 is characterized by an artificially high yield stress and a reference temperature of $20^{\circ} \mathrm{C}$, contrary to the other analyses; but most important are the differences in the deformation boundary conditions on the ends of the cylinder. Missing rotational restraints in analysis 3 are responsible for the significantly higher J-integral values. Analysis 7 is an axisymmetric solution of the 3-D problem with an approximation of the partially circumferential crack by a $360^{\circ}$ fully circumferential crack. Therefore, the results overestimate the measured data. The J-integral results of ES analyses 12 and 13 are $i_{i}$ the scatterband of the 3-D FE results. Figures 4.17-4.20 show effective stresses on the ligament, and Figs. 4.21-4.24 show stress triaxiality values in front of the deepest point of the crack that are close to plan: strain values. Therefore, the behavior of the crack center can bu assessed by CT- $25 J_{R}$ curves. The crack extension calculated from an isothermal $J_{R}$ curve ( $\mathrm{T}=240^{\circ} \mathrm{C}$; see Fig. 2.17) ranges from 2 to $3.2 \mathrm{~mm}$ (measured: $1.5 \mathrm{~mm}$, i.e., $5 \%$ of the initial crack depth). The influence of thermal gradients on crack resistance is not known. In Ref. 2 of Chap. 2, it is shown that in front of the crack tip near the surface with nearly plane stress conditions (i.e., $q \approx 2$ ), the crack resistance can be described by a CT specimen with reduced thickness.

In conclusion, the results show that with the available material properties, the structure and fracture mechanics behavior of this 3-D problem were analyzed quite well. The scatter of the results is quite large, but the main reasons could be identified. Crack-extension assessments based on $\mathrm{J}_{\mathrm{R}}$ methodology at the center of the crack 


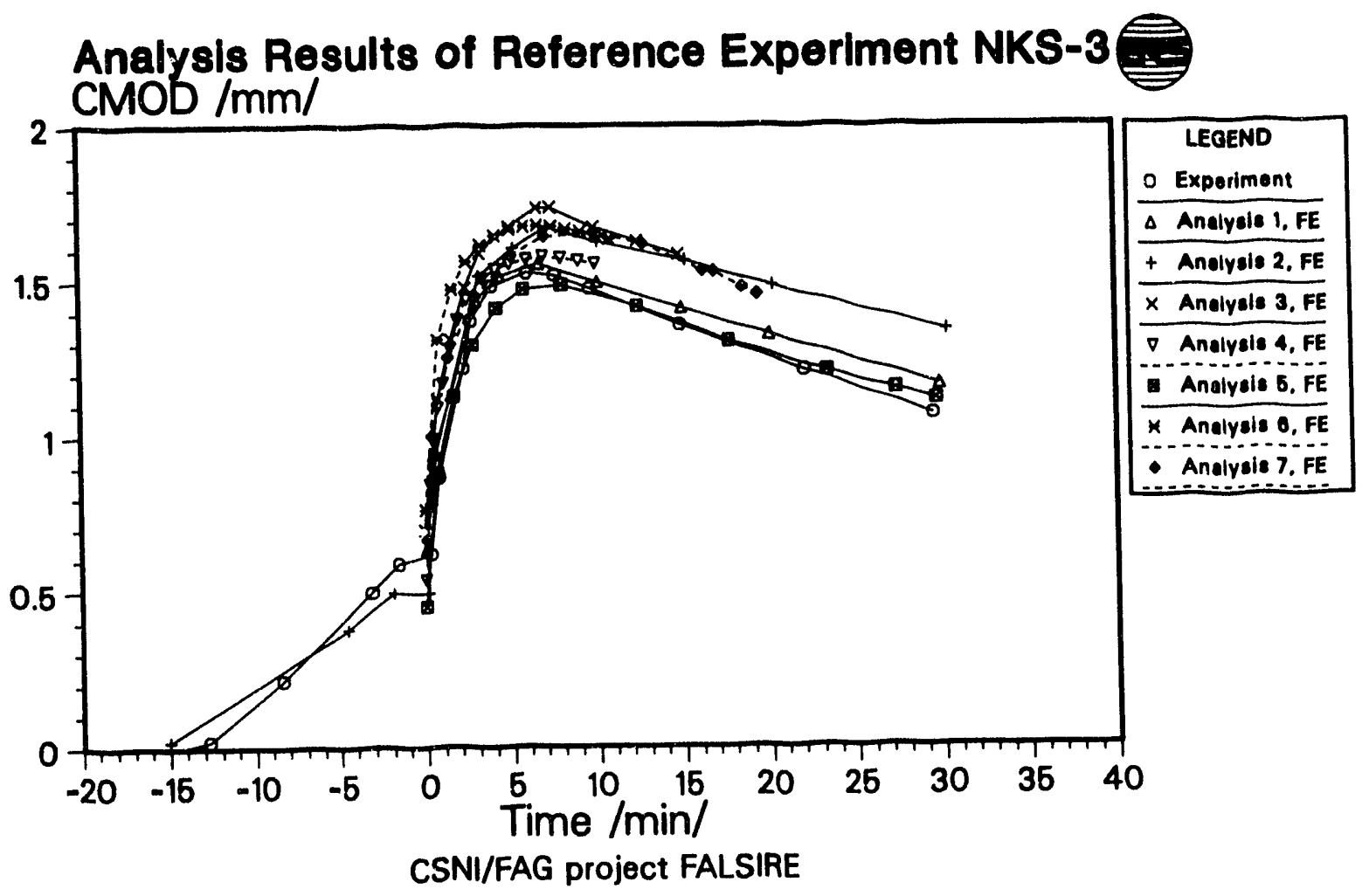

Fig. 4.1. CMOD vs time for NKS-3 experiment.

ORNL-DWG 93-2282 ETD

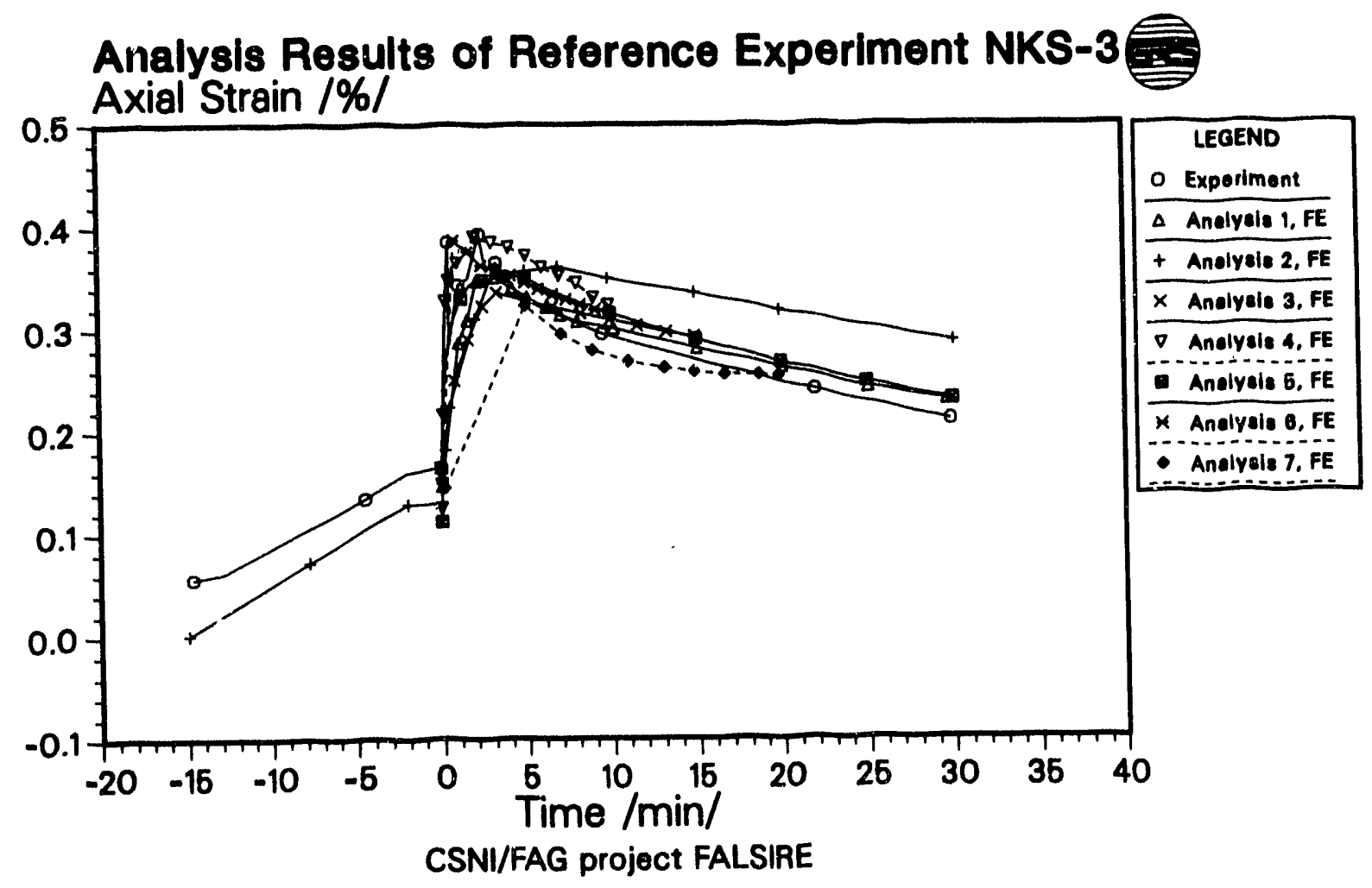

Fig. 4.2. Axial strains at inner surface $18 \overline{8} 4 \mathrm{~mm}$ above crack ligâmeñt vs time for NKS-3 experiment. 


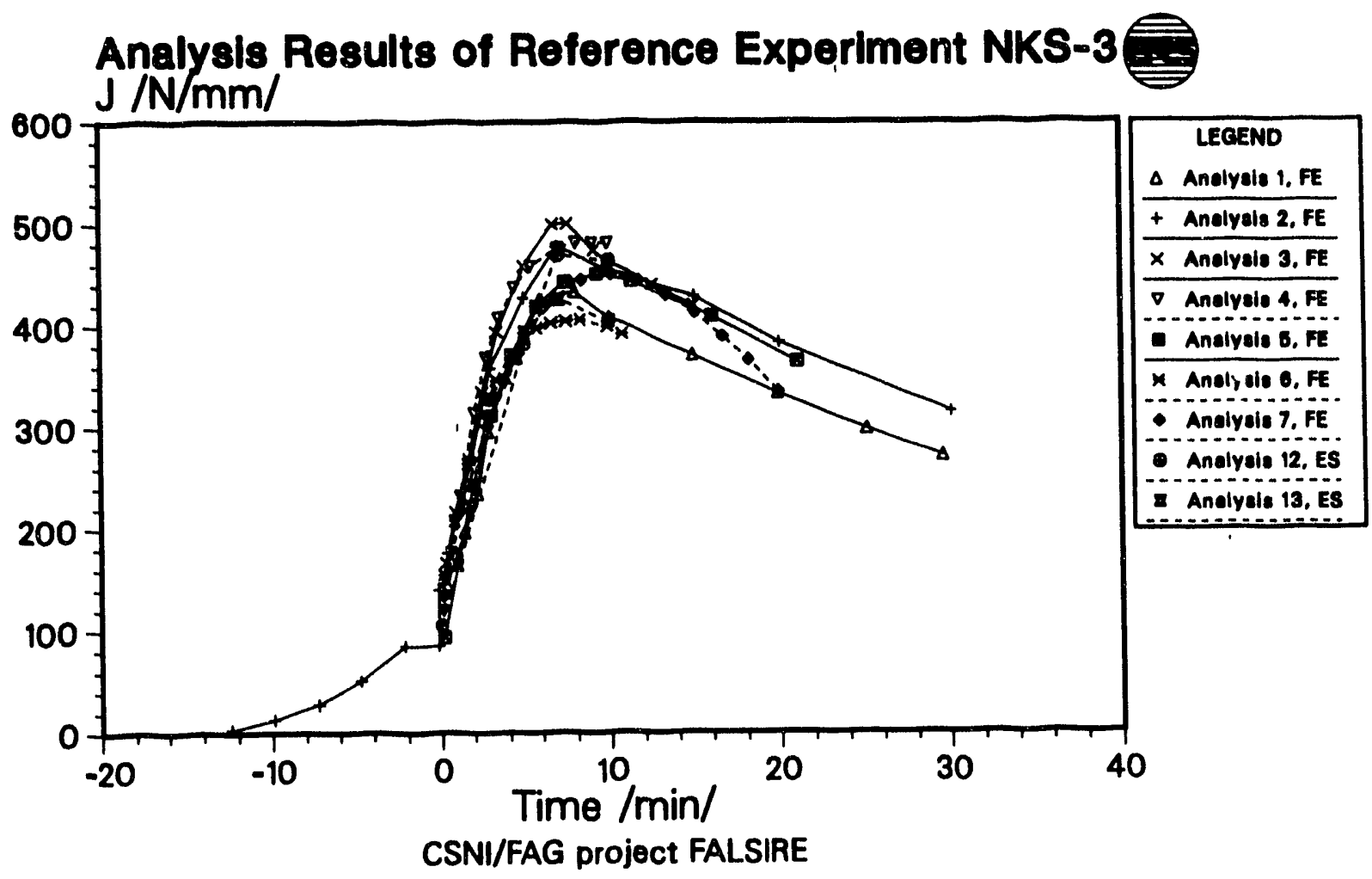

Fig, 4 2. J-integral vs time for NKS-3 experiment.

overestimate the measured value. Consideration of stress triaxiality on the ligament provides an explanation for the crack behavior, especially at the surface.

\subsection{PTSE-2A}

The time histories of CMOD and the J-integral are presented in Figs. 4.25-4.26, and selected characteristics are summarized in Table 4.3. The comparisons in Fig. 4.25 show that all analyses underestimate the experimental results of CMOD. Note that the lack of temperaturedependent data concerning the stress-strain curve and the thermal expansion coefficient $(\alpha)$, as well as the use of an $\alpha$-value based on a reference temperature of $20^{\circ} \mathrm{C}$, could be important factors in this underestimation of CMOD. Also, recent evaluations of the PTSE-2 data indicate that the measured CMOD values show a strong dependence on axial position in the vessel.

The FE results are strongly dependent on the approximation of the stress-strain data, the effect of whether crack extension has been considered, and the coefficient of thermal expansion. Anaiysis 10 has $\sim 30 \%$ luwer CMOD at $t=185 \mathrm{~s}$ thañ anialysis 5 and $-40 \%$ higher $\mathrm{J}$-value. The reason is the different hilincar approximiltion of the stress-strain data. The measured onset of yield is very low $(70 \mathrm{MPa})$ compared with the engineering yield stress (255 MPa) quoted for the vessel insert. The value used in the calculations ranges from 200 to $495 \mathrm{MPa}$, dependent on whether the small strain or the larger strain region of the stress-strain curve is approximated well.

Furthermore, an increase of $50 \%$ in $\sigma_{0.2}$ was measured for the vessel insert after transients A and B. The artificially high yield stress used in analysis 10 results in higher stresses on the ligament (Figs. 4.27-4.30, especially Fig. 4.30), with a smaller plastic zone and, therefore, smaller CMOD but higher J-integral. In analysis $5^{\prime}$, the final crack length after the first period of stable crack extension $(5.1 \mathrm{~mm}$ after $185 \mathrm{~s})$ was used, which produces an increase of CMOD at $t=185 \mathrm{~s}$ of $\sim 30 \%$ compared with analysis 5. Based on the experiences with other calculdtions, a $20 \%$ higher coefficient of thermal expansion was used to demonstrate the effect of a change in reference temperature from room temperature to $300^{\circ} \mathrm{C}$. This change produces a CMOD increase of $13 \%$. The change in the approximation of the stress-strain data (pretest set 5 ) by a multilinear curve causes a CMOD decrease of $\sim 13 \%$. Perhaps because of uncertainties concerning the loading assumptions as indicated by the axial dependence of CMOD, a $17 \%$ underestimation of the measured CMOD remains all 18.5 s. The sciallerhand of the results is also 


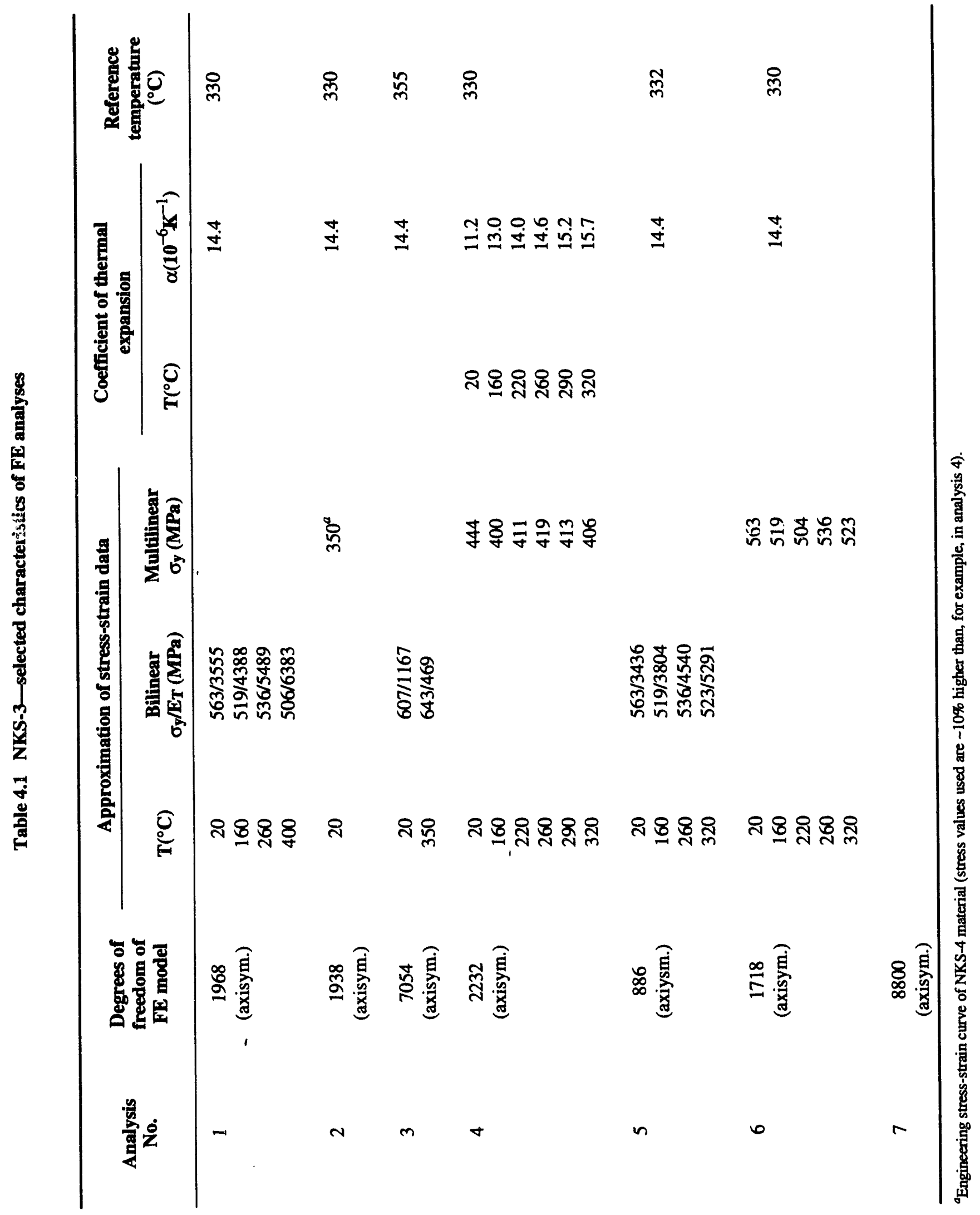




\section{Analysis Results of Reference Experiment NKS-3}

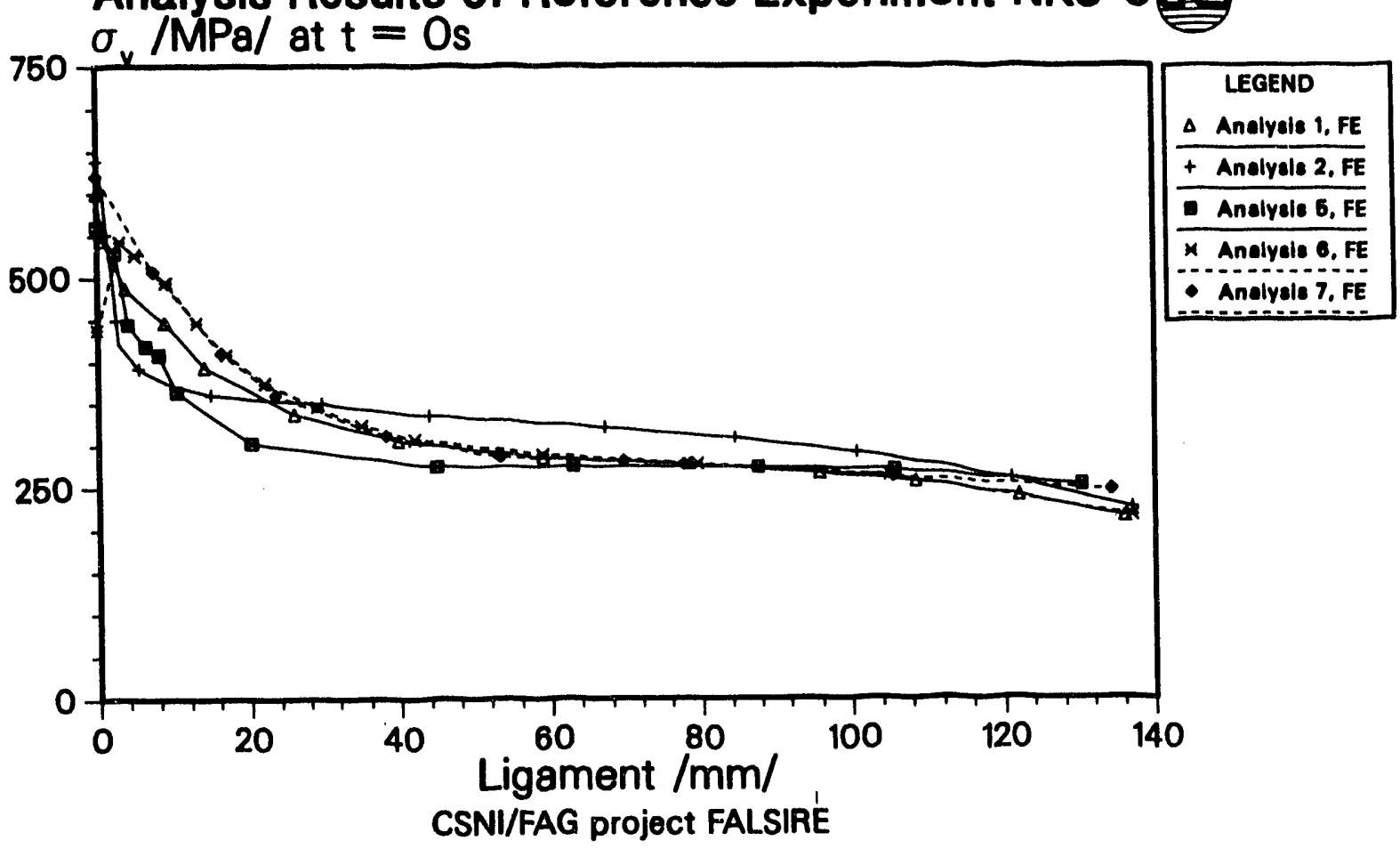

Fig. 4.4. Effective stresses on ligament $t=0 \mathrm{~s}$ (NKS-3 experiment).

ORNL-DWG 93.2285 ETD

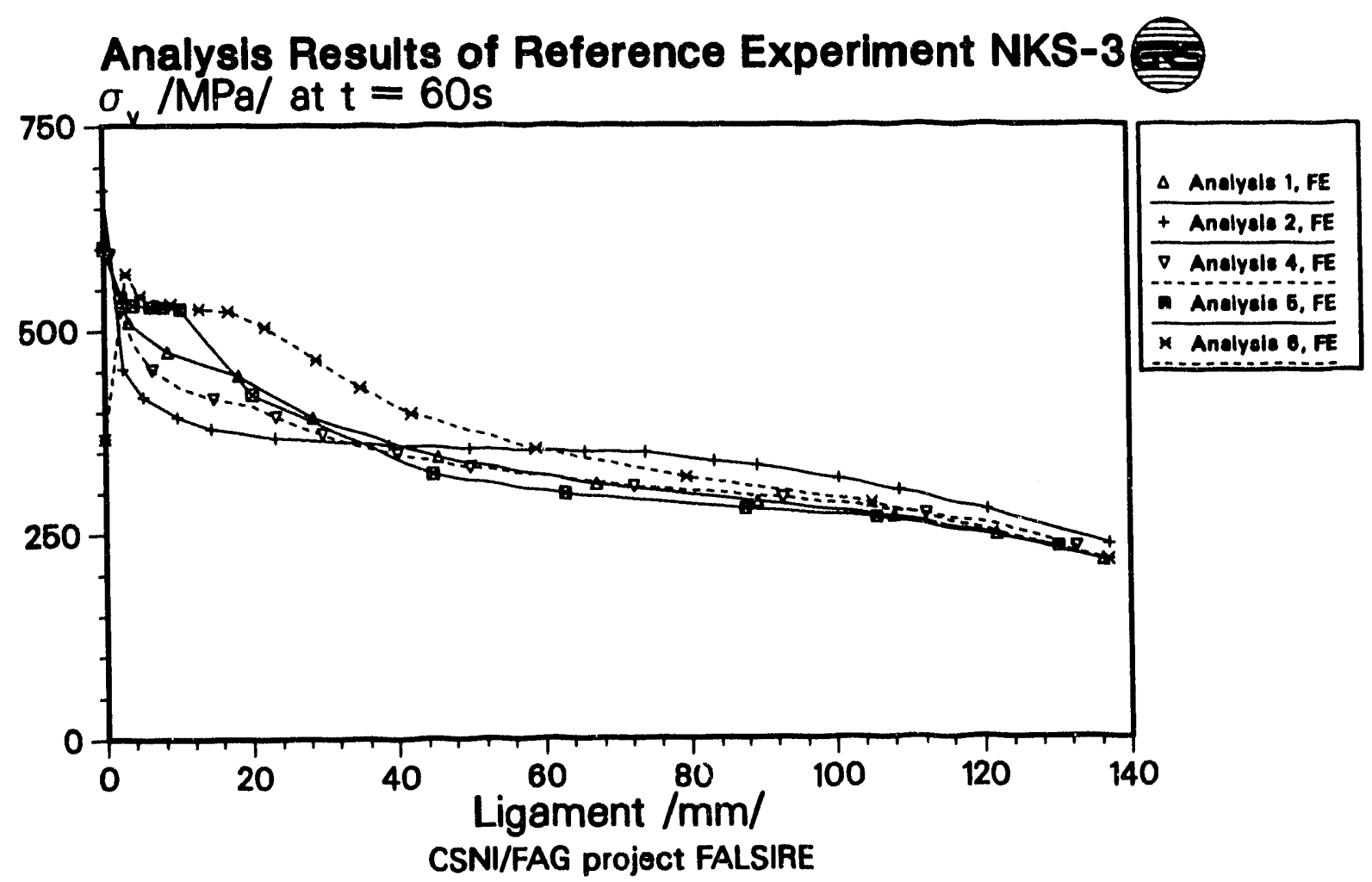

Fig. 4.5. Effective stresses on ligament $t=60 \mathrm{~s}$ (NKS-3 experiment). 


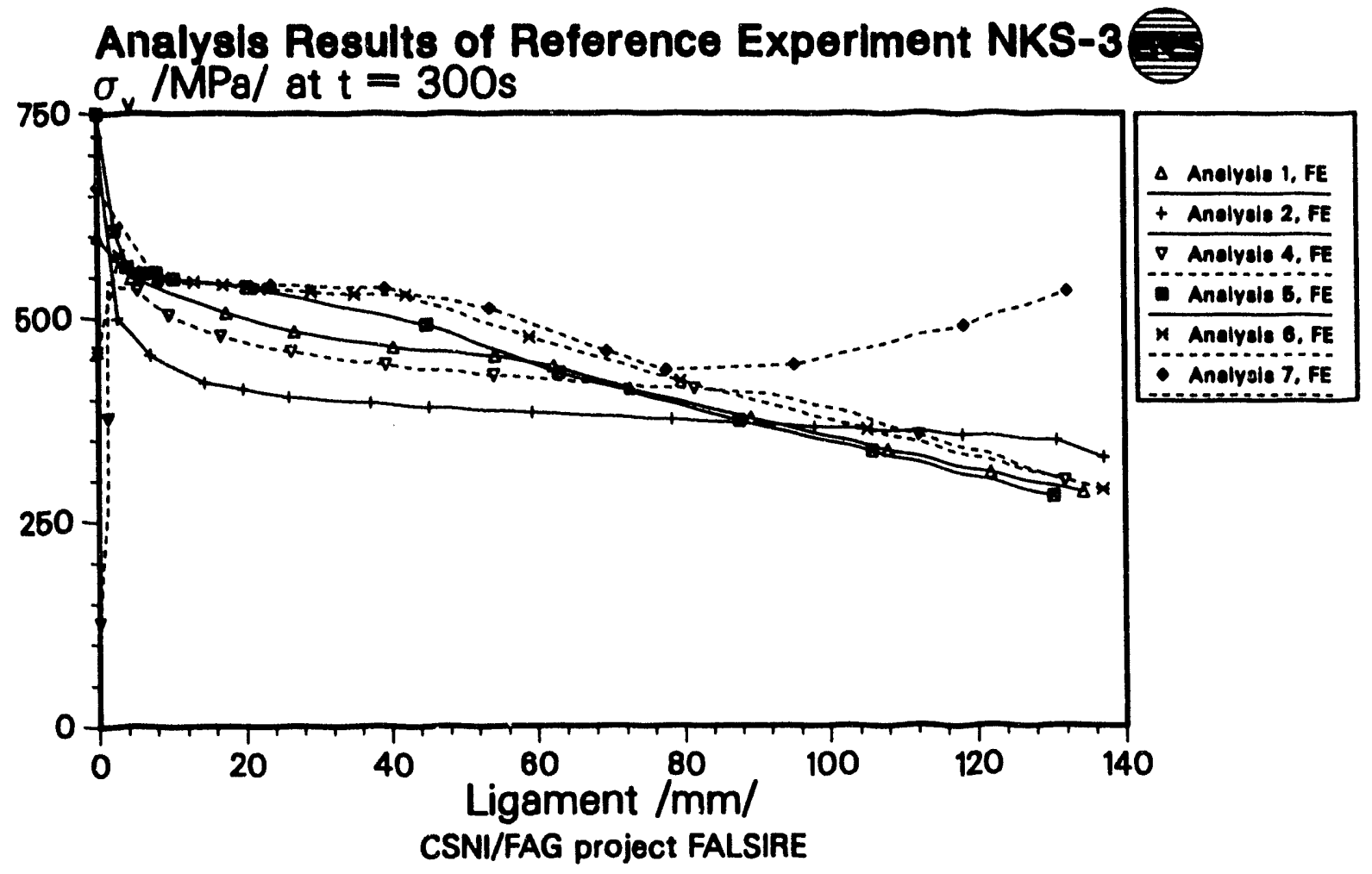

Fig. 4.6. Effective stresses on ligament $t=300 \mathrm{~s}$ (NKS-3 experiment).

ORNL-DWG 93-2287 ETD

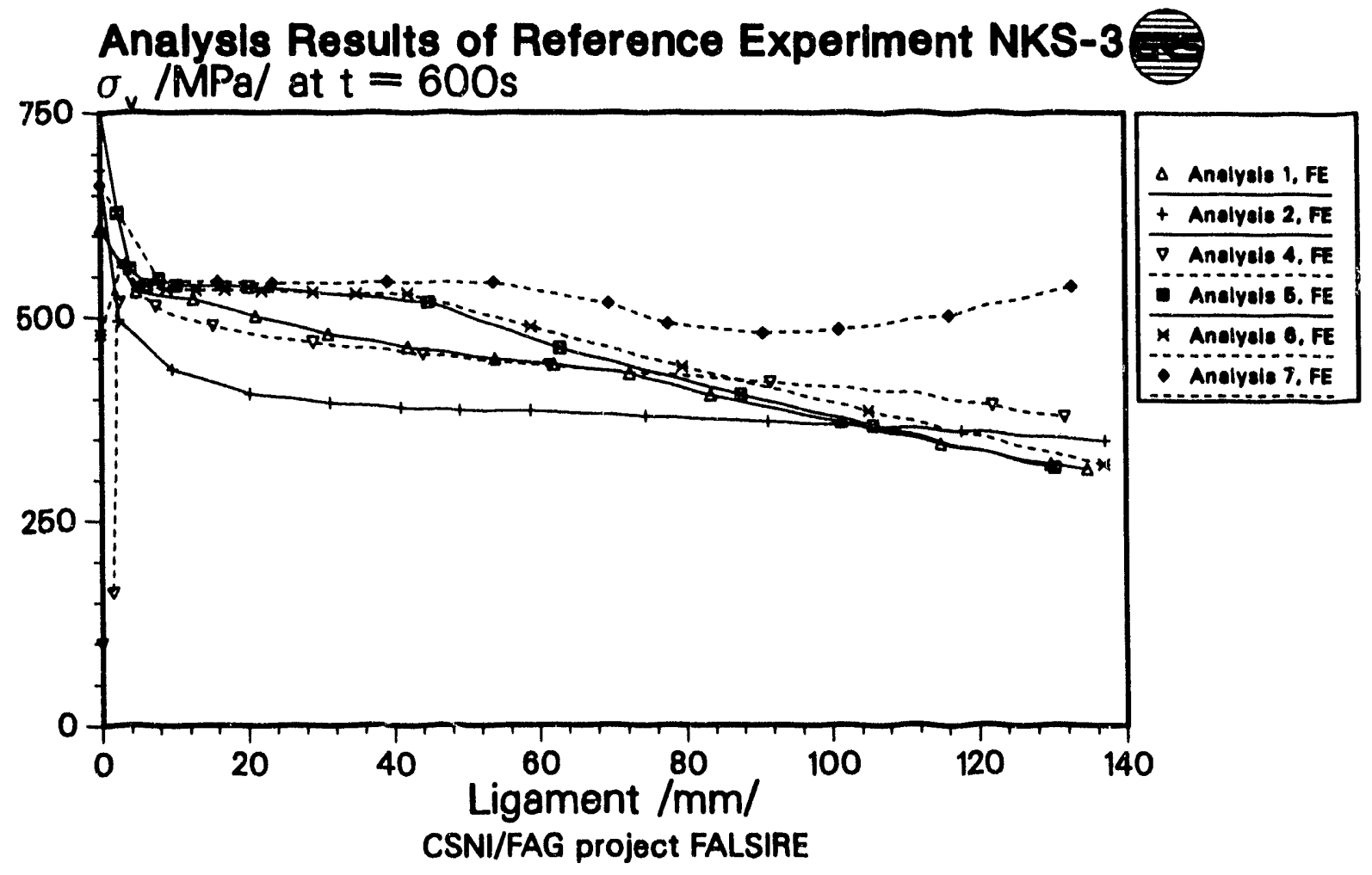

Fig. 4.7. Effective stresses on ligament $t=600 \mathrm{~s}$ (NKS-3 experiment). 


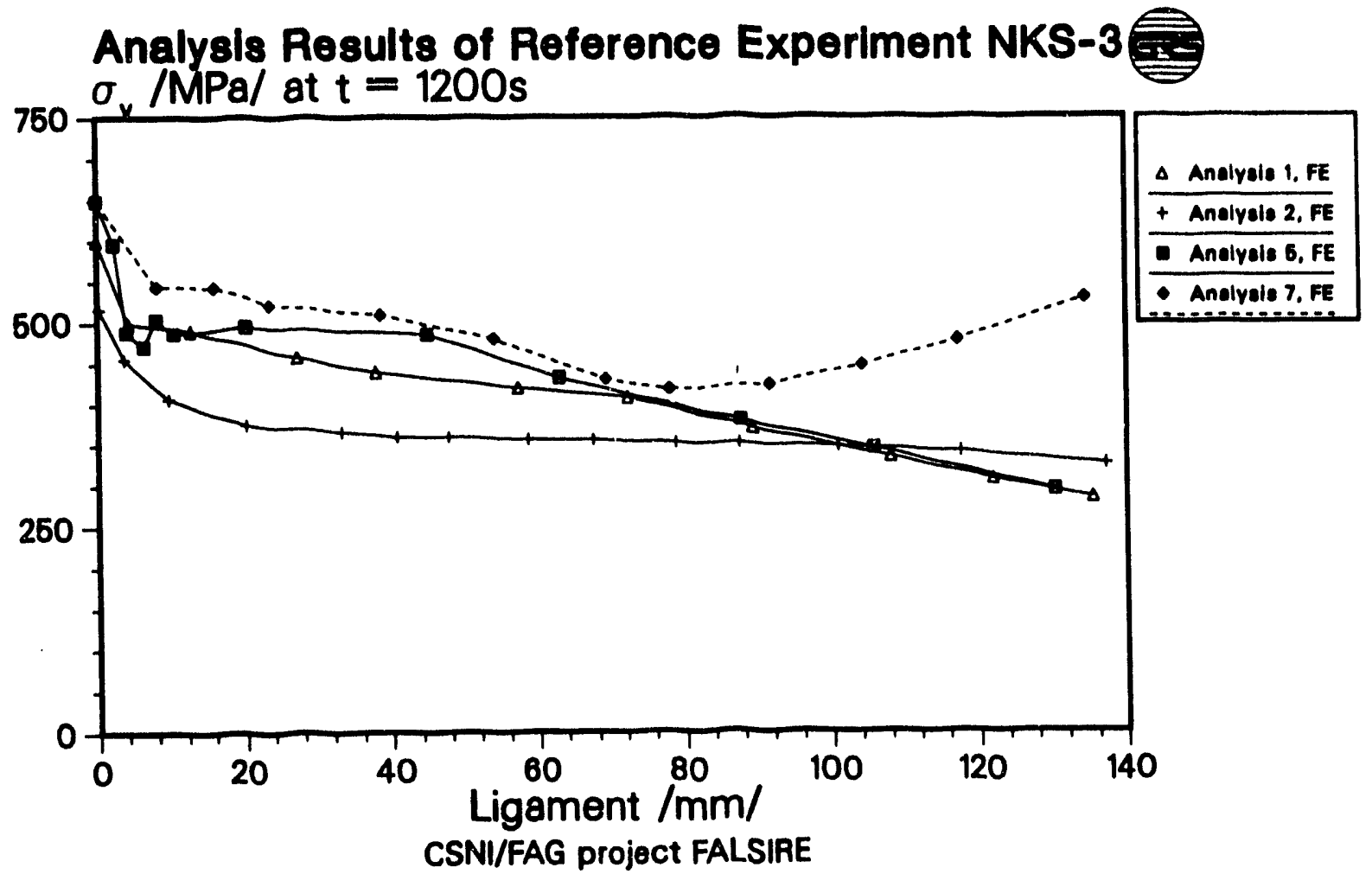

Fig. 4.8. Effective stresses on ligament $t=1200 \mathrm{~s}$ (NKS-3 experiment).

ORNL.DWG 93-2289 ETD

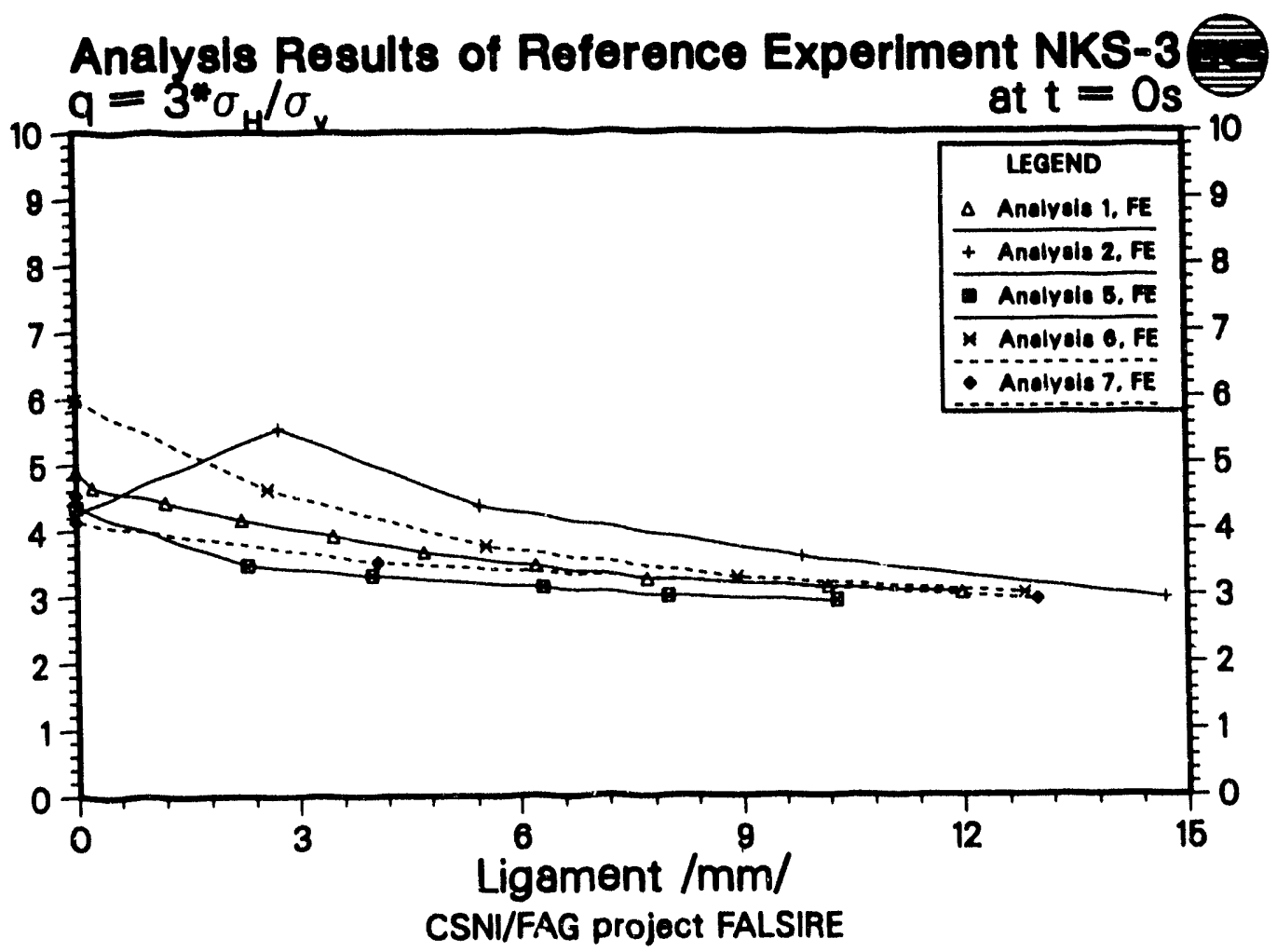

Fig. 4.9. Stress triaxiality on ligament $t=0 \mathrm{~s}$ (NKS-3 experiment). 


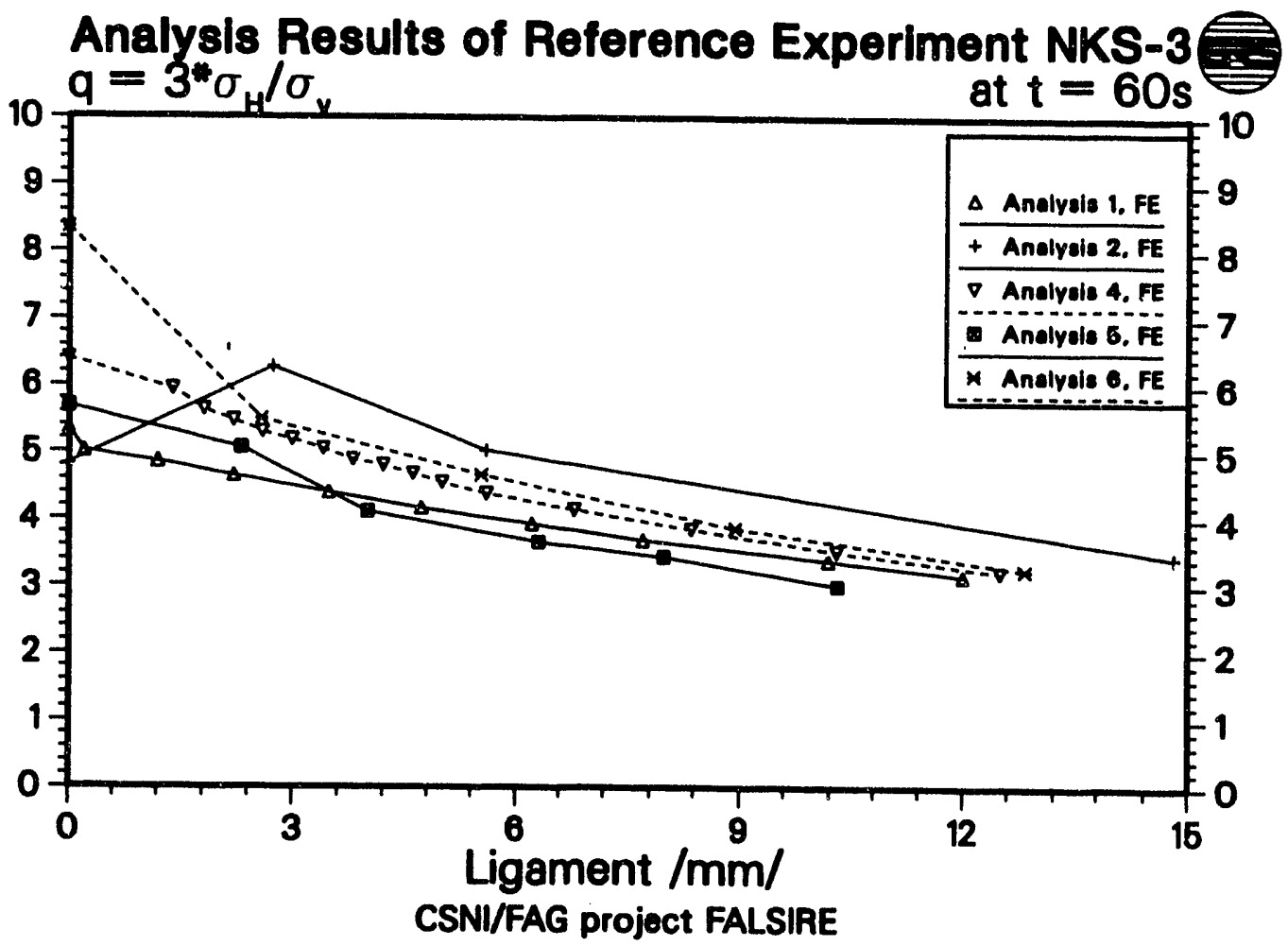

Fig. 4.10. Stress triaxiality on ligament $t=69 \mathrm{~s}$ (NKS-3 experiment).

ORNL-DWG 93-2291 ETD

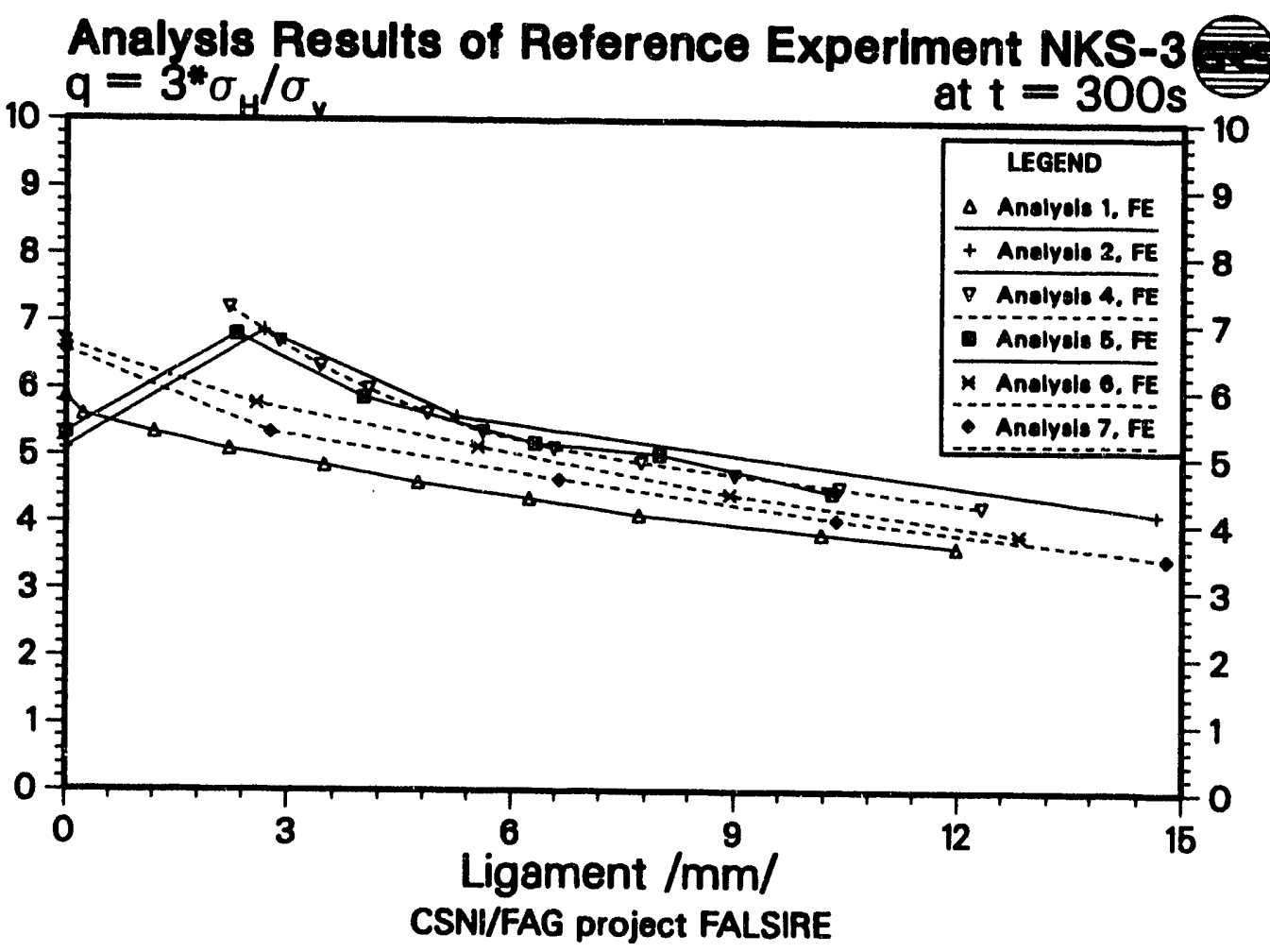

Fig. 4.11. Stress triaxiality on ligament $t=300 \mathrm{~s}$ (NKS-3 experiment). 


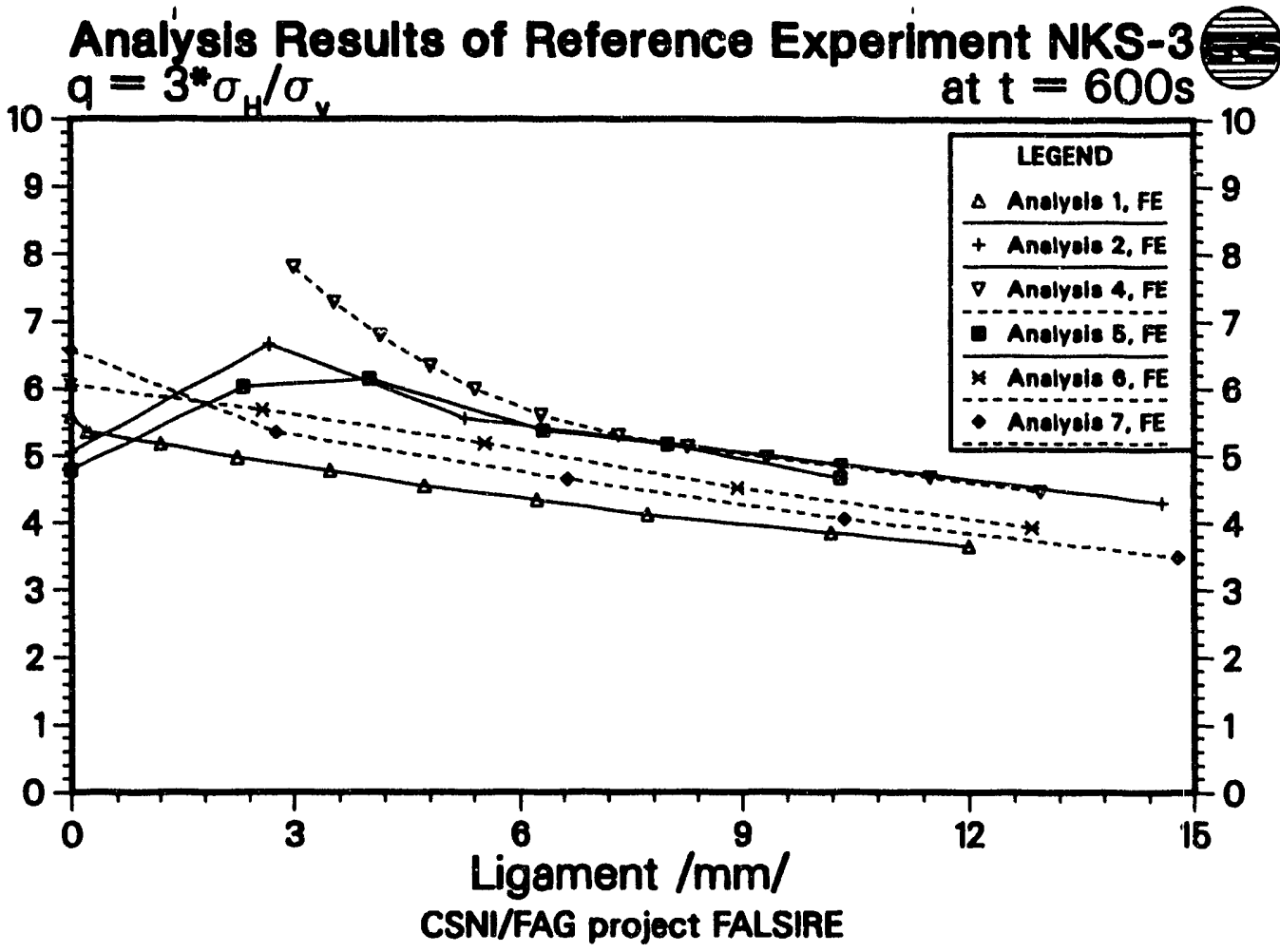

Fig. 4.12. Stress triaxiality on ligament $t=600 \mathrm{~s}$ (NKS-3 experiment).

ORNL-DWG 93-2293 ETD

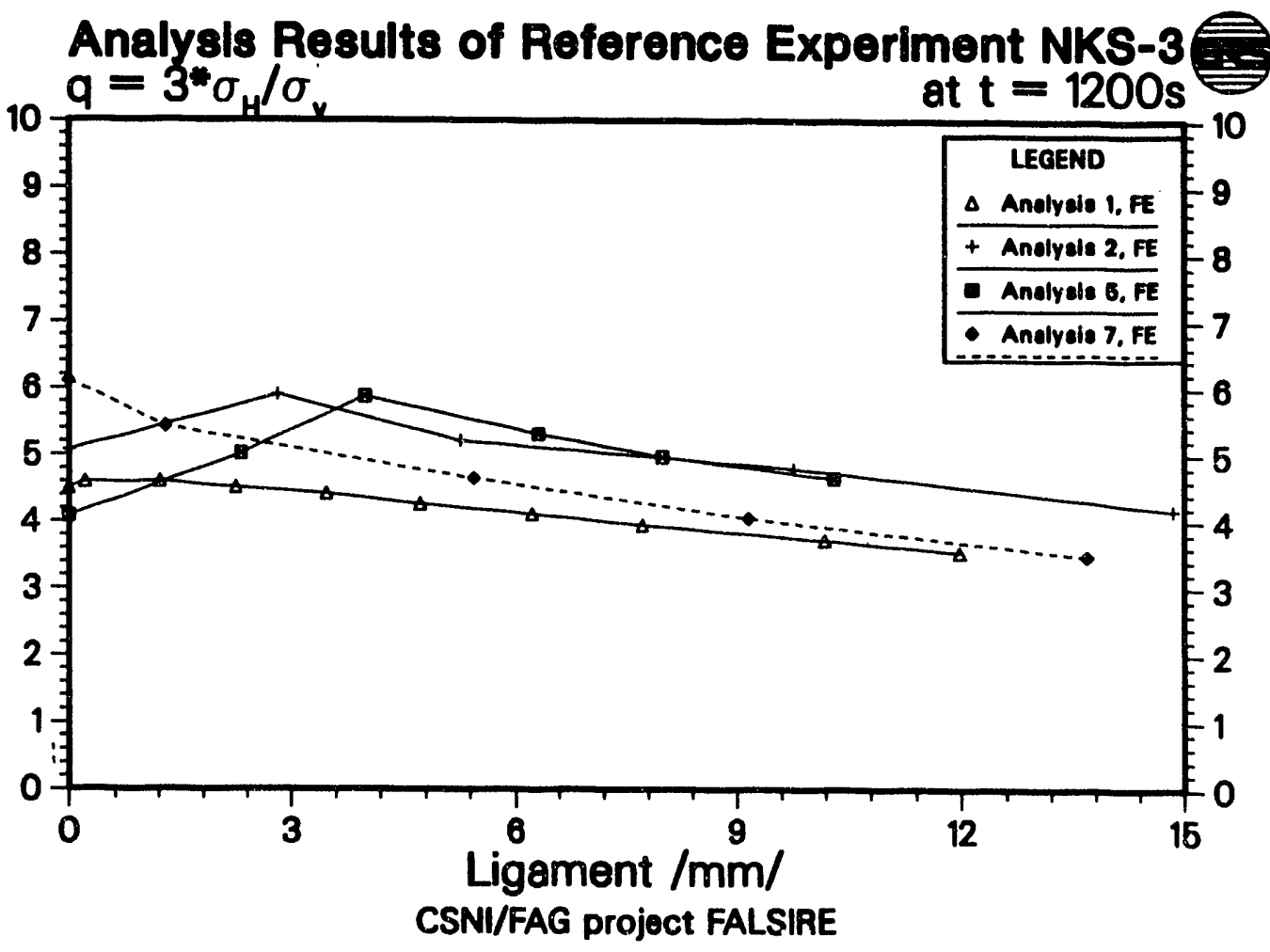

Fig. 4.13. Stress triaxiality on ligament $t=1200 \mathrm{~s}$ (NKS-3 experiment). 


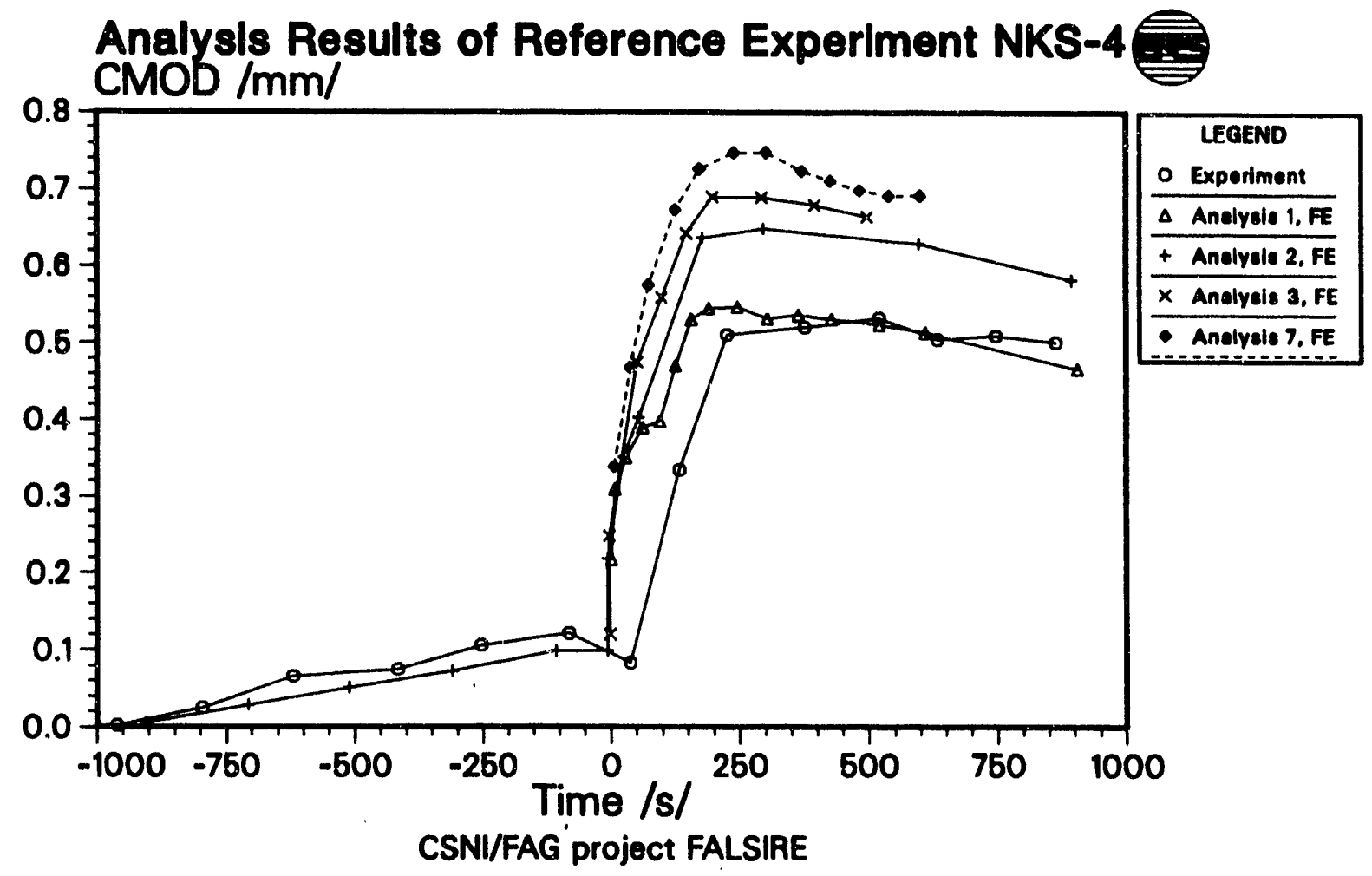

Fig. 4.14. CMOD vs time for NKS-4 experiment.

ORNL-DWG 93-2295 ETD

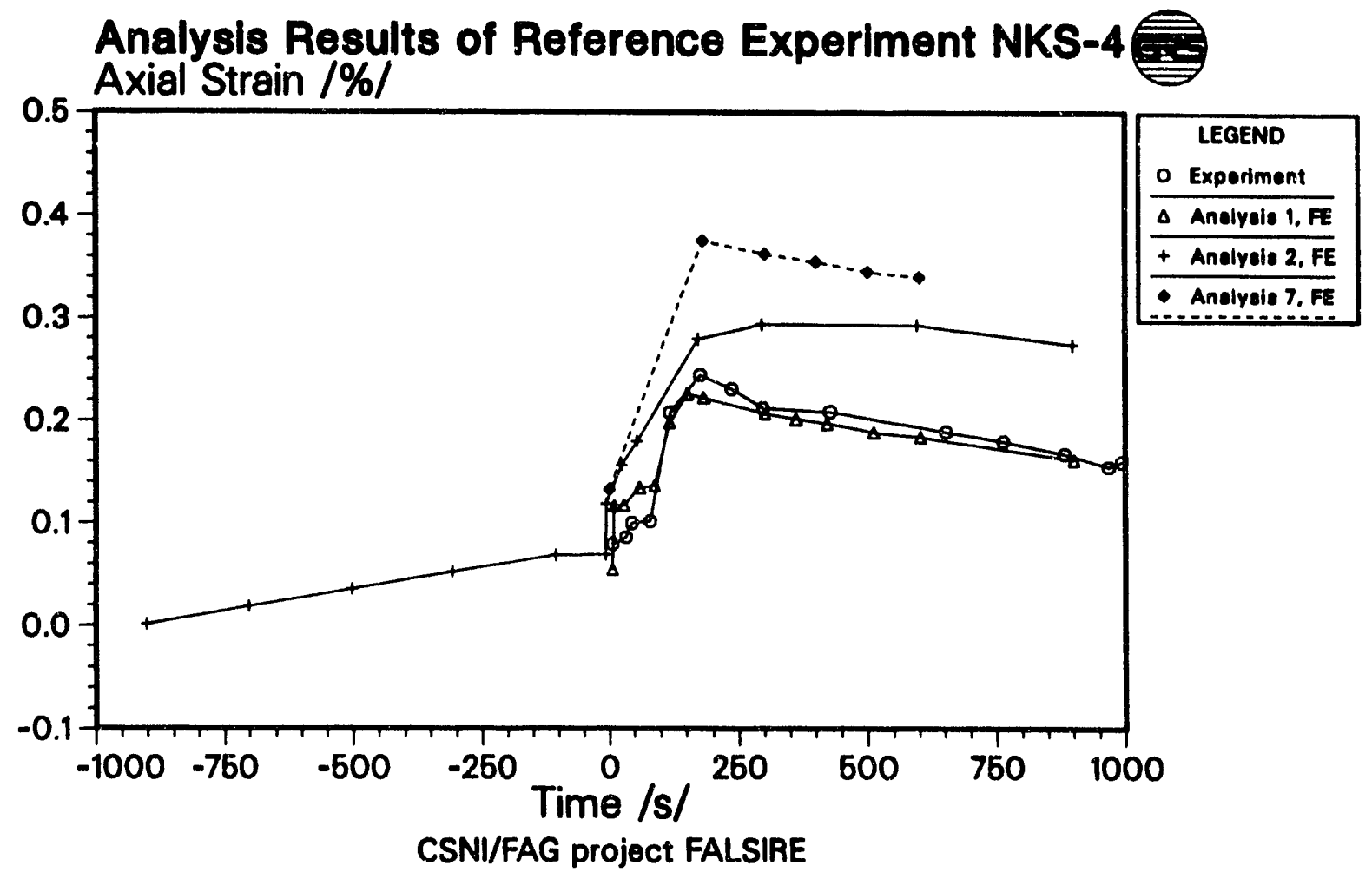

Fig. 4.15. Axial strains at inner surface $184 \mathrm{~mm}$ above crack ligament vs time for the NKS-4 experiment. 


\section{Analysis Results of Reference Experiment NKS-4}

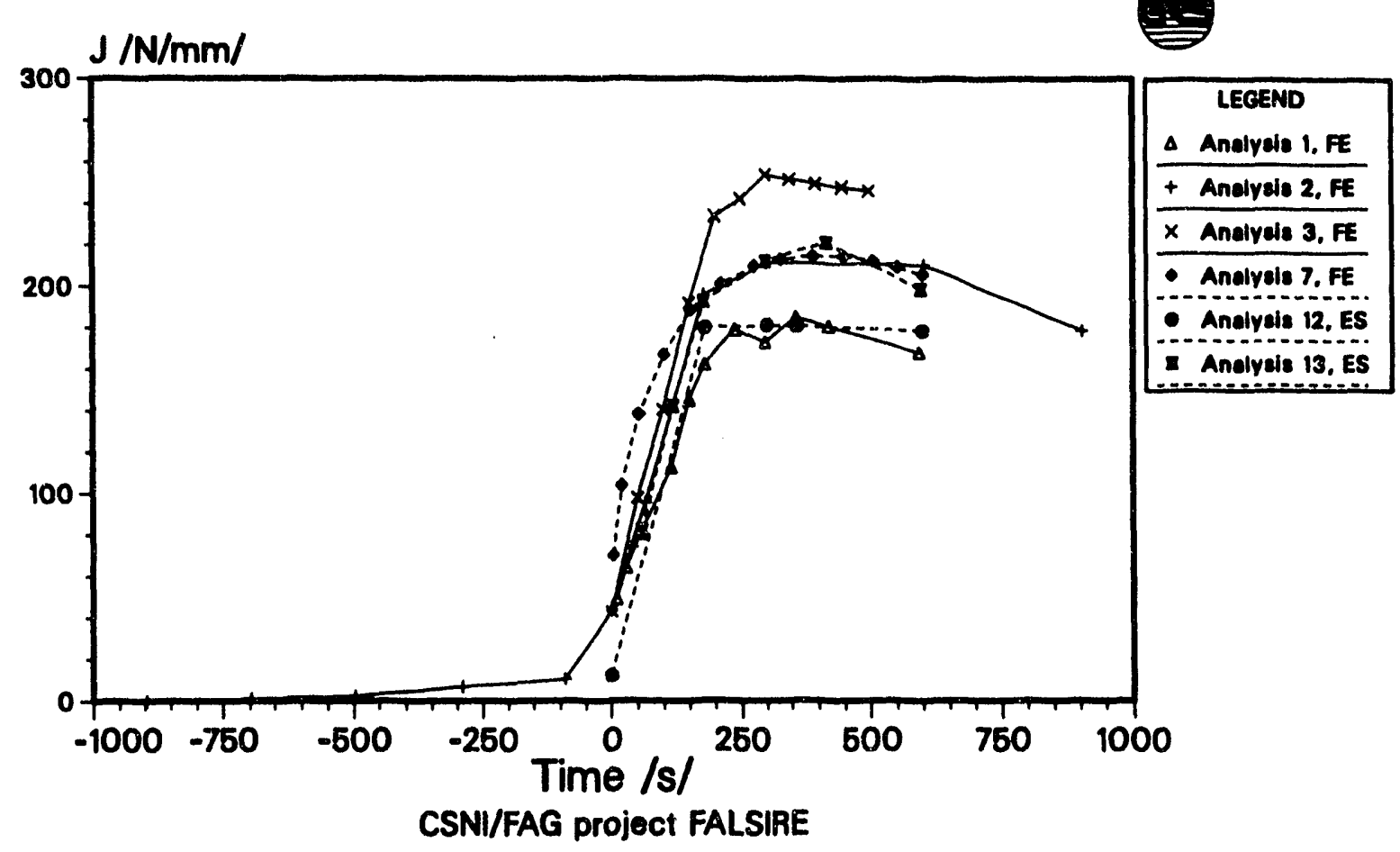

Fig. 4.16. J-integral vs time for the NKS-4 experiment.

enlarged because different assumptions concerning the crack depth have been chosen (initial depth or depth after first phase of stable crack extension).

Analysis 8 simulated the measured crack extension, but the higher yield stress makes the model more stiff, which results in lower CMOD values. ES analyses 15 and 15' used influence coefficients based on infinitely long cracks and on finite-length 3-D cracks, respectively. Therefore, when the fracture assessment is done excluding analysis 15 (because the latter assumes infinite crack length) and analyses $5^{\prime}$ and 8 (because the latter already took crack extension into account), a crack extension estimate of 1 to $2.5 \mathrm{~mm}$ (measured $5.1 \mathrm{~mm}$ ) is obtained from isothermal CT-25 specimen $J_{R}$ curves (Fig. 2.29). The underestimation of crack loading and crack extension has to be considered in connection with the underestimation of CMOD; that is, without good structural mechanics simulations, a good fracture mechanics approximation cannot be achieved. The temperature dependence of $J_{R}$ is strong, and it is not known what the effect of temperature gradient in the test cylinder is on the crack resistance.

Oscillations of $q$ (Figs. 4.31-4.34) in front of the crack tip (e.g., analysis 5) can be reduced by a finer mesh on the ligament (e.g., analyses 7,9, and 10). The necessary material properties, especially the temperature dependence, were not available totally. Therefore, reasons for the large difference between results of the analyses and the experiment could be provided only partly. However, some parameters that show significant influence on the analysis results have been identified.

\subsection{PTSE-2B}

Figures 4.35 and 4.36 show the time dependence of CMOD and the J-integral, and Table 4.4 shows selected characteristics of the FE analyses. The FE analyses underestimate CMOD (as in PTSE-2A), which may be because of the same reasons just discussed [e.g., lack of temperature-dependent material data for $\sigma(\varepsilon)$ and $\alpha$ ]. Differences in the stress behavior on the ligament, especially at the beginning of the transient (Figs. 4.37-4.39), are caused by the inclusion of residual stresses from transient $A$ in analyses 5 and 8 but not in analysis 7 . Furthermore, different material property sets were used, set 7 in analysis 5 and set 5 in analysis 7 (Fig. 2.27). These assumptions lead to differences in CMOD and J-integral values.

Negative J values are calculated at the beginning of the transient in analyses 5 and 8 because of the compressive residual stresses in front of the crack tip caused by transient $A$. The hoop stresses of analyses 12 and 15 (see 


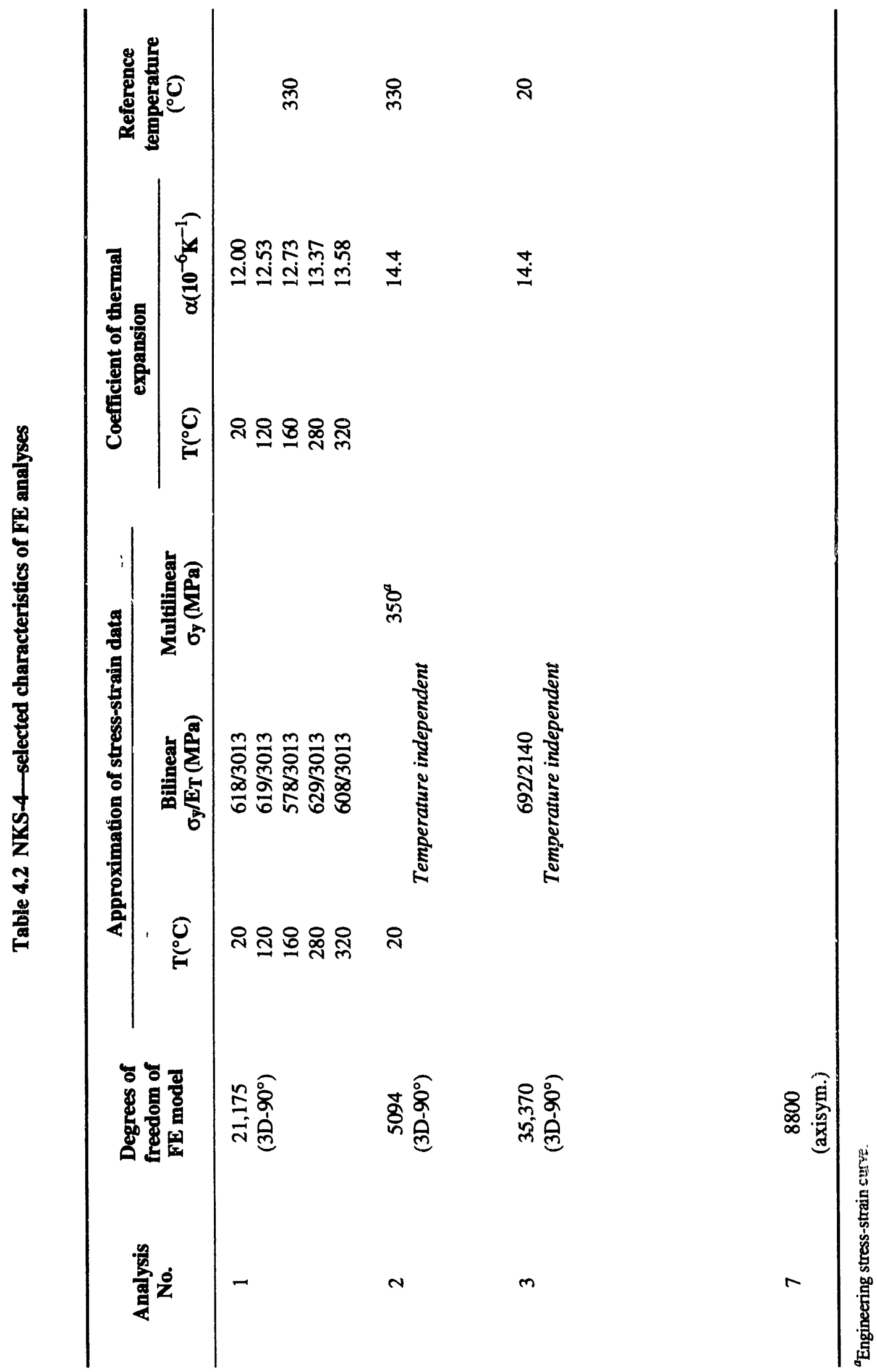


ORNL-DWG 93-2297 ETD

\section{Analysis Results of Reference Experiment NKS-4}

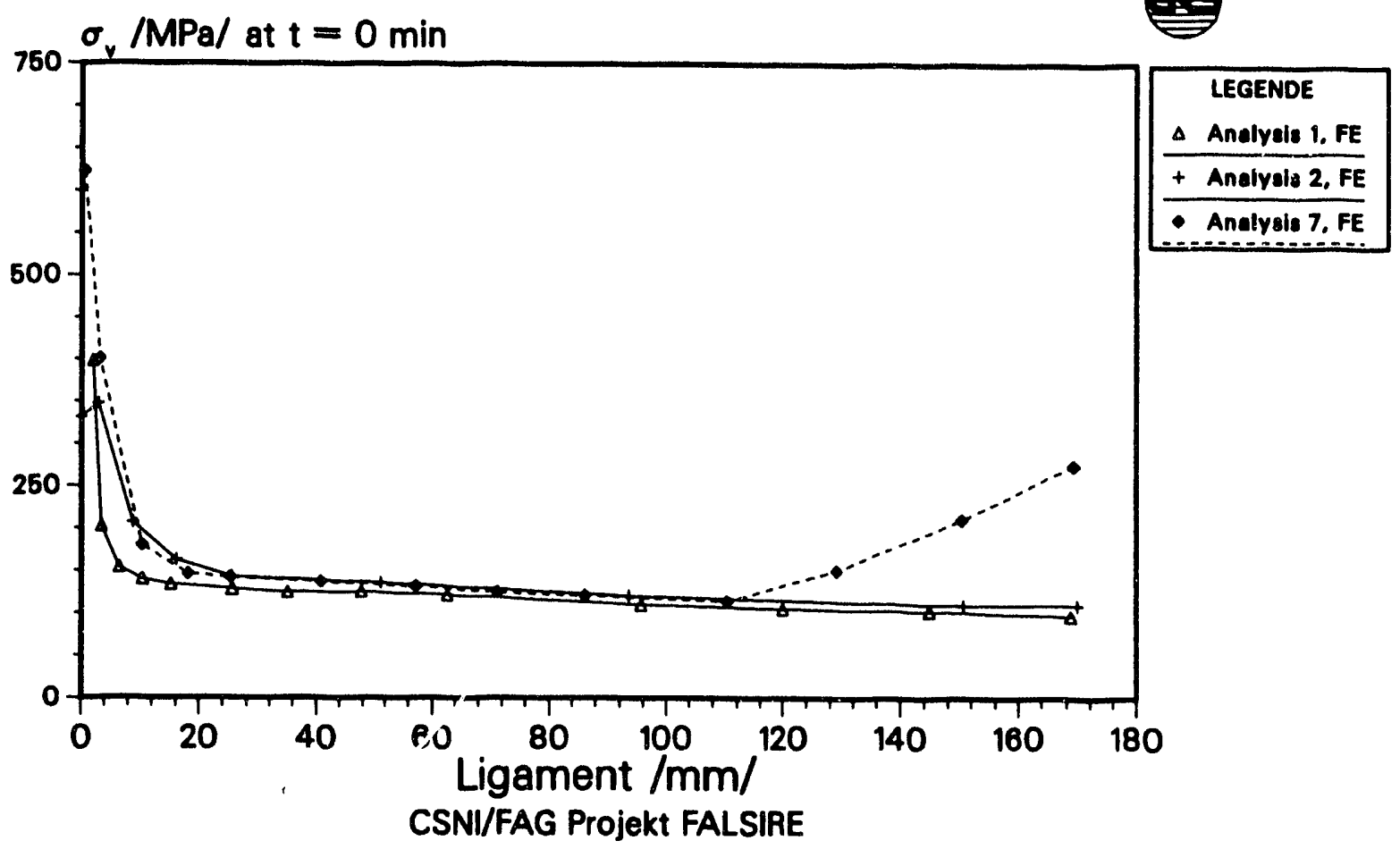

Fig. 4.17. Effective stresses on ligament $t=0$ min (NKS-4 experiment).

\section{Analysis Results of Reference Experiment NKS-4}

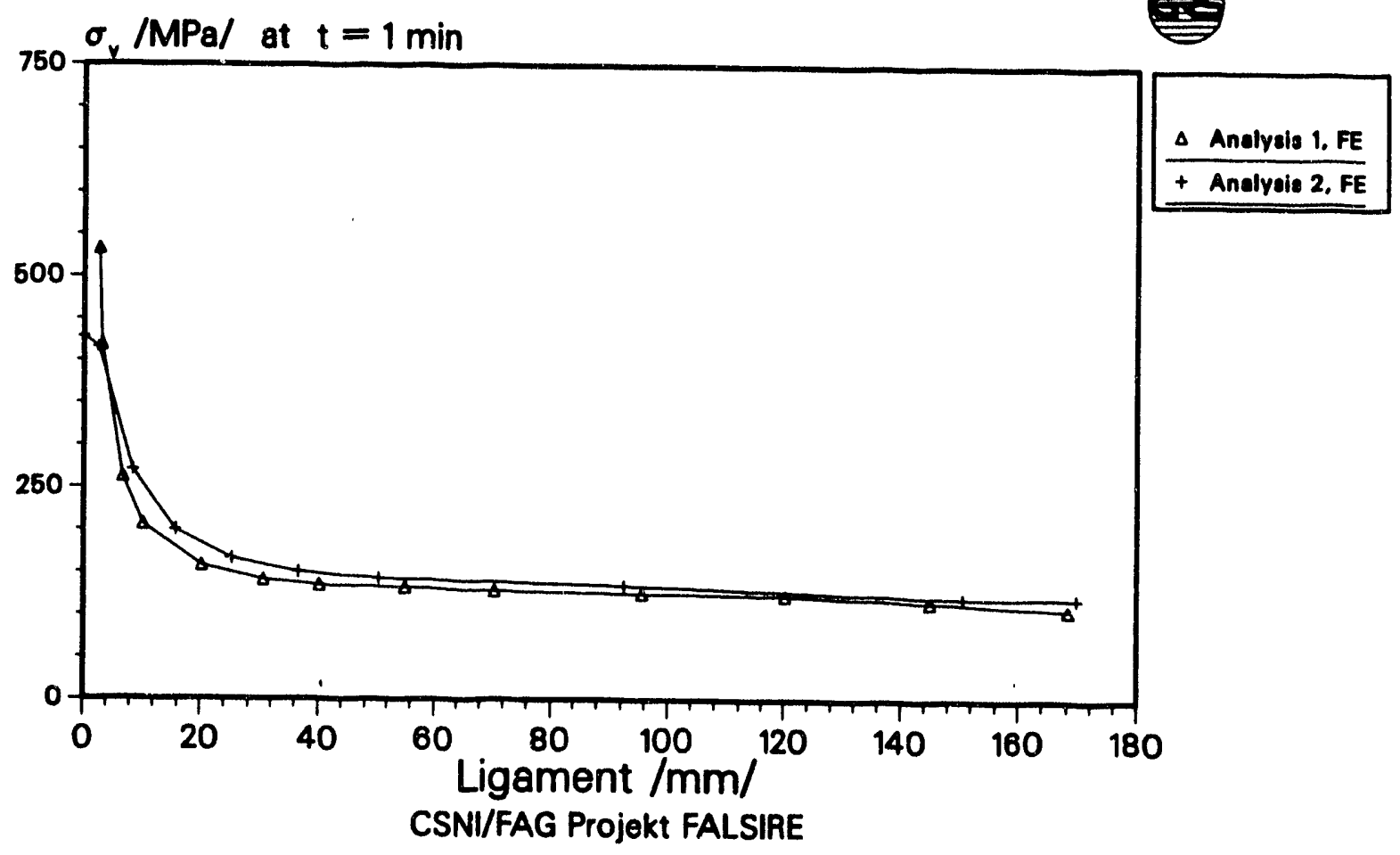

Fig. 4.18. Effective stresses on ligament $t=1 \mathrm{~min}$ (NKS-4 experiment). 


\section{Analysis Results of Reference Experiment NKS-4}

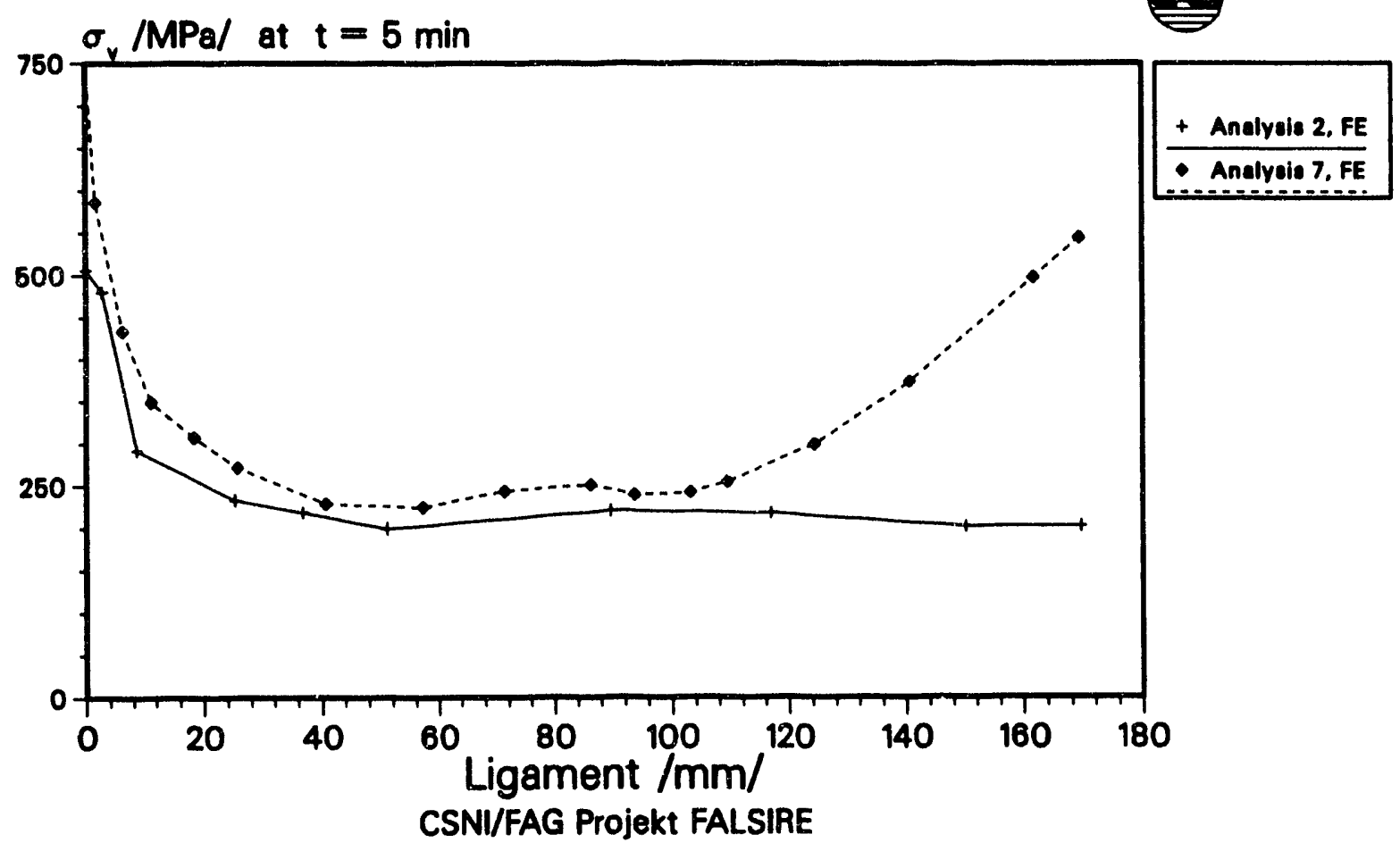

Fig. 4.19. Effective stresses on ligament $t=5 \mathrm{~min}$ (NKS-4 experiment).

ORNL-DWG 93-2300 ETD

\section{Analysis Results of Reference Experiment NKS-4}

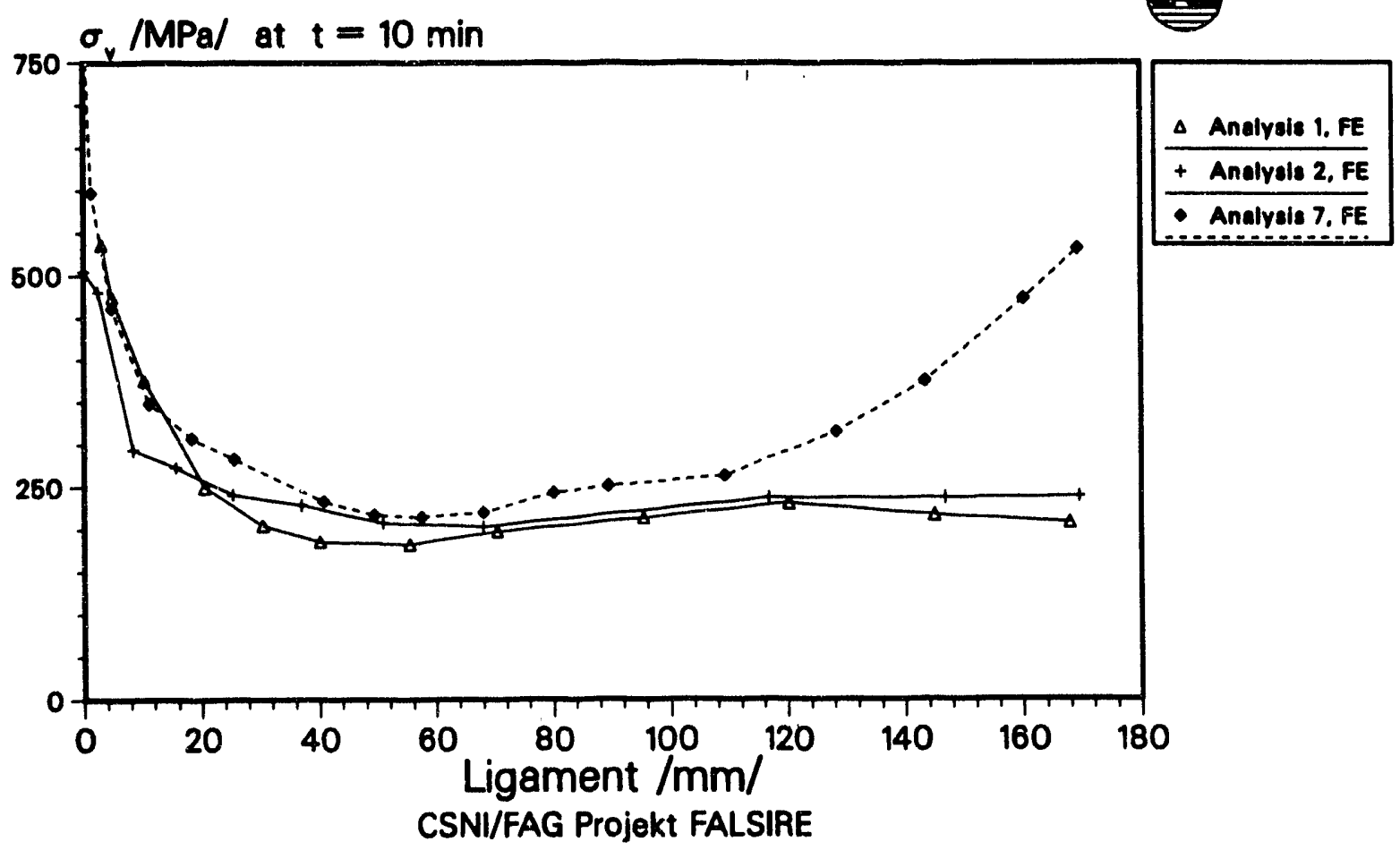

Fig. 4.20. Effective stresses on ligament $t=10 \mathrm{~min}$ (NKS-4 experiment). 
Analysis Results of Reference Experiment NKS-4

$\mathrm{q}=3^{*} \sigma_{\mathrm{H}} / \sigma_{\mathrm{y}}$

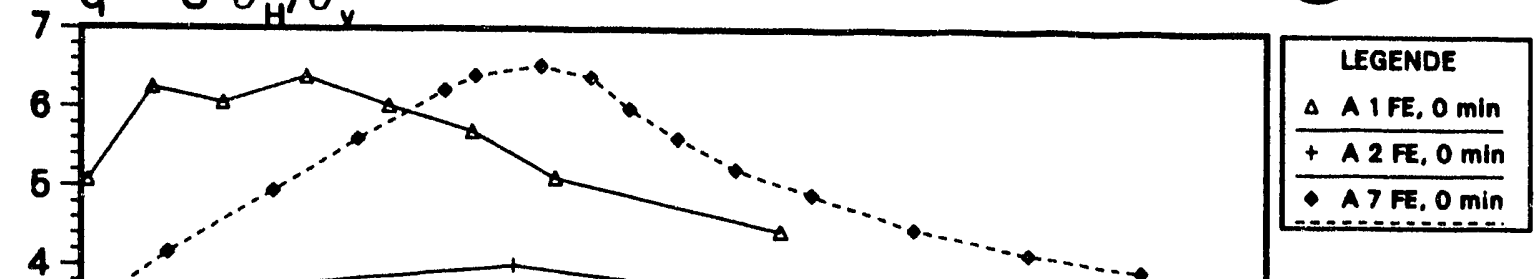

$-1$

$-2$

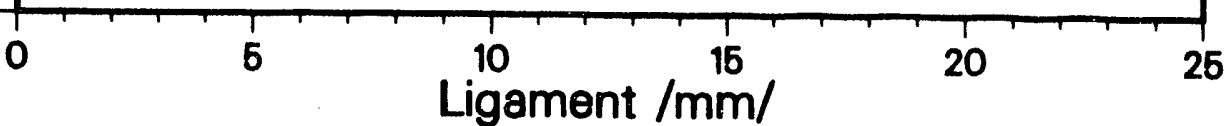

CSNI/FAG Projekt FALSIRE

Fig. 4.21. Stress triaxiality on ligament $t=0 \mathrm{~min}$ (NKS-4 experiment).

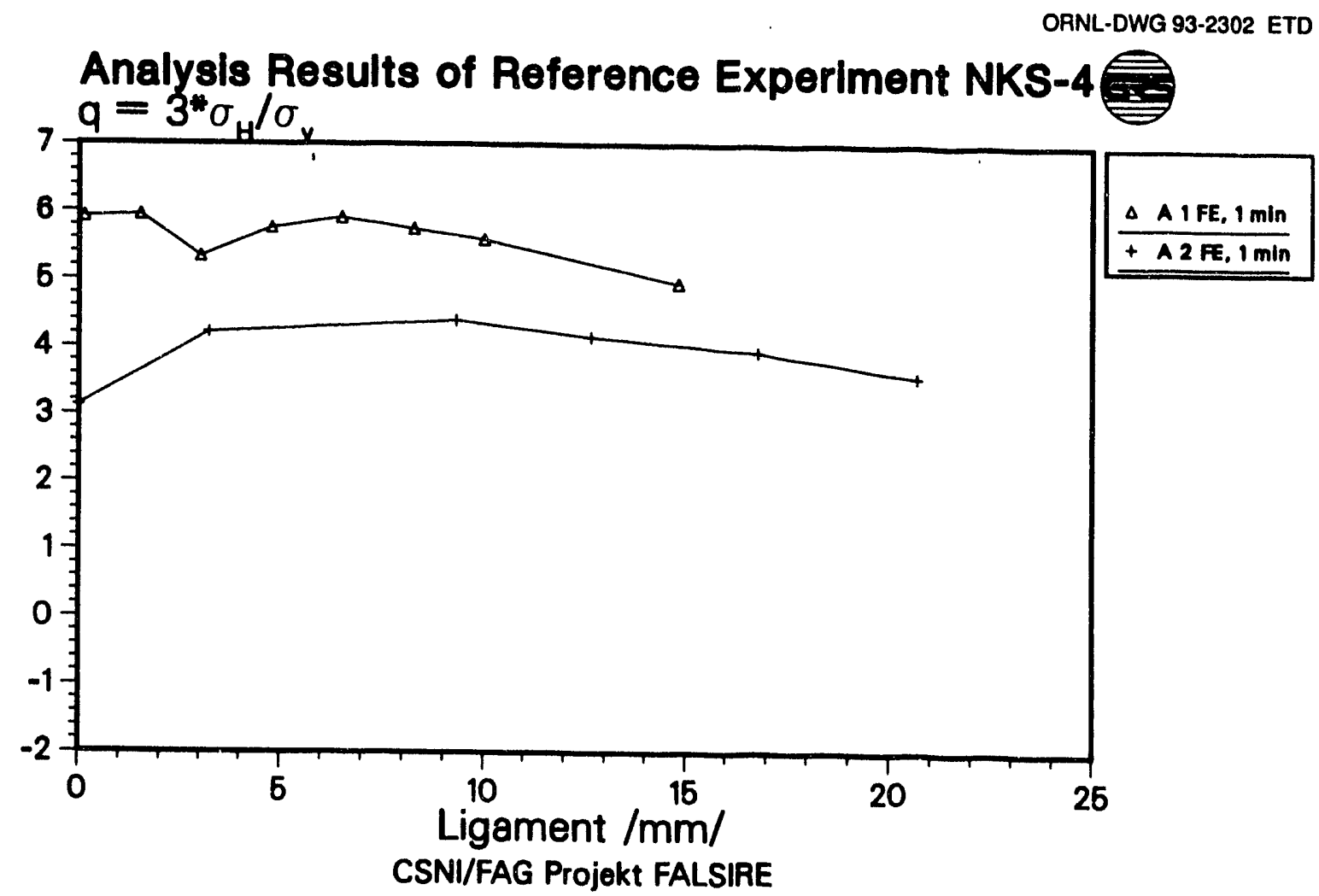

Fig. 4.22. Stress triaxiality on ligament $t=1 \mathrm{~min}$ (NKS-4 experiment). 


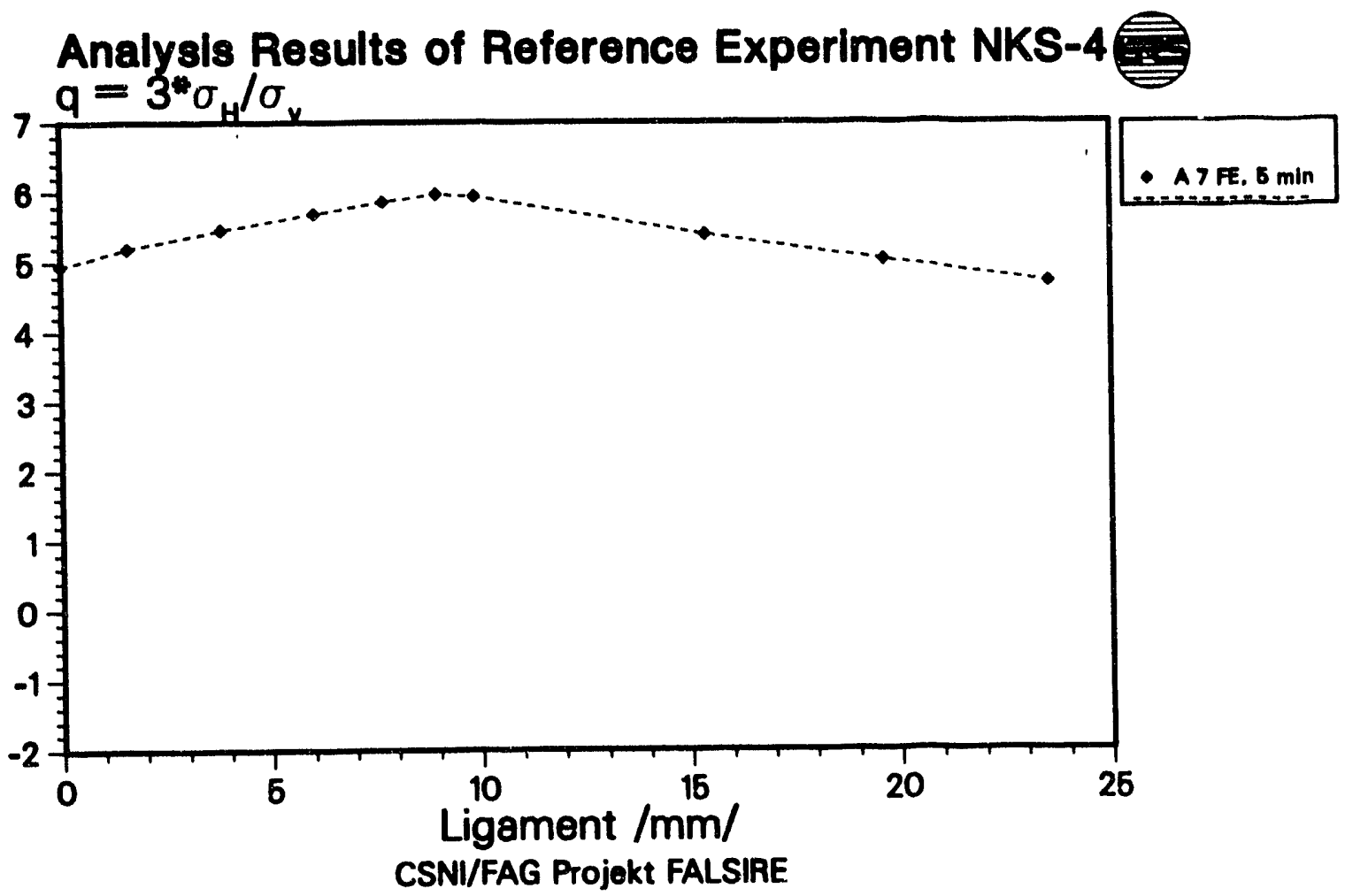

Fig. 4.23. Stress triaxiality on ligament $t=5 \mathrm{~min}$ (NKS- 4 experiment).

ORNL-DWG 93-2304 ETD
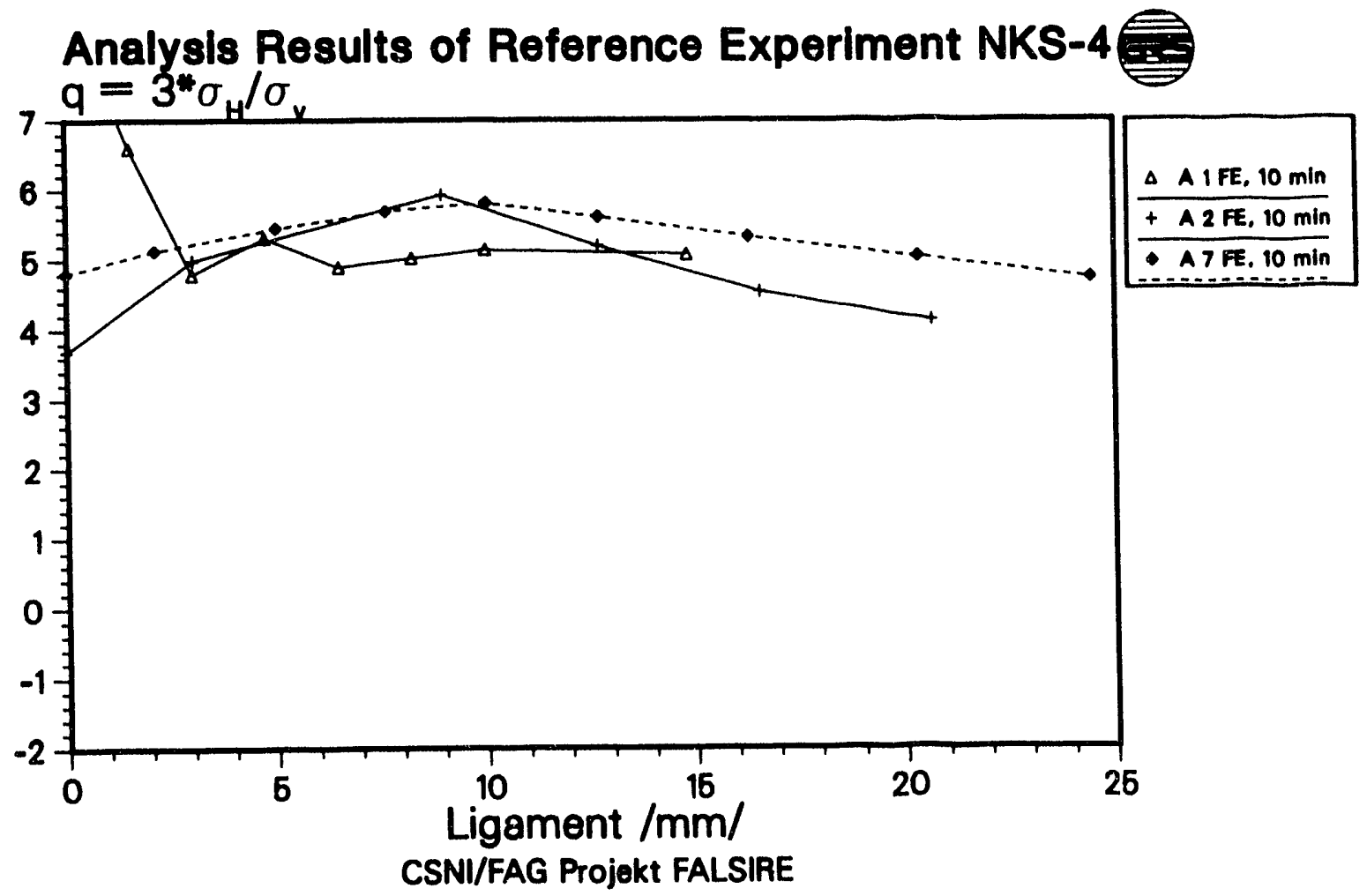

Fig. 4.24. Stress triaxiality on ligament $t=10 \mathrm{~min}$ (NKS-4 experiment). 


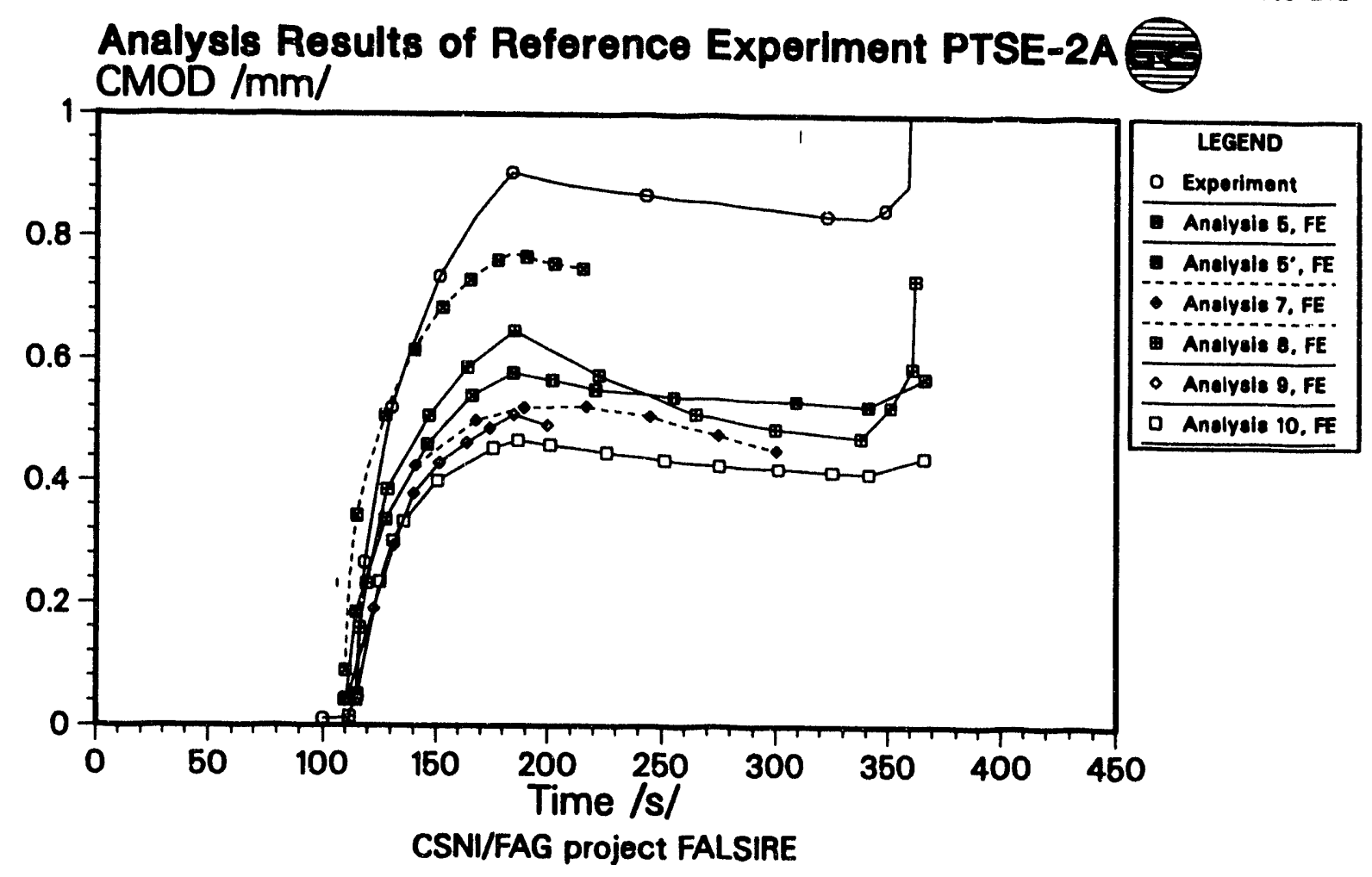

Fig. 4.25. CMOD vs time for PTSE-2A.

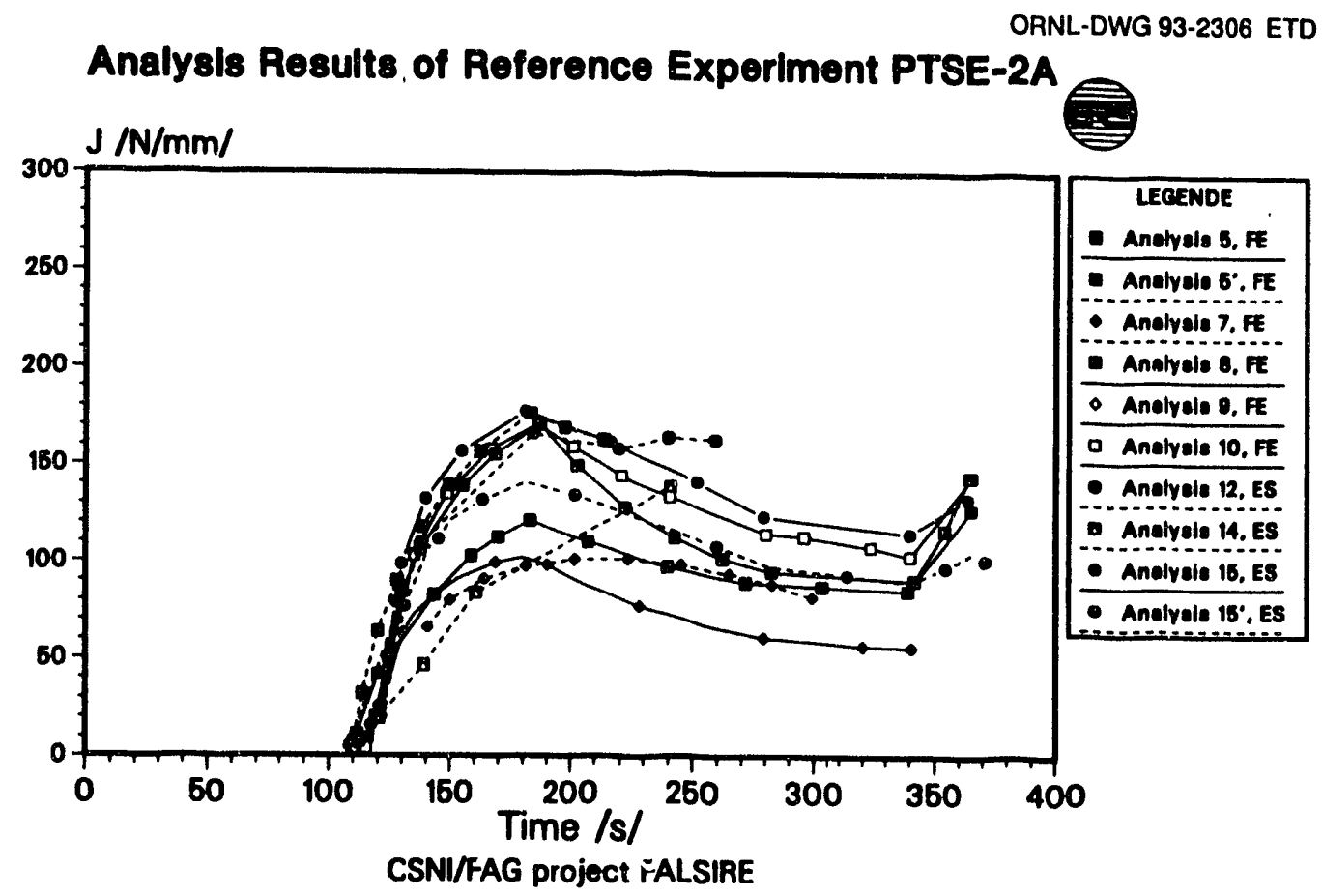

Fig. 4.26. J-integral vs time for PTSE-2A. 


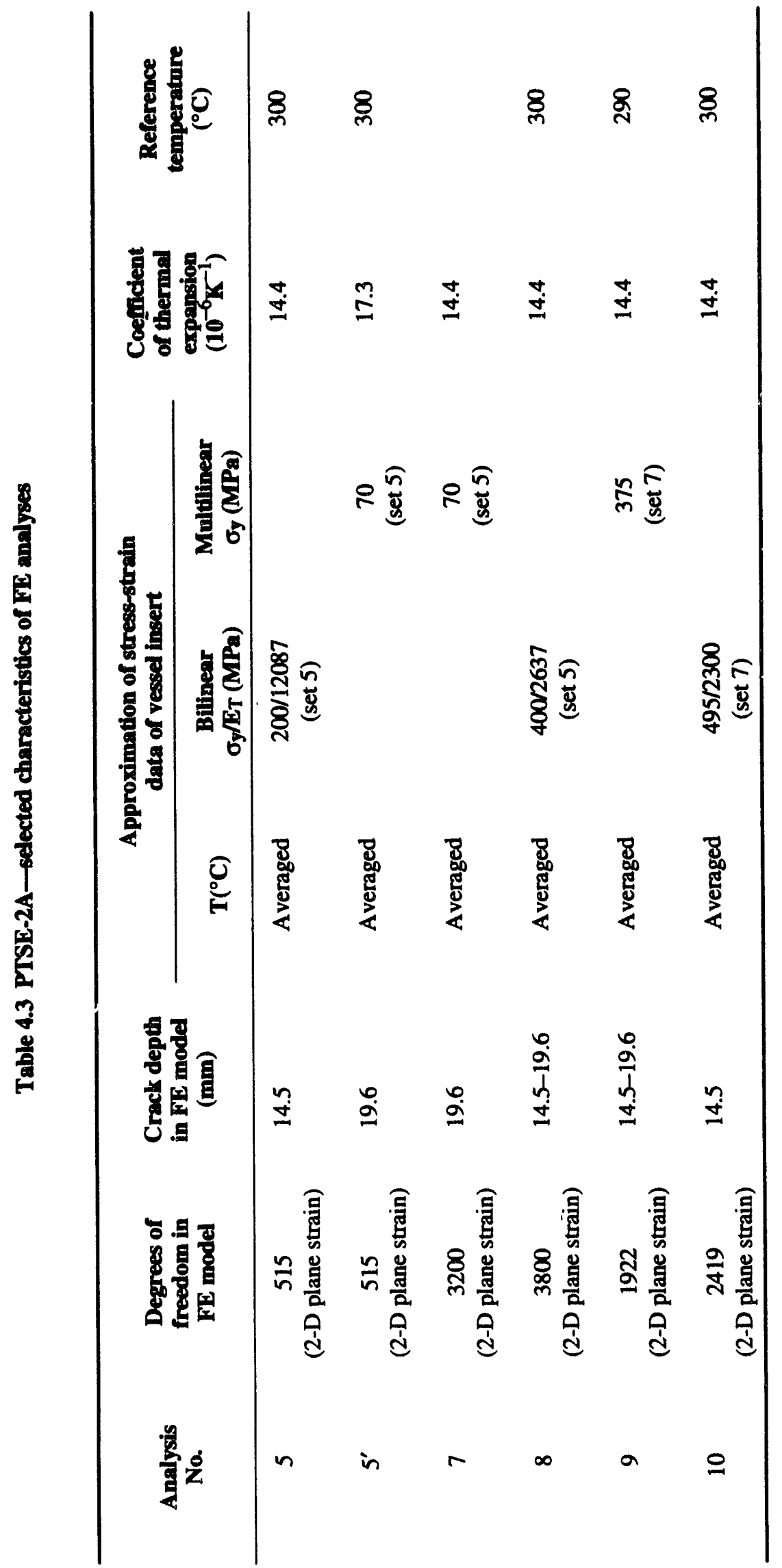




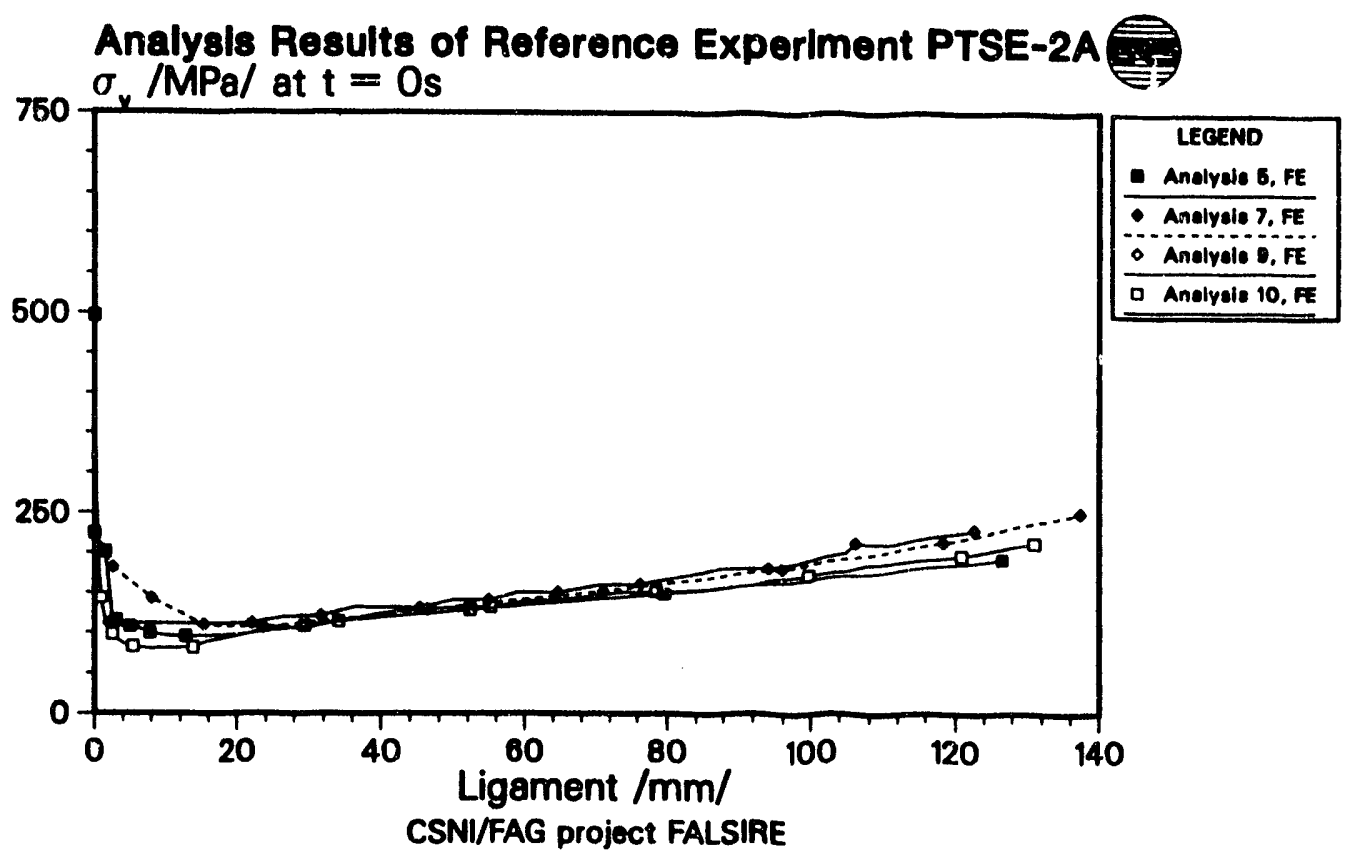

Fig. 4.27. Effective stresses on ligament $t=0 \mathrm{~s}$ (PTSE-2A experiment).

ORNL.DWG 93-2308 ETD

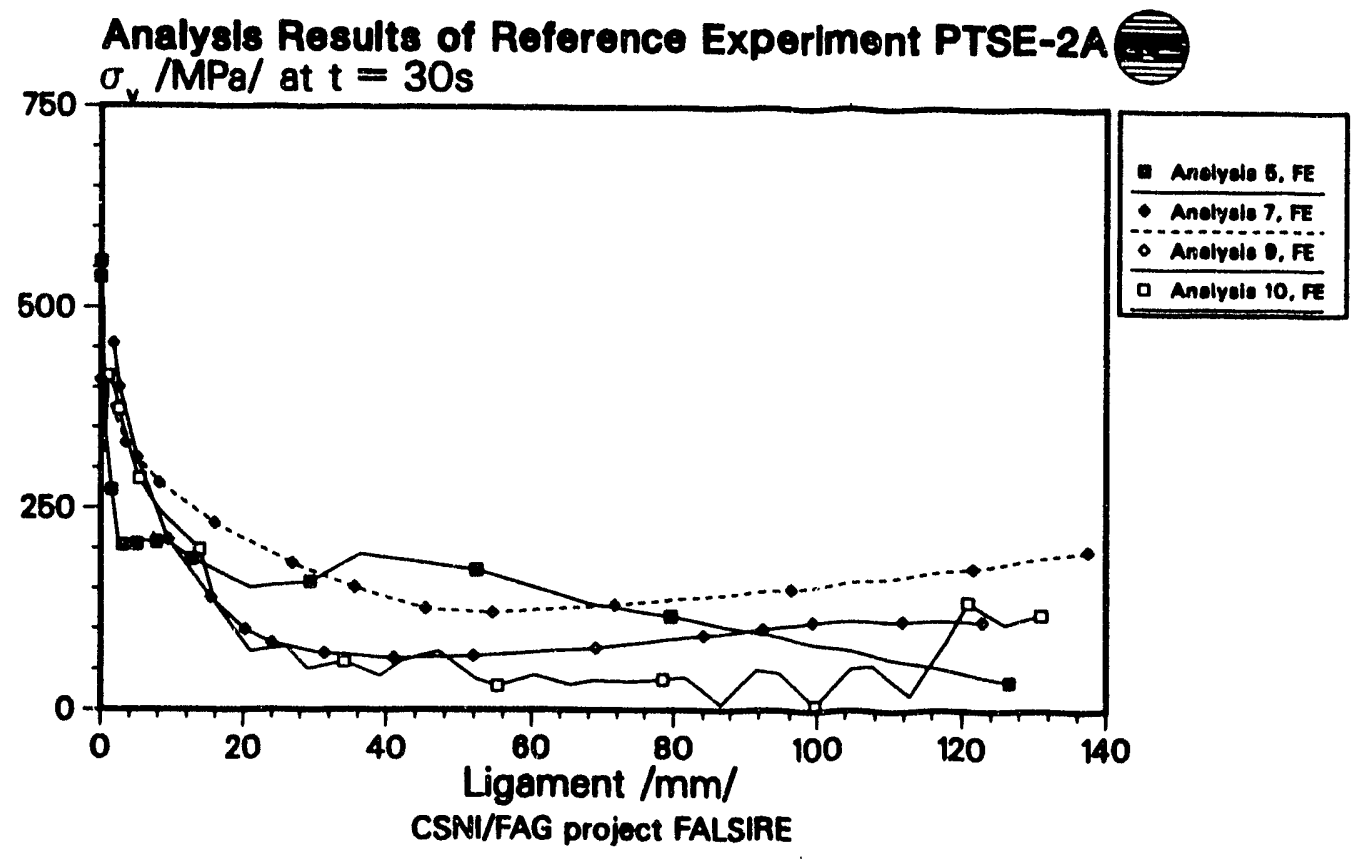

Fig. 4.28. Effective stresses on ligament $t=30$ s (PTSE-2A experiment). 


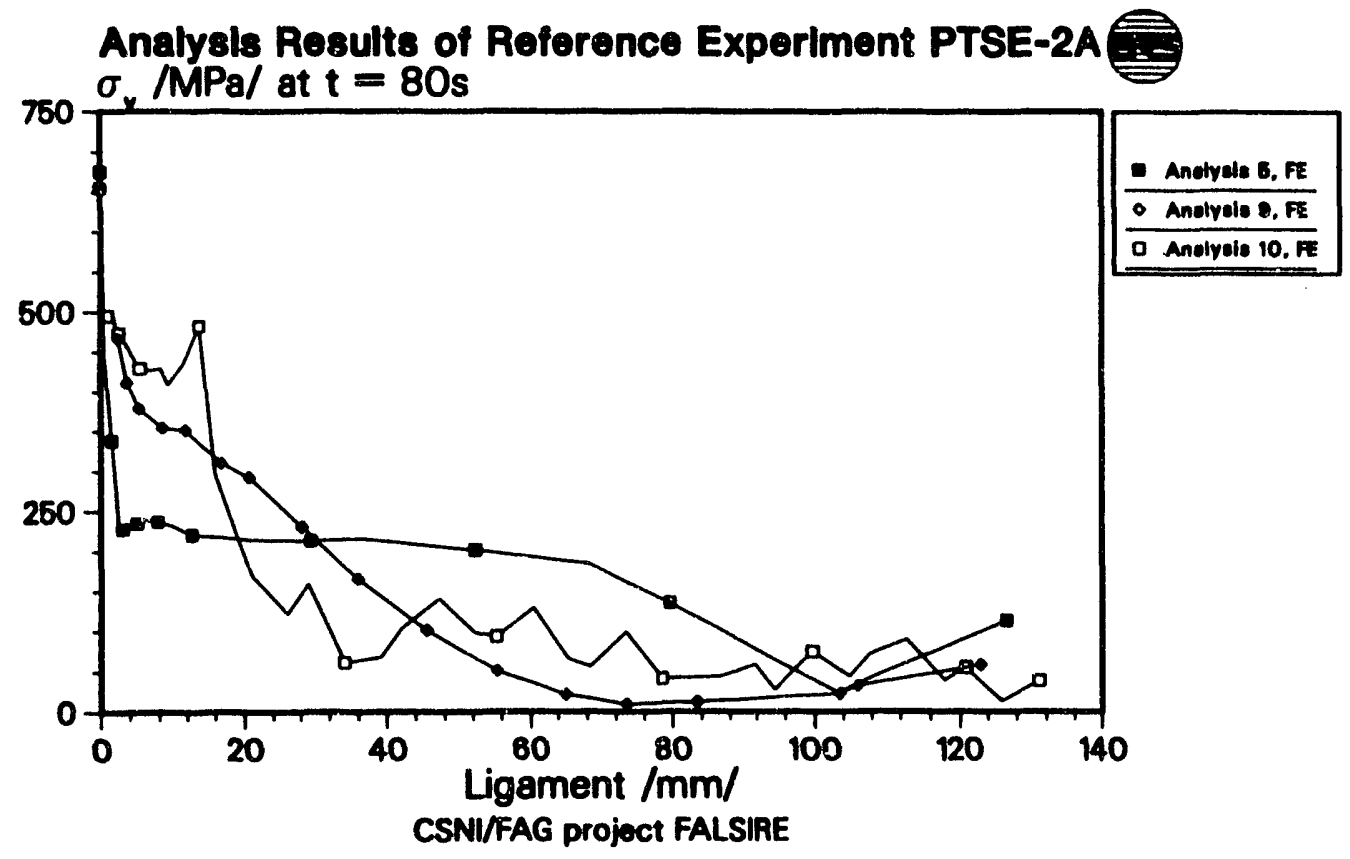

Fig. 4.29. Effective stresses on ligament $t=80 \mathrm{~s}$ (PTSE-2A experiment).

ORNL-DWG 93-2310 ETD

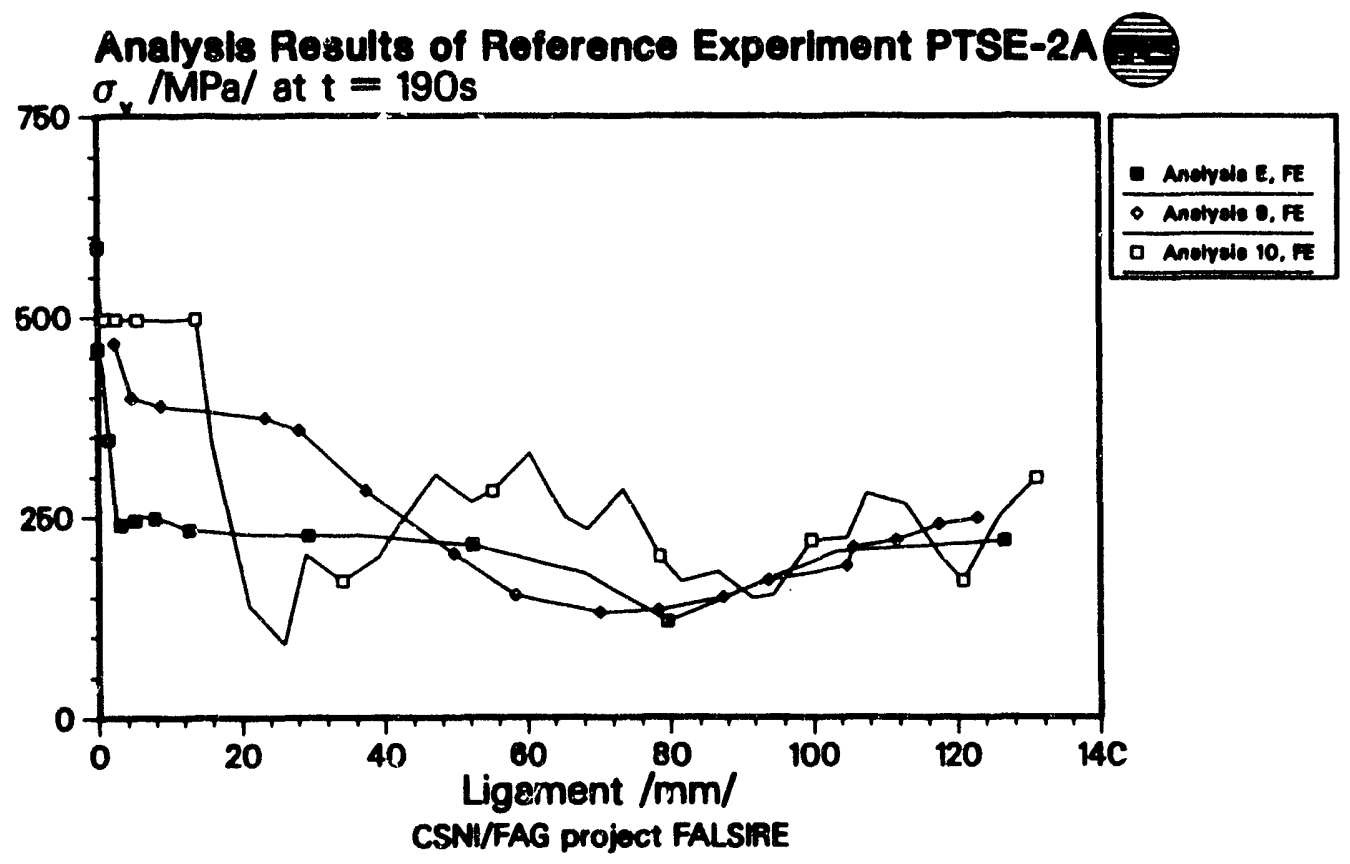

Fig. 4.30. Effective stresses on ligament $t=190 \mathrm{~s}$ (PTSE-2A experiment). 


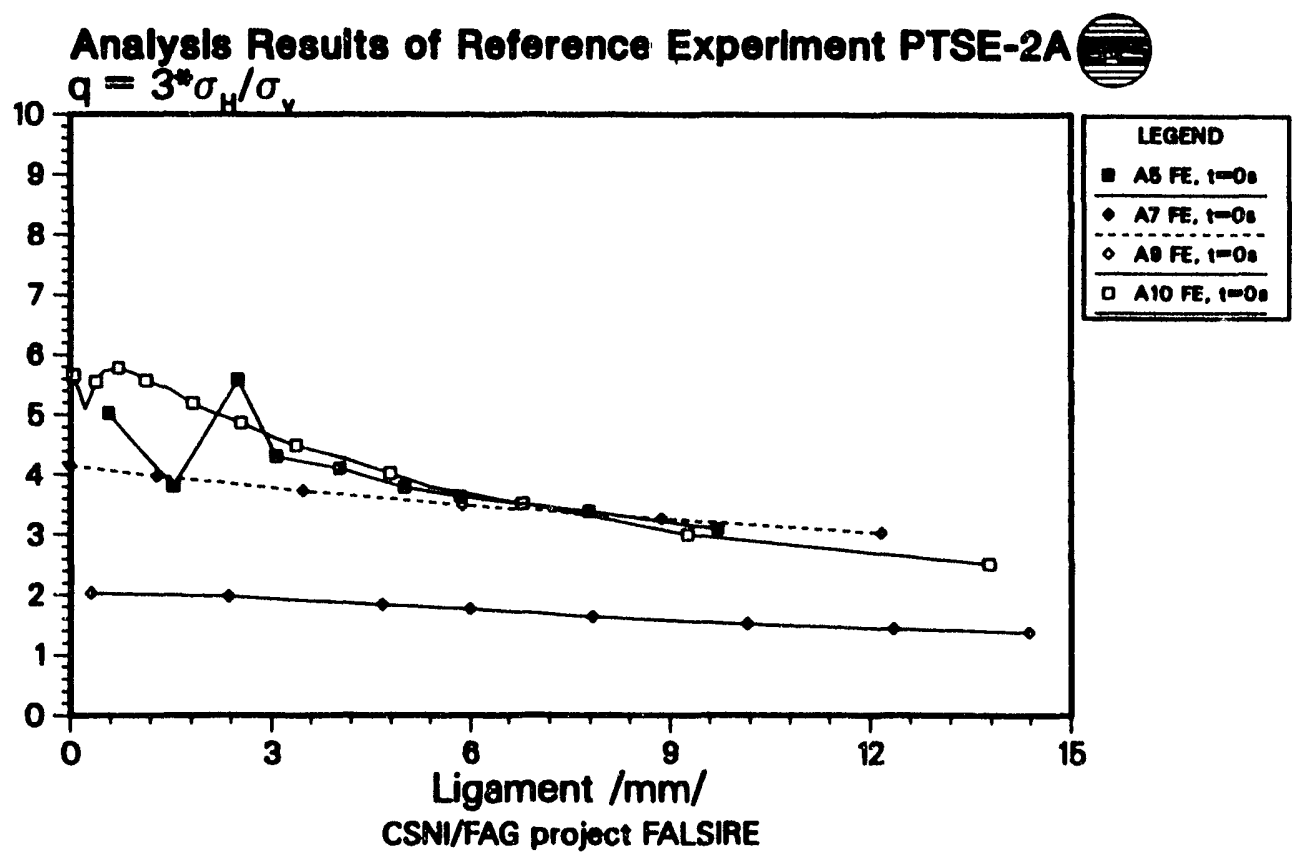

Fig. 4.31. Stress triaxiality on ligament $t=0 \mathrm{~s}$ (PTSE-2A experiment).

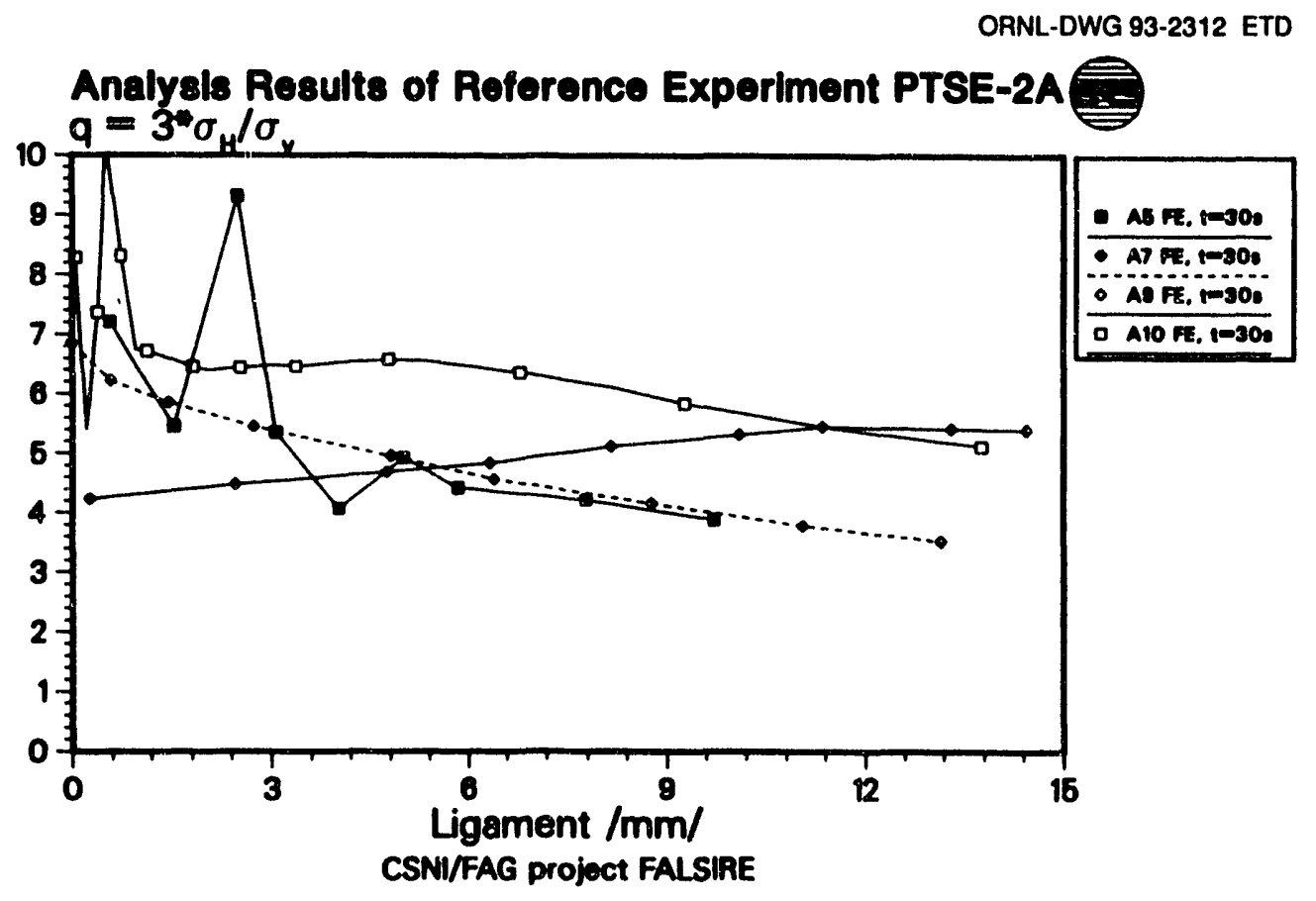

Fig. 4.32. Stress triaxiality on ligament $t=30 \mathrm{~s}$ (PTSE-2A experiment). 
ORNL-DWG 93-2313 ETD

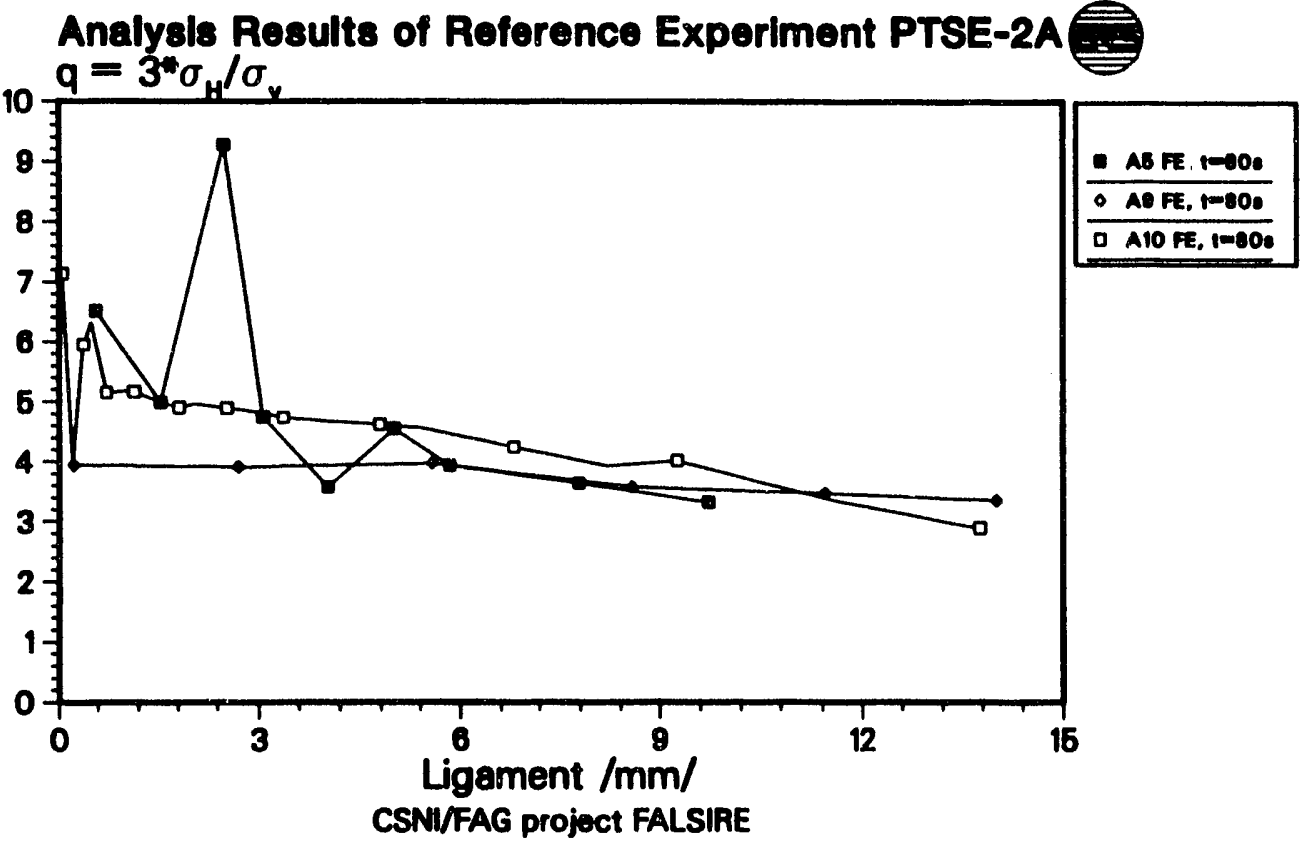

Fig. 4.33. Stress triaxiality on ligament $t=80 \mathrm{~s}$ (FTSE-2A experiment).

ORNL-DWG 93-2314 ETD

Analysis Resulte of Reforence Experiment PTSE-2A

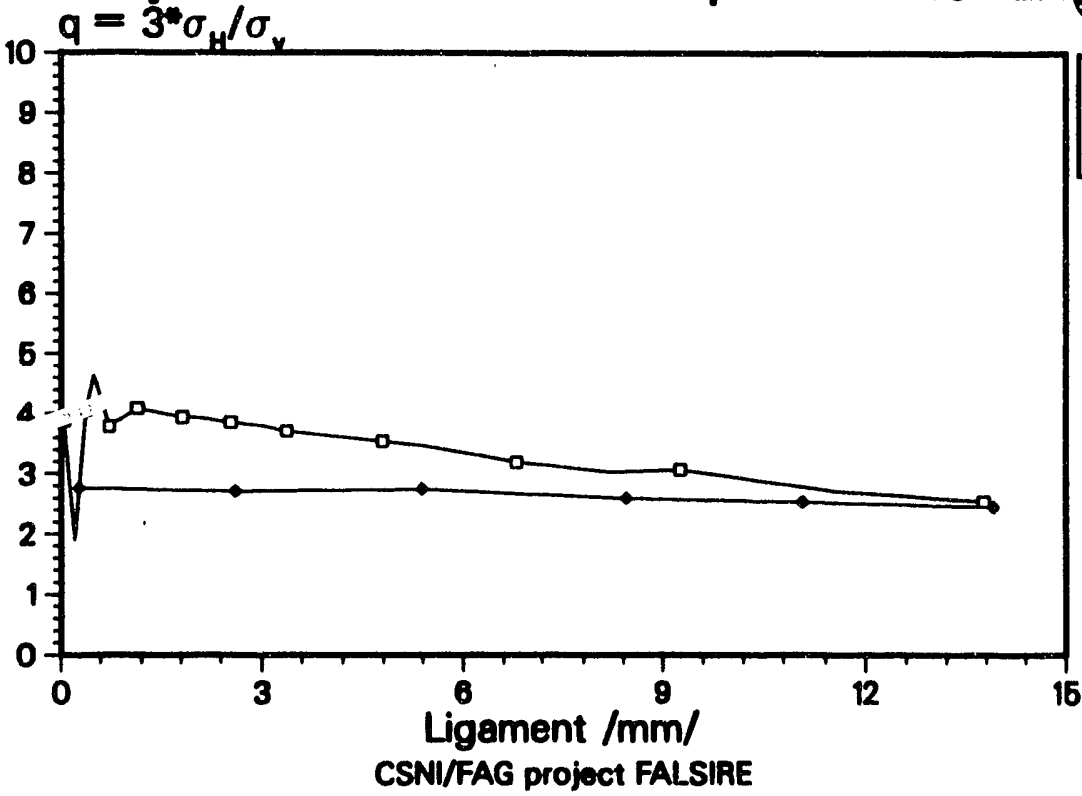

Fig. 4.34. Stress triaxiality on ligament $t=190 \mathrm{~s}$ (PTSE-2A experiment). 
ORNL-DWG 93-2315 ETD

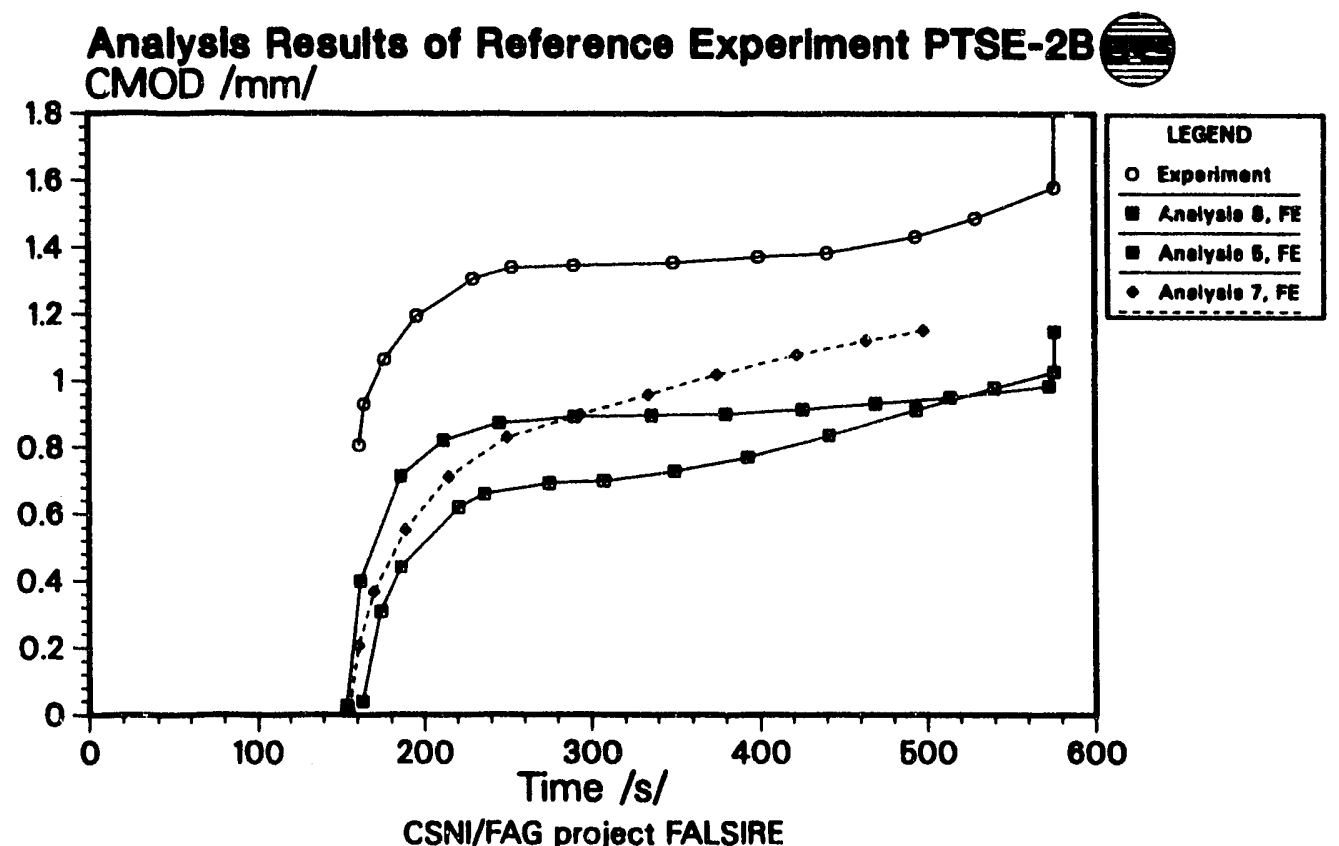

Fig. 4.35. CMOD vs time for PTSE-2B.

\section{Analysis Results of Reference Experiment PTSE-2B}

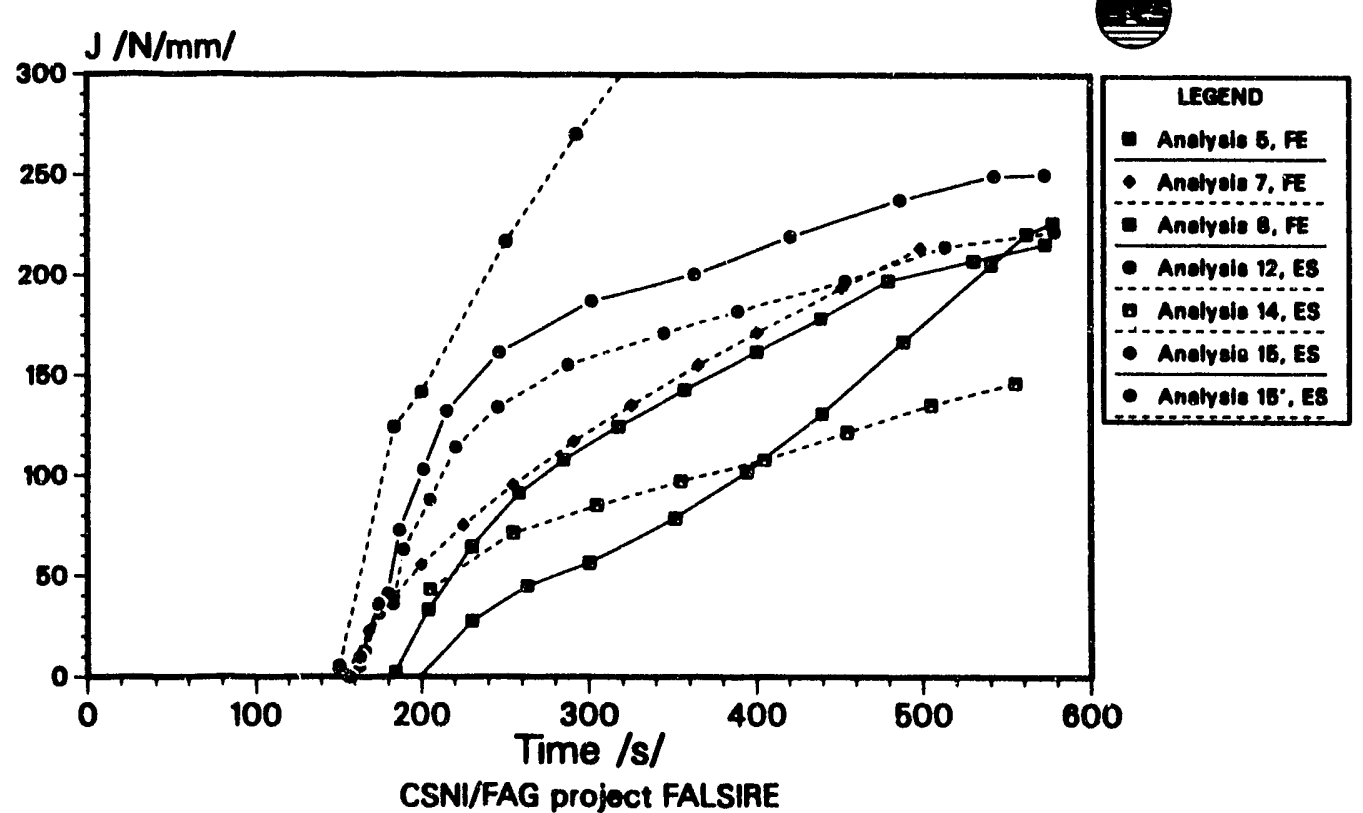

Fig. 4.36. J-integral vs time for PTSE-2B. 
Comparative

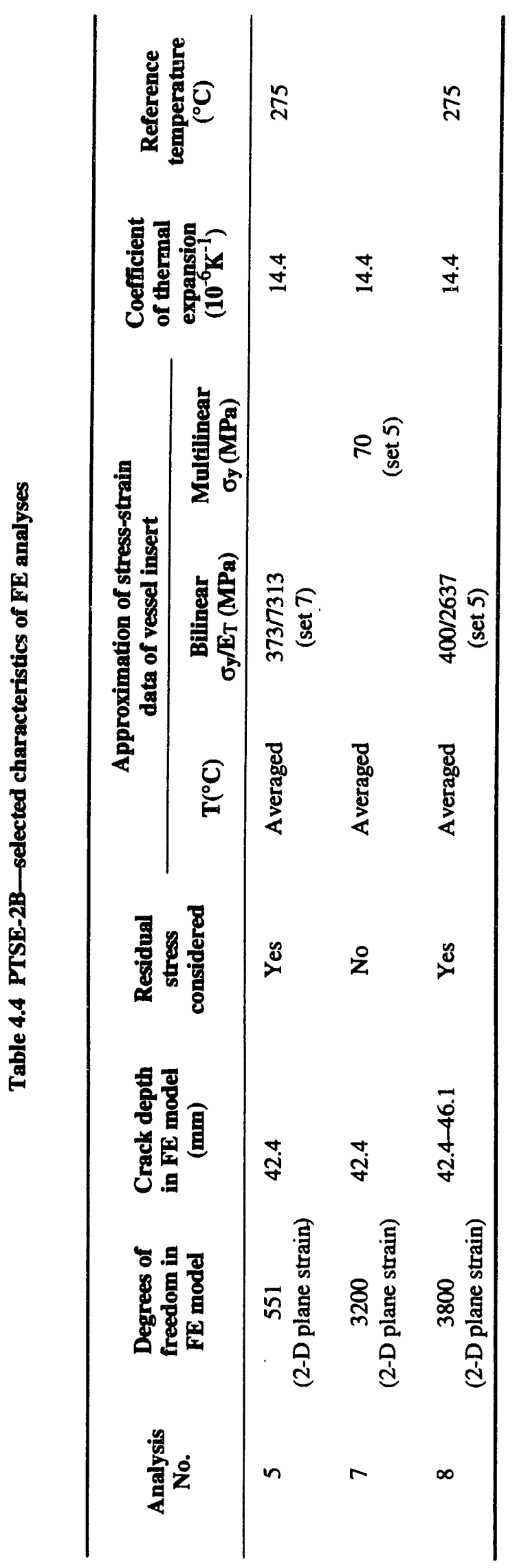


ORNL-DWG 93-2317 ETD

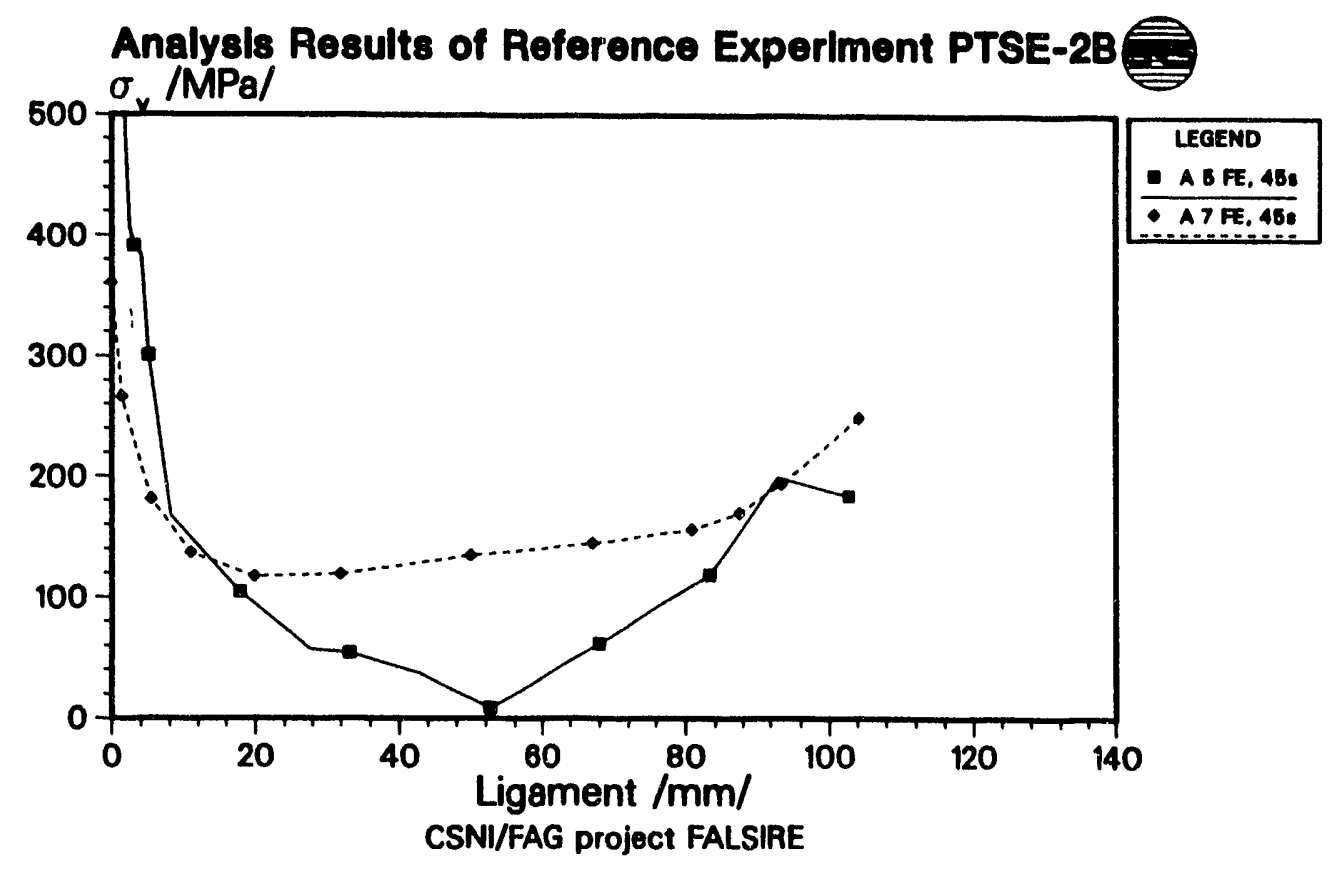

Fig. 4.37. Effective stresses on ligament $t=45 \mathrm{~s}$ (PTSE-2B experiment).

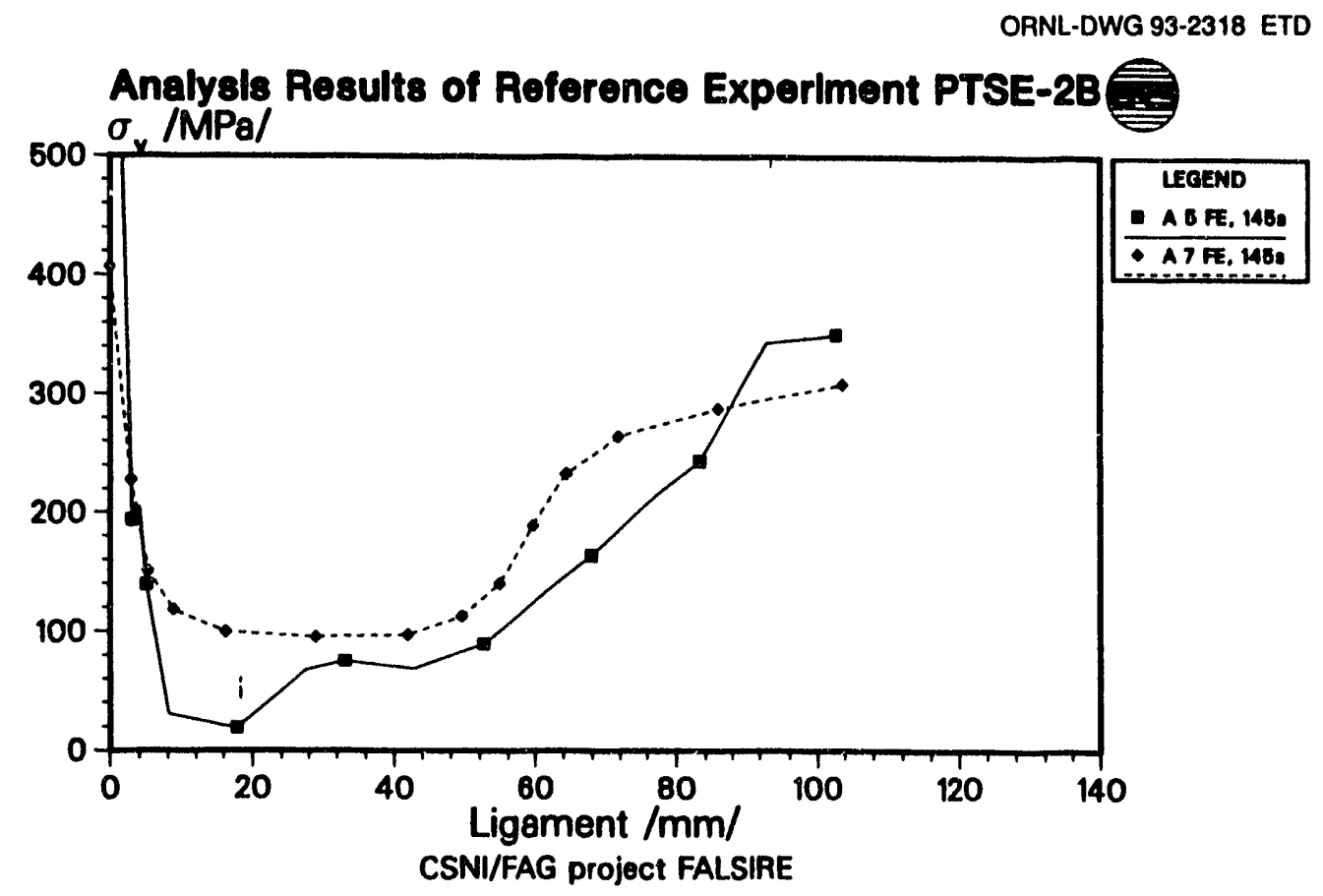

Fig. 4.38. Effective stresses on ligament $t=145 \mathrm{~s}$ (PTSE-2B experiment). 


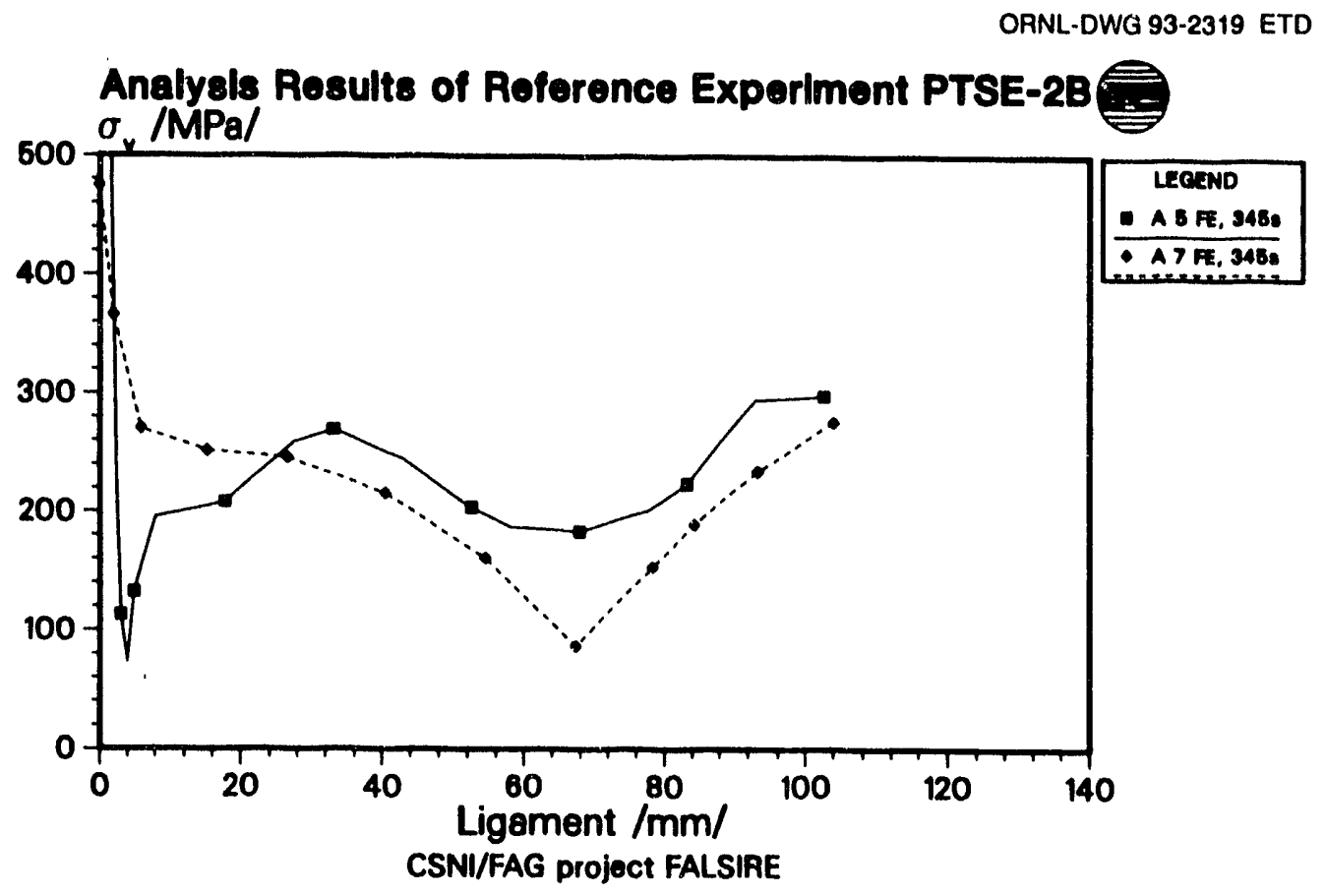

Fig. 4.39. Effective stresses on ligament $t=345 \mathrm{~s}$ (PTSE-2B experiment).

Fig. 4.40) compare well, but the J values have large differences because of the ES methods applied.

A range of stable crack extension is calculated using isothermal $J_{R}$ curves and the $J$-integral scatterband obtained by excluding analyses 12 and 15 from the set given in Fig. 4.36. Possibly, analysis 12 fails because of the deep crack and analysis 15 because of the assumption of infinite crack length (as compared with analysis $15^{\prime}$, which assumed a finite crack length). The calculated crack extension ranges from 1.4 to $2.9 \mathrm{~mm}$ (measured $3.7 \mathrm{~mm}$, i.e., 9\% of the initial crack depth in PTSE-2B). The underestimation of the crack exfension is not as large as in PTSE-2A, but another factor that could reduce the crack extension has not been considered. The stress state in front of a crack that has already seen a transient (A) could be altered due to blunting and could lead to an increase in crack resistance compared to that of a standard specimen. To summarize, differences between the analysis results and the experimental data could not be clarified totally, but additional factors that could influence the quality of fracture assessment based on $J_{R}$ methodology have been identified.

\subsection{SC-I}

In Figs. 4.41 and 4.42, CMOD and J-integral values are plotted vs the angular velocity that represents the loading of the test. The stress-strain approximations used in the plane strain FE analyses 8 and 9 are multilinear. Measured CMOD or strain values were not available to the analysts. Some CTOD data were made available only after evaluation of the analysis results of the Project FALSIRE Workshop [Fig. 2.46(b)]. In Fig. 4.42, the J-integral results of the FE and ES analyses show a small scatterband around the experimental curve extracted from the $J_{R}$ curve measured with the SC-I test cylinder. The curve of analysis 9 has a weaker slope, which could not be explained. Analyses 12 and 16 show differences up to $50 \%$ because of different ES fracture methods used in the analyses. Note that the hoop stresses (Fig. 4.43) are the same.

In conclusion, only fracture results could be compared with the experiment. These comparisons show that crack extension based on $J_{R}$ methodology can be described quite well with the crack resistance curve of the large-scale test 
ORNL-DWG 93-2320 ETD

\section{Analysis Results of Reference Experiment PTSE-2B}

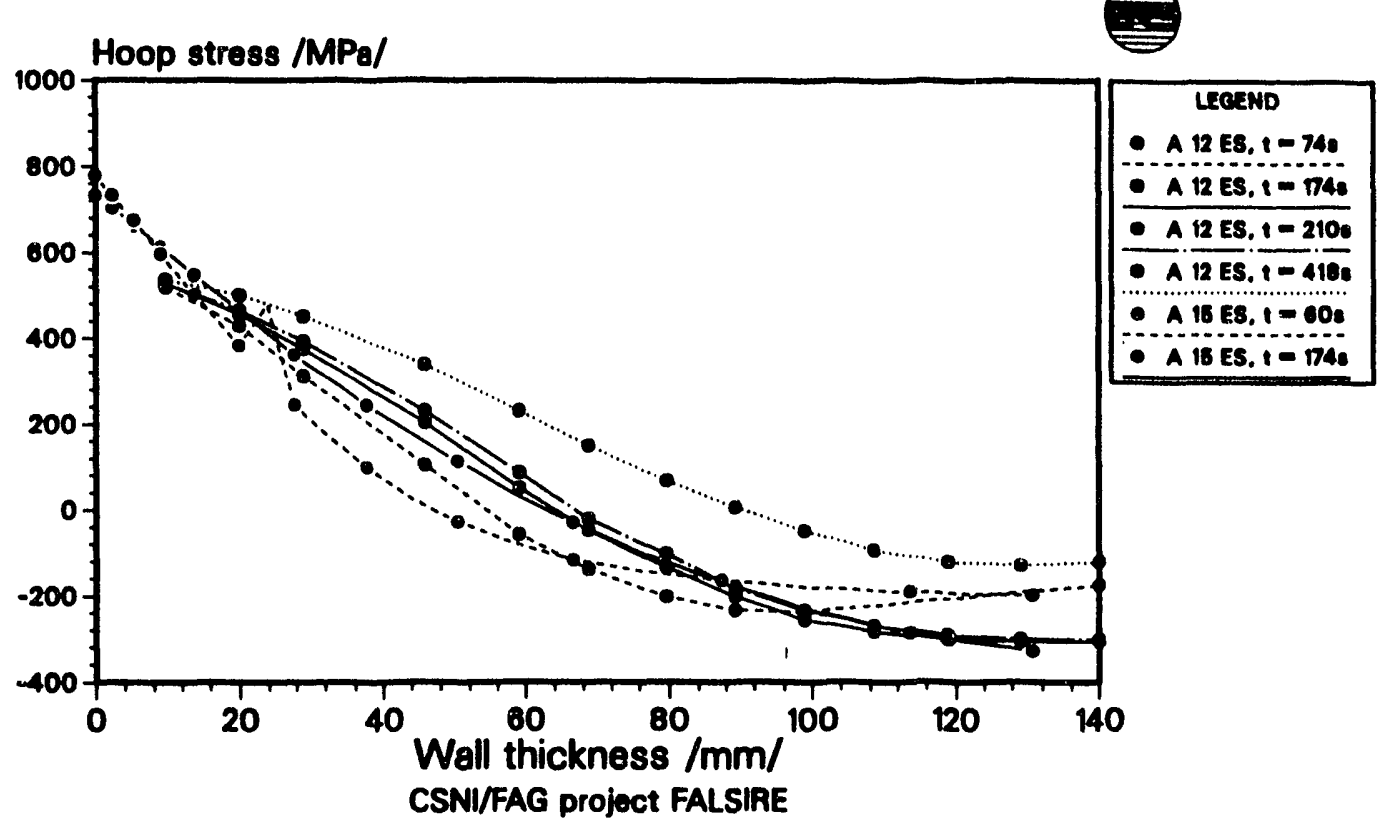

Fig. 4.40. Hoop stresses vs wall thickness for PTSE-2B.

ORNL-DWG 93-2321 ETD

Analysis Results of Reference Experiment Spln. Cyl. I CMOD $/ \mathrm{mm} /$

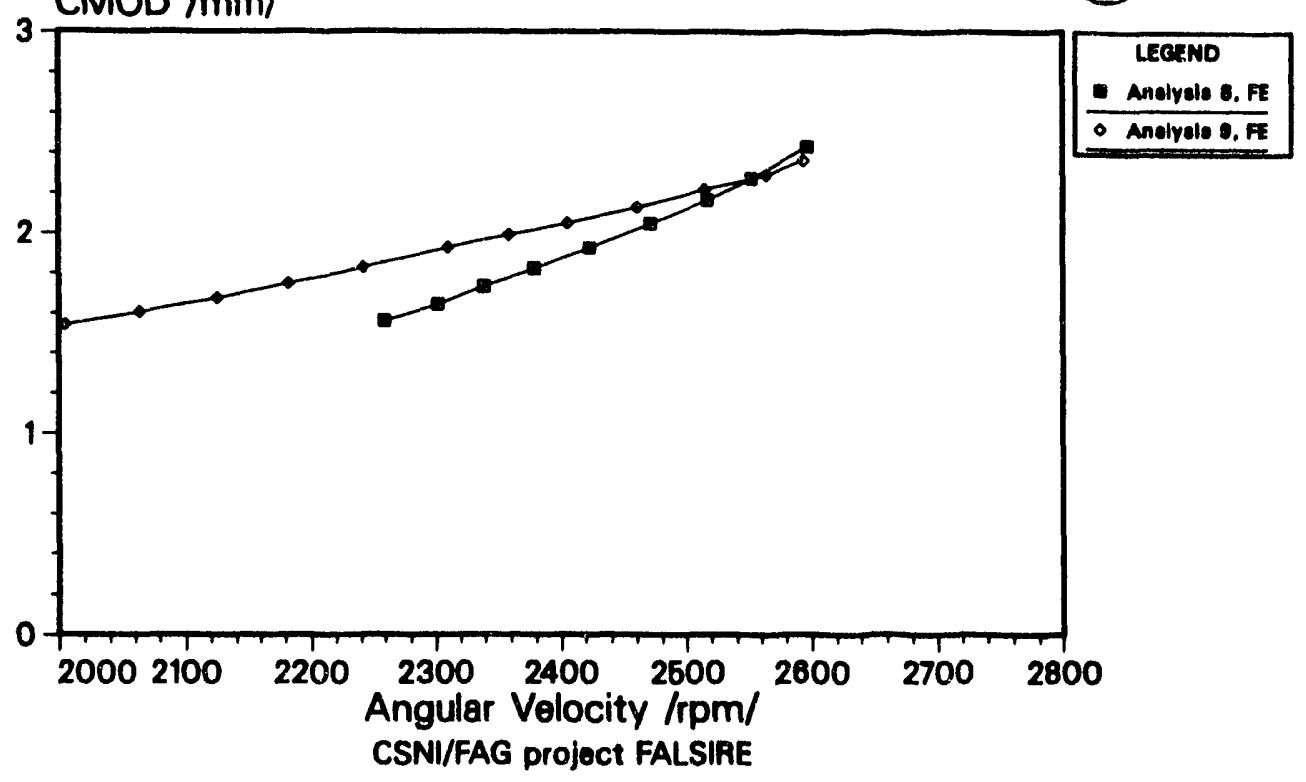

Fig. 4.41. CMOD vs angular velocity for SC-I. 


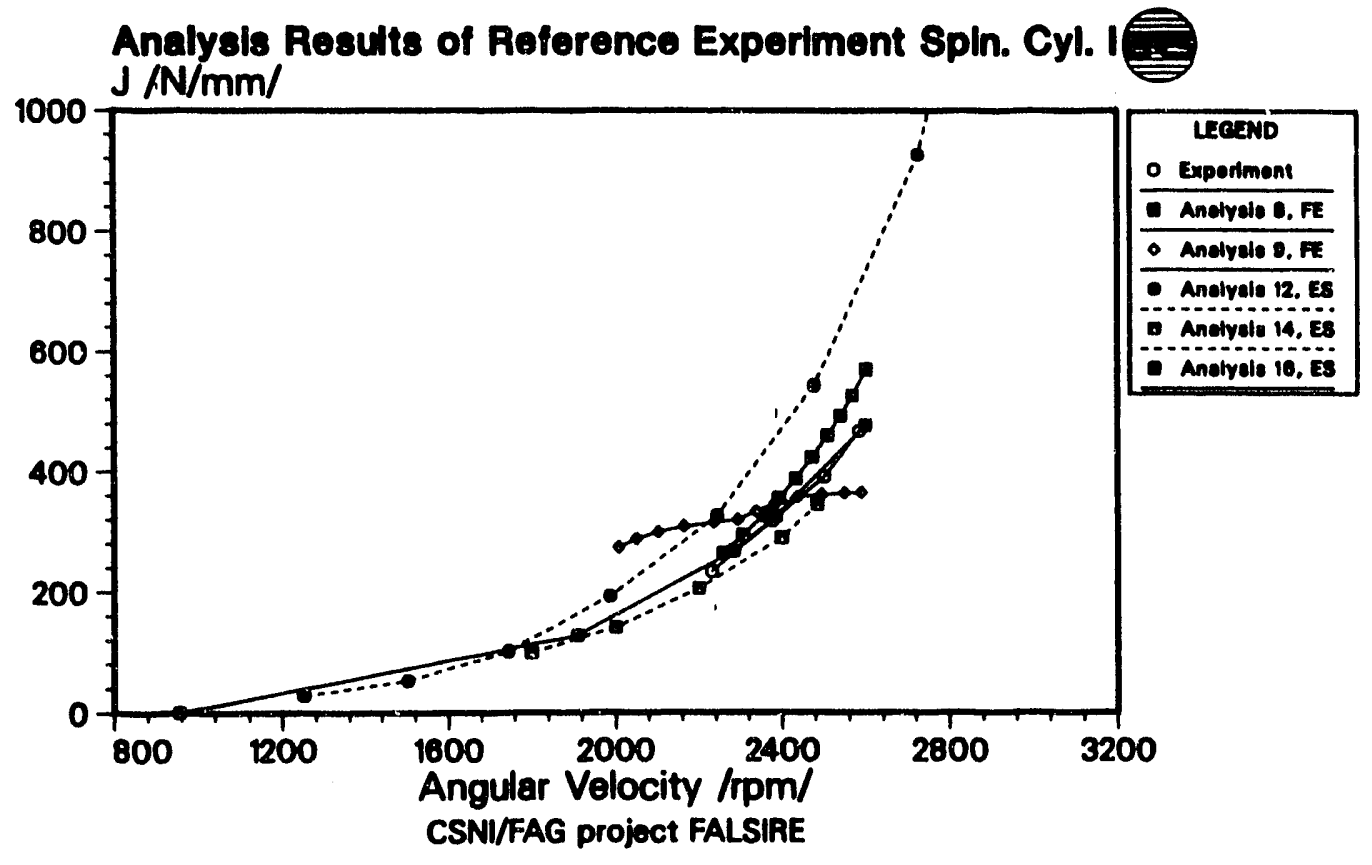

Fig. 4.42. J-integral vs angular velocity for SC-I.

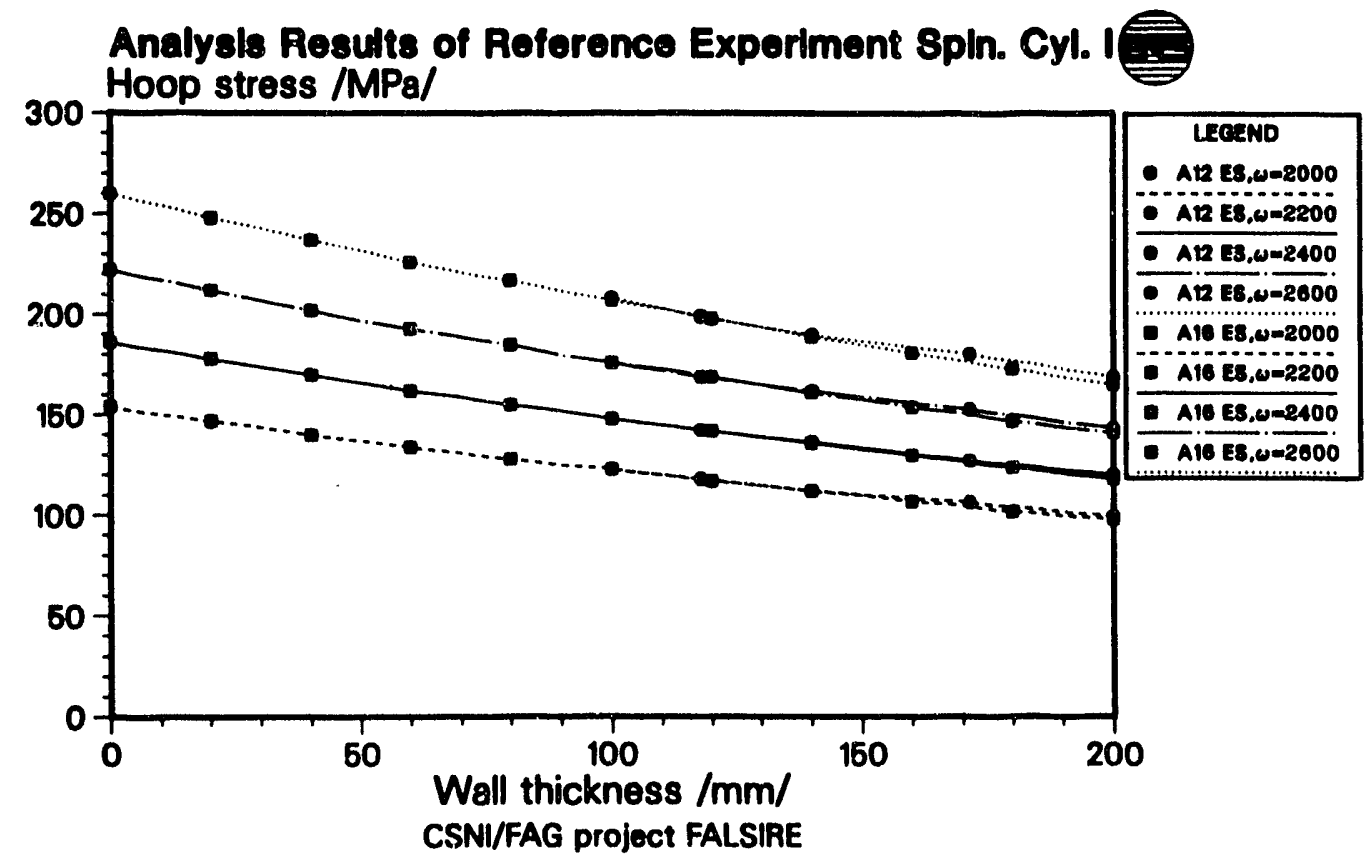

Fig. 4.43. Hoop stresses vs wall thickness for SC-I. 
specimen. However, the crack resistance curves depicted in Fig. 2.48 indicate that the fracture toughness measured with the small-scale CT specimens is substantially lower than that obtained for the large-scale SC.

\subsection{SC-II}

The time dependence of the $\mathrm{J}$-integral is presented in Fig. 4.44. For the deep crack, the weight function method used for fracture assessment in analysis 16 gives quite conservative results, primarily because of stress calculations resulting from the assumption of free-end boundary conditions. Analysis 11, which used the Bamford and Buchalet $K_{I}$ solution given for a wall thickness to internal radius $(t / R)$ ratio of 0.1 (but $S C-I I, t / R=0.4$ ), shows the lowest values. Because of the scatterband, the crack extension calculated from the SC-II specimen $\mathrm{J}_{\mathrm{R}}$ curve (Fig. 2.48) ranges from 0.0 to $1.4 \mathrm{~mm}$ (measured value in the middle of the crack is $0.75 \mathrm{~mm}$, i.e., $0.7 \%$ of the initial crack depth), but the four analyses $8,12,13$, and 14 range from 0.2 to $0.8 \mathrm{~min}$.

As in SC-I, the fracture assessment based on the large-scale test specimen $J_{R}$ curve gives suitable results, but the crack-tip loading is strongly dependent on the estimation scheme method used and the boundary conditions assumed for the model. In particular, free-end boundary conditions, which best fit the test conditions, produce an axial decrease of crack-tip loading, as indicated by the 3-D results from analysis 17 given in Fig. 4.45. Measured COD and hoop strains were made available only after evaluation of the analysis results of the Project FALSIRE Workshop [Fig. 2.50(c) and (d)].

\subsection{Step B PTS}

Only one FE analysis is available for this test. Therefore, no comparative assessment is possible, and the results have not been put into the data base. The calculated and measured time histories of specimen deformations and strains near the crack compare well. The fracture assessment based on the $\mathrm{J}$-integral concept with $\mathrm{J}_{\mathrm{R}}$ curves of CT-25 specimens for three temperatures predicts that the crack extension at the deepest point of the crack is $\sim 2.5 \mathrm{~mm}$ (measured $1.0 \mathrm{~mm}$, i.e., $4 \%$ of the initial crack depth).

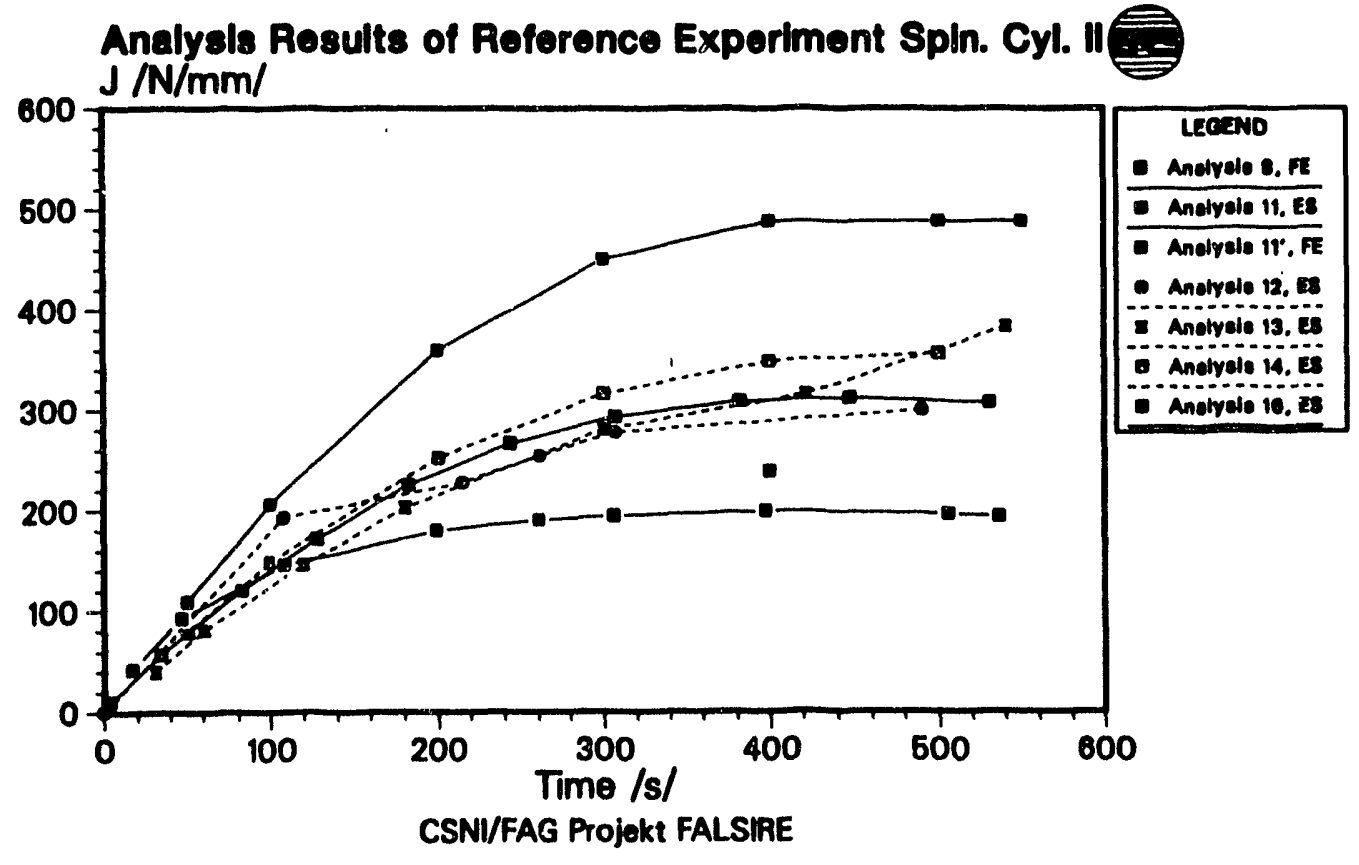

Fig. 4.44. J-integral vs time for SC-II. 


\section{Comparative}

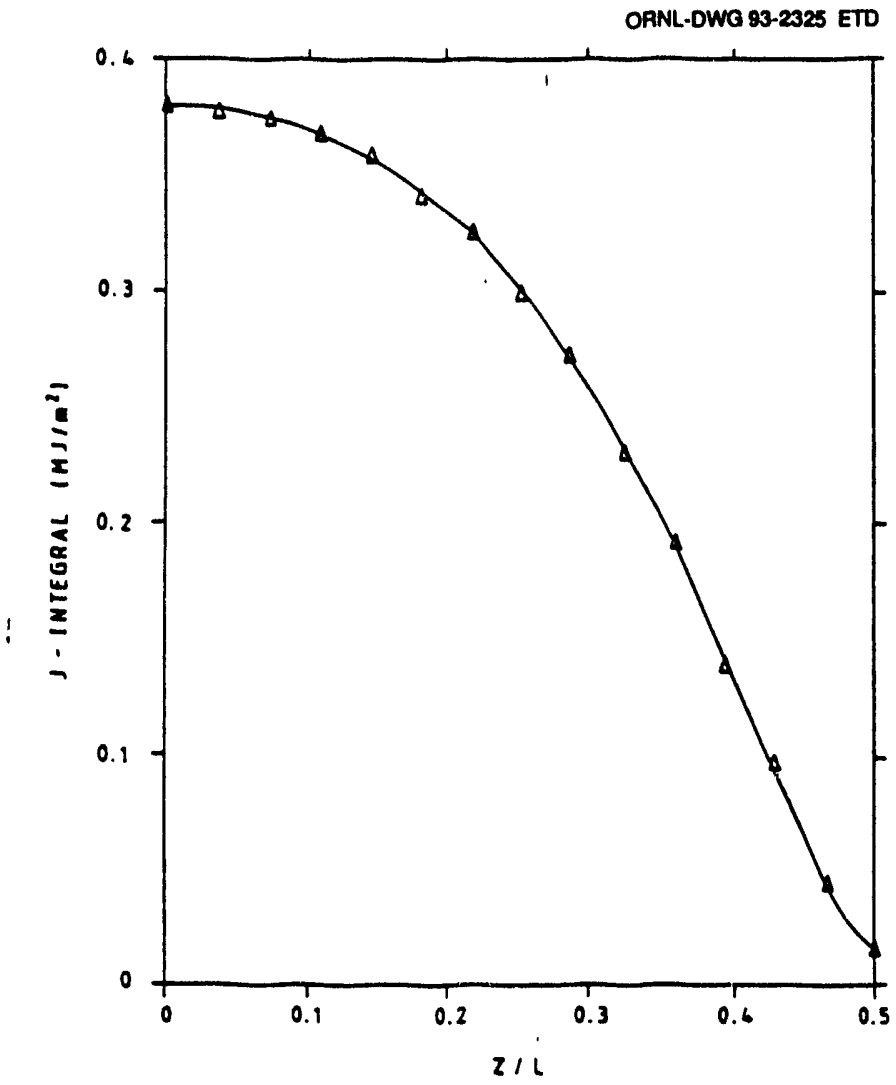

Fig. 4.45. Results of 3-D elastic plastic analysis (analysis 17) for SC-II. 


\section{Conclusions and Recommendations}

Based on results from the Project FALSIRE Workshop, several observations can be made concerning predictive capabilities of current fracture assessment methodologies as reflected in the large-scale experiments described in the previous chapters.

Generally, these experiments were designed to evaluate fracture methodologies under prototypical combinations of geometry, constraint, and loading conditions. However, because complexities of the experiments do not permit a clear separation of the effects of the many variables involved, it has proved difficult to interpret the analyses of those transients for which expected results were not achieved.

Modeling requirements for the experiments incorporate history-dependent mechanical, thermal, and body force loadings; temperature-dependent material and fracture-toughness properties; specially designed materials; residual stress states; and 3-D effects. Interactions of both cleavage and ductile modes of fracture must be modeled for certain transients. For these reasons, it could be anticipated that comparisons of analysis predictions with available structural data from the experiments would yield results that vary significantly.

The discussion of the analysis results in Chap. 4 has focused on the discrepancies of the finite-element results and on comparisons with the estimation scheme analyses. Many effects from the comparative assessment of the analysis results have not yet been explained, but with this report there is a data base available for further studies on separate effects. Examples of these comparisons were shown in CMOD vs time plots for experiments NKS-3, -4 , and PTSE-2 A/B in Figs. 4.1, 4.14, 4.25, and 4.35, respectively. The structural mechanics behavior of the test specimens could be approximated well in case of the NKS experiments, but not in PTSE-2 (see Table 5.1). In the SC tests, structural mechanics results could not be compared with experimental measurements. The largest differences are seen to occur in the PTSE-2A transient (Fig. 4.25). On the other hand, recent evaluations indicate a strong axial dependence of measured CMOD values, which has to be investigated further in connection with the loading assumptions. The restrictions in some finite-element codes to input stress-strain curves only by bilinear approximations produced large scatterbands in the results (CMOD and J-integral). The measured onset of yield is very low $(70 \mathrm{MPa}$ ) compared with the engineering yield stress (255 MPa) quoted for the vessel insert. The value used in the calculations ranges from 200 to $495 \mathrm{MPa}$, dependent on whether the small strain or the larger strain region of the stress-strain curve is approximated well. Furthermore, an increase in 00.2 of $50 \%$ from the vessel insert after transients A and B has been found. All the analyses in Fig. 4.25 assumed material and physical properties to be independent of temperature because corresponding measured data were not available. These factors may have contributed to the large underestimation of the measured CMOD in the experiment. These analysis results highlight the importance of obtaining high-quality material properties and structural response data (CMOD, strains, etc.) from the experiments to model structural behavior of the specimen before performing fracture mechanics evaluations. In particular, variables must be carefully selected and reliably measured to provide a

Table 5.1 Comparative assessment of structural behavior in Project FALSIRE reference experiments

\begin{tabular}{|c|c|c|c|c|c|c|}
\hline & \multicolumn{2}{|c|}{$\begin{array}{c}\text { Availability of mechanical } \\
\text { properties }\end{array}$} & \multicolumn{2}{|c|}{$\begin{array}{c}\text { Measured structural } \\
\text { data }\end{array}$} & \multicolumn{2}{|c|}{$\begin{array}{c}\text { Scatterband of structural } \\
\text { analysis }{ }^{a}\end{array}$} \\
\hline & $T^{b}$-dependent & T-independent & $\begin{array}{c}\text { CMOD }_{\max } \\
(\mathbf{m m})\end{array}$ & Strains & $\begin{array}{c}\Delta \text { CMOD }_{\max } \\
(\%)^{c}\end{array}$ & $\begin{array}{l}\text { Strains } \\
(\%)^{c}\end{array}$ \\
\hline NKS-3 & $\mathbf{X}$ & & 1.5 & $\mathbf{x}$ & 17 & 13 \\
\hline NKS-4 & $\mathrm{x}$ & & 0.54 & $\mathbf{X}$ & 8 & 7 \\
\hline PTSE-2A & & $\mathrm{X}$ & 0.9 & $\mathrm{x}$ & $35^{d}$ & \\
\hline PTSE-2B & & $\mathrm{x}$ & 1.6 & $\mathrm{x}$ & $21^{d}$ & \\
\hline SC-I & $\mathbf{X}$ & & $e$ & & & \\
\hline SC-II & $\mathrm{X}$ & & $e$ & $e$ & & \\
\hline
\end{tabular}

${ }^{a}$ Analysis results with wrong boundary conditions or crack assumptions ignored

${ }^{b} \mathrm{~T}=$ Temperature.

'Relative to measured value.

${ }^{d}$ Underestimation of measured data.

'Some data of crack-tip opening have been provided after evaluation of the analyses. 
minimum set of data for validating these structural models. This requirement was not uniformly achieved in all of the large-scale experiments examined in the Project FALSIRE Workshop.

In applications of $\mathrm{J}_{\mathbf{R}}$ methodology based on smallspecimen data, all analyses correctly distinguished between stable crack extension and ductile instability conditions for each experiment. These include both ES and detailed FE analyses. However, as a technique to predict crack extension, $J_{R}$ methodology was partially successful in some cases (NKS experiments) but not in others (PTSE-2 and SC experiments). Fracture assessments based on CT specimens overestimated stable crack growth in the case of NKS-4, SC-I and -II, and Step B PTS because the crack resistance in the large-scale test specimens is greater than predicted by small specimens (e.g., CT-25). SC-I and -II fracture results show that crack extension can be described quite well with the $J$-integral and the $J_{R}$-curves of the large-scale test specimen. In PTSE-2A, the first phase of stable crack extension is underestimated because the crack loading also represented in CMOD is underestimated. Furthermore, differences between pretest characterization data and posttest in situ data for material and fracturetoughness properties gave rise to questions concerning whether $J_{R}$ curves from $C T$ specimens were representative of the flawed region of the vessel. None of these temperature-dependent $J_{R}$ curves were consistent with all phases of ductile tearing observed in PTSE-2. It should be pointed out that the PTSE-2A transient included load-history (i.e., warm-prestressing) effects that were not incorporated into the $J_{R}$ methodology. A summary of the fracture results is given in Table 5.2.

The substantial differences between fracture toughness curves generated from the SCs and from CT specimens focused attention on other factors. These included the possibility that crack-tip behavior in the SC is not characterized by a single parameter fracture mechanics in terms of J. Alternative criteria under consideration include two-parameter models in which $\mathrm{K}$ or $\mathrm{J}$ is augmented by the next higher order T (Ref. 1) or Q (Ref. 2) in the series expansion of the stresses around the crack tip. Other measures considered in dealing with the transfer of small specimen data to large structures include the stress triaxiality parameter $q$, which is proportional to the rate of hydrostatic to effective stress (Ref. 3). Values of $q$ on a part of the ligament in front of the crack are presented for some experiments in Chap. 4 and Appendix B. These results indicate that $q$ on the ligament is not sensitive enough to represent changes of stress triaxiality responsible for geometry effects on crack resistance. The temperature dependence of the crack resistance measured with $C$ ' $\Gamma$ specimens shows an increase with increasing temperature only for NKS-4 material but a decrease in the cases of PTSE-2 and Step B PTS. Also, the Local Approach has been applied as an alternative to $J_{R}$ methodology for performing fracture-toughness evaluations in the case of NKS-3. For the SCs, clarification of the initial stress state in front of the crack tip (caused by cyclic fatiguing) may be an important consideration.

Table 5.2 Comparative assessment of fracture behavior in Project FALSIRE reference experiments

\begin{tabular}{llccc}
\hline & \multicolumn{1}{c}{$\begin{array}{c}\text { Availability of crack } \\
\text { resistance curves }\end{array}$} & $\begin{array}{c}\text { Measured crack } \\
\mathbf{g r o w t h} \\
\Delta \mathbf{a}(\mathbf{m m})\end{array}$ & \multicolumn{2}{c}{$\begin{array}{c}\text { Scatterband of fracture } \\
\text { analyses }^{a}\end{array}$} \\
\cline { 5 - 5 } & & & $\mathbf{J}(\mathbf{N} / \mathbf{m m})$ & $\Delta \mathbf{a}(\mathbf{m m})$ \\
\hline NKS-3 & $\mathrm{CT}-25, \mathrm{~T}=160 / 220^{\circ} \mathrm{C}$ & 3.6 (averaged) & $410-500$ & $3.0-4.8$ \\
& $\mathrm{CT}-50, \mathrm{~T}=220^{\circ} \mathrm{C}$ & & \\
NKS-4 & $\mathrm{CT}-25, \mathrm{~T}=160 / 240 / 280^{\circ} \mathrm{C}$ & $1.5^{b}$ & $180-220^{b}$ & $2.0-3.2^{b}$ \\
& $\mathrm{CT}-25\left(10 \mathrm{~mm}\right.$ thick), $\mathrm{T}=160^{\circ} \mathrm{C}$ & & & \\
PTSE-2A & $\mathrm{CT}-25, \mathrm{~T}=100 / 175 / 250^{\circ} \mathrm{C}$ & 5.1 & $100-175$ & $1.0-2.5$ \\
PTSE-2B & $\mathrm{CT}-25, \mathrm{~T}=100 / 175 / 250^{\circ} \mathrm{C}$ & 3.7 & $145-225$ & $1.4-2.9$ \\
SC-I & $\mathrm{CT}-35, \mathrm{~T}=290^{\circ} \mathrm{C}$ & 2.8 (averaged) & $470-560$ & $3.2-4.2^{d}$ \\
& $\mathrm{SC}-\mathrm{I}$ test specimen & & & \\
SC-II & $\mathrm{CT}-35, \mathrm{~T}=150 / 290^{\circ} \mathrm{C}$ & 0.75 & $200-490$ & $0.2-0.8^{d}$ \\
& $\mathrm{SC}-\mathrm{II}$ test specimen & & & \\
\hline
\end{tabular}

${ }^{a}$ Analysis results with wrong boundary conditions or crack assumptions ignored.

${ }^{\circ}$ Deepest point of partly circumferential crack.

'Midrle of axial crack.

${ }^{d}$ Det.rmined with $\mathrm{J}_{1}$ curves of $\mathrm{SC}$ test specimen. 


\section{References}

1. A. M. Al-Ani and J. M. Hancock, "J-Dominance of Short Cracks in Tension and Bending," $J, M \in c h$. Phys. Solids 39(1), 23-43 (1991).*

2. N. P. O'Dowd and C. F. Shih, "Family of Crack-Tip Fields Characterized by a Triaxiality Parameter: Part I-Structure of Fields," J. Mech. Phys. Solids 39(8), 989-1015 (1991).*
3. H. Clausmeyer, K. Kussmaul, and E. Roos, "Influence of Stress State on the Failure Behavior of Cracked Components Made of Steel," ASME Bcok No. AMR090, Appl. Mech. Rev. 44(2) (February 1991)."

*Available in public technical libraries. 


\section{Proposals fo- Future Work}

In Phase I of the FALSIRE Project. a variety of different large-scale experiments were analyzed by a large number of research teams from different countries. Five out of the six experiments analyzed were experiments that showed a limited amount of stable crack extension, 1 to $6 \%$ of the initial crack depth, all in the ductile regime. Only one experiment included crack extension in a cieavage anc unstable mode. In four experiments, the initial crack was rather deep, a/t ranging between 0.3 and 0.54 .

For mosi of the experiments, three or more analyses were performed by teams that were not connected to the organization performing the tests. Through the broad international participation, the number of applied analyses, and the intensive communication between the different experts, a good understanding of the treatmer $i$ nf combined thermal and mechanical loawing in fracture mecharics analysis was achieved. The comparison of different steps of the analyses, including the influence of input parameters to the analyses on the results, provided further insignt into applications of the fracture methodclogy. As a result of this exercise conclusions can be drawn regarding the exterit 0 : the companion materials investigation programs necessary for such tesis, as well as the extent of the instrumentation used to measure the structure arid fracture mechanics parameters. Important observations in these arens follow:

- Material investigations in thic whole range of temperatures experienced in the tests are necessary.

- Extended fracture resistance tests to measure the geometry dependence are r.ecessary.

- Pretest calculations are very helpful in determining the extent and location of instrumentation.

- In some cases, the information on the final unloadirg paths has not been recorded; this information is very holpful in determining the state of residual stresses.
Further clarification of differences in the results of the analyses could be achieved if limited additional investigations were conducted in the following areas: (1) missing material properties, for example, constraint-dependent crack resistance curves in case of the Step B test, NKS-4, and SC-I/-II; and (2) further test information, for example, the loading conditions in the case of PTSE-2. However, the information contained in this report could be used for further analysis based on individual interest.

Organizations involved in Phase I of the FALSIRE Project have a desire to proceed with this work regarding the verification of fracture mechanics analysis methods for combined mechanical and thermal loading conditions in a following Phase II. Stimulated by the somewhat unfavorable results of the analyses of the PTSE-2 experiment, the main objective of Phase II should be to investigate cracks of linited depth and preferably, showing two stages of crack extension. An example would be limited stable crack extension followed by limited unstable crack extension. Furthermore, special attention should be given to the behavior of shorter cracks. Investigation of crack extersion in connection with clad surfaces is of special interest.

Ongoing experimental research programs are being performed in this area in France, Germany, Japan, the U.K., and also in the Russian Republic. Contacts have been established with the different organizations involved in these tests. Reference documents that could be used to document the information available are uncer preparation. Two or three tests that would fulfill the outlined goals will be selecteo in the coming months. A call for participation in Phase II is foreseen in the first half of 1993. 


\section{ACKNOWLEDGMENTS}

We thank the sponsoring national organizations and the participants (see Table 1.2) for their cooperation in supplying the experimental data and performing the analytical work for the CSNI/FAG Project FALSIRE.
Appreciation is extended to B. R. Coppin of Martin Marietta Energy Systems, Inc. (U.S.A.), for typing the manuscript. 
Appendix A

Standard Format for Test and Analysis Documentation 


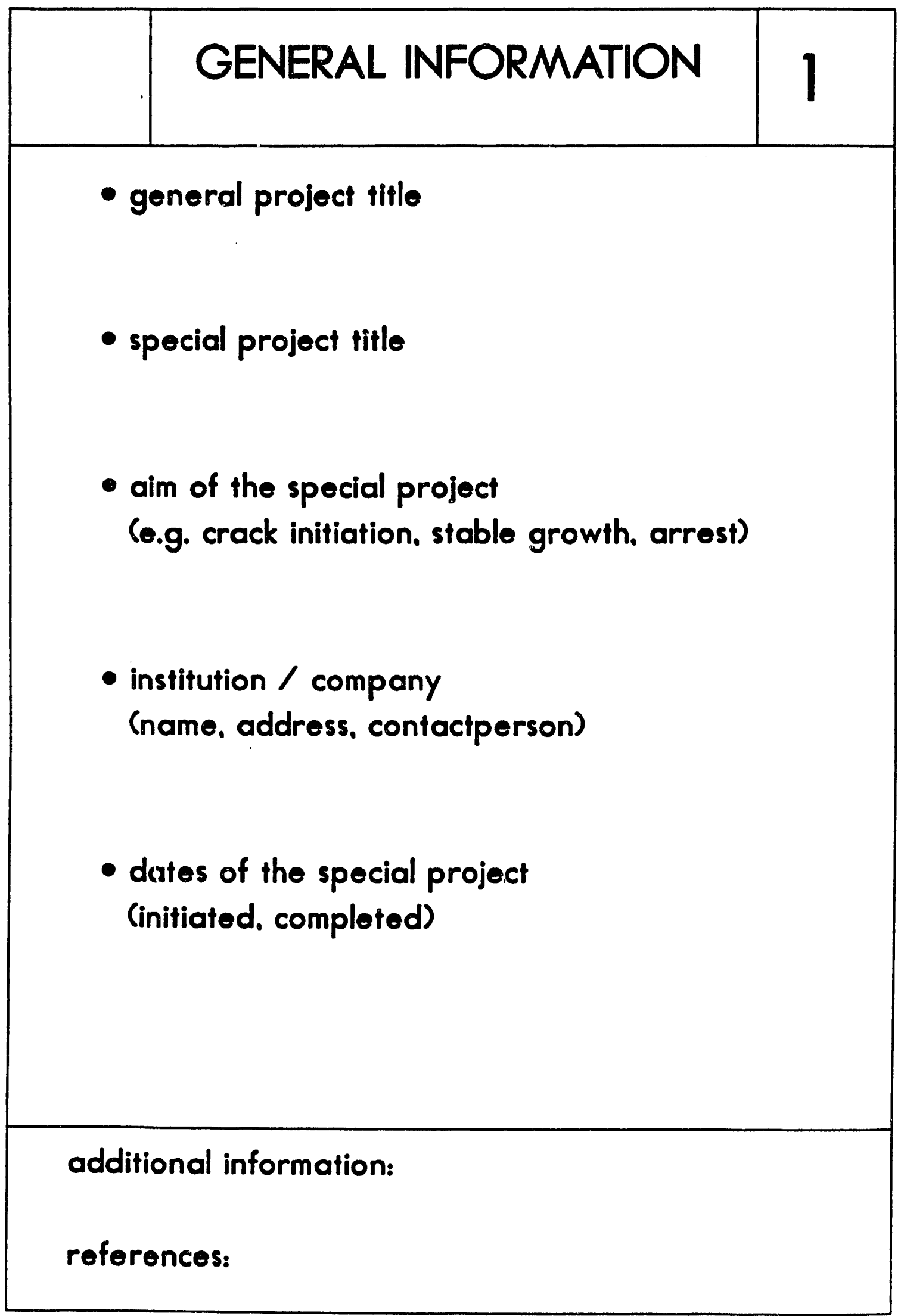


Appendix A

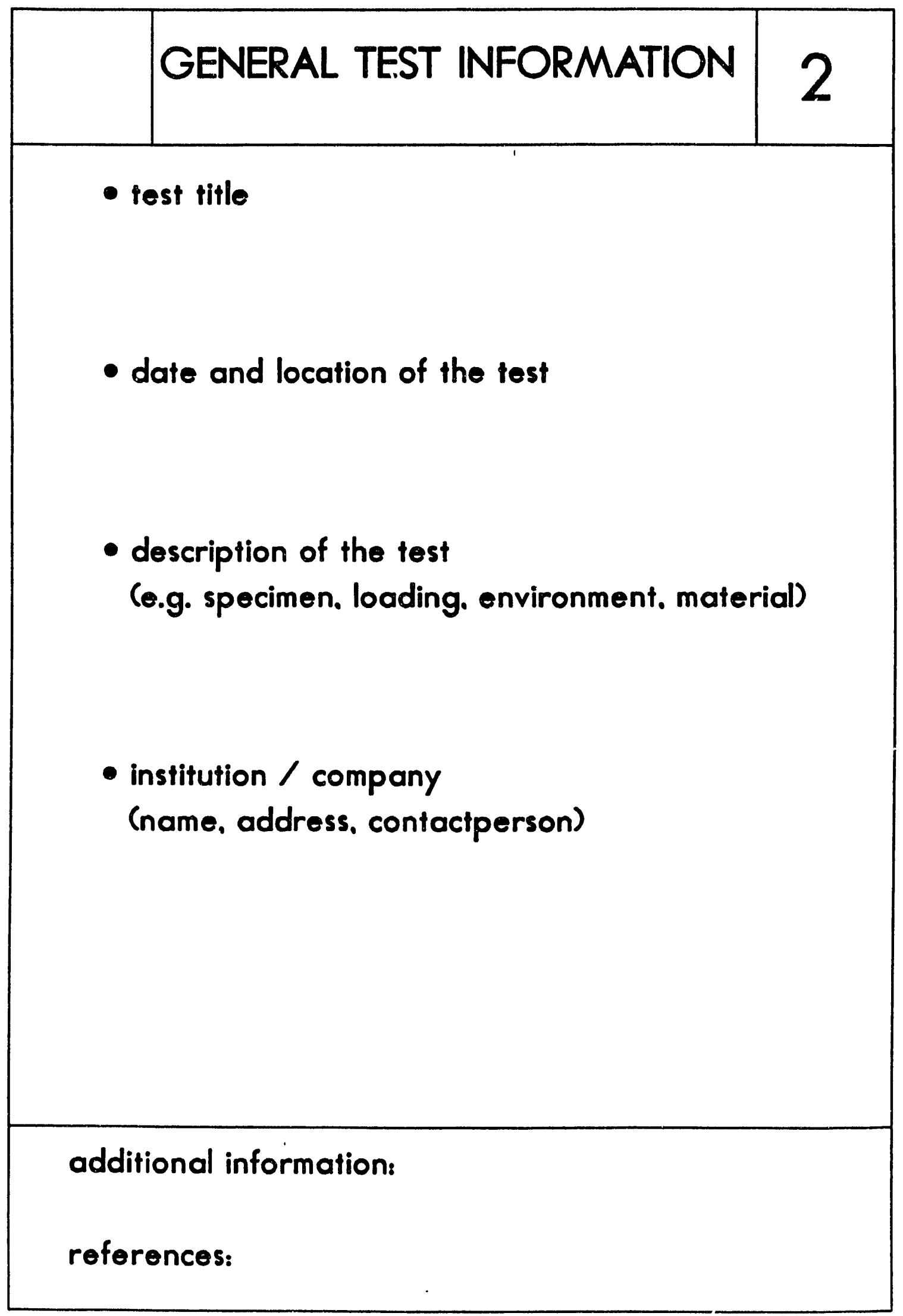




\section{GENERAL INFORMATION ON DOCUMENTATION . DATE:

- description of documentation (experiment. pre/postcalculation)

- institution \% company

(name, address, contactperson)

- dates of the project (initiated. completed)

additional information:

references: 


\section{LOADING CONDITIONS}

- initial conditions

(e.g. pressure, temperature, environment)

- loading during the test

(e.g. pressure, temperature, axial force)

additional information: 


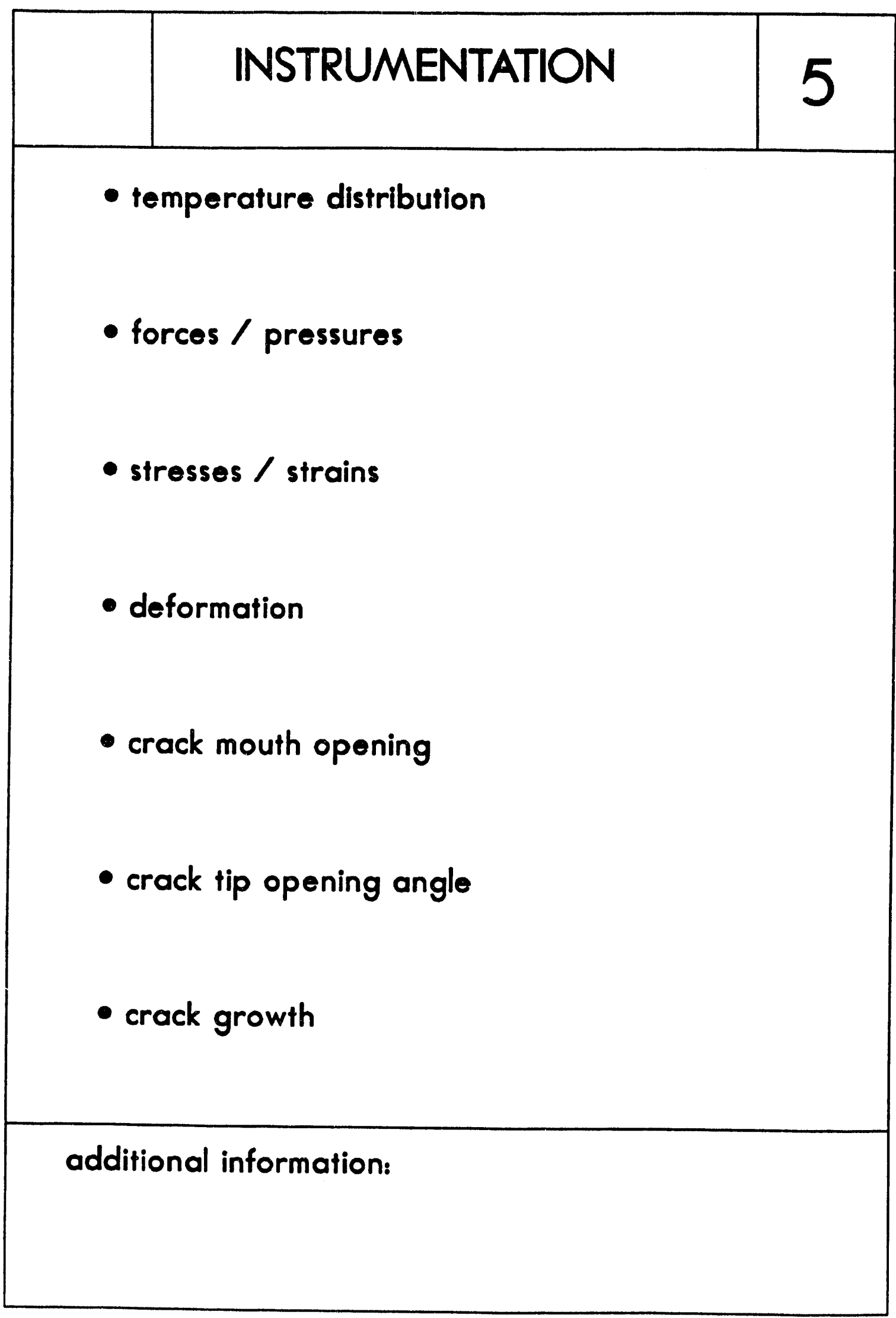




\section{GEOMETRICAL CHARACTERISTICS}

- component geometry (figures)

(e.g. radius, thickness)

- flaw characteristics (figure)

(e.g. crack profile, direction)

- fatigue pre-cracking $\mathrm{Y} / \mathrm{N}$

- cladding Y/N

(thickness)

additional information: 


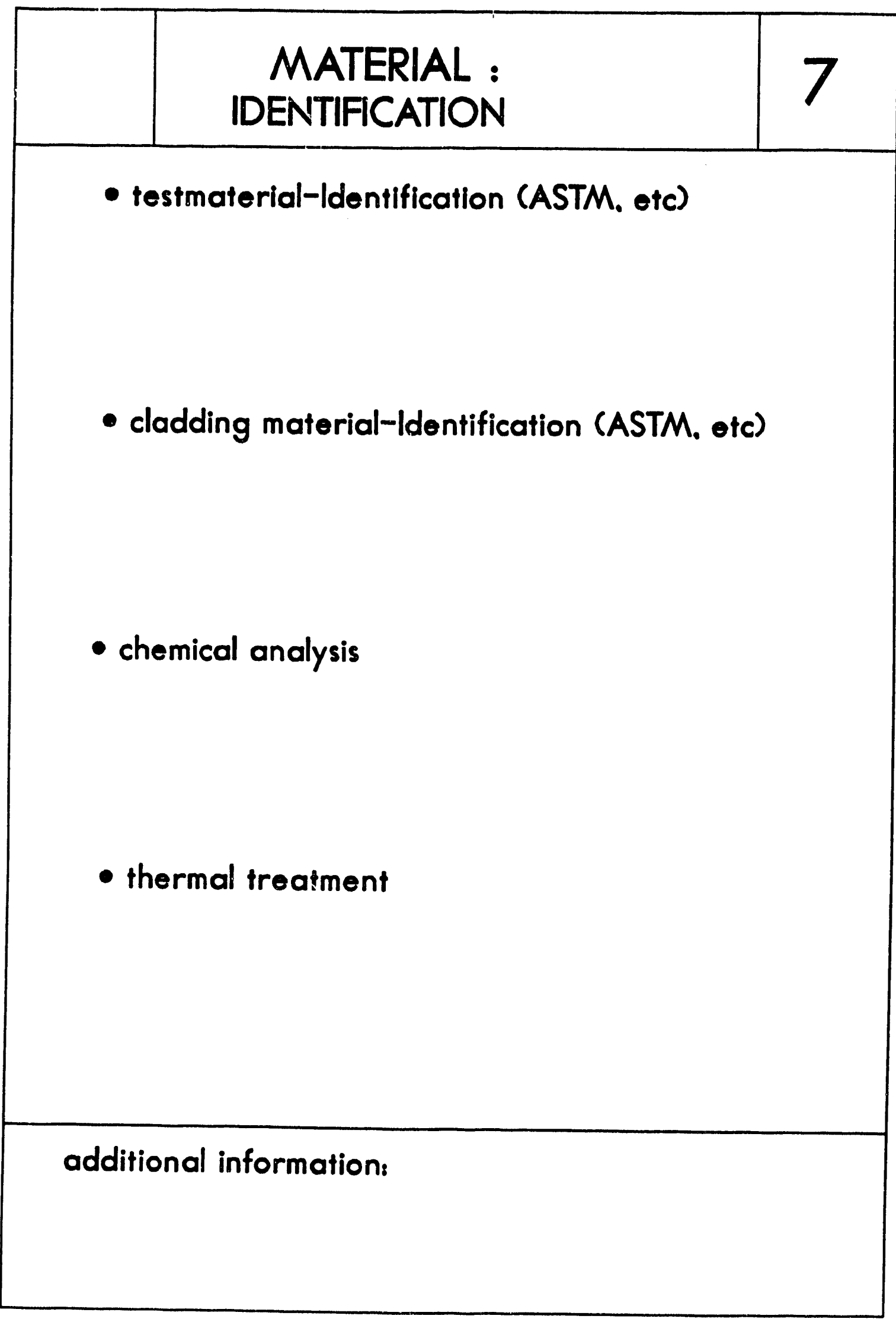


Appendix A

\begin{tabular}{|l|c|}
\hline & MATERIAL : \\
MECHANICAL PROPERTIES & 8 \\
\hline - test temperatures & \\
- engineering and true stress - strain \\
tensile data and curves, numerical approximation for \\
analysis (temperature dependence. multi/bilinear...) \\
E-Modul [ MPa ] \\
$R_{\text {po.2 }}[$ MPa ] \\
$R_{M}[$ MPa ] \\
As and Z \\
Poisson'ratio \\
Ramberg-Osgood-coefficients:
\end{tabular}




\section{MATERIAL : PHYSICAL PROPERTIES}

- heat convection coefficient *)

$\mathrm{h}\left[\mathrm{W} / \mathrm{m}^{* * 2} \mathrm{~K}\right]$

- thermal conductivity *)

$\lambda[\mathrm{W} / \mathrm{m} \mathrm{K}]$

- specific heat capacity *)

$$
\mathrm{c}_{\mathrm{p}}[\mathrm{kJ} / \mathrm{kg} \mathrm{K}]
$$

- density *)

$\rho\left[\mathrm{kg} / \mathrm{m}^{* * 3}\right]$

- coefficient of thermal expansion *)

$\alpha[1 / \mathrm{K}]$

additional information:

*) numerical approximation for analysis

(time/temperature dependence. multi/bilinear) 


\section{MATERIAL : \\ FRACTURE MECHANICS PROPERTIES

- Charpy energy versus temperature (curve)

- Charpy impact energy for upper shelf

- RT-NDT

- $K_{\mathrm{lc}}$ versus temperature (curve)

- $K_{\mathrm{la}}$ versus temperature (curve)

additional information: 


\section{MATERIAL : \\ FRACTURE MECHANICS PROPERTIES}

- $J_{R}$ curve *): specimen / geometry $(a / w)$

- fatigue pre-cracking $Y / N$

- $J_{R}$ curve determination method

- J, fracture initiation value

- J, determination method

additional information:

*) with respect to the dependence of $J_{R}$ - curves on specimen geometry a series of curves is desirable. 
Appendix A

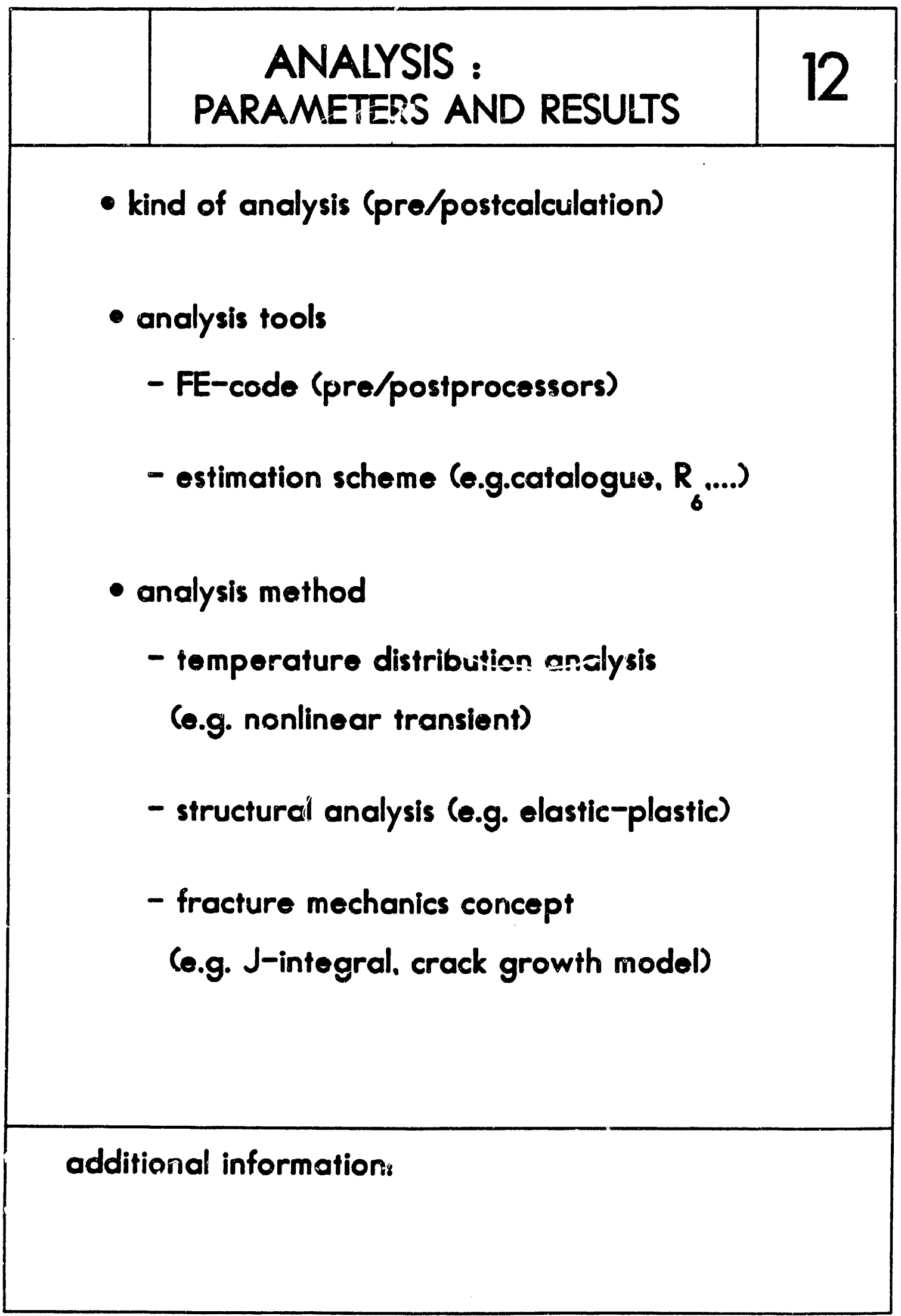




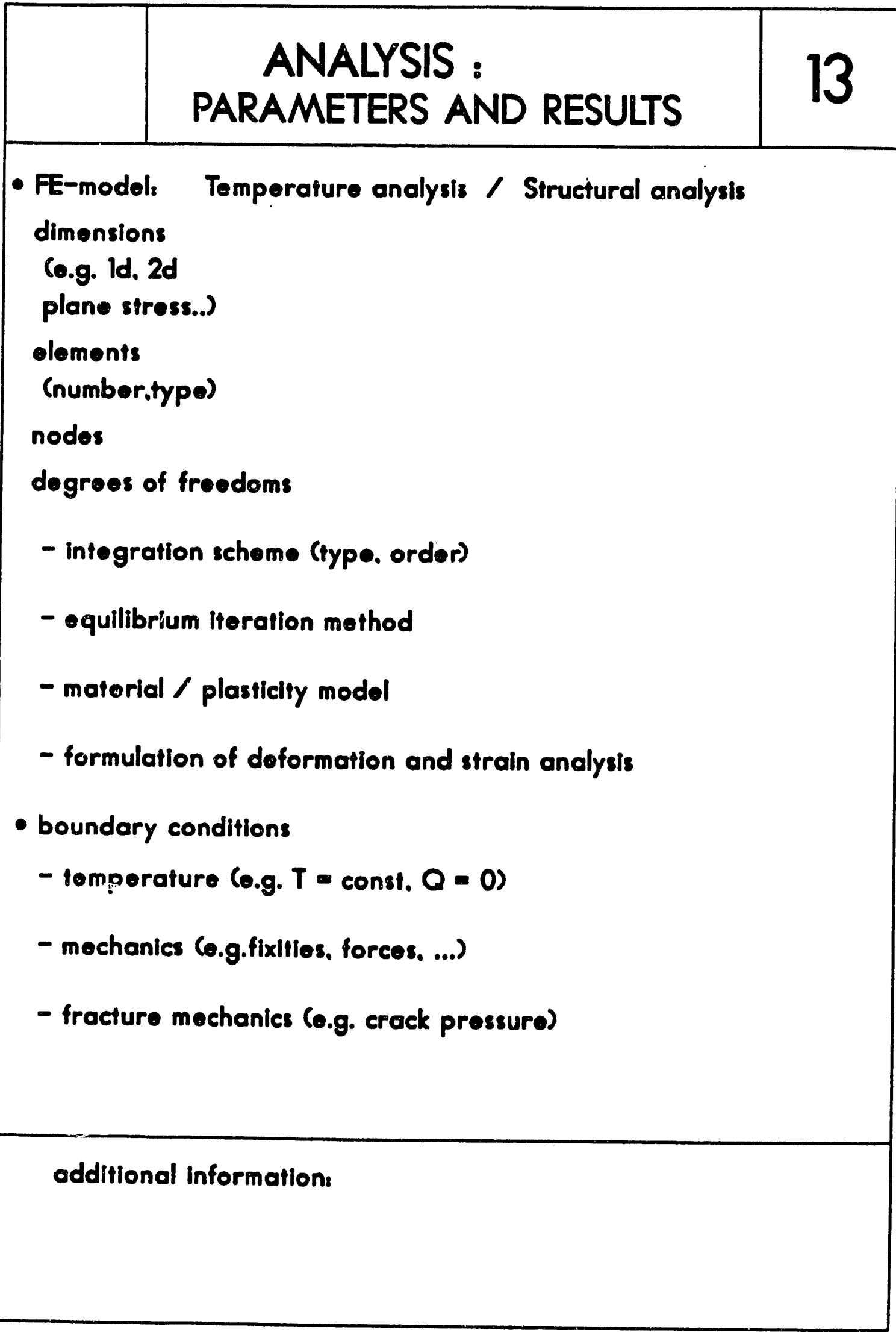




\section{ANALYSIS : PARAMETERS AND RESULTS}

- results (values,lists,diagrams,comparision with experiment)

- temperature distribution (time history:radial.axial..)

- deformed geometry

- crack opening (time history)

- stresses / strains (time history. plastic zone)

- J-integral (time history, along crackfront....)

- J-path dependence

- crack growth

- maximum loads

- failure assessment additional information: 


\section{EXPERIMENT : DETAILS AND RESULTS}

- measured data

(vulues, lists, diagrams, comparison with analysis)

- temperature distribution (time history:radial,axial..)

- deformation (time history)

- crack opening (time history)

- stresses / strain (time history)

- forces (time history)

- J-integral (method, time history)

- crack opening angle

- crack growth (time history)

additional information: 
Appendix A

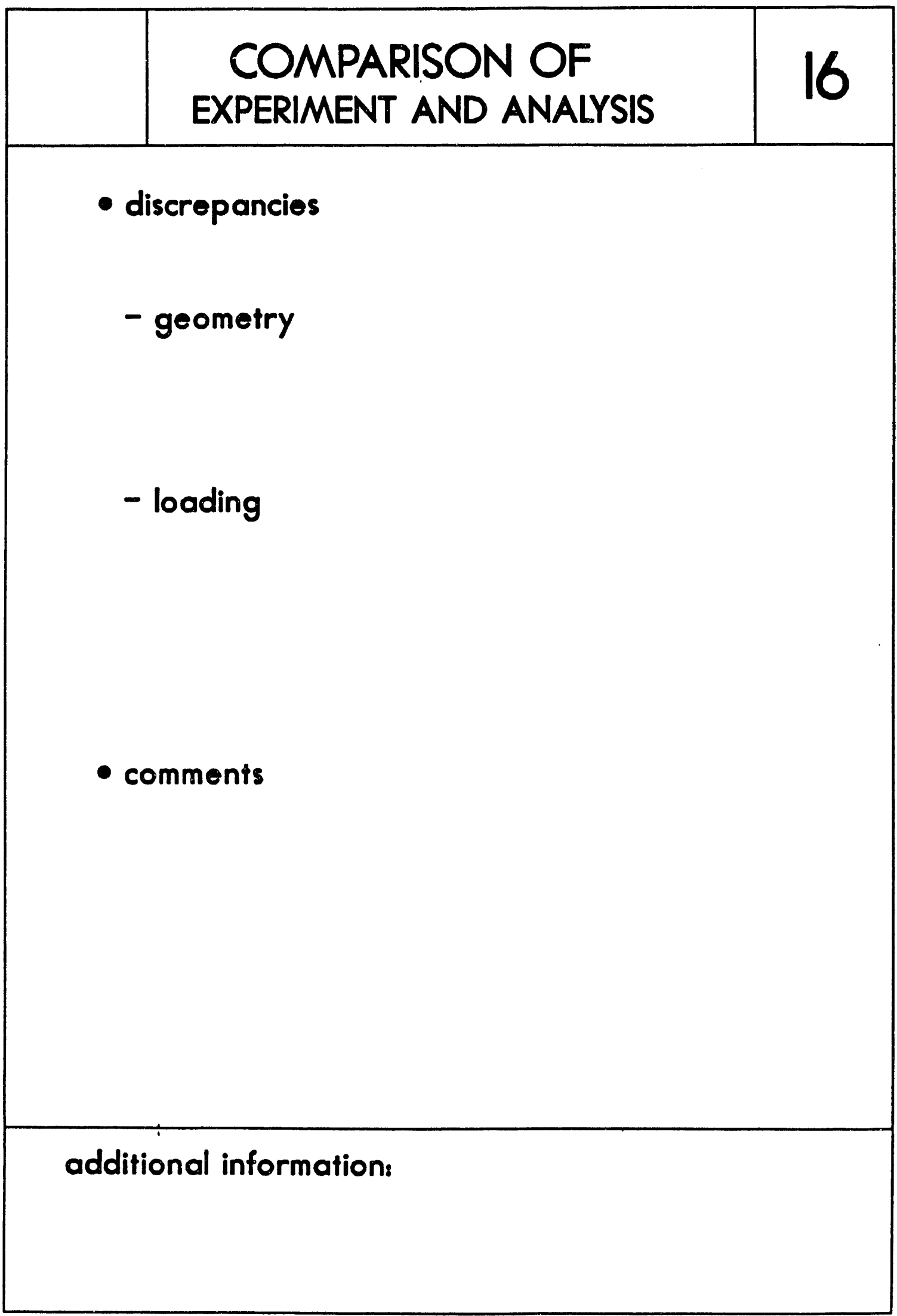


Appendix B

Additional Analysis Results from Project FALSIRE 
ORNL-DWG 93-2326 ETD

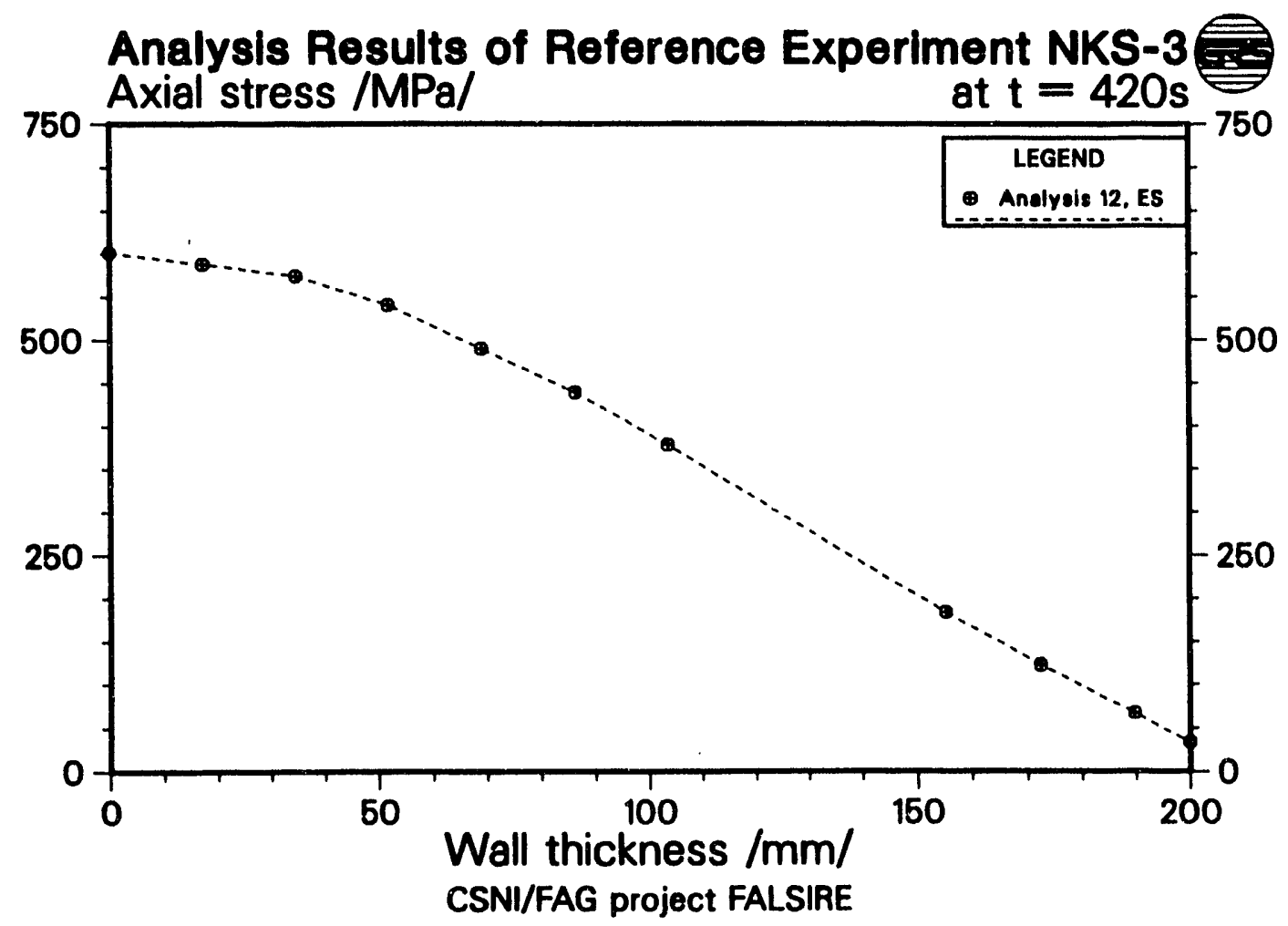

Fig. B.1. Axial stresses vs wall thickness $t=420 \mathrm{~s}$ (NKS-3 experiment).

ORNL-DWG 93-2327 ETD

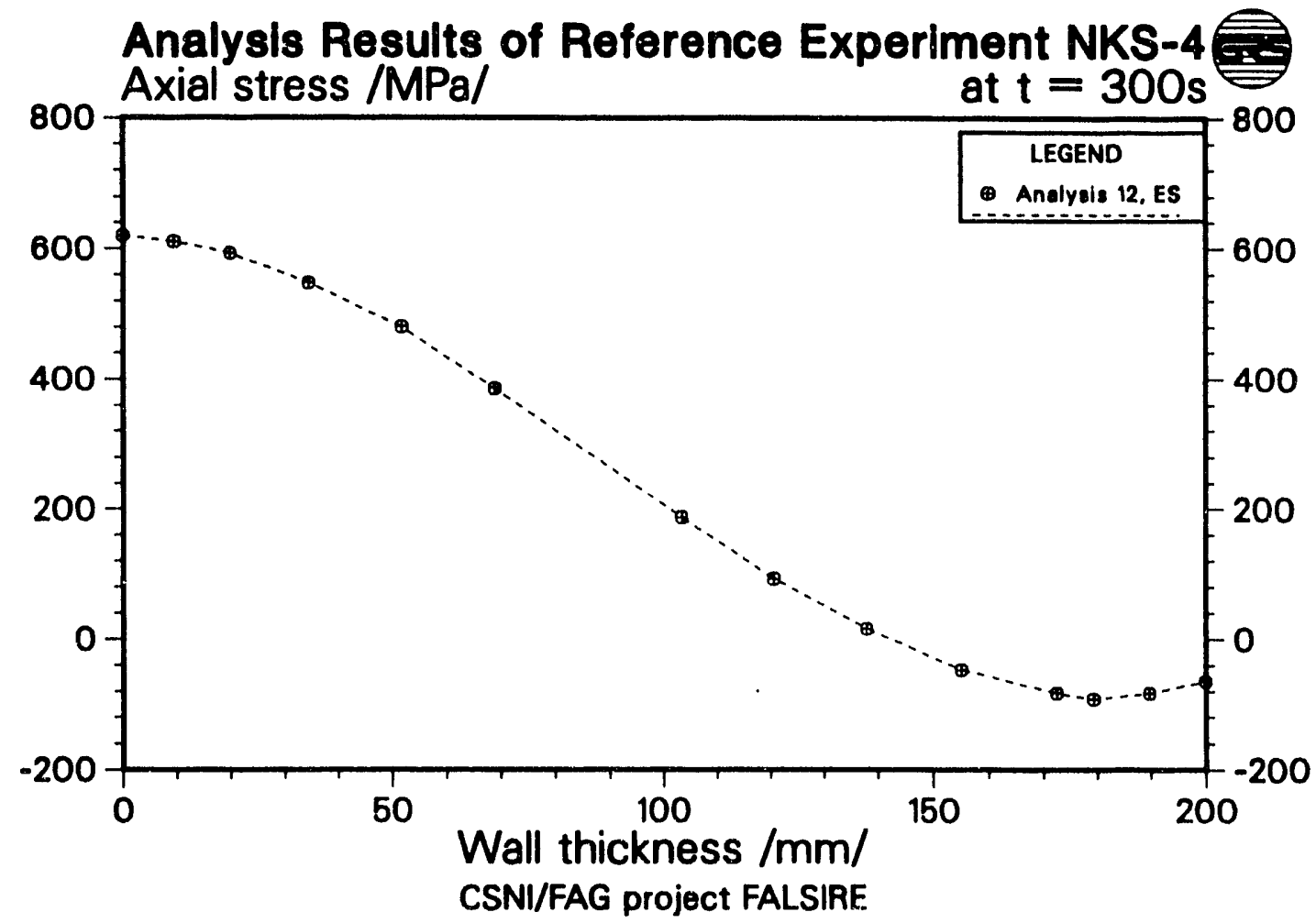

Fig. B.2. Axial stresses vs wall thickness $t=300 \mathrm{~s}$ (NKS-4 experiment). 


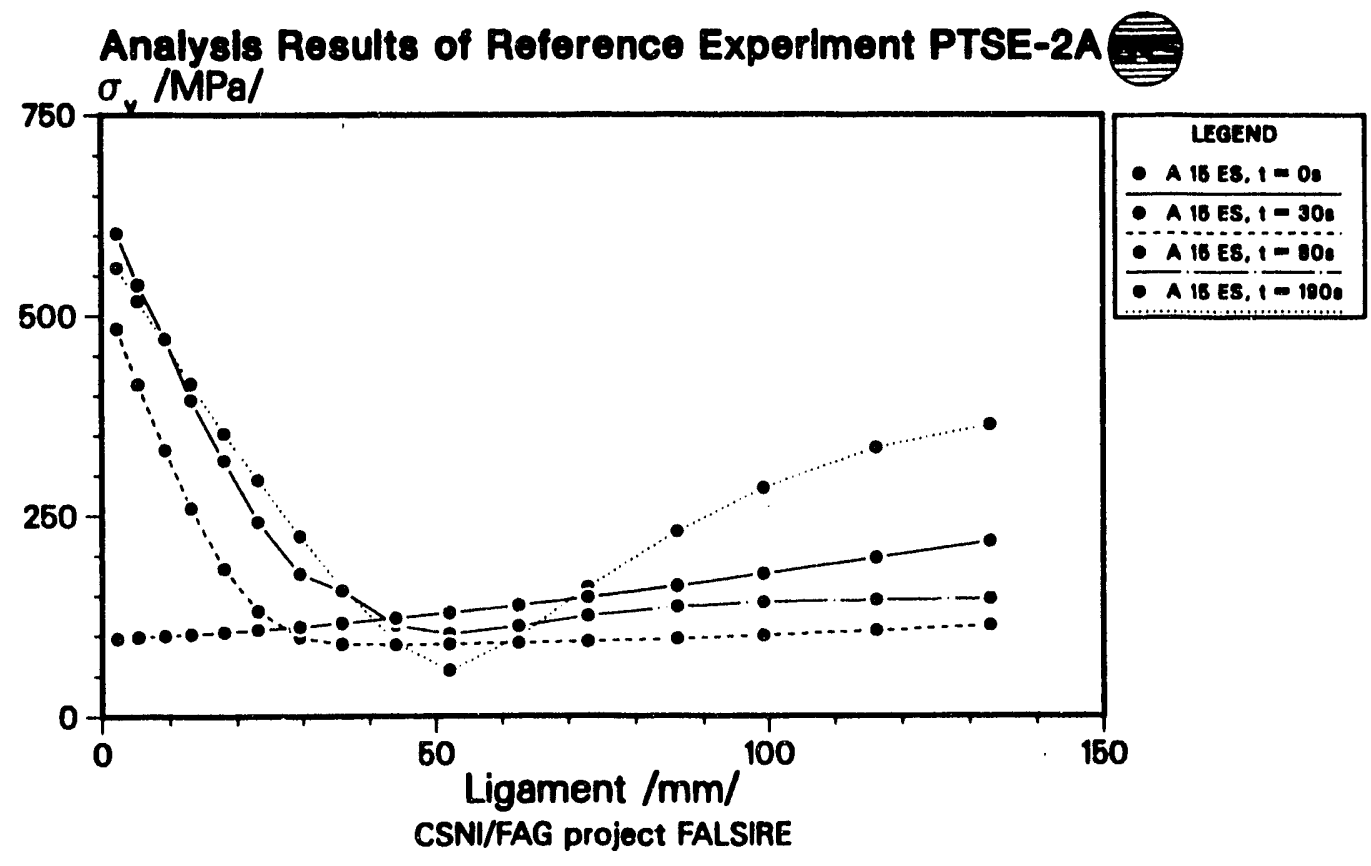

Fig. B.3. Effective stresses on the ligament $t=0,30,80$, and $190 \mathrm{~s}$ (PTSE-2A experiment).

ORNL-DWG 93-2329 ETD

\section{Analysis Results of Reference Experiment PTSE-2A}

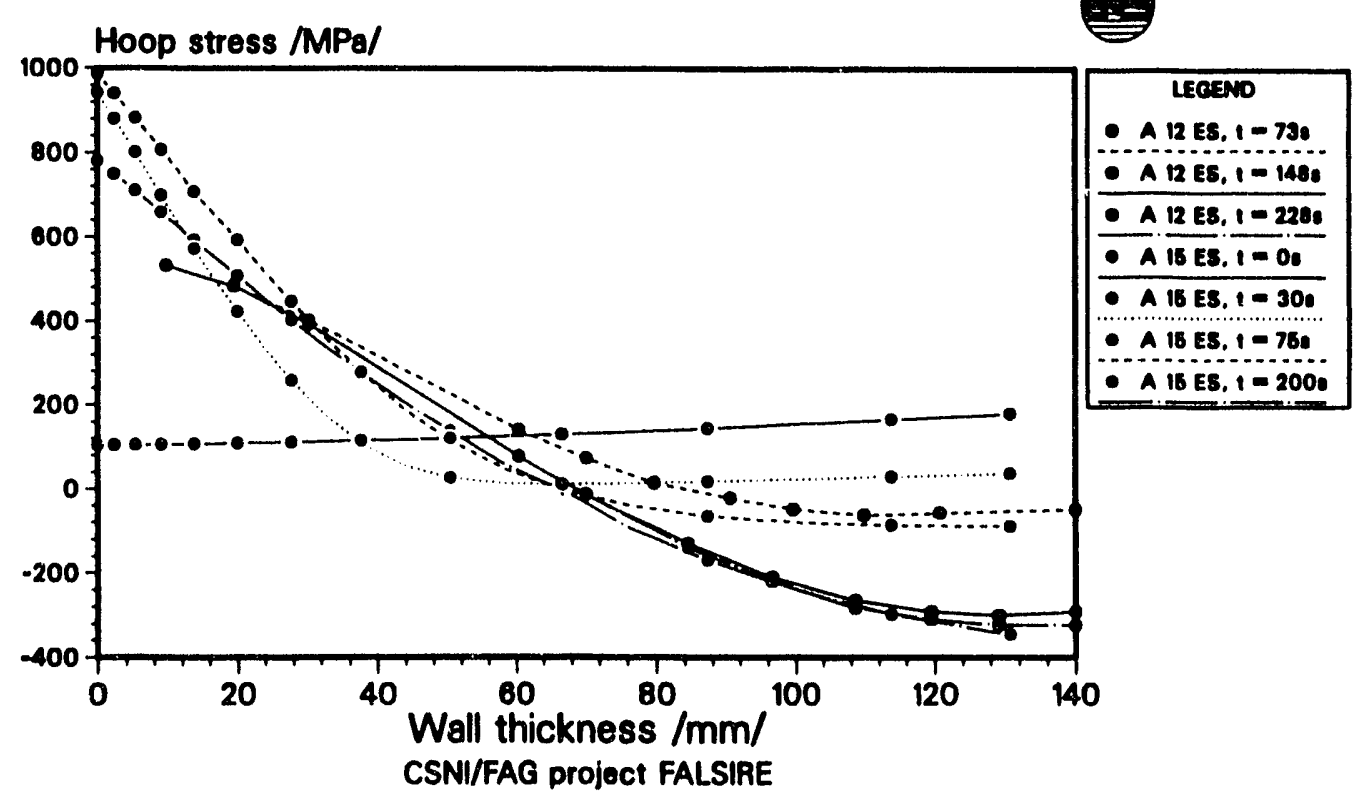

Fig. B.4. Hoop stresses vs wall thickness for PTSE-2A. 
ORNL-DWG 93-2330 ETD

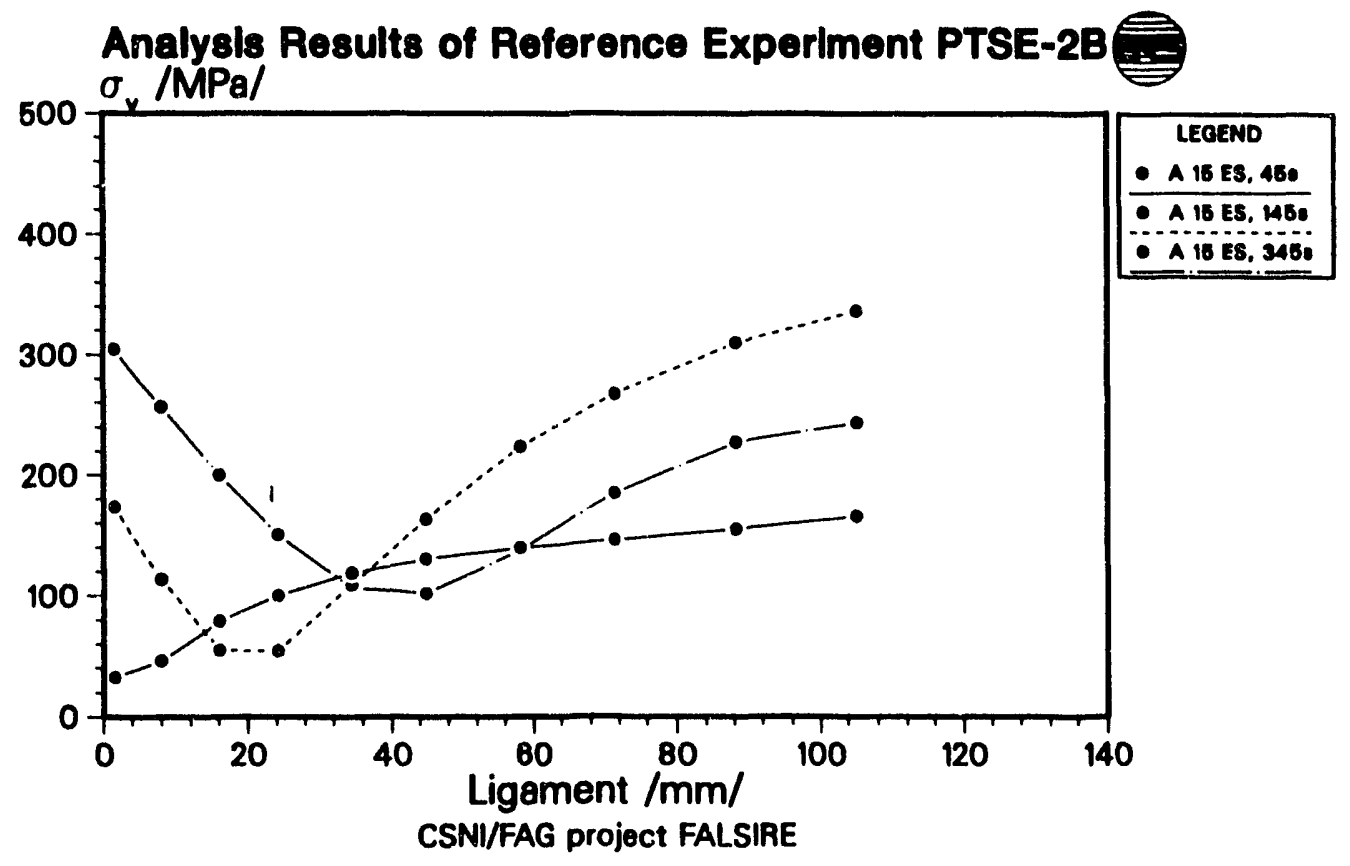

Fig. B.5. Effective stresses on ligament $t=45,145$, and $345 \mathrm{~s}$ (PTSE-2B experiment).

ORNL-DWG 93-2331 ETD

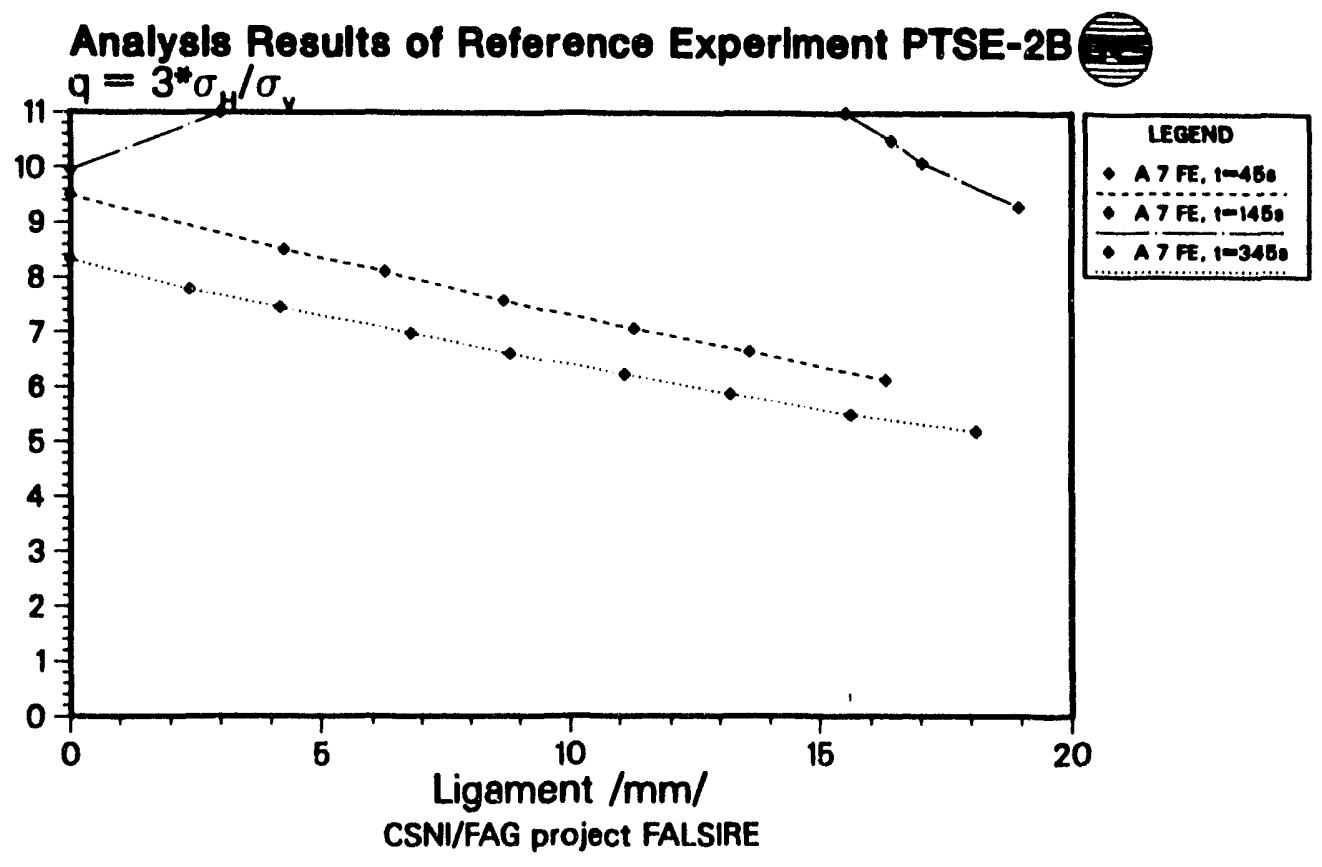

Fig. B.6. Stress triaxiolity on ligament for PrSE=2B. 
Appendix B

ORNL-DWG 93.2332 ETD

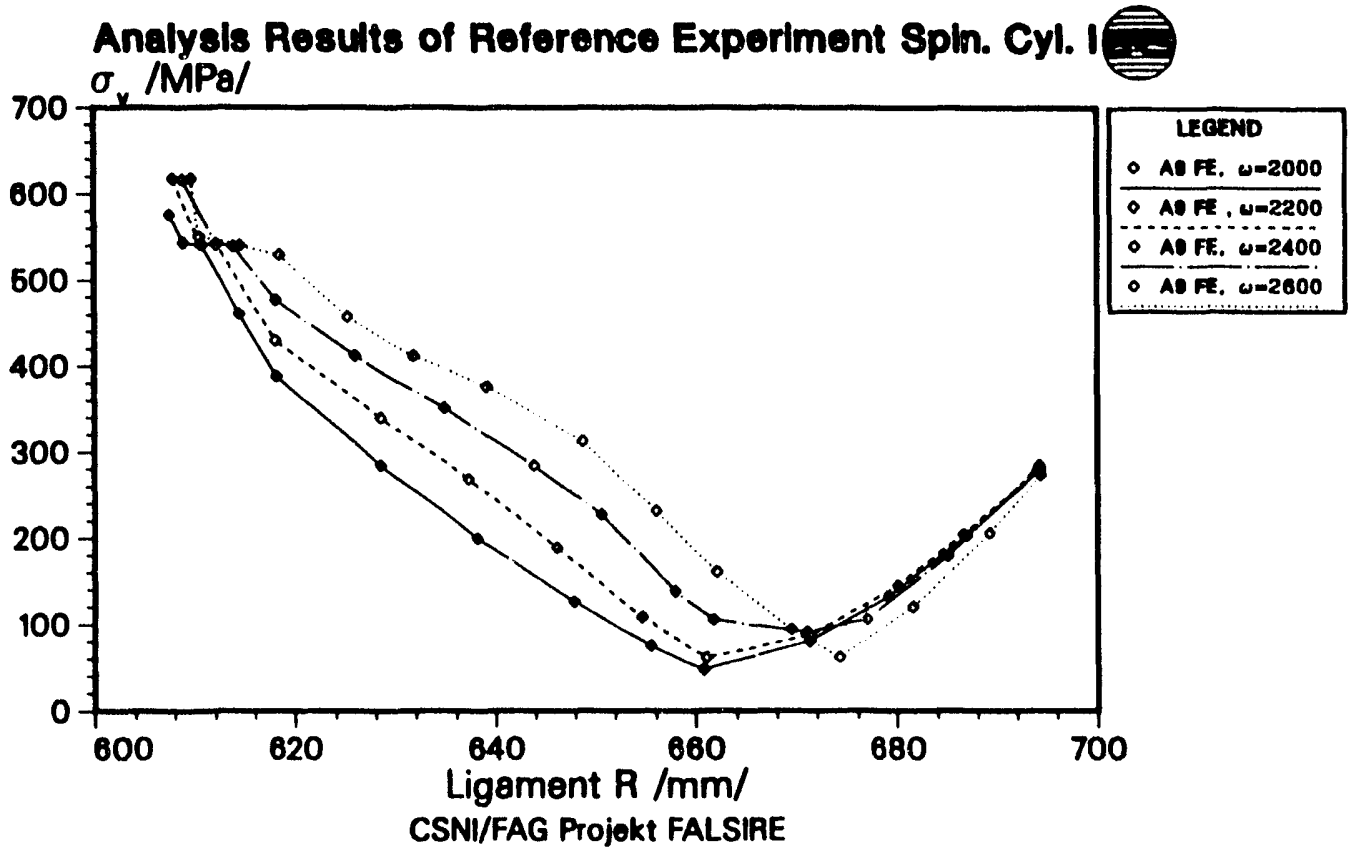

Fig. B.7. Efrective stresses on ligament for SC-I.

ORNL-DWG 93-2333 ETD

Analysis Results of Reference Experiment Spln. Cyl. I

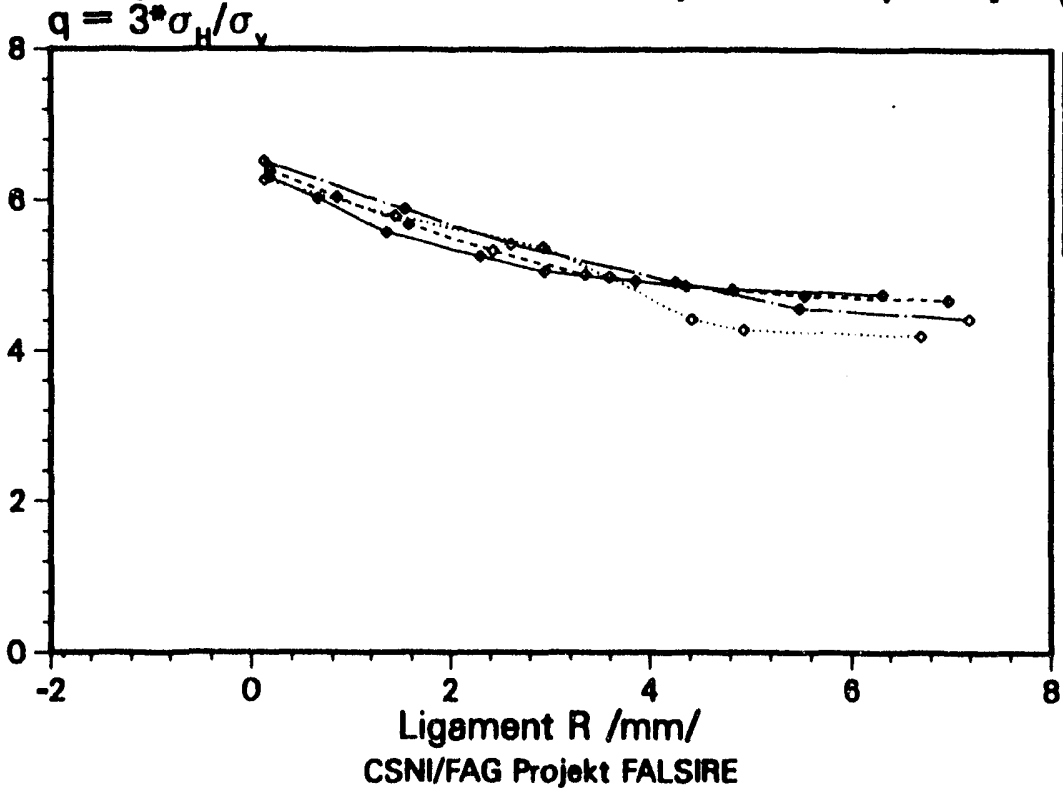

LEOEND

- AD FE, -2000

- A FE,W $=2200$

- $A O P E, \omega=2400$

- $A O \overline{F . \omega}=2600$.

Fig. B.8. Stress triaxiality on ligament for SC-I. 
OANL-DWG 93-2334 ETD

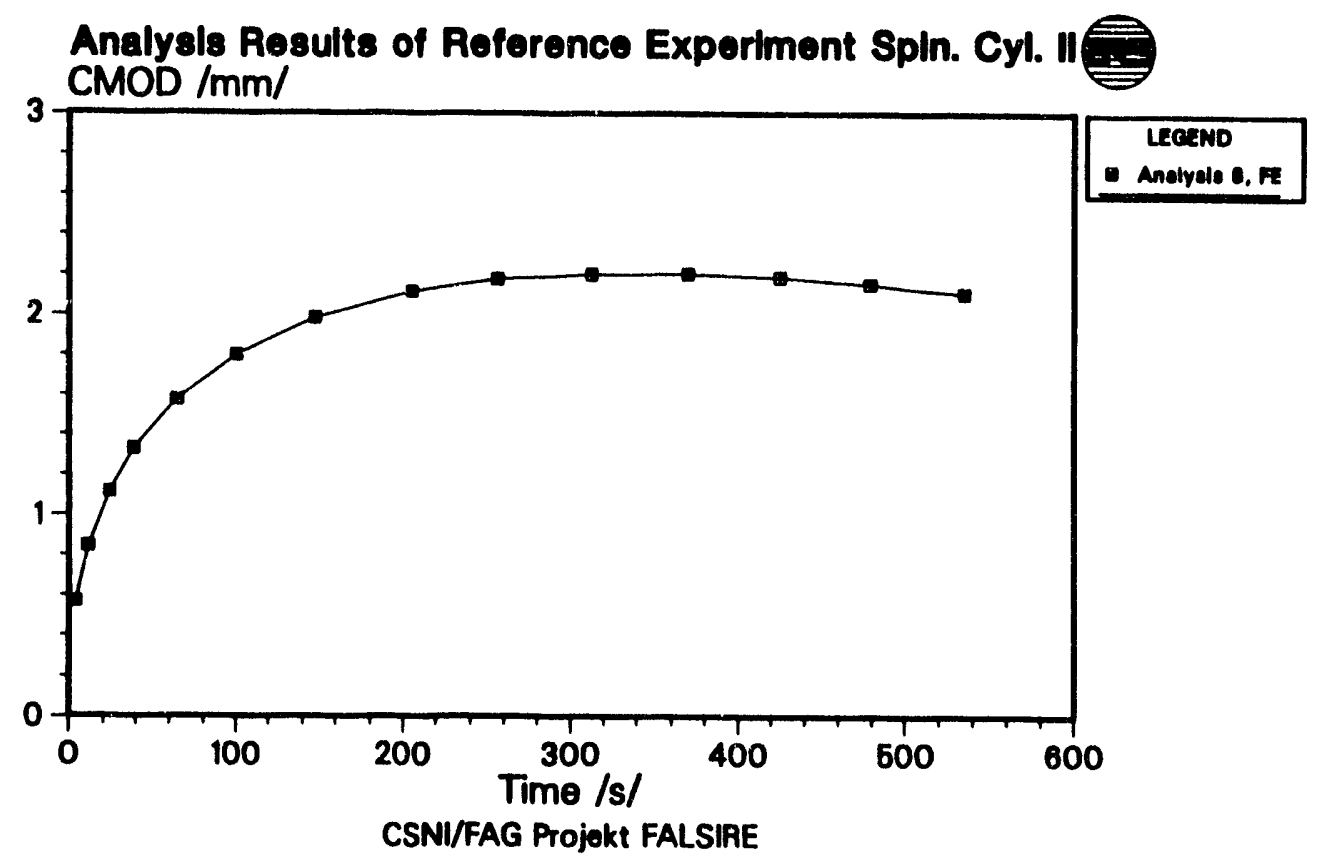

Fig. B.9. CMOD vs time for SC-II.

ORNL-DWG 93-2335 ETD

Analysis Results of Reforence Experiment Spln. Cyl. ॥

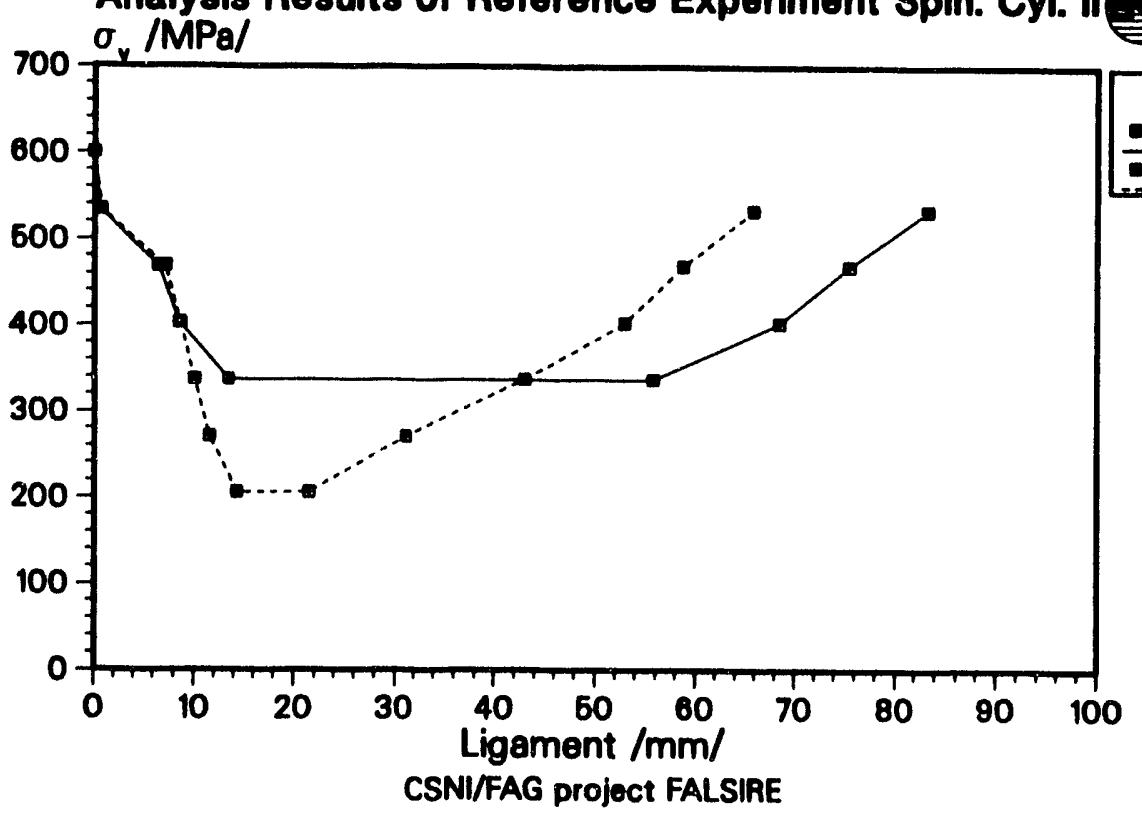

LECEND

$\frac{A O F_{E}, 1-1000}{-A B E_{1} 1-4800}$

Fig. B.10. Effective stresses on ligament (SC-II experiment). 
ORNL-DWG 93-2336 ETD

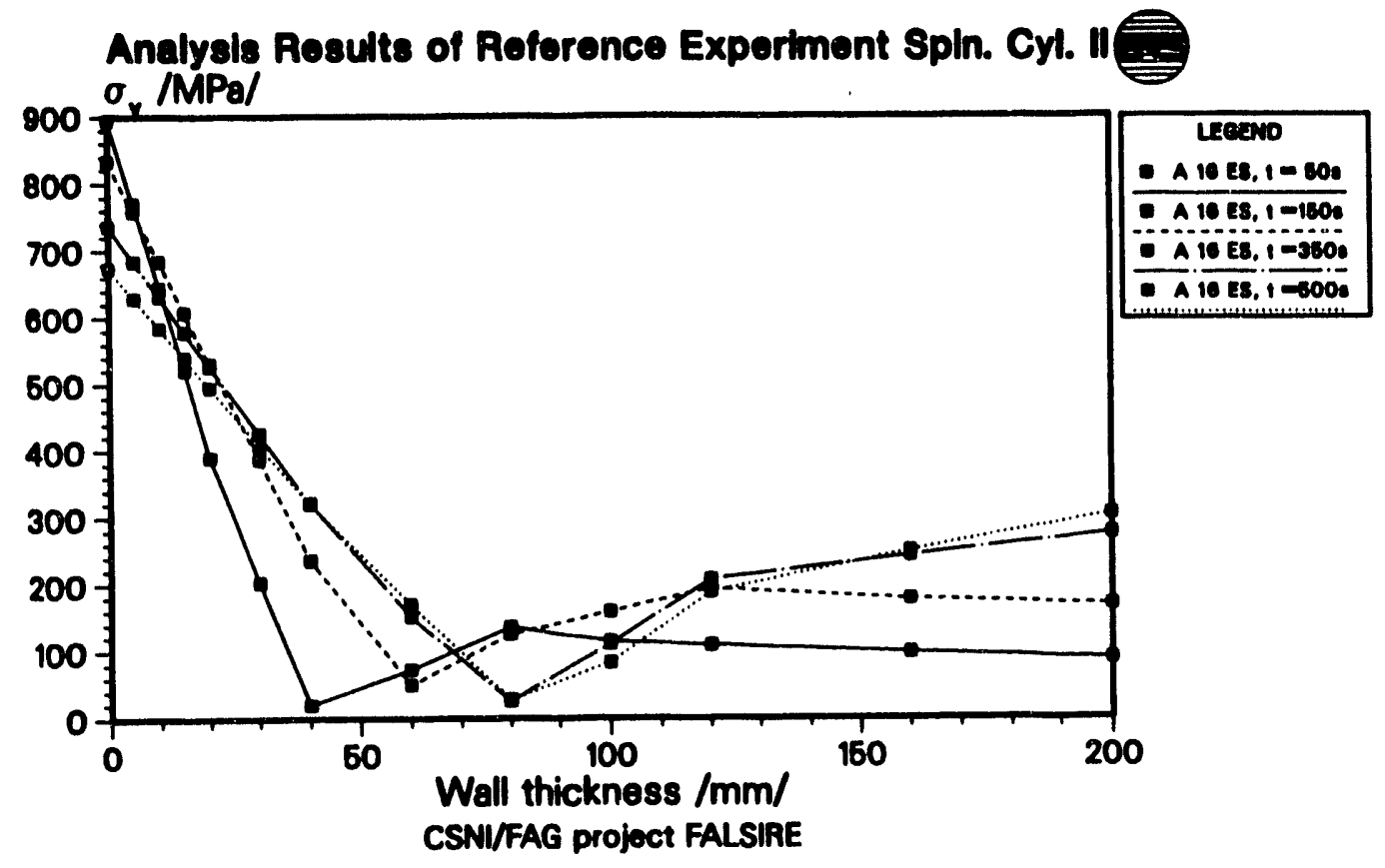

Fig. B.11. Effective stresses vs wall thickness (SC-II experiment).

OANL-DWG 93-2337 ETD

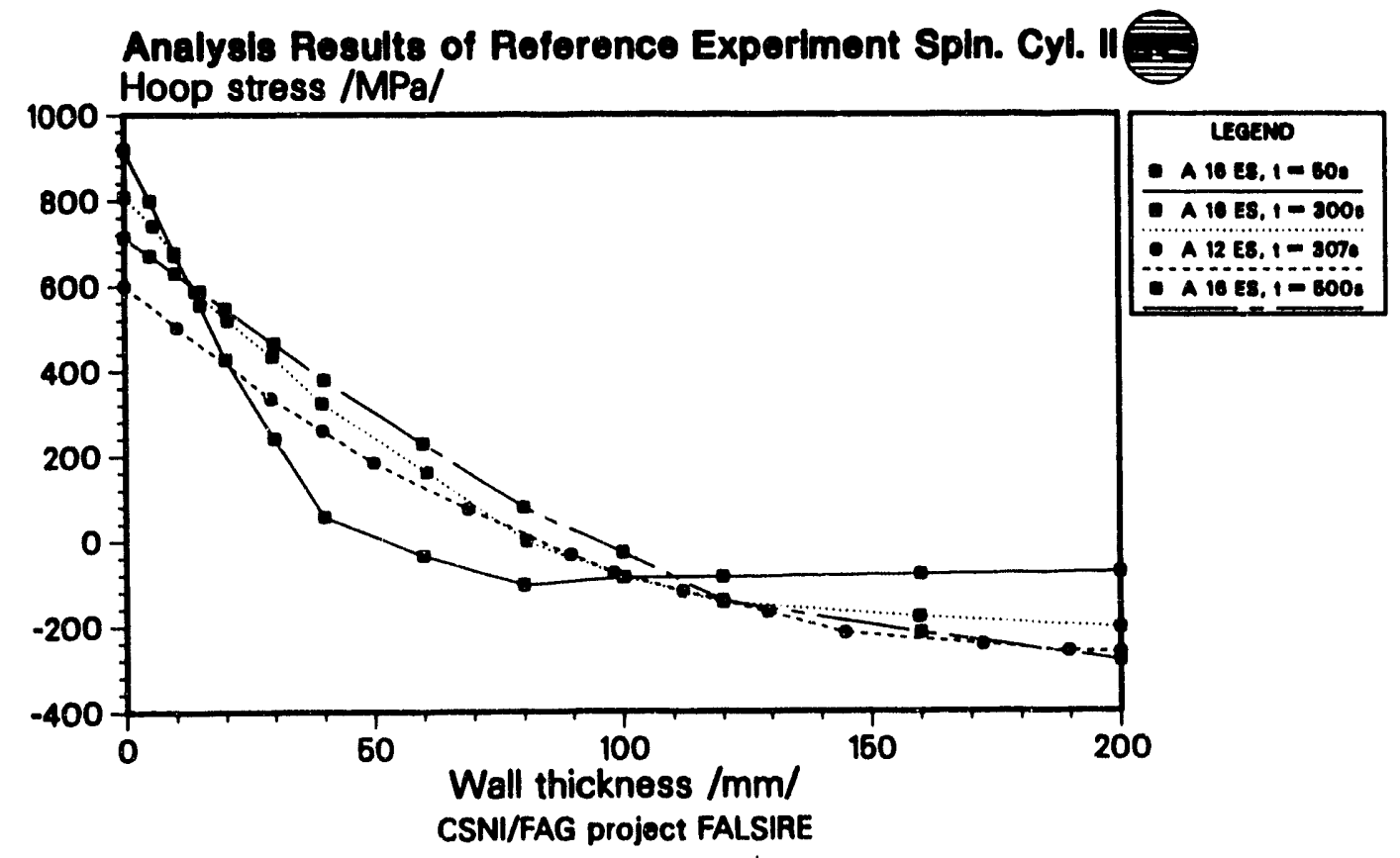

Fig. B.12. SC-II, hoop stresses vs wall thickness (SC-II experiment). 

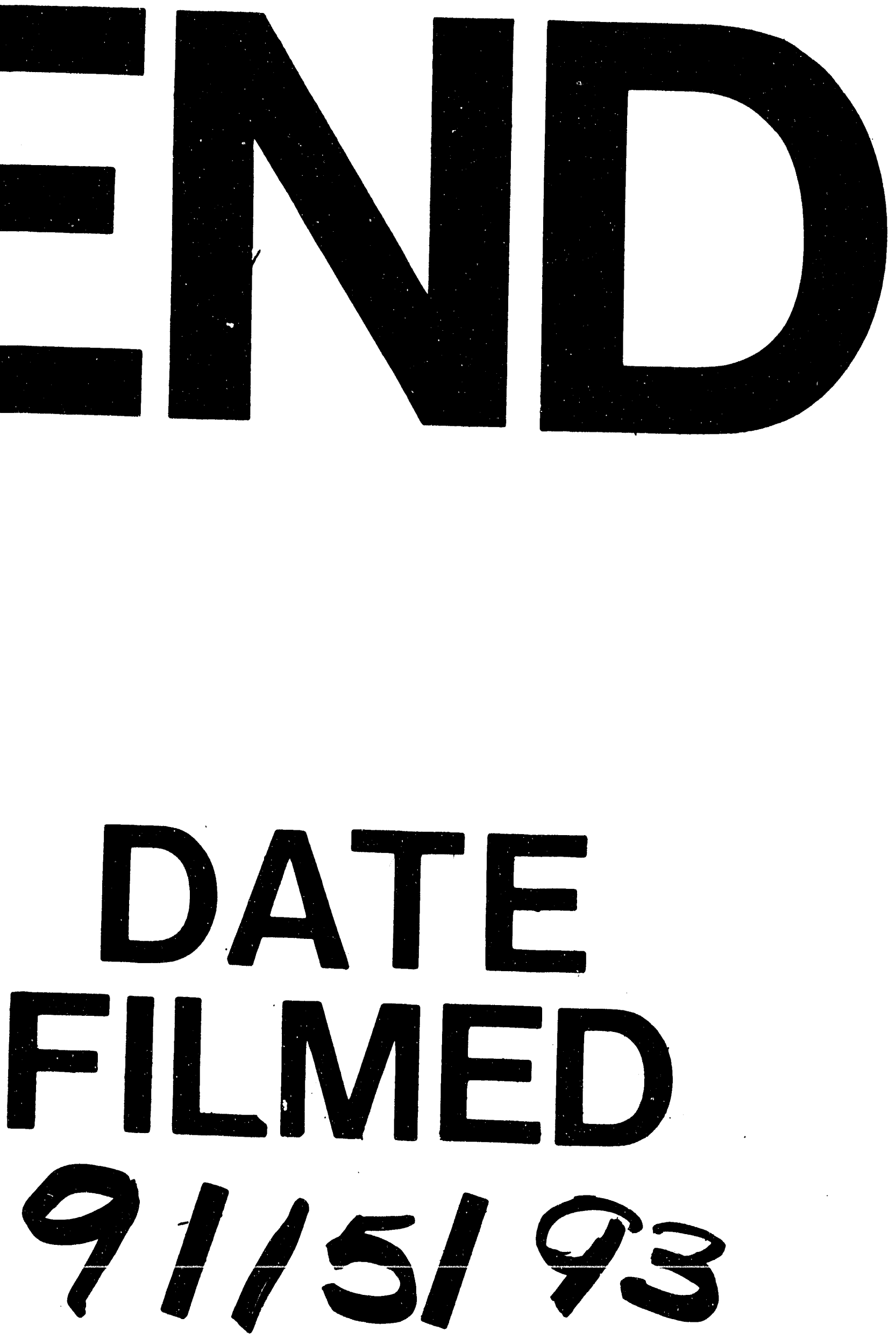
